\title{
ARE WE KNOWN BY THE COMPANY WE KEEP? EFFECTS OF NAME-DROPPING ON FIRST IMPRESSIONS
}

\author{
Thesis
}

presented to the Faculty of Arts

of

the University of Zurich

for the degree of Doctor of Philosophy

by

Carmen Lebherz

of Germany

Accepted in the winter semester 2006 on the recommendation of Prof. Dr. Klaus Jonas and Prof. Dr. Carmen Tanner

Zürich 2006 



\section{Acknowledgments}

I am grateful to my advisor Klaus Jonas for mentoring all my projects from start to finish. He continuously supported my ideas, read drafts, and generously provided resources.

I am grateful to Carmen Tanner for her thoughtful advice and her willingness to share her experience.

I have immensely enjoyed working with, and benefited from, my fellow doctoral students Katrin Wodzicki, Michela Schröder-Abé, Bettina Ryf, and Martin Hanselmann. They were always willing to exchange ideas, discuss drafts, provide emotional support, cooperate in sample recruitment, and share resources. Cooperation could hardly be more pleasant.

A special thank goes to Barbara Tomljenovic, who excelled as student, research assistant, recruiter, and, finally, colleague. Esther Maier, Olivia Santella, and Stoilka Krasteva were inspiring students.

Thanks also to Christian Fichter, Katrin Wodzicki, Martin Hanselmann, Bettina Ryf, Hanno Klemm, André Körner, Jessica Schnelle, and Ulf-Dietrich Reips for their technical expertise and support with audio files, film shootings, and the peculiarities of online research.

I was lucky to be surrounded by enthusiastic students who worked as research assistants and interns and thus helped conduct the experiments that culminate in this dissertation: Barbara Tomljenovic, Ruedi Stirnimann, Monika Stoll, Nathalie Schröder, Stoilka Krasteva, Bea Knopf, Olivier Meyenhofer, Jeannette Oostlander, Franziska Luthiger, Caspar Coninx, Silvan Winkler, Ursina Minder, Sandra DePasquale, Christian Schmid, Selina Lauber, Michèle Nägeli, Isabelle Ehlers, Yeshi Ngingthatshang, Julia Stahel, Christine Halder, Amanda Keller, Jana Vontobel, Marija Povilonyte, Rahel Anderegg, Karin Maag, Anita Stalder, Susan van Schie, Olivia Santella, Patrick Meier, Anna Vonhoff, Bettina Keller, Lea Brägger, and Diego Cardenal. Thank you!

I appreciate the possibility of conducting experiments at the Psychology Departments of Tuebingen and Heidelberg, Germany.

Finally, I am grateful to Hanno Klemm for all his help. 



\begin{abstract}
Five experiments manipulate whether or not a first acquaintance uses namedropping and measure how name-dropping affects the audience's impression of that acquaintance. I consider name-dropping a self-presentational tactic by which an actor associates himself positively with another person.

The research described in Paper 1 shows positive effects of name-dropping when implemented by a university lecturer: Students who listen to the lecturer find him more competent, in general and with regard to his research abilities, and more likeable as a person. I also show that a minority of students reacts decidedly negatively to the manipulation and that the positive effect increases in the total sample if the negative reaction is controlled for. Thus, a potential for both positive and negative reactions on name-dropping is established.

The research described in Paper 2 shows negative effects of name-dropping when implemented by actors who are the study subjects' equals with regard to status: A student job applicant who mentions former supervisors during the job interview and a student acquaintance who associates him-/herself with tennis world champion Roger Federer both elicit negative reactions.

Two variables mediate the effects: If a professor mentions his colleagues' names during a university lecture, student participants assume that the professor knows the mentioned individuals personally, and rate him more competent. If a student associates himself with Roger Federer, student participants assume that he is manipulative, and like him less.
\end{abstract}




\section{Zusammenfassung}

Fünf Experimente manipulieren, ob eine neue Bekanntschaft Name-Dropping einsetzt oder nicht und messen, wie Name-Dropping die Wahrnehmung dieser Bekanntschaft durch das Publikum beeinflusst. Name-Dropping verstehe ich dabei als eine Selbstdarstellungstaktik, bei der sich ein Akteur positiv mit einer anderen Person assoziiert.

Die Forschung, die in Paper 1 beschrieben wird, zeigt positive Effekte von NameDropping, wenn es von einem Dozenten im Hochschulkontext angewendet wird. Studierende, die dem Dozenten zuhören, beurteilen diesen als allgemein kompetenter, als besseren Forscher, und finden ihn sympathischer. Ich zeige ausserdem, dass ein kleiner Teil der Studierenden entschieden negativ auf die NameDropping-Manipulation reagiert und dass die positiven Effekte in der Gesamtstichprobe grösser werden, wenn diese negativen Reaktionen statistisch kontrolliert werden. Name-Dropping hat demnach das Potenzial, sowohl positive als auch negative Reaktionen hervorzurufen.

Die Forschung, die in Paper 2 beschrieben wird, zeigt negative Effekte von NameDropping, wenn es von einem Akteur eingesetzt wird, der/die den gleichen Status besitzt wie die studentischen Versuchspersonen. Ein studentischer Stellenbewerber, der im Interview Namen früherer Vorgesetzter einfliessen lässt und eine studentische Bekanntschaft, die sich mit Tennis-Champion Roger Federer assoziiert, rufen negative Reaktionen beim Publikum hervor.

Zwei Variablen mediieren nachweislich den Effekt: Wenn ein Dozent die Namen seiner Kollegen während einer Vorlesung einfliessen lässt, nehmen die studentischen Versuchspersonen an, dass der Professor diese Personen persönlich kennt, und beurteilen ihn als kompetenter. Wenn sich dagegen ein Studierender mit Roger Federer assoziiert, nehmen die studentischen Versuchspersonen an, dass er manipulativ ist und beurteilen ihn als weniger sympathisch. 


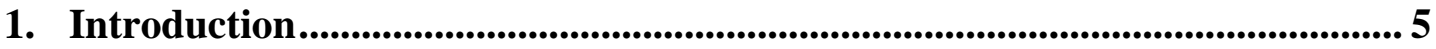

1.1 Person Perception in First Encounters................................................... 7

1.1.1 The Importance of First Encounters ........................................ 7

1.1.2 The Automaticity of First Impressions ..................................... 10

1.1.3 The Content Dimensions of Person Judgments....................... 12

1.1.4 Categorical Thinking in First Encounters .............................. 13

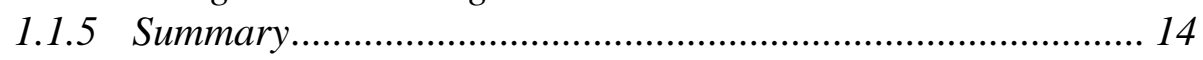

1.2 Impression Management and Impression Formation:

The Actor and the Target ........................................................................ 15

1.2.1 Impression Management Classification Schemes ................... 15

1.2.2 Actor Abilities and Target Reactions .................................... 17

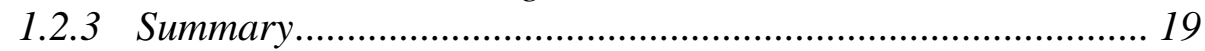

1.3 First Encounters in the Workplace: Target Effects in the

Selection Process......................................................................................... 20

1.3.1 Ingratiation vs. Self-Promotion............................................... 20

1.3.2 Impression Management Effects on Liking and Perceived Competence ........................................................................... 21

1.3.3 Beyond First Impressions: Enduring Encounters at the Workplace................................................................................. 23

1.3.4 Adverse Effects of Impression Management ........................... 24

1.3.4.1 Impression Management, Modesty, and "Too Much of a Good Thing"................................... 24

1.3.4.2 Appropriateness and Transparency of Impression Management Tactics .............................................. 27

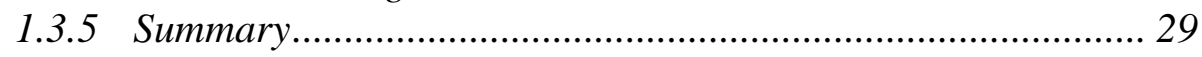

1.4 Name-Dropping as Impression Management ..................................... 29

1.4.1 Evidence from Social Psychological Research ....................... 30

1.4.1.1 Actor Goals ........................................................... 30

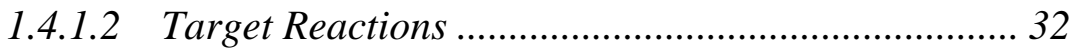

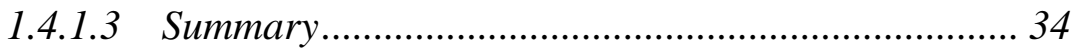

1.4.2 Evidence from Social Cognition Research.............................. 35

1.4.2.1 Direct Categorization Effects.................................... 35

1.4.2.2 Indirect Categorization Effects .............................. 37

1.4.2.2.1 Attitude Activation .................................. 37

1.4.2.2.2 Assimilation Effects................................ 38

1.4.2.2.3 Spontaneous Trait Transferences.............. 39

1.4.2.2.4 Source Confusion.................................... 41

1.4.2.2.5 Exemplars: The Famous and the Significant .................................... 41

1.4.2.2.6 Behavioral Priming ................................... 43

1.4.2.3 Summary .............................................................. 43

1.4.3 Adverse Effects of Name-Dropping ......................................... 44

1.4.3.1 Contrast Effects vs. Assimilation.............................. 44

1.4.3.2 Person Exemplars vs. Trait ..................................... 46 
1.4.3.3 A Caveat: How Applicable is the Concept of Spontaneous Trait Transferences to Name-Dropping....................................................... 46

1.4.3.4 Actor and Target Characteristics............................. 47

1.4.3.5 Summary................................................................ 48

1.5 Table and Figure 49

2. Lebherz, C.: Name-Dropping as a Self-Presentational Tactic:

Does It Work? 53

3. Lebherz, C., \& Tomljenovic, B: Two Applications of Name-Dropping in First Encounters: Job Interview and Get-Acquainted Conversation 123

4. General Discussion 201

4.1 Summary of Papers 202

4.2 Synopsis: Effects of Name-Dropping on First Impressions.......... 202

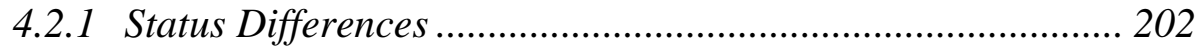

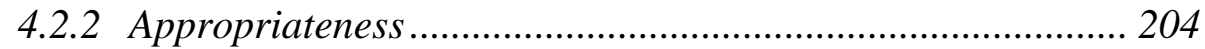

4.2.3 Target's Assumptions about Ulterior Motives ....................... 204

4.2.4 Name Valence and Exemplar Extremity ................................ 206

4.2.5 Name-Dropping as Referencing ......................................... 207

4.3 Methodological Issues .............................................................. 208

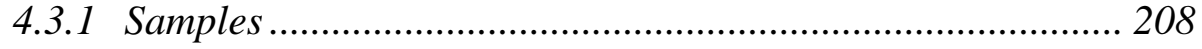

4.3.2 Effect Size ...................................................................... 210

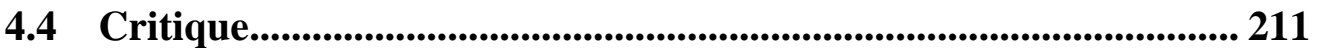

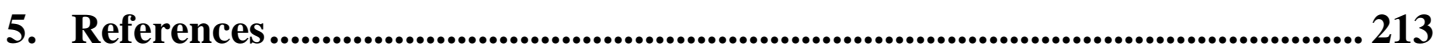

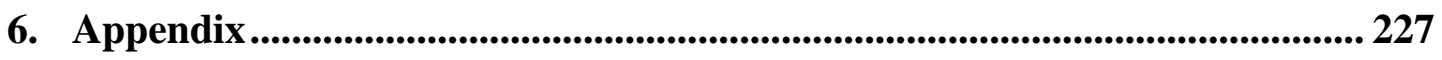

6.1 Lebherz, C.: Name-Dropping as a Self-Presentational Tactic:

Does It Work? ........................................................................................ 228

6.1.1 Appendix A-1: Instruction Study 1...................................... 229

6.1.2 Appendix B-1: Transcript of Name-Dropping Manipulation on Audio Tape (Two Versions) ................................................. 238

6.1.3 Appendix C-1: Manipulation Check Questionnaire Study 1.. 245

6.1.4 Appendix C-2: Manipulation Check Questionnaire Study 2.. 249

6.1.5 Appendix C-3: Manipulation Check Questionnaire Study 3.. 253

6.1.6 Appendix D-1: Instruction Study 2 ..................................... 257

6.1.7 Appendix E-1: Pretest Questionnaire Study 3 ...................... 259 
6.2 Lebherz, C., \& Tomljenovic, B: Two Applications of Name-Dropping in First Encounters: Job Interview and Get-Acquainted Conversation. 262

6.2.1 Appendix F-1: Transcript of Name-Dropping Manipulation on Video Tape (Four Versions)................................................... 263

6.2.2 Appendix G-1: Manipulation Check Questionnaire Study 1. 286

6.2.3 Appendix H-1: Instruction Study 1 ...................................... 290

6.2.4 Appendix I-1: Email Questionnaire Study 2 ........................ 292

6.2.5 Appendix J-1: Email with Name-Dropping Manipulation (Four Versions) Study 2 ....................................................... 296

6.2.6 Appendix K-1: Paper-Pencil Questionnaire Study 2 ............. 301 
1. Introduction 
Every day in our lives we encounter new people. We make up our minds about how much we like those new acquaintances, how well they do their job, how intelligent they are, or whether we want to get to know them better. This thesis concerns an impression management tactic that is hypothesized to influence, if used in social interactions, the way a person is perceived by others. I will call this tactic "name-dropping" and define it as an indirect self-presentational tactic that establishes psychological closeness between the actor who employs the tactic and the individual whose name is mentioned. I will place particular focus on how name-dropping affects the impression an audience forms of the individual who employs the tactic.

For example, a new acquaintance might mention his school day friendship with tennis champion Roger Federer, thus establishing a positive association with a famous and generally well-liked individual. University lecturers might call their students' attention to the merits of their faculty colleagues, hoping that some of the glory reflects on them. How does such name-dropping change the first impression we form of our new acquaintance? Do students attribute more competence to a namedropping lecturer than to one who does not mention other researchers?

The studies reported in the thesis are based on the current understanding of person perception in social psychology. This introduction will outline findings from social cognition research and the impression management literature that I consider relevant to the topic of name-dropping. First, I will present some general evidence on how individuals perceive others: I will outline the importance of first encounters and the perception process' degree of automaticity, content dimensions, and relation to categorical thinking. Second, I will present evidence on how impression management tactics influence the perception process. Third, I will emphasize research on impression management at the workplace, because most effects have been investigated in this context. Last, I will discuss in some detail how name-dropping could be used as an impression management tactic, and how and by which processes it might affect person perception. 


\subsection{Person Perception in First Encounters}

\subsubsection{The Importance of First Encounters}

First encounters can have a strong impact, with lasting effects on future relationships. Evaluations of individuals are formed instantly (Hastie \& Park, 1986) and may color our subsequent inferences about that individual's specific traits. Sunnafrank and Ramirez (2004) found that quality evaluations of very short getacquainted conversations predicted whether relationships developed between these new acquaintances over a 9-week period and how close those relationships became. Research on so-called zero acquaintance shows that even the thinnest slices of an actor's behavior (of one or two seconds) are powerful in forming impressions in a target who observes this behavior (Ambady \& Rosenthal, 1992), even as powerful as much longer exposure to such behavior (Ambady \& Rosenthal, 1993).

First encounters can cause self-fulfilling prophecies. According to Merton (1948, p. 423), a self-fulfilling prophecy is a false definition of the situation that evokes "a new behavior which makes the originally false conception come true” and leads the prophet to "cite the actual course of events as proof that he was right from the very beginning”. Similar evidence stems from the literature on hypothesis testing, suggesting that once a hypothesis is selected it is often tested by focusing on hypothesis-consistent evidence (e.g., Snyder \& Swann, 1978; Trope \& Liberman, 1996).

Social cognition research has considered the underlying processes of this phenomenon. For example, our first impressions guide not only the way we weight all subsequent person information (e.g., Farr, 1973) or how we relate person information to situational information (Trope, 1986), but our search for additional information to begin with (De Bruin \& van Lange, 2000). This is true for negative impressions that lead us to color subsequent information negatively (e.g., Blakeney \& MacNaughton, 1971; Springbett, 1958) or even to abandon any further information search on a person (De Bruin \& Van Lange, 2000), as well as for impressions that make us look for additional favorable information (e.g., Dougherty, Turban, \& Calender, 1994). Studies on primacy effects or priming show that every stage in the person perception process is influenced by what happened before or, to 
put it with Bruner and Tagiuri (1954, p. 650), “The first step in reacting to another is forming an impression of him. Later reactions depend on this first step“.

First impressions are very influential on further interaction because it is impossible to undo, and very difficult to revise, a first impression, even if we deliberately tried to. This, however, is unlikely to begin with, because as consistency-seekers we tend to stick to previously formed impressions: Whether our first impressions are positive or negative, we often process future person information in a way that ensures the maintenance of that impression. That is, we engage in biased hypothesis testing and information gathering (Dougherty \& Turban, 1999; Snyder \& Swann, 1978)

Negative person information weighs more heavily than positive information in decision processes (e.g., in selection decisions, Peters \& Terborg, 1975) and is more stable in memory (De Bruin \& van Lange, 2000; Skowronski \& Carlston, 1989). This inordinate influence of an actor's negative behaviors and traits is called negativity bias and has been found pervasively in different areas of person perception research. Pratto and John (1991) used the stroop paradigm with traits instead of color names. They showed that the task to name the print color took more time for negative traits, and took the longer the more negative the traits were. They also showed that the tendency to linger at negative words is based on automatic vigilance, a preconscious focus on negative stimuli.

Denrell (2005) states that the negativity bias might indeed be caused by the quality of first impressions. He argues that if initial impressions are negative, we avoid future interactions with that person and thus never even get the chance to correct our first impression. If initial impressions are positive, we initiate approach behavior; during future interactions we can encounter either more positive or new negative information (or both). Thus, whereas initial positive impressions can be qualified later on, negative impressions can not. Recent research found that negative information interacts with the quality of the information that is given about a newly encountered person. That is, negativity bias is likely to occur when person information concerns morality, but the opposite, a positivity bias, is likely to occur when information concerns competence (De Bruin \& Van Lange, 2000; Skowronski, 2002). One explanation is that some information is more diagnostic for the perceiver than the other: It is hard to fake good in competence related tests, therefore, good performance is diagnostic of high competence and weighed more heavily than 
negative performance in the overall evaluation (which might always be explained by situational circumstances or faking bad). On the other hand, "a good person must act good most of the time to retain that categorization (of morality), whereas a bad person need act bad only some of the time“ (Skowronski \& Carlston, 1989, p. 137), thus an observed negative behavior weights more heavily than positive behavior in morality judgments (see also Birnbaum, 1973). Either way, first impressions guide future impressions.

When people observe behavior, they spontaneously draw inferences about traits from that behavior. They even show strong preferences toward trait-related rather than situational information when thinking about others. The first phenomenon is called spontaneous trait inference. I will discuss this area of research in detail in section 1.1.2. The latter phenomenon is well-known as the correspondence bias (Gilbert \& Malone, 1995; Ross, 1977), and both phenomena further heighten the importance of first impressions. Whereas trait inference has been suggested as the automatic first stage of person information processing, the correspondence bias has originally been named the fundamental attribution error and has been subject to research on the more controlled, conscious, and effortful processes of causal attribution (Ham \& Vonk, 2003; Krull, 2001).

Self-presentational efforts might have a stronger impact on new acquaintances than on people we know well. When getting to know new people, we give them the benefit of the doubt: We believe much of what they want us to believe (Arkin, 1981; Blumberg, 1972; Schlenker, 2003). Also, people are generally good at expressing themselves, and they can convince an audience of their attitudes or traits even when they are in fact playing a role or expressing attitudes that they do not personally endorse (Toris \& DePaulo, 1984). Even if targets are aware of the fact that actors are role-playing or being coerced to favor a certain statement, they fail to take it into account when judging the actor: Individuals tend to underestimate situational constraints on behavior (Jones \& Harris, 1967; Kassin \& Sukel, 1997; Ross, Amabile, \& Steinmetz, 1977; Snyder \& Frankel, 1976). However, this is true for new acquaintances more than for friends or long-time colleagues (Higgins \& Judge, 2004); it is harder to convey a certain impression of ourselves to people who have already formed an opinion about what kind of person we are, who have seen us acting before in different situations and over long periods of time. Thus, the same self-presentation tactic might loom larger in first encounters than in long-term 
relationships. In addition, employing self-presentation tactics consistently over time might have a completely different impact, in strength as well as in direction, than a single tactic use.

A meta-analysis of effects of impression management in the workplace supports this view that first impressions are developed differently than impressions in longterm relationships: Higgins, Judge, and Ferris (2003) found that the source of performance assessment, i.e., whether the assessor was the supervisor or an interviewer, was a strong moderator of the relationship between different impression management tactics and the performance assessment. That is, studies using supervisor's assessment ratings found that impression management correlated negatively with assessment, but studies using interviewer's assessment found a strong positive relationship. Supervisors have a history of interaction and cooperation with the assessee whereas interviewers form first impressions, thus, supervisors react quite differently to influence attempts than interviewers (see also Wortman \& Linsenmeier, 1977).

To sum, the impression somebody gets of us in a first encounter sticks with us. First encounters allow for more intensive impression management in the actor, while at the same time lacking validation opportunities for the target.

\subsubsection{The Automaticity of First Impressions}

An important question in the area of person perception is: To what degree are our evaluations of other people spontaneous, and to what degree are they controlled? Which parts of the perception process happen automatically, and which are guided by intent and effort?

With regard to trait activation, most authors suggest high degrees of automaticity. This assumption dates back as far as to Ichheiser (1943) and Tagieri (1958). A spontaneous trait inference is said to occur when perceiving another person's behavior produces a trait inference in the absence of intention to infer traits of that person and without awareness of the perceiver (Uleman, Newman, \& Moskowitz, 1996). When we observe behavior, we spontaneously (automatically) activate our concepts of the traits that are implied by the behavior. This process seems almost inevitable. Although recently conditions have been specified that can promote or inhibit spontaneous trait inference (Wigboldus, Dijksterhuis, \& van Knippenberg, 2003; Wigboldus, Sherman, Franzese, \& van Knippenberg, 2004), avoidance seems 
to be the exception rather than the rule. For example, Todorov and Uleman (2002, 2003) showed research participants pictures of 120 novel faces, together with a behavioral description to each picture. They found with a false recognition paradigm that research participants inferred traits from those faces based on the behaviors they read, and they did so unintentionally and remarkably quickly.

The meaning of automaticity has varied in cognition and social cognition research over time and between authors. It was Bargh (1994) who built a common ground on this issue by describing four elements of automaticity: lack of conscious intent to process, efficiency, lack of awareness, and lack of control. He states that only few processes fulfill all four criteria. To deal with different degrees of automaticity, Bargh (1994) suggested the terms "preconscious automaticity" for processes that possess all four features, such as the perception of color (see Stroop, 1935); "postconscious automaticity” for unintentional processes that lack awareness, such as sending out nonverbal cues to a person with whom we intentionally interact; and "goal-dependent automaticity" for processes such as car-driving, which can occur without conscious awareness and with great efficacy, but which requires a conscious goal (i.e., to drive) in order to initiate the process (Moskowitz, 2005).

Current models that view person perception as a process of several consecutive stages agree in that our default reaction to observed behavior is quick, spontaneous, and highly automatic. It might later be followed by more controlled processes such as causal attribution - but only if several necessary conditions apply (Ham \& Vonk, 2003). Similarly, we know from stereotype research that stereotypes are dominant social categories with strong influence on evaluations of others, whereas individuation of a person beyond the social categories she fits into is not spontaneous but effortful, and not the default process but rather the exception (Fiske \& Neuberg, 1990).

Gilbert (1998) and Ham and Vonk (2003) give excellent overviews of the current stage models of person perception. The primary stage of person information processing comprises spontaneous trait inferences that are drawn very quickly from the trait-implying behaviors observed in an actor. These inferences fit Bargh's (1994) four criteria of automaticity: They are drawn without awareness or intention, are highly efficient, and cannot easily be controlled (Carlston \& Skowronski, 1994; Uleman, Newman, \& Winter, 1992). Temporary processing goals and cognitive load do not affect spontaneous trait inferences (Uleman et al., 1996). 
Secondary stages request more attention by the receiver (Gilbert \& Malone, 1995; Krull \& Erikson, 1995). Just as in dual-process models of person perception (Brewer, 1988; Fiske \& Neuberg, 1990) and attitude change (Chaiken, 1980; Petty \& Cacioppo, 1981), motivation and ability are central to those more elaborate processes in stage models. If either motivation or ability is depleted, those processes fail, which reduces the person perception process to the quick and spontaneous inferences of the first stage (Ham \& Vonk, 2003).

Recently, spontaneous trait inferences have also been shown to be highly persistent in memory. Todorov and Uleman (2004) found that the traits that research participants inferred about others were inextricably linked to participants' representation of these others, and this effect lasted until the recognition test one week after the initial trait inference. Thus, the automatically activated traits form an anchor for judging the actor that is hard to adjust in subsequent processing stages (Gilbert, 1989; Trope, 1986).

\subsubsection{The Content Dimensions of Person Judgments}

Individuals infer others' personality characteristics from observed behavior. However, not all traits are created equal when it comes to person perception. Research on stereotype content furthers our knowledge on the relative importance of certain characteristics. Fiske and colleagues (e.g., Fiske, Cuddy, Glick, \& Xu, 2002) as well as Wojciszke and colleagues (e.g., Wojciszke, 1994; Wojciszke, 2005) found that stereotypes can be described on two major dimensions, competence and warmth/morality. These core dimensions of person perception and evaluation were in fact found as early as 1946, in Asch's seminal publication on the warm-cold dimension vs. competence-related adjectives. Rosenberg, Nelson, and Vivekanathan (1968) and Rosenberg and Olshan (1970) were the first to empirically find two dimensions by multidimensional scaling of trait descriptions. They named them social and intellectual. In the domain of leadership it has been suggested that leader behaviors can be categorized by subordinates as person-focused versus task-focused (e.g., Bales, 1970). Thus, similar core dimensions have been repeatedly found. As Fiske et al. (2002, p. 879) summarized, "people want to know others' intent (i.e., warmth) and capability to pursue it (i.e., competence)".

Gurevitch (1984, 1985), who came from the impression management domain, suggested manipulativeness to be a third major factor of person evaluation. 
According to Gurevitch (1985), targets not only encode the content of information they receive from an actor, but might also encode the act of impression management itself. Thus, beyond the information that is conveyed and that might indeed lead to favorable impressions, the target might also take into account the actor's manipulation attempts. If this is the case, a third dimension that should be found in person evaluation is manipulativeness.

Thus, when we investigate the impressions individuals form of others, we should focus on these core dimensions as dependent measures. Despite their discriminant validity (Gurevitch, 1985), the dimensions are correlated: We usually form a holistic impression of a person, even at first sight, and this impression is evaluative in nature, either rather positive or rather negative (e.g., Byrne, 1961)

Perceived similarity between the new acquaintance and the perceiver is reliably found to influence impression formation. The perceived degree of similarity has a strong impact on initial attraction. Much empirical evidence has been gathered over the decades that shows our preference for people who share similar values, attitudes, and beliefs (e.g., Berscheid, 1985), and who have similar personality traits (Wetzel \& Insko, 1982). The robust finding that similarity to oneself is positively related to our evaluation of others is explained by Byrne's (1971) similarity-attraction theory. It suggests that we are attracted to similar others because the attitudes we share with these others a) validate our own attitudes, thus boosting self-esteem, and b) affirm mutual group membership, thus boosting belonging (Fiske, 2004).

\subsubsection{Categorical Thinking in First Encounters}

A major characteristic of person perception is top-down-processing of person information, i.e., categorical thinking. We use our prior knowledge about individuals in the way it is organized in our cognitive schemas. Traditional impression formation models such as the ones by Fiske and Neuberg (1990) or Srull and Wyer (1989) assume that the basis for social information processes is a search through memory for a knowledge structure that fits the available (bottom-up) information on a person. This available person information has cues that trigger available concepts in the human mind. Thereby activated concepts then influence further processing and judgment of that person information. One example is the application of stereotypical thinking. Stereotypes are among the best-established social categories in the human mind, encompassing the sum of our learned knowledge about specific social groups. 
Stereotypes are used as effective heuristics that guide us effortless through many, if not most, of our daily person encounters and impression formation processes (for a review, see Macrae \& Bodenhausen, 2000).

One important heuristic based on our prior knowledge about social groups is the expertise heuristic. Groups such as "professors” or "nobel prize winners” influence our competence impressions toward a newly encountered group member in accordance with the content of the respective social category. We know, for example, from research on attitude change that the same persuasive message is more influential for our opinion when endorsed by an expert rather than a lay person (Petty \& Cacioppo, 1981). Expertise, like all heuristics and all cognitive short-cuts along the peripheral road of information processing, is most influential when we lack motivation and/or ability to process the persuasive messages thoroughly, and can only be outperformed in its impact by argument quality of the messages if we are motivated and able to "piecemeal process" the given information (Fiske \& Neuberg, 1990).

As stated above, high motivation and high ability are not necessarily the default setting when we process our random daily encounters; thus, heuristics and social categories such as stereotypes play a major role in person perception and serve us well, most of the time, by economizing our processing efforts and preventing information overload.

\subsubsection{Summary}

This section on person perception in first encounters has shown that we form person impressions automatically and fast. Due to their potential to be stable, impressions formed of an individual in a first encounter are influential even if we later get to know that individual better. We tend to evaluate individuals on core dimensions, i.e., competence, warmth/morality, and manipulativeness.

In the next section I will define the impression management tactics that are central to this thesis and that have received prior research attention. 


\subsection{Impression Management and Impression Formation: The Actor and the Target}

Closely linked to the question how we form impressions of others is the topic how we actively manage the impressions we want others to form of us. Whereas researchers of social cognition have been eager to understand how targets process, encode, and retrieve person information, researchers of impression management provide additional insight on the other side of the equation: the actor. Impression management is an individual's attempt to control the images that are projected of herself/himself in social interactions. Throughout this introduction, the term actor denotes the person who in some way or other provides information about herself/himself. Synonyms found in other publications are communicator, agent, or speaker. The target or perceiver, on the other hand, is the receiver or audience of person information.

\subsubsection{Impression Management Classification Schemes}

Impression management and self-presentation (the terms will be used interchangeably in this thesis, but see Schlenker, 2003), have attracted researchers since Goffman’s seminal publication in 1959, “The presentation of self in everyday life”. Influential definitions include the one provided by Tedeschi and Riess (1981), who understood impression management as any behavior that has the purpose of controlling or manipulating the attributions and impressions formed of that person by others. The means were further specified by Schneider (1981), who viewed impression management as attempts by individuals to control the image they portray in social interactions by presenting or limiting information available to others. Furthermore, Schlenker (1980) as well as Gilmore, Stevens, Harrell-Cook, and Ferris (1999) stated that this endeavor can be both conscious and unconscious and includes the use of verbal statements, nonverbal and expressive behaviors, more complex behavior patterns such as doing favors, and modifying one’s physical appearance (Schneider, 1981).

In the beginning of impression management research, authors focused on single aspects, for example, ingratiation and its component behaviors such as flattery and opinion conformity (Jones, 1964; Jones \& Wortman, 1973). Meanwhile, many 
classification schemes have been suggested, in parts theoretical in nature, in parts based on empirical self-report data or behavior observation. Schlenker (1980) assigned the specific tactics to verbally promote oneself to one of four categories: positive self-descriptions, entitlements (i.e., claims of responsibility for positive events), enhancements (i.e., claims that the positive event is more positive than it initially appears), and descriptions about how one overcame obstacles while pursuing goals. Jones and Pittman (1980) differentiated four categories of tactics according to their implied goal: ingratiation (to be liked), self-promotion (to appear competent), exemplification (to show high morality), and intimidation (to be feared). Differentiating ingratiation from self-promotion according to their goals also refers to the more general claim in person perception research that trait inferences can be divided in social vs. competence traits (Heider, 1958; Rosenberg et al., 1968, see section 1.1.3): Ingratiation is related to liking, whereas self-promotion is related to competence (see also Godfrey, Jones, \& Lord, 1986).

Tedeschi and Melburg (1984) as well as Schlenker and Weigold (1992) differentiated between assertive and defensive tactics, a higher-order classification that has since been used by many authors. Whereas assertive tactics such as ingratiation or self-promotion are used to acquire and promote favorable impressions and thus bolster one's image proactively, defensive tactics such as excuses, apologies, or justifications are designed to protect or repair one's image. This is very similar to Arkin's (1981) acquisitive versus protective tactics. Ellis, West, Ryan, and DeShon (2002) taped and categorized applicants’ verbal behaviors in structured job interviews and confirmed the categories of assertive vs. defensive tactics in their empirical data. Ferris and colleagues (e.g., Ferris, Judge, Rogland, \& Fitzgibbons, 1994; Kacmar, Delery, \& Ferris, 1992; Wayne \& Ferris, 1990) suggest that intentions to influence others' impressions of oneself (assertive tactics) can be either self-focused such as in self-enhancement or entitlements, or other-focused such as in favor doing or opinion conformity. Furthermore, Tedeschi and Melburg (1994) separated strategic (long-term) from tactical (short-term) impression management, suggesting a 2 (duration: long vs. short) x 2 (assertiveness: assertive vs. defensive) classification. A comprehensive overview of tactics has recently been provided by McFarland, Yun, Harold, Viera, and Moore (2005, p. 953f) and is provided in Table 1. 
Table 1.

Impression Management Classification Scheme

See Section 1.5

For this thesis yet another classification is important: the differentiation in direct versus indirect tactics provided by Cialdini and Richardson (1989). In direct selfpresentation, "individuals strategically manage information about attributes of themselves" (Cialdini \& Richardson, 1989, p. 627), i.e., they directly tell others about their favorable characteristics or abilities. In indirect self-presentation, "individuals actively arrange to connect themselves to favorable entities and disconnect themselves from unfavorable entities in observers' eyes" (Cialdini \& Richardson, 1989, p. 627) by strategically managing information about the people and things to which they are merely connected. Thus, they do not directly speak about themselves, but present themselves favorably by associating with positive people or objects.

With regard to this classification, self-promotion is a direct strategy, i.e., directly describing one's past experience and accomplishments in a positive manner in order to generate a perception of competence (Stevens \& Kristof, 1995). Whereas selfpromotion is a direct strategy to appear competent, ingratiation is also highly direct in nature but is employed with the aim to appear likeable, to invoke interpersonal attraction (Jones \& Pittman, 1982).

\subsubsection{Actor Abilities and Target Reactions}

As most social psychological phenomena, impression management is an activity that is shaped by a combination of actor personality, audience characteristics, and situational conditions (e.g., Schlenker, 1985). According to Schlenker (2003), the self-presentation domain pursues two lines of research, (1) investigating how people, as actors, try to shape impressions of audiences through the presentation of selfrelevant information, and (2) examining how people, as targets, respond to self- 
presentational activities of others. The focus of this thesis is on the last matter. Its goal is to further our knowledge on effects of self-presentation on an audience.

Up to now, actor's employment of tactics has received much more research attention than target's reactions (Gardner \& Martinko, 1988; Kipnis \& Schmidt, 1988), and, consequently, we currently know much more about when and how people present themselves than whether it actually works along their intentions (for excellent reviews of the actor research, see Schlenker, 2003; Schlenker \& Weigold, 1992). Leary and Kowalski (1990) called the "when" impression motivation and the “how” impression construction. However, as Kacmar and Carlson (1999, p. 1293f) state, "focusing only on the actor side of this process does not allow the effectiveness of the impression management attempts to be evaluated as the target makes this determination”. Thus, what do we know about the effects of self-presentation on an audience?

As already mentioned, individuals have very strong abilities in convincing others that they have traits and characteristics that they really do not have but fake (e.g., Lippa, 1976). However, deception can be detected, and ironically, detection is most likely when stakes are highest, i.e., when successful deception would be most beneficial to the actor. The reason for this is that the actor's high motivation to get away with the deception can, in combination with doubts about one's ability to deceit, lead to signs of social anxiety such as sweating and nervous body movements that can be deciphered by the audience. Also, social anxiety associated with anticipated deception hampers the deception performance itself, for example through self-preoccupation and withdrawal behavior (e.g., DePaulo, 1992; Leary \& Kowalski, 1995; Schlenker \& Leary, 1982a). However, actors seem to be successful in self-presentation when they have both the motivation to impress and the confidence that they can (Schlenker, Britt, \& Pennington, 1996).

Actors are also quite capable of restoring impressions after they have found themselves in situations that threaten their desired identities. Remedial activities such as accounting or apologizing can reduce negative reactions by others, provided they appear to be sincere (e.g., Rosenfeld, Giacolone, \& Riordan, 1995; Schlenker, Pontari, \& Christopher, 2001; but see negative effects of excuses and justifications according to Higgins \& Snyder, 1989).

Gordon (1996) performed a meta-analysis on the effects of ingratiation on person judgments in general (disregarding the quality of the relationship between actor and 
target) and reports that ingratiation affects liking evaluations significantly stronger than it does affect perceived competence. The main effect is qualified, however, by moderators such as the specific tactic used by the actor and the settings of data collection (laboratory vs. field, and sample type).

In a study on the consequences of self-enhancing, self-critical, or neutral behavior, Powers and Zuroff (1988) found that participants rated the female confederate more competent but less socially attractive when she had previously commented her performance in a self-enhancing manner. Thus, self-enhancing lead to the intended impression of good task performance, but participants also rated her less desirable for future interactions and less likeable than participants in the self-critical and neutral conditions. This again indicates that there are at least two core dimensions of impression formation, and that impression management tactics might exert differential influence on them.

\subsubsection{Summary}

This section on impression management and impression formation discussed the different kinds of impression management tactics proclaimed and empirically found and their classification. It has also shown that it is worthwhile to differentiate between actors' goals and motivations on the one hand and targets' reactions on the other hand.

The next section deals with effects of self-presentation in organizational selection settings. Interviews and assessment centers are ambiguous first-encounter situations in which neither party has extensive, first-hand knowledge about the other (Judge \& Ferris, 1993; Parsons, Liden, \& Bauer, 2001). Stakes are high, and both parties attempt to gather as much information about the other as possible. Thus, impression management is likely to result, and target effects in this domain are of great relevance to the issue of name-dropping. 


\subsection{First Encounters in the Workplace: Target Effects in the Selection Process}

Impression management has received much attention by applied research. As Schneider (1981) states, impression management may well be regarded as applied person perception. A field experiment using video-tapes of applicants as stimulus material and employment interviewers as subjects showed that overall levels of impression management (regardless of specific tactics employed) improved interviewers' ratings of likelihood of hiring, perceived qualification, and interview performance (Gilmore \& Ferris, 1989). Even more, the quality of the applicant's credentials did not interact with this impression management effect. This provides experimental support that impression management is important during interviews, and might even overrule the impact of objective applicant characteristics.

\subsubsection{Ingratiation vs. Self-Promotion}

With regard to specific tactics that might be employed, the categories of ingratiation and self-promotion have received most research attention, especially with regard to their effects on liking and competence perceptions. Yukl and Falbe (1990) found in self-reports of both actors and targets that influence tactics are prevalent in organizations and used in all hierarchies. Research on long-term relationships in organization, such as between supervisors and subordinates, showed that performance appraisals and supervisory liking of subordinates are indeed associated with self-presentation tactics, especially with ingratiation and selfpromotion (see also research on influence attempts and politics in organizations, e.g., Harrell-Cook, Ferris, \& Dulebohn, 1999; Judge \& Bretz, 1994; Rao, Schmidt, \& Murray, 1995).

However, is this effect also found in research on first encounters, namely in selection situations such as the employment interview? Interviews have long since been and still are organizations' most favorite tool of applicant assessment - despite methodological critique concerning reliability and validity, especially in unstructured interviews (e.g., Arvey \& Camion, 1982; Dipboye \& Gaugler, 1993). As in the research on general person perception, liking and perceived competence are crucial dependent variables. Ferris and Judge (1991) suggested that they mediate the relationship between person perception and later selection decisions to large degrees. 
I will now present relevant research from laboratory as well as field studies with a focus on the effects of verbal tactics on liking and perceived competence.

\subsubsection{Impression Management Effects on Liking and Perceived Competence}

Stevens and Kristof (1995) measured naturally occurring impression management in real job interviews with self-report surveys for applicants and interviewers. They controlled for students' Grade Point Average (GPA), job type, and gender, and found that the use of self-promotion, acclaimed fit with organization, and otherenhancement (i.e., statements that enhance others' performances instead of one's owns) predicted interviewers' evaluations of applicants, whether applicants later were invited for site visits, and whether they received job offers. Similar results have been obtained in mock interviews in laboratory studies: Self-promotion, entitlements, other-enhancement, and smiling positively influenced applicant evaluation (e.g., Kacmar et al., 1992). Kacmar and Carlson (1999) replicated and validated the effect in an experimental field study with human resource professionals who were positively affected by applicant's self-focused self-promotion efforts.

Higgins et al. (2003) performed a meta-analysis on the influence of impression management tactics on performance in organizational selection processes. With regard to employment interviews, they found a strong positive effect of selfpromotion on interviewers' assessments of the applicant with an averaged corrected correlation of $r=.60$, and a similarly strong effect of ingratiation with a correlation of $r=.58$.

Ellis et al. (2002) specifically investigated the effects of impression management use in structured interviews. They had audiotapes of real interviews for an entry-level firefighter position coded by two trained and highly agreeing raters. They found that both candidate self-promotion $(r=.21)$ and ingratiation $(r=.26)$ were positively related to interviewers' candidate evaluation. Kristof-Brown, Barrick, and Franke (2002) replicated these results with students' self-reported use of self-focused tactics (i.e., self-promotion) and professional interviewers in mock interviews and found that self-reported self-promotion also predicted interviewers' perceived person-job fit. They suggested that interview outcomes are positively influenced by selfpromotion because it enhances perceived person-job fit.

Recently, McFarland et al. (2005) investigated impression management in assessment centers. Because assessors in this sample had not known the research 
participants before the assessment center, the setting qualifies as first encounter. McFarland et al. (2005) used firefighters who applied for a promotion and therefore underwent several exercises. Exercises were audio-taped and coded for verbal impression management use by trained raters who were blind to the performance ratings given by the assessors. Other-focused tactics correlated with assessors ratings of technical and professional knowledge ( $r=.38$ and $r=.32$, depending on exercise) as well as with oral communication $(r=.25)$ and reasoning and resolution skills ( $r=$ .25). Self-focused tactics correlated with technical and professional knowledge only in the role-play exercise $(r=.29)$. In a second study using a mock presentation exercise, correlations between other-focused tactics performance evaluation were even stronger, ranging from $r=.42$ to $r=.56$. Thus, although the correlations varied depending on the demands of the situation (i.e., what the exercises assess), direct, assertive tactics of self-presentation were found to be positively correlated with performance ratings. Hierarchical regression analysis also showed that, in the mock presentation exercise, both verbal and nonverbal impression management tactics significantly predicted performance evaluation.

Another recent study by Higgins and Judge (2004) found that only ingratiation, but not self-promotion, predicted hiring recommendations and job offers for undergraduates applying for jobs. Using structural equation modeling, the authors showed that the effect of ingratiation was fully mediated by interviewer fit perceptions, i.e., ingratiation caused interviewers to assume greater overall fit between the applicant and both the organization and the job, which then increased the likelihood of hiring recommendations, and, thus, job offers. It remains unclear why self-promotion, in this study, did not exert an influence, neither directly nor indirectly on evaluation of the candidate. The authors found that applicants in their sample focused more on ingratiation than on self-promotion to begin with.

One possible explanation is that recruiters were members of the hiring company, thus possibly future colleagues with whom applicants wanted to stress their likeability more than their competence. Another reason might be the different sample, compared, for example, to Stevens and Kristof (1995); the liberal arts and business majors with Higgins and Judge (2004) applied for jobs that requested more interpersonal than technical skills, which might cause both actors and targets to focus more on ingratiation. Engineering majors, on the other hand, might be applying for jobs that cause them and the recruiters to focus more on specific skills and prior 
achievements. Also, the interviews were meant to screen applicants rather than to hire them for specific jobs. Thus, self-promotion might not have as strong an impact on the recruiters because they focused more on overall fit than on specific job fit (this is in line with the results of the mediation analysis that shows only indirect effects for ingratiation), whereas ingratiation does clearly affect impressions of overall fit.

Paper credentials such as resumes, cover letters, and letters of recommendation are important components of the selection process. The encounter is "data-based" as opposed to interactive and therefore different from the above mentioned first encounters in the workplace. For the applicant, tailoring content and style to the audience in a favorable way is not easy. On the other hand, content and style are flexible to some degree toward creativity, thus allowing for impression management use (Knouse, 1994). Knouse (1994) found positive effects of self-enhancement and entitlement in the resume. He placed five self-descriptive statements in the education and prior job experience sections of the resume and found that professionals rated the applicant's overall competence and hireability significantly more favorably.

Knouse, Giacolone, and Pollard (1988) found that impression management in the resume and cover letter can backfire if the applicant is perceived to have exaggerated, which results in the assessor's downgrading of impressions. They used more and stronger statements of enhancement, entitlement, and flattery (ingratiation) than Knouse (1994) and found that it reduced believability of the content, thus leading to negative effects.

\subsubsection{Beyond First Impressions: Enduring Encounters at the Workplace}

Workplace relationships that go beyond first impressions, especially between supervisors and subordinates, have also been shown to be influenced by impression management. However, impression management efforts in enduring encounters yield results that are different from the research on first encounters, namely, they are prone to have negative effects. Also, results are more mixed, probably due to the influence of third and situational variables that do not play a role in first encounters.

For example, positive impressions may be fostered by ingratiation efforts such as agreeing with a recruiter's opinion because the recruiter assumes that the applicant shares similar attitudes, beliefs, or values. Similarity is a strong predictor of liking (Byrne, 1971). However, similarity perceptions might become more ambivalent over time, when actions complement words. Also, positive impressions might be 
enhanced by self-promotion because self-promoters highlight their achievements and abilities and downplay negative aspects of their background. However, real performance over time allows the target to interpret a broad variety of work and social behavior first-hand, and the observed outcome might be more balanced with regard to success and failure than indicated by the actor's self-report.

Due to the completely different nature of the relationship between actor and target in enduring as opposed to first encounters, target effects related to long-term relationships are not further discussed in this introduction. The interested reader will find discussions of impression management effects on performance appraisals, promotion, and general career success in the areas of organizational influence and organizational politics (e.g., Higgins et al., 2003; Judge \& Bretz, 1994; Thacker, 1999; Wayne \& Kacmar, 1991; Wayne, Kacmar, \& Ferris, 1995; Wayne \& Liden, 1995), and in the area of impression formation in politics (e.g., McGraw, 2003).

\subsubsection{Adverse Effects of Impression Management}

The research on effective impression management in first encounters, especially with regard to selection in organizations, might convey the impression that selfpresentation is at best highly favorable to the actor, or at worst no harm is done. As clear as the results may be for employment interviews and assessment centers, in general, favorable self-presentation is a tricky business. As Knouse et al. (1988) found for the resume: When self-aggrandizement is pushed too hard, it might backfire.

\subsubsection{Impression Management, Modesty, and "Too Much of a Good Thing”}

Baron (1986) suggested that there might be "too much of a good thing" when individuals use influence behaviors to achieve an outcome. Specifically, whereas a certain level of ingratiation or self-promotion may be effective, excessive use of these tactics makes the intentions of the individual obvious to the target and thereby backfires. Gurevitch (1985) found that perceivers evaluate an actor more negatively on all major dimensions (sociability, ability, manipulativeness, see section 1.1.3) when they interpret the actor's behavior as tactic self-presentation. However, the procedure of this study can be criticized because Gurevitch asked research participants to pick one of the "tactic self-presentation behaviors" just seen and 
evaluate it, which might have led to a negative hindsight bias. In real first encounters, targets are less prejudiced because they do not yet have a general evaluation that might color memory and guide memory search. In general, manipulativeness is a trait (or core evaluation) with a strong negative connotation. Thus, when the employed self-presentation tactic is transparent, the target presumes manipulativeness of the actor and the tactics boomerangs, i.e., instead of the intended positive impression, the actor creates a negative impression. If the self-presentation concerns ability more than likeability, it works as a double-edged sword: It increases perceived competence as intended but decreases liking at the same time.

Gardner (1992) further regarded the situational aspects and suggested the selfpromoter's paradox: Situations in which the benefit of self-promotion is greatest are also the situations in which the tactic is most expected and, thus, most easily detected. To avoid the target's suspicion, the actor must take great care.

Robinson, Johnson, and Shields (1995) asked students to read (bogus) selfdescriptions of other students and rate the ostensible authors on traits such as honesty, self-knowledge, and liking. Bogus self-descriptions that used self-enhancing tactics were perceived less positive than a more balanced tactic in which positive and negative self-related statements were used in equal shares, yet more positive than self-depreciation tactics.

Is there evidence that some tactics work better than others? Bolino and Turnley (2003) differentiated five different tactics, namely ingratiation, self-promotion, exemplification, supplication (presenting oneself as needy), and intimidation. They postulated that individuals differ in their pattern of self-presentation, and that these patterns might have differential effects on targets. They found empirical support for the five tactics and used hierarchical cluster analysis of self-report questionnaires to identiy three clusters of impression management use in college students: Students in cluster 1 used only positive tactics (ingratiation, self-promotion, supplication) and were named "positives". Students in cluster 2 tended to use all five tactics (“aggressives”), and students in cluster 3 did not use any category to large degrees (“passives”). Students evaluated each other on several Likert scales that formed an overall impression of how desirable as a work colleague each student was to the others. Bolino and Turnley (2003) reported that passive and positive tacticians did not differ in their ratings, whereas aggressive tacticians were perceived significantly 
less desirable as colleagues. Thus, the authors found that specifically supplication and intimidation have negative effects.

Modesty is a highly valued attribute in our society, and there is evidence that individuals who are modest about their performance are better liked than individuals who are boastful (Bond, Leung, \& Wan, 1982; Forsyth, Berger, \& Mitchell, 1981). However, Tetlock (1980) as well as Schlenker and Leary (1982b) found that only moderate modesty has such positive effects, whereas high modesty is not preferred by targets.

Although self-presentation and modesty seem to be at odds, modesty might in fact be used deliberately as a self-presentational tactic. Cialdini and Richardson (1989) define self-presentational modesty as under-representation of one's positive traits, contributions, or accomplishments. Wosinska, Dabul, Whetstone-Dion, and Cialdini (1996) made students read a scenario in which a company employee responded to congratulations concerning a productivity award. Responses were either highly modest ("it was mostly luck"), moderately modest ("I heard about it unofficially this morning”), or not modest at all (“I just knew I would win”). They found that for female self-presenters, high modesty resulted in most positive evaluation (with moderate modesty second-best), whereas for male self-presenters, moderate modesty was best (with high modesty second-best). Thus, the effects of modesty on targets are complex. The boastful condition always induced, however, the most negative evaluation.

Knouse et al. (1988) reported that an applicant's overt boasting with past accomplishments (entitlements, self-enhancing) in cover letter and resume reduced perceived truthfulness of the applicant and believability of the content of letter and resume, and decreased perceived quality of the paper credentials as well as backfired on the impression the applicant conveyed to the reader. Their operationalization of the impression management statements was much stronger than that used by Knouse (1994), which implies that there is indeed too much of a good thing that turns potentially successful tactics into failures. 


\subsubsection{Appropriateness and Transparency of Impression Management Tactics}

Reactions might also be strongly influenced by characteristics of the audience and the accountability of the proclaimed performance. Beyond main effects, it is also possible that the employment of self-presentation tactics interacts with factors that are beyond the actor's power to influence (Tesser, 1988). For example, Schlenker et al. (2001) reported that self-promotion backfired when it was not fully matched by corresponding accomplishments (see also Giacalone, 1985; Schlenker \& Leary, 1982b). Vonk (1998) found that ingratiation attempts can backfire when they are perceived as insincere and self-serving. Baron, Fortin, Frei, Hauver, and Shack (1990) reported that being overly friendly (ingratiating) towards opponents in harsh negotiations is perceived as inappropriate and negative. Thus, self-presentation can backfire if it is done so blatantly that the underlying self-presentation goal is transparent to the target, or if it is socially inappropriate.

With regard to appropriateness, Ferris, Judge, Rowland, and Fitzgibbons (1994) as well as Gardner and Martinko (1988) argued that undesirable attributions and negative affective reactions are likely if the impression management tactic is incongruent with the observer's view of situationally appropriate behavior.

With regard to transparency, Gordon (1996) found in his meta-analysis that the degree of transparency is indeed a moderator in the relationship between ingratiation and outcome in organizations. Why is this? Fandt and Ferris (1990) and Ferris, Bhawuk, Fedor, and Judge (1995) spoke of imputed intentionality (see also Crant, 1996), the observer's attribution of the intention underlying an actor's behavior. Fein, Hilton, and Miller (1990) as well as Vonk (1999) conducted research on suspicion of ulterior motives in the area of correspondence bias. They found that if the target suspects the actor to have ulterior motives for his behavior, correspondence bias is less likely to occur. This indicates that situational constraints are taken into account (and in-depth processing occurs) if targets are suspicious about what the actor strives to achieve by showing that particular behavior. Similarly, selfpresentation efforts may be useless or even detrimental when they foster suspicion in the target. For example, complimenting one's supervisor (a) and asking for a salary raise (b) within one meeting might lead the supervisor to conclude that not impressions of her performance is the reason for (a), but the ulterior motive to 
achieve (b). The concept of blatant vs. subtle self-presentation is closely related to the above mentioned concept of manipulativeness. If a target assumes ulterior motives, then he imputes the actor to be manipulative.

Holtgraves and Srull (1989) reported that impression management use is perceived negative if the actor volunteers information about his own competence or achievements without a specific request from the audience. Coupland, Coupland, and Giles (1991) differentiated three forms of what they called "self-representation”, and Bangerter (1999) applied them to job interviews: In the elicited form, predetermined questions on the interview agenda cause applicants to talk more about themselves; in the emergent form, applicants use self-presentation as a response to unforeseen conversational situations; in the strategic form, self-presentation is not related to the progress of the previous conversation, therefore, the interviewer can attribute selftalk to conversational goals on the part of the applicant (Foppa, 1990). Bangerter (1999) showed that this strategic form of self-presentation is found inappropriate by interviewers, and that the interviewers' reactions include interrupting the discurse and getting back to the agenda. This, too, indicates that an audience perceives the strategic form of impression management as a breach of behavioral codex, a deviation of behavior from the socially expected.

Appropriateness might explain the almost unanimously positive results of impression management in employment interviews: Targets expect the actor to present herself favorably, and as long as the behavior follows social rules and norms, it does not exert negative impressions of bragging or boasting. Support for this view comes from Knouse's (1994) research on the effects of self-enhancement and entitlements. He found that five such impression management statements in the resume caused significantly greater overall competence impressions and improved hireability judgments of the applicant in a sample of business professionals and managers, although the very same professionals and managers acknowledged a significantly higher motivation to impress the reader with the resume. They also rated the applicant higher on self-competence and interpersonal skills, suggesting that they considered impression management not only appropriate but diagnostic with regard to applicant's suitability. Interestingly, the resume was considered just as believable as in the condition without self-enhancing and entitlement statements. 


\subsubsection{Summary}

Although situational variables such as job type might play a role in the relative impact of tactics, both experimental laboratory studies and correlational field studies strongly suggest that direct impression management tactics may have a positive effect on first encounters in the workplace. For paper credentials, backfire effects have been shown for too blatant, too strong impression management use that results in doubts regarding the credibility of the written material.

Situational appropriateness and social norms moderate the effects of impression management tactics: If targets assume ulterior motives or if social norms of modesty are breached, impression management backfires.

From these general effects of impression management and the prior research on certain tactics I will now move on to name-dropping, an impression management tactic that has not received any research attention until now.

\subsection{Name-Dropping as Impression Management}

Name-Dropping is defined in this thesis as an indirect self-presentational tactic (Cialdini \& Richardson, 1989) that establishes psychological closeness between the actor who employs the tactic and the individual who is mentioned. The concept of closeness can take different forms, ranging from trivial associations such as having the same birthplace or going to the same college as the mentioned individual, to substantial associations such as being friends or working together (see also definitions of closeness and relatedness by Heider, 1958, and Tesser, 1988). The valence of the person can also differ both in strength, ranging from commonly unknown individuals to celebrities, and in direction, ranging from individuals with very negative characteristics to highly popular individuals.

I have mentioned in section 1.2.1 on impression management classification schemes that the differentiation in direct versus indirect tactics provided by Cialdini and Richardson (1980) is important to this thesis. Direct tactics of self-presentation are quite effective in first encounters, clearly suggesting positive effects for the actor who employs these tactics. What about the use and effectiveness of indirect tactics? Is it possible to influence how we are perceived by managing information about the 
people and things to which we are merely connected? The following sections summarize evidence from classic social psychological and recent social cognitive research that support the hypothesis that name-dropping affects what impression an audience forms of an actor.

\subsubsection{Evidence from Social Psychological Research}

Cialdini (1989, p. 47) defined indirect impression management as "techniques undertaken to enhance or protect one's image by managing information about the people and things to which one is simply associated”, or, stated differently, indirect self-presenters are "trumpeting some connection with a successful other" (Richardson and Cialdini (1981, p. 42), even if this connection is superficial or trivial.

This notion is very close to my understanding of name-dropping. Voluntary statements of information about the people and the things to which an individual is connected might be used successfully to share the positive reputation or to avoid the negative reputation of these people or things.

\subsubsection{Actor Goals}

With regard to the actor side, Richardson and Cialdini (1981) attributed such behavior to a strong desire to be associated with a winner. Because the social groups to which we belong are "layered notions of the self" (Moskowitz, 2005, p. 336), individuals can gain perceptions of a positive self through promoting positive social identities (Brewer, 1991; Tajfel \& Turner, 1986). Cialdini and colleagues described anecdotal evidence, for example of state officials publicizing the birthplaces of native sons and daughters, even if these individuals had gone on to greatness elsewhere, or of people who recount the time when they crossed paths with a celebrity.

There is also empirical evidence that actors strive for shared reputation. Cialdini, Borden, Thorne, Walker, Freeman, and Sloan (1976) conducted three studies showing that college students actively associated themselves with their home university's football team, but only when the team had won the match the previous day. After the team's victory, students used significantly more often the connecting pronoun "we" to describe the match ("we won") and were more likely to wear t- 
shirts with their university's emblem up front. Cialdini et al. (1976) named this phenomenon "basking in reflected glory" (BIRG) because students were eager to show their association with the winning team. However, after the team's defeat, students made more use of the distancing pronoun "they" to describe the match ("they lost”), thus dissociating themselves from the losing team.

Snyder, Lassegard, and Ford (1986) showed that students were significantly more likely to wear a team identity badge when their team had been successful than when it had failed. Recently, End, Dietz-Uhler, Harrick, and Jacquemotte (2002) replicated the BIRG effect: College students were more likely to identify with successful than unsuccessful sports teams.

Bizman and Yinon (2002) found that engaging in distancing had positive effects on self-esteem and on the emotional responses of the actors themselves, i.e., actors stated more positive and less negative emotions after the chance to engage in distancing behavior concerning a losing team.

Boen et al. (2002) showed that Belgian households were more likely to remove lawn signs supporting a political party if that party had lost the election and more likely to keep the signs for a week or longer after the election if that party had won. Thus, actors also employ BIRG in political contexts, associating themselves with successful parties while distancing themselves from unsuccessful ones.

There is also evidence that people tend to enhance the favorable features of linked others in order to improve self-esteem: Cialdini and Richardson (1980) reported that students described their home university the more favorably, the more negative the (bogus) feedback regarding their test performance had been shortly before. Similarly, Finch and Cialdini (1989) found that the Russian Grigori Rasputin (“mad monk”, a healer and prophet in czarist Russia who had a questionable reputation and was depicted by American media during the cold war as the embodiment of communist Russia) was rated more favorably when participants thought his birthday date and month matched their own, than when they did not have that association. As it is beyond participants' power to undo the birthday association, they have to assimilate their evaluation of Rasputin instead. Also, participants in the shared birthday condition were more reluctant to name the birthday when asked for possible connections between Rasputin and themselves. This indicates that actors look for association with positive individuals or groups as an impression management tactic 
that ensures or restores a positive private or public image and high self-esteem, and that they are eager to dissociate themselves from less favorable others.

Andrews and Kacmar (2001) recently validated an impression management scale that measures, besides other tactics, the basking tactic as suggested by Cialdini and colleagues. The scale is meant to measure impression management in organizations, including endorsement of BIRG statements such as, "I let others know about my friendships with superiors in my organization", and "I let others know that I am friends with people in informative or powerful departments”. Thus, actors do engage in tactics with the goal to associate themselves with positive others and with the intent to thereby improve their image.

The need to associate oneself with a group, as shown in the BIRG research, can also be explained in the context of social identity theory (Tajfel \& Turner, 1986). Individuals are motivated to achieve positive self-esteem, and one way to achieve this is through positive social identities, i.e., the groups to which they belong. Membership with a positive group improves social identity and allows for favorable social comparisons. As Sloan (1989) put it: What one's team achieves, one personally achieves. End et al. (2002) suggested that actors are aware of these positive effects for both the self and public image and make use of it by associating themselves with positive groups.

\subsubsection{Target Reactions}

With regard to targets, Miller, Campbell, Twedt, and O’Connell (1966) reported that observers assumed friends to be similar to one another. Cialdini, Finch, and De Nicholas (1990, p. 194) reasoned that "on the basis of a simple friendship connection, observers may make personality and behavioral attributions that are independent of a person's true traits and actions”. Thus, these authors assume positive target effects for indirect self-presentation.

Is it plausible that such mere associations with positive others influence a target favorably? According to Heider (1958), even the most elementary forms of association can produce psychological effects within targets. Because targets strain for cognitive balance, when they are exposed to connections, even simple unit connections, they will tend to see positively connected objects as alike and negatively connected objects as unalike. Thus, if the actor succeeds in establishing a 
positive unit connection with a thing or person that is evaluated positively by the target, the target will evaluate the actor positively as well. Figure 1 shows Cialdini's BIRG constellation as an example of Heider’s concept of a balanced triad.

Figure 1.

Example of a balanced triad according to Heider (1958)

See Section 1.5

Although these theoretical effects have until now not been tested empirically, there is related evidence from research on the perception of messengers. If they transmit positive information, the recipients of the information like the messengers more than when they transmit negative information (Manis, Cornell, \& Moore, 1974), independent of whether the messengers endorse the communicated information or not. Cialdini (1989) argues that this effect, known from the proverb "killing the messenger" and dating back to the Persian royal messengers who were killed when they brought news of defeat, is based on a simple association of a person and the valence of that person's message.

Kernis and Wheeler (1981) provided additional empirical evidence for target effects of BIRG. They found assimilation effects of attractive (same-gender) partners on individuals associated by friendship: Individuals with attractive friends were found more likeable and friendly than individuals with unattractive friends or, in other words, people were more attractive if they were with an attractive person. Thus, the "what is beautiful is good" stereotype can be transferred on associated individuals (see also sections 1.4.2.1 and 1.4.2.2.3). Very similarly, Noffsinger, Pellegrini, and Burnell (1983) investigated the “déjà connu” phenomenon that some strangers remind us of individuals we know. They found that the characteristics ascribed to the known individuals are highly correlated with the characteristics ascribed to on the strangers. Thus, first impressions were strongly affected by the attitudes (attraction, liking) the subjects fostered toward a known individual, as long as there was a felt association between the stranger and the known individual.

Fletcher (1989) stated that claiming association with prestigious figures might be applicable in employment interviews. He assumed that a candidate who has 
previously been chosen to work for a leading industrialist or politician might appear very competent to interviewers. Furthermore, association with institutions might enhance positive impressions, e.g., by way of former employment and job experience with distinguished organizations.

Human evaluative conditioning refers to changes in the liking of a stimulus that are due to pairing that stimulus with another stimulus. Name-dropping might be such an associative transfer of valence from one person to another. Cialdini et al. (1990) suggested that indirect self-presentations take advantage of the evaluative generalization that occurs when two concepts are linked in the minds of perceivers. Research on evaluative conditioning found that person stimuli such as pictures (Conditioned Stimulus, CS) can be associated with the valence of another stimulus, for example, pleasant or unpleasant smells or painful electric shocks (Unconditioned Stimulus, US), to elicit conditioned reactions. However, there seems to be no research to date that uses person-person paradigms, i.e., both CS and US are person stimuli such as pictures, which would explain name-dropping effects as a form of evaluative conditioning. Also, the use of person stimuli as US, which would be a necessary condition to test name-dropping effects, has failed (De Houwer, Thomas, \& Baeyens, 2001).

\subsubsection{Summary}

Traditional social psychological research indicates how name-dropping might work as a self-presentational tactic, and three lines of research are of special importance: First, Cialdini’s BIRG concept is similar to name-dropping, although the respective research is limited to the question what actors do (impression construction) as opposed to how targets react (impression formation). Second, Heider's balance theory states that mere associations establish relatedness between person and object as well as between persons. Third, social identity theory explains why associations with successful others are an important part of the self-concept. The following section deals with evidence from social cognition research. 


\subsubsection{Evidence from Social Cognition Research}

We know from the area of categorizing that first impressions are often a function of the category of which the social target is a member. People tend to compare an individual with their notions about what other members of the category are like, and the ease with which a new acquaintance is assigned to a preexisting category depends on how well the available information on the acquaintance fits those notions. Accessible trait concepts that belong to such categories have been repeatedly found to influence the categorization of an ambiguous target (Sedikides \& Skowronski, 1991). Just as the actor perspective suggests direct versus indirect tactic use in impression management, we can divide the social cognition evidence with respect to name-dropping in direct and indirect categorization effects. Direct categorization applies to the valence and processing of the names mentioned by the actor. Indirect categorization applies to the processes that link the names to the actor, and to the results thereof. I will now work out the details of this difference, starting with direct categorization effects in the next section.

\subsubsection{Direct Categorization Effects}

The direct effects have been, for example, the subject of stereotype research. They consider which social categories are activated by the actor's physical appearance, gender, and other readily available information. What makes the categorization direct in this sense is that it remains focused on that specific actor. Processes concern the actor herself: to which category she belongs, how a perceiver achieves categorization, and how the fit of available information about her and the perceiver's prior knowledge structures affects the perceiver's judgment of her. Activation of a concept spreads along the associative network of our knowledge structure and increases accessibility of related concepts (the closer in the network, the faster and the more likely is activation). Activation spreading is one of the fundamental pillars of social perception. Even though these related concepts may have no counterpart in the available person information (bottom-up), they exert their influence on subsequent processing of person information.

With regard to name-dropping, the names mentioned by an actor should elicit linked concepts in the associative network of the target. For example, mentioning 
Roger Federer could trigger activation of "athletic", "tennis”, "Swiss", and each of these could trigger more related concepts: "Athletic" is likely to be associated with "healthy" or "agile”, and "Swiss" with "Alps" and "money". Indeed, research on stereotypes has repeatedly shown that images of individuals (on photographs or in movies) as well as meeting people (in real or imagined) increases accessibility of the concepts associated with the social group to which these individuals belong.

Fazio, Sanbonmatsu, Kardes, and Powell (1986) stated that evaluation (or affect) associated with an object can be automatically activated by the presence of the object. Our example, the exemplar Roger Federer, is a highly acclaimed tennis professional and adored for his charisma by his fellow countrymen. Thus, we can assume that when a Swiss sees Roger Federer's picture - or hears his name -, positive evaluation is triggered in his mind. In addition, category activation may lead to evaluation spreading, i.e., the evaluation attached to one trait observed in a person imposes itself on the evaluation of other behaviors and traits. This effect has first been acknowledged by Asch (1946) and became known as the halo effect. The judgment of a trait as positive or negative (especially of so-called “central traits”, such as "warm” or "cold”) establishes a general evaluative impression, a halo that illuminates the person and colors all future behavior observations and trait inferences concerning this person. Thus, if we admire Roger Federer as much as the Swiss do, we are likely to find him not only charismatic but also honest as opposed to dishonest, sympathetic as opposed to egocentric, and intelligent as opposed to stupid.

Halo seems particularly common in physical attractiveness. We tend to ascribe beautiful individuals many (unrelated) positive traits, and more so than we ascribe these traits to less beautiful individuals. According to Dion, Berscheid, and Walster (1972), this is based on the stereotype of beautiful individuals, "what is beautiful is good” (but see Eagly, Ashmore, Makhijani, \& Longo’s, 1991, meta-analysis).

Any object can trigger an evaluation (Bargh, Chaiken, Govender, \& Pratto, 1992). However, the stronger the attitude toward the object or person, the more likely it is that the object attracts attention and therefore the more likely that evaluations are triggered and spread (Roskos-Ewoldsen \& Fazio, 1992). With regard to namedropping, the names of famous individuals should trigger evaluations very reliably.

In their recent work, Macrae and colleagues shed further light on the process of person construal. Macrae, Bodenhausen, Milne, Castelli, Schloerscheidt, and Greco (1998) showed with an interference paradigm similar to the stroop paradigm that 
person-based exemplars are automatically activated when subjects read the surnames of famous people on a screen. This result is highly relevant for the question how effective name-dropping might be as a self-presentational tactic: Names are likely to evoke mental representations of the bearer of the name in an automatic, preconscious way, including the categorical information associated with the name.

\subsubsection{Indirect Categorization Effects}

The indirect effects of categorization concern how categorizing somebody can exert influences that go beyond the evaluation of that particular individual. Two areas in person perception research show that evaluations as a consequence of categorization spread not only within the observed individual (such as in a halo effect), but also between different individuals. Actors and their respective categorical belongingness function as comparison standards in the evaluation of other individuals. For example, when an individual has been categorized, the activated categories can strongly influence the perception of successive individuals.

Evidently, such research is of great interest to the topic of name-dropping. I will therefore describe these areas in detail.

\subsection{Attitude Activation}

One route of influence is via the attitudes associated with the activated categories. As discussed above, Fazio et al. (1986) reported that attitudes or evaluations are activated automatically when the association between attitude object and evaluation is strong. This was found both when the strength of the association was measured and when it was manipulated. In accordance with Fazio's MODE model, the authors concluded that strong attitudes are spontaneously (automatically) activated when the attitude object is presented. The associative network model of person memory supports this idea, because attitudes, just as affect, valence, prior knowledge, and single characteristics are closely linked to exemplars. Also, as with significant others, objects that are associated with a strong attitude are well-established and should show high accessibility. Indeed, Bargh et al. (1992) argued that attitudes need not even be strong for automatic evaluations to occur. Furthermore, emotions have been shown to spread along the associative network when triggered (Niedenthal, Halberstadt, \& Setterlund, 1997). 


\subsection{Assimilation Effects}

With regard to an actor mentioning famous individuals and associating with them, the attitude linked to and emotions triggered by these individuals might become associated with the actor in the minds of the targets, especially if the targets foster strong attitudes toward the individuals, and especially in first encounters, where information about the actor is sparse. The social cognitive concept of assimilation states that person interpretation is done in the light of simultaneously accessible constructs (Bruner, 1957; Heider, 1944). More interestingly, accessible constructs are used for interpretations without awareness of their influence, and the prime that activated the concept does not have to be the same person or object as the judgmental target. I will now outline relevant evidence from this field of research in detail.

Moskowitz (2005) calls such assimilations "misattributions", in that one attributes an accessible concept, for example, "sportive", to an individual (e.g., the namedropping actor) who is not directly responsible for the concept's influence (instead, the mentioning of Roger Federer has functioned as the prime that activated the concept). Thus, the actor who mentions Roger Federer might be assimilated with the attributes that are part of the target's concept of Roger Federer: sportive, Swiss, nice guy, tennis, champion, etc. When it comes to name-dropping, the actor is, of course, at least indirectly responsible for such assimilation effects.

Necessary condition for assimilation to occur is that the activated concept is in any way relevant to the judgmental target, that it is applicable. Higgins, Rholes, and Jones (1977) manipulated in their famous "Donald" study whether or not accessible constructs (trait words) were relevant to Donald's behavior to be judged. They found that trait primes that were not applicable to the following behavior did not lead to assimilation of the behavior according to the trait. For example, the prime "shy" did not make Donald seem shyer than in the no-prime condition when Donald's behavior was not ambivalent with regard to shyness (instead, it was ambivalent with regard to persistent vs. stubborn). However, applicability is relative. As Higgins and Brendl (1995) report, very strong activation of a construct can compensate for only weakly relevant target behaviors, i.e., even if the observed behavior/trait is very vague and hardly relevant to the prime, assimilation in the interpretation of the observed behavior/trait can occur if the primed construct is highly accessible. 
A second condition for assimiliation to occur is a certain degree of ambiguity in the behavior or person that is interpreted. As Moskowitz (2005, p. 412) states, "If someone acts in a clearly counter-stereotypical way, an accessible stereotype will not be used in our impression”. Also, this is an argument for the point made before, that name-dropping might be most effective on new acquaintances because they know less about the actor and therefore find him more ambivalent with regard to the trait in question (e.g., sportiveness) than old friends do (e.g., who know for sure that the actor hates working out).

A third condition is assertibility. Assimilation will not occur if the target does not feel allowed to judge the actor in an assimilative way, for example, because she has just been instructed to avoid stereotypical thinking (thus, no assimilation along stereotypes will occur), or because she thinks that she is being held publicly accountable for her decision (which fosters systematic, thorough thinking, see Tetlock, 1985).

Last, the targets must not be aware of the assimilative influence on their judgment, otherwise they will take steps to avoid assimilation. This is in line with the finding that suspicion about ulterior motives can hinder the intended effects of impression management tactics on a target (Fein et al., 1990; see also Gilbert, 1989).

\subsection{Spontaneous Trait Transferences}

In section 1.1.2, I have described the spontaneous processes of trait inference that individuals engage in when they observe a person's trait-implying behavior. Recent research has extended this notion to spontaneous trait transferences (Andersen \& Glassman, 1996).

Skowronski, Carlston, Mae, and Crawford (1998) found that communicators become associated with the traits they describe in others. In other words, traits are transferred from the described individual to the describing actor. In this experiment, the authors used a savings-in-relearning paradigm based on the premise that it is easier to relearn previously learned associations than to form new associations. Research participants saw photographs of a communicator and read trait-implying behaviors that this communicator assigned to an acquaintance, for 8 seconds per photograph/behavior. After 15 minutes with a distraction task, participants were asked to learn pairs of photographs and traits that were presented to them a pair at a time. Some pairs were familiar (i.e., communicators who had before implied these 
traits in the description of their acquaintance's behavior) and some were new. If research participants recalled more traits correctly when the traits are cued from old than from new photographs, this would indicate that they had associated the communicator with the respective trait even though the communicator was not talking about himself.

This is exactly what the authors found. Interestingly, research participants maintained these associations between communicator and the traits of the other person over a two-day period, but only if they had not been warned about possible trait transferences before, i.e., if they were naïve to this effect. When they had been warned, they nevertheless showed transference within the initial session, but not any more on the second session two days later. This indicates that spontaneous transference is impossible to avoid, but encoding in memory might be less stable when individuals try to avoid it. These spontaneous trait transferences were measured both as recall and on Likert-type trait rating scales.

The inferences are trait-specific, i.e., recall is not improved for other traits, be they similar or dissimilar to the learned trait, thus it is more than just a general evaluative reaction to the communicator. In addition, it has been ruled out that research participants merely misinterpreted the communicator's others-description as selfdescription (study 2). The authors also showed that these associations are indeed spontaneous in nature, lacking any conscious or controlled processes such as attribution or reasoning (study 3 and 4).

Skowronski et al. (1998) put this effect to a test in a more natural setting (study 4) by asking research participants to watch a video tape in which a communicator gave a trait-implying description of either self or another person and either gave a positive description (e.g., honest) or a negative description (e.g., dishonest). Two days later, research participants rated the communicators on trait ratings scales, each ranging from positive to negative. It was found that communicators who described another person as positive were perceived more positive themselves than communicators who described the other person as negative. Again, this was a trait-specific effect that occurred only for the traits mentioned in the tape, not a general evaluation in the sense that communicators who talk positively about others are perceived more positively in general.

Thus, not only do people infer traits automatically when they observe traitrelevant behavior, they also transfer these traits from the described individual to the 
actor who gave the description, and they even do so in quite natural settings and with trait rating scales as dependent measures (which indicates conscious processing to some degree). Also, these effects have been shown to be quite persistent, affecting ratings up to two days after the spontaneous association of trait and person. A caveat is indicated: Recent evidence suggests that transference effects might not be special to the person perception process but instead apply to inanimate objects as well (Brown \& Bassili, 2002).

\subsection{Source Confusion}

Additional indirect support for transference effects stems from research on disregard for source information: People sometimes forget that events were described to them rather than directly experienced (Johnson, Hashtroudi, \& Lindsay, 1993). Also, research on the sleeper effect indicates that perceivers tend to overlook the proper source of a persuasive message, which even enhances the impact of the message (Pratkanis, Greenwald, Leippe, \& Baumgardner, 1988). Source confusion can lead to misattributions, i.e., one individual's traits or behaviors are associated to another individual in the mind of the perceiver.

\subsection{Exemplars: The Famous and the Significant}

What role plays the valence of the mentioned names? Social cognitive research provides information on the effects of particularly significant exemplars. Some such exemplars are important only to a particular group of people or even individuals (e.g., "Aunt Maggie”), others are famous and thus well-known to most people (e.g., world tennis champion Roger Federer) - what they have in common is a strong positive or negative valence.

For example, Macrae et al. (1998) showed that behavior can be primed by famous exemplars: When research participants participated in the "Schumacher Word-Reading Test”, they were faster in their test responses than research participants in unnamed or neutrally named tests. Thus, the prime "Schumacher" activated speed concepts and caused research participants to complete a wordproduction task significantly faster than those who had not received an equivalent prime (but see also sections 1.4.3.1 and 1.4.3.2).

If perceivers automatically activate exemplars when presented with triggering verbal stimuli, and if they even change their behavior according to the information 
associated with these exemplar, the mentioning of such exemplars by an actor might very well activate the respective categories in a target and influence his perception of the actor. As Macrae et al. (1998) stated, “Activated exemplars ought to have pervasive effects on our evaluations of others" (p. 347).

When names elicit not just any category but our well-established associative network of close others, such as friends and family, the activated categories and exemplars are especially powerful. Andersen and Cole (1990) hypothesized that memory representations of significant others can be activated in social interaction and that they then influence inferences about new people and affective responses. They found that the representations of significant others are richer than other social categories, that they are more easily accessible, and that more inferences about an unfamiliar individual are made when that individual is assimilated into an existing similar-other representation compared to any another type of social category.

Chen (2001, 2003) argued that our mental representations of significant others are more complex than other social categories, that they are whole theories about the interactions of situations and the behavior of a significant other, and mediating psychological states of the significant other that explain the link between situation and behavior. Chen and Andersen (1999) and Chen, Andersen, and Hinkley (1999) found that people attribute characteristics of a significant other to a new acquaintance if the significant other and the acquaintance have something in common. Thus, if there is a commonality, people extrapolate to other characteristics and view the two individuals as more similar, beyond the evidential commonality.

With regard to affective components of these representations of significant others, Fiske (1982) reported evidence for what she calls "schema-triggered affect”, i.e., affective transference from a significant other (a past romantic partner or crush) to a new individual, triggered by category activation (“my old flame”). Similarly, Gilovitch (1981) reported the “coloring” of judgments of new people by comparison with others one knows something about.

It is clear from this evidence that name-dropping should be more effective for associations with famous individuals. Familiarity enhances the efficiency (and speed) of judgments in general (Prentice, 1990). Also, descriptors that bear a reference to the self or to a familiar other are more easily encoded and retrieved, probably because organization of such stimuli is enhanced and they are, thus, highly accessible. Due to the network organization of our person and social memory, 
accessibility is not only heightened for significant others, but for all the concepts associated with these, e.g., affect and valence as found by Fiske (1982) or Gilovitch (1981).

\subsection{Behavioral Priming}

Another domain that shows the influential nature of activated categories beyond the prime itself is behavioral priming. Specifically, participants' behavior can be primed with categories as well as exemplars (see also Macrae et al., 1998). Bargh, Chen, and Burrows (1996) presented research participants with words that are related to the stereotypes of elderly people, e.g., “old”, “gray”, or “Florida” and found that participants afterwards walked away from the laboratory more slowly, as if they were enacting the stereotype. Similarly, priming of rudeness elicited interrupting of the experimenter. Dijksterhuis and van Knippenberg (1998) activated the category "professor" in research participants and found that accessibility of that category enhanced participants' performance in a game of trivial pursuit. Similarly, they found that the trait prime "intelligent" made participants show better general knowledge in subsequent tests. They reasoned that assimilation is not restricted to judging other individuals, that accessible categories also influence the target's own behavior. Priming intellectual performance is an impressive accomplishment that shows just how influential activated categories are.

\subsubsection{Summary}

With regard to evidence from social cognition research, indirect categorization effects are of special relevance to the name-dropping concept. Indirect categorization occurs if categorization exerts influences beyond the categorized individual. I assume that in name-dropping, categorizing a mentioned individual influences perceptions and evaluations of the actor who mentioned that individual.

Evidence from attitude activation, assimilation, and trait transferences suggests that impressions can transfer from one individual to the other, and research on exemplars and behavioral priming shows how influential associations evoked by names are on impression formation and behavior. 


\subsubsection{Adverse Effects of Name-Dropping}

Special to the name-dropping tactic is that the picture of another individual is evoked. Person perception activates our rich associative network of categories, and this bears the danger of backfire effects that are not likely in other tactics. For example, social comparison theory suggests that every other individual we meet triggers comparison processes between ourselves and the other (Festinger, 1954). Also, priming studies show that not only the self is influenced but also another individual that is part of the comparison process, e.g., an actor. As a result of such comparison processes, assimilation or contrast can occur. If we assume that namedropping is used as a tactic to appear favorable in the eyes of a target and thus positive individuals are mentioned by an actor, assimilation is likely to occur. However, contrast effects might lead to backfire effects if the actor is contrasted against the mentioned positive individual.

\subsubsection{Contrast Effects vs. Assimilation}

Just as categories can lead to contrast effects in judgments of others, they can also, via behavioral priming, cause performance to diminish. Dijksterhuis and van Knippenberg (1998) used an extreme exemplar instead of stereotypes and traits, namely Albert Einstein, to prime intelligence. Faced with Einstein's brilliancy, participants showed a contrast effect, i.e., their performance in general knowledge deteriorated. Dijksterhuis et al. (1998) replicated this finding for non-intellectual behavior: Primed with the Dutch Queen Mother as an exemplar of an elderly person, participants walked faster following the priming. When it comes to name-dropping as an association tactic as opposed to a distancing tactic, such contrast effects are detrimental to the actor's intentions. He might be contrasted against the mentioned individual and make an unfavorable impression on the audience.

According to the set/reset model by Martin (1986), contrast effects occur when first impressions are overcorrected. This happens when an individual assumes that she has been "set" on her impression by accessible constructs and that she is about to show assimilation due to that. She will therefore correct her initial impression in the opposite direction. While adjusting for a potential biasing influence ("reset”), she is likely to overcorrect. Thus, if the target feels that the mentioning of Roger Federer 
might have lead her to assimilate the actor's sportsmanship to those high standards, if she is aware that the source of her high ratings on actor's sportsmanship are due to Roger Federer instead of the actor himself, she will correct this bias and end up perceiving the actor as less sportive than without his mentioning of Roger Federer. Thus, if indirect self-presentation is done too blatantly, awareness of potential biasing influences motivate the target to attempt to remove the bias from judgment. Individuals then tend to leap to the opposite conclusion, to "reset" their previous impression in an exaggerated way, contrasting the actor against the source (Martin, Seta, \& Crelia, 1990).

Mussweiler (2003a, 2003b) has suggested a model to predict when contrast as opposed to assimilation occurs. His explanation is different to Martin's (1986) and based on stage-models of person judgment and selective hypothesis-testing (Trope \& Liberman, 1996). Mussweiler predicts that assimilation will occur whenever the target is compared to a standard that is perceived as similar to the target, and contrast will occur whenever the standard is perceived as dissimilar to the target. Thus, if an audience perceives Roger Federer as the standard of sportiveness and popularity to which the actor is compared, and if the audience in a first stage of judgment concludes that the actor is dissimilar to this standard, the actor will be contrasted against Roger Federer and found less sportive and less likeable.

Conditions for assimilation vs. contrast also differ with regard to awareness. Whereas assimilation has been shown to work best without awareness, contrast effects might be greatest when an individual is aware of potential influencing behaviors. Moskowitz and Roman (1992) either presented trait-implying behaviors subtly (participants were asked to memorize the descriptions) or blatantly (participants were asked to form an impression based on the description). When participants afterwards read about an ambiguous trait-relevant behavior in an ostensibly unrelated experiment, they showed assimilation effects with regard to the unconsciously inferred traits (subtle condition), but contrast effects with regard to the consciously inferred traits (blatant condition). Strack, Schwarz, Bless, Kübler, and Wänke (1993) replicated this finding, using reminders of previous primes as a means to make participants aware of potential biasing influences. They also found both assimilation and contrast effects, depending on the participants' awareness. This is in line with the prediction that impression management efforts backfire when the target suspects ulterior motives in the actor. 


\subsubsection{Person Exemplars vs. Traits}

Stapel and colleagues (Stapel \& Koomen, 2001; Stapel, Koomen, \& van der Pligt, 1996, 1997) state that person exemplars, as opposed to other primes such as traits, can lead to both assimilation and contrast, depending on the extremity of the exemplar. Extreme exemplar priming overrules assimilation by contrastive comparison processes because the degree of distinctness is different: Extreme exemplars (i.e., prototypes) are narrower and more distinct and separate entities and therefore more likely to be used as a comparison standard. According to these authors, abstract traits lack this distinctiveness and can therefore not be as readily used as comparison standard, thus, traits instead tend to assimilate judgments. However, Moskowitz and Skurnik (1999) showed that traits can nevertheless result in contrast effects when the trait prime is moderate rather than extreme. Thus, extremity exerts opposite effects on trait versus exemplar primes.

Person exemplars have also more "comparison relevance" when a person is supposed to be the target of the judgment because, according to Brown (1953), person exemplars have in common with the person target that they are both part of the same (person) category. Adverse effects of name-dropping might occur if the actor is, with regard to the relevant association made, clearly not part of the same social group as the individual mentioned. For example, if an undergraduate student associates with a specific Nobel prize winner, the student's academic performance might be perceived as less impressive than without the name-dropping tactic.

\subsubsection{A Caveat: How Applicable is the Concept of Spontaneous Trait Tranference to Name-Dropping?}

I have drawn on findings of spontaneous trait inference and transference to suggest positive effects of name-dropping. However, name-dropping is itself a behavior. If it is a trait-implying behavior, the inferred trait will influence the evaluation of the target accordingly. Recall Skowronski's et al. (1998) relearning paradigm that I described in detail in section 1.4.2.2.3, and imagine that participants have to learn pairs of person pictures and sentences such as "John told his girlfriend that he had met Brad Pitt" or "Clarissa mentioned that she knows Bill Gates 
personally" - would those sentences imply any traits, and if so, would those traits be regarded positive or negative? We do not know that so far. In fact, complex traits such as being showy or urbane have, to my knowledge, not yet been used in the paradigms of spontaneous trait inference research. Although a related trait, “conceited”, has been used by Carlston and Skowronski (1994), the trait-implying behavior description has been very strong $(100 \%$ of the pretest subjects spontaneously assigned “conceited” to the statement). Name-dropping as a behavior might be less trait-implying regardless of the way the behavior description is given. Additionally, just as impression management use in the resume, name-dropping might have differential effects for the tactician depending on the description itself: It might backfire if it is done too blatantly or it might have no effect at all if it is done in a way that does not imply traits.

\subsubsection{Actor and Target Characteristics}

We know from impression management research that appropriateness of tactics is central to their success. To evaluate appropriateness, we have to go beyond the actor and the selected individual to associate with, and draw on target characteristics. Appropriateness might be in the eye of the beholder and conceived differently depending on the role of the actor, the role of the target, and status differences between them. For example, a professor who mentions a Nobel prize winning colleague in her lecture might bask successfully in that colleague's glory and be found influential and admirable by her students. However, if one student tries to impress a fellow student with his friendship with a Nobel prize winner, the association might be seen as inappropriate, even unlikely and questionable. Similarly, target age and background might lead to different outcomes of namedropping; older targets might be less naïve and more readily suspicious than younger targets.

Although it is beyond this introduction to discuss all target characteristics and their possible interactions with actor characteristics and context circumstances, one influential line of research should be mentioned. With regard to social comparison processes Tesser's (1988) Self-Evaluation Maintenance (SEM) model states that the effects of the comparison on our self-esteem and the impression we develop of the individual that we compare ourselves with depend not only on whether we are 
outperformed or not, but also on how relevant the topic at question is to us. If we are outperformed and the topic is highly important to our self-concept, outperformance is a threat to self-esteem. In order to restore self-esteem, we might devaluate the rival and/or attribute outperformance to situational, external causes. However, if we are outperformed and relevance to our self-concept is low, the SEM predicts that we would not see the other as a rival but rather as a possibility to associate with and bask in his glory. Thus, even if an actor's name-dropping elicits social comparison processes, characteristics of the target himself might decide whether the he reacts positively or negatively.

\subsubsection{Summary}

This last section of the introduction dealt with possible negative effects of namedropping on the impressions a target forms of the name-dropping actor. Central evidence stems from social cognition research on contrast effects: Associating oneself with a positive individual might sometimes lead not to assimilation with the individual's desired characteristics and abilities, but to looking pale in comparison, i.e., being less desirable. This is central to the construct of name-dropping because exemplars as opposed to traits seem especially prone to contrast effects. 
1.5 Table and Figure 
Table 1

\section{Impression Management Classification Scheme}

\begin{tabular}{|c|c|}
\hline Impression Management Tactic & Definition \\
\hline \multicolumn{2}{|l|}{ Verbal tactics } \\
\hline Assertive tactics & Attempts to actively construct an image \\
\hline \multicolumn{2}{|l|}{ Other-focused } \\
\hline Other-enhancement & The praising of another person, being complimentary \\
\hline Opinion conformity & $\begin{array}{l}\text { Expressions of beliefs, values, or attitudes that are known } \\
\text { or that could reasonably assumed to be held by the target }\end{array}$ \\
\hline \multicolumn{2}{|l|}{ Self-focused } \\
\hline Self-promotion & $\begin{array}{l}\text { Verbally demonstrates the possession of desirably } \\
\text { qualities, such as competence, reliability, } \\
\text { conscientiousness }\end{array}$ \\
\hline Entitlements & Claims of responsibility for positive events \\
\hline Enhancements & $\begin{array}{l}\text { Claims that the values of a positive event for which the } \\
\text { candidate was responsible are greater than most people } \\
\text { might think }\end{array}$ \\
\hline Overcoming obstacles & $\begin{array}{l}\text { Descriptions of how the candidate circumvented problems } \\
\text { or barriers impeding progress toward a goal }\end{array}$ \\
\hline Basking in reflected glory & $\begin{array}{l}\text { Enhancing one's image by claiming association with } \\
\text { prestige figures or prestigious institutions }\end{array}$ \\
\hline Goal setting & $\begin{array}{l}\text { Setting a clear goal for oneself or someone else (plans for } \\
\text { the future) }\end{array}$ \\
\hline Personal stories & $\begin{array}{l}\text { Descriptions of specific past events or actions, such as } \\
\text { recounting the details of one's work experiences in a } \\
\text { particular instance }\end{array}$ \\
\hline Intimidation & $\begin{array}{l}\text { Seeking to appear threatening in an attempt to have others } \\
\text { view him/her as dangerous }\end{array}$ \\
\hline Supplication & $\begin{array}{l}\text { Advertising one's shortcomings in an attempt to be } \\
\text { viewed as needy, and elicit sympathy from others }\end{array}$ \\
\hline Defensive tactics & $\begin{array}{l}\text { Attempts to respond to a perceived, potential, or actual } \\
\text { threat to the candidate's image }\end{array}$ \\
\hline Excuses & $\begin{array}{l}\text { Statements in which the candidate denies responsibility } \\
\text { for the negative consequences of an action }\end{array}$ \\
\hline Justifications & $\begin{array}{l}\text { Statements in which the candidate accepts responsibility } \\
\text { for the effects of his/her behavior but denies the negative } \\
\text { implication of such responsibility }\end{array}$ \\
\hline Apologies & $\begin{array}{l}\text { Accepting responsibility for a negative outcome/behavior } \\
\text { along with the acknowledgment that certain actions were } \\
\text { unacceptable and should be punished }\end{array}$ \\
\hline Disclaimers & $\begin{array}{l}\text { Attempts to remove oneself from possible negative results } \\
\text { that may occur in the future }\end{array}$ \\
\hline \multicolumn{2}{|l|}{ Nonverbal tactics } \\
\hline Smiling & The number of times the candidate smiles \\
\hline Hand movement & $\begin{array}{l}\text { The number of times the candidate moves one or both } \\
\text { hands, without gesturing toward anyone }\end{array}$ \\
\hline Eye-contact & $\begin{array}{l}\text { The number of times the candidate makes eye-contact } \\
\text { with the target }\end{array}$ \\
\hline Head nods & $\begin{array}{l}\text { The number of times the candidate nods in agreement } \\
\text { with the target }\end{array}$ \\
\hline Hand gestures toward the target & $\begin{array}{l}\text { The number of hand movements the candidate makes } \\
\text { toward the target }\end{array}$ \\
\hline Hand gestures toward objects & $\begin{array}{l}\text { The number of hand movements the candidate makes } \\
\text { toward objects }\end{array}$ \\
\hline Hand shakes & The number of times the actor shakes hand with the target \\
\hline
\end{tabular}

Note. Adapted from McFarland et al. (2005), p. 953f. 
Figure 1. Example of a balanced triad according to Heider (1958).

$+$

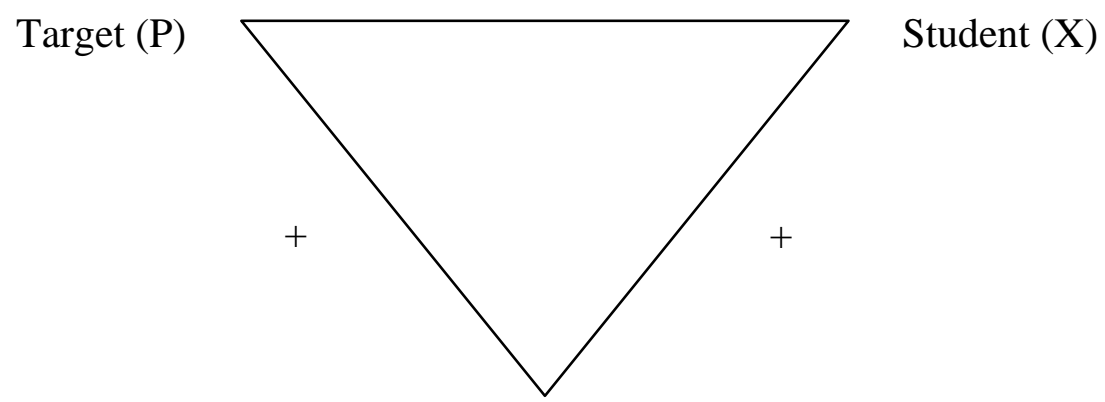

Successful Football Team (O) 
Running Head: NAME-DROPPING AS A SELF-PRESENTATIONAL TACTIC

Name-Dropping as a Self-Presentational Tactic: Does It Work?

Carmen Lebherz

University of Zurich 


\begin{abstract}
Prior research on impression management has looked at the kinds of tactics that people use to be perceived by others as likeable and competent (e.g., Schlenker \& Wowro, 2003), and some, but much less, research was devoted to the effects: Do these tactics actually improve the way others see us? I hypothesize that name-dropping, defined as mentioning other people by giving their full name and by assigning a subtle positive valence to those people, is one such tactic that improves the spontaneous impression others form of a person. In Study 1, students listened to a short recording allegedly taken from a lecture and then stated their impression of the lecturer. The results confirm that the use of name-dropping improves the audience's impression of the lecturer's general competence and qualification as a researcher. Two replication studies partially confirm the results and provide information on mediating variables.
\end{abstract}




\section{Name-Dropping as a Self-Presentational Tactic: Does It Work?}

Since Ervin Goffman's seminal publication “The presentation of self in every-day life" in 1959, much has been published on the tactics people use to present themselves favourably to others. Many classification schemes have been developed, for example along whether the tactics intend to improve liking vs. perceived competence, whether

they are assertive vs. defensive, or whether they are self-directed vs. other-directed (e.g., Jones \& Pittman, 1980; Kacmar, Delery, \& Ferris, 1992; Stevens \& Kristof, 1995). Recently, Ellis, West, Ryan, and DeShon, (2002) gave an excellent overview of the different classifications.

Cialdini and Richardson (1989) differentiated between a direct and an indirect route of what they called "strategic self-presentation". When people present themselves to others via the direct route, they directly tell those others about their favourable characteristics, skills, or accomplishments. When people present themselves to others via the indirect route, they do not explicitly state this information about themselves, but convey it via people or things associated with them. For example, if a person wants to be regarded as public spirited, she might convey this impression by buying fair trade products. If someone wants to be regarded as intellectual and thoughtful, he might carry Nietzsche's "Zarathustra” about with him everywhere he goes.

We are known by the company we keep, and this company's influence might be strongest not for groceries or books, but for people. As Cialdini, Finch, and De Nicholas (1990) state, "for most observers, what we do is often less important than whom we do it with" (p. 194). Thus, the personal associations we have and show are central to the impressions others form of us. We know that people actually use this tactic of association. 
Cialdini and De Nicholas (1989) found that college students used the personal pronoun "we" much more often in an description of a football match when their university's football team had won that match as opposed to lost it, thus associating themselves with the team or not, depending on the valence of the association. Cialdini and colleagues termed this specific form of self-presentation "basking in reflected glory", or BIRG. End, Dietz-Uhler, Harrick, and Jacquemotte (2002) recently replicated their results that individuals actively bask in the glory of successful others.

However, Kacmar and Carlson (1999) rightly state, "focusing only on the actor side of this process does not allow the effectiveness of the impression management attempts to be evaluated, as the target makes this determination" (p. 1293f). There is a general lack of research on the effectiveness of self-presentation endeavors, and a specific lack regarding the effects of BIRG. To my knowledge, it has so far not been tested whether basking improves the impression an audience forms of the respective person.

The studies presented in this paper investigate the effects of a particular tactic on an audience, a tactic that shares some features with the BIRG concept. Specifically, I hypothesize that the BIRG results apply to name-dropping, a tactic that I define as mentioning other people whose names bear a subtle positive valence and establishing a positive association with these others. Just as Cialdini and De Nicholas (1989) tested whether people use BIRG, I want to test whether a person using such tactic is actually perceived more positively by others. My hypothesis is that name-dropping has a positive effect on an audience.

The core dimensions of person perception in a target of self-presentational efforts (and in any process of person perception) are competence and liking (see Rosenberg, Nelson, \& Vivekanathan, 1968; Rosenberg \& Olshan, 1970). I suggest that a person who 
uses name-dropping is perceived as more competent and is liked better in first encounters when target otherwise now little about that person's competence and likeability. This paper aims at testing this hypothesis on two German and one Swiss student samples and at discussing possible processes that might mediate the effect of name-dropping as a self-presentational tactic.

\section{Overview}

This article describes three studies that document the name-dropping effect. Study 1 was designed to show that name-dropping is a self-presentational tactic that improves competence and liking of a lecturer in the eyes of a Swiss student audience. Study 2 replicates the results of Study 1 on a sample of German students and gives further insight into mediating processes of the name-dropping effect. Study 3 investigates whether different domains of names used (e.g., names of other teaching lecturers vs. names of the general public) differentially affect competence domains (e.g., teaching vs. general knowledge), or whether the names mentioned work as a general heuristic regardless of domain.

\section{Study 1}

The aim of Study 1 is to test whether an actor who employs name-dropping is perceived differently by an audience than an actor who does not employ this selfpresentational tactic. My hypothesis is that name-dropping is beneficial for a university lecturer who mentions his colleagues during his lecture, i.e., that he is perceived more competent and is liked more by the student subjects who listen to the lecture.

In addition, I manipulated that subjects either did or did not expect to take a test on 
the lecture content. My hypothesis is that subjects' expectation to take a test induces high motivation to follow the lecture, and that this increases the name-dropping effect.

Last, I manipulated that subjects either expected a research lecture or a teaching lecture. My hypothesis is that announcing a research lecture makes subjects focus on the lecturer's research abilities and thus specifically increases research competence ratings, whereas a focus on teaching specifically increases teaching competence ratings. Due to the directional hypotheses, one-sided testing is used in all analyses.

Method

\section{Experimental Design}

The experiment is a $2 \times 2 \times 2$ factorial between-subjects design, manipulating three independent variables: name-dropping applied by the lecturer (name-dropping vs. no name-dropping), motivation of the audience to follow the lecture (high vs. low), and focus of the audience (research quality vs. teaching abilities). The dependent variables of interest are perceived competence with regard to teaching and research, perceived general competence, and liking of the lecturer.

\section{Sample}

168 students of the University of Zurich participated in this study. One case was discarded because he correctly guessed the research goals, despite the cover story. From the final sample, $51 \%$ were female, $49 \%$ male. $35 \%$ were psychology majors, $23 \%$ economics majors, and $10 \%$ law majors. The remaining $32 \%$ of the subjects split into a variety of subjects from the Humanities, Fine Arts, and Social and Behavioral Sciences. Ten students were psychology minors.

The mean age was 24.8 years, with a median of 23 years. $83 \%$ of the subjects were 
not further than in their sixth semester of studies. Students were recruited on campus and participated voluntarily. To provide an incentive to participate, I raffled 2 x CHF 100 amongst all subjects. Psychology majors received additional credit towards research credit requirement. All students were randomly assigned to one of the eight conditions.

\section{Procedure}

Up to four subjects were present in the laboratory at the same time. Subjects were welcomed and asked to choose one of four work stations, each supplied with a computer, head phones, written instructions, and the questionnaires. They were then asked to read the instruction and were $i$ that the proceeding was described in there.

In the instruction they read that they would now listen to a tape recording of a lecture, then work through the four folders in front of them in the prepared order, and that the experiment would take approx. 30 minutes. As a cover story I told subjects during recruitment and in the instruction that I was doing a study on didactics in higher education and therefore looking for students' opinion on courses.

The instruction manipulated two factors, motivation and focus. Descriptions are given in the manipulations section. The four full versions of the instruction are provided in Appendix A-1.

The end of the tape recording was indicated by a female voice who asked the subjects to open folder 1. Folder 1 contained the dependent measures in Likert scales, some free space for voluntary comment on the tape recording, and the request to close folder 1 and move on to folder 2. Folder 2 contained the manipulation check items in Likert scales and the request to close folder 2 and open folder 3 . Folder 3 asked about subjects' familiarity with and prior knowledge on the lecture topic, work organization. They were also asked whether they had participated in a similar experiment six months before, and 
what they thought was the research goal of the experiment. On a second sheet, subjects provided information about their study subjects, study year, gender, age, nationality, and mother tongue. ${ }^{1}$ They were requested to open folder 4 , which contained my thanks for participation and the written debriefing. Subjects in the high motivation condition were also informed that anticipation of a multiple choice test should heighten their motivation to listen carefully to the recording, and that the test would not take place.

Before the students left, they were offered to receive notice of the experiment's results. Interested students left their email address and were later contacted with information on the results by the author.

\section{Manipulations}

The factor name-dropping was manipulated in the tape recording. Two versions exist, and transcriptions of both are provided in Appendix B-1.

The factors motivation (motivation of the audience to follow the lecture) and focus (focus of the audience on research quality vs. teaching abilities) were manipulated in the written instruction.

Name-Dropping: In the condition without name-dropping, subjects listened to an alleged section of a lecture on work organization. The male lecturer defined and explained the terms job enlargement, job enrichment, and job rotation during the approx. seven-minute section. In the condition with name-dropping I used the same tape, but the lecturer added a total of nine name-dropping sequences during his lecture: three regarding teaching aspects (e.g., "I agree with textbook authors such as Ansfried Weinert..."), three regarding research aspects (e.g., "I refer you to research done by Klaus Giersiepen and his colleagues at the Institute for Prevention Research and Social Medicine in Bremen"), and three regarding general knowledge on the topic of work 
organization (e.g., "The journalist Dieter E. Zimmer took up this aspect in a recent article”). The full list of name-dropping sequences is provided in Appendix B-1.

Motivation: In the high motivation condition, subjects read in the instruction that they were to take a five-question multiple-choice test on the content of the lecture recording after completing the questionnaires in the folders. In the low motivation condition, no such test was mentioned.

Focus: In the research focus condition, subjects read that the tape recording was a research lecture on work organization, and that the aim of the lecture was to provide the audience with information on relevant research. In the teaching focus condition, subjects were told that the tape recording was a teaching lecture on work organization, and that the aim of the lecture was to provide the audience with knowledge on the topic.

\section{Measures}

\section{Dependent Measures}

I assumed that there are three dimensions of competence relevant to the lecture setting that can be perceived by students of a lecturer: teaching competence, research competence, and general competence (such as intelligence). Liking is a fourth dimension that has been found central to person perception. Thus, I suggest four dimensions as dependent measures. Table 1 lists the dimensions and their items, descriptive statistics, Cronbach's $\alpha$, and item-total correlations in this sample.

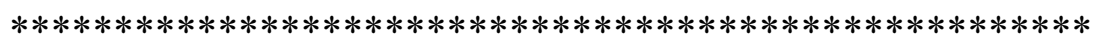

Table 1

Suggested Dimensions of the Dependent Measure 
Teaching Competence and Research Competence comprised four items each, General Competence comprised five items, and Liking two items. All items were rated on 7point Likert scales ranging from 1 ("not at all true)" to 7 ("absolutely true").

\section{Manipulation Check}

The manipulation check questionnaire contained 17 items, four seven-point Likert scales to check on the name-dropping manipulation (e.g., "The lecturer quotes authors and publications"), two seven-point Likert scales to check on the motivation manipulation (e.g, "While listening, I zoned out from time to time"), and two dichotomous items to check on the focus manipulation (e.g., "While listening to the tape, I focused primarily on a) how the lecturer explains and conveys knowledge, b) how the lecturer presents research”.) All manipulation check items were part of the second questionnaire, which is provided in Appendix C-1.

\section{Control Variables}

Several items were included as control variables. Four items measured the general quality of the lecture, and no differences between the experimental conditions were expected on these. Two items measured the subjects' ability to understand the lecture, and high scores were expected on these items for all conditions. One variable controlled for the possibility that the name-dropping manipulation was interpreted as additional information by the subjects. A pretest had shown that previously used sequences had confounded name-dropping with practical examples, and that students considered those examples an important indicator of the lecture's quality. To control for this possibility, the item "The lecturer provides practical examples" was included. These control variables were part of the second questionnaire, which can be found in Appendix C-1. 
In addition, several biographical data were included to ensure that conditions do not differ systematically with regard to subjects' gender, age, year of study, prior knowledge in the topic of the lecture, and having psychology as a major or minor.

\section{Results}

\section{Manipulation Check}

To test the manipulation, a MANOVA was calculated with the manipulation check items as dependent variables. For this, the variables were aggregated to form a namedropping scale (4 items, $\alpha=.78$ ) and a motivation scale (two items, $\alpha=.18$ ). For the focus items, alpha reliability was not calculated due to the dichotomous nature of the items.

The name-dropping manipulation was successful: A main effect on the mean of the name-dropping scale $(F=404.38, p<.001)$ indicated that subjects in the name-dropping condition were more likely to acquiesce that names were mentioned on the tape.

The motivation manipulation was not successful, there was no difference between the conditions. Due to the scale's low reliability of $\alpha=.18$, both items were also analyzed as separate dependent variables; however, none of the items yielded a significant difference between the experimental conditions. Thus, the motivation manipulation was not successful.

The focus manipulation was not successful, only $46 \%$ of subjects applied the correct focus according to self-report, and only $74 \%$ correctly remembered the instruction, i.e., whether the tape was introduced as a research lecture or a teaching lecture.

There were no interaction effects of the independent variables on the manipulation check items. Thus, I discarded the motivation and focus manipulations and considered only name-dropping the independent variable for all further analyses. Subsamples in the 
conditions were comparable, thus, all cases remained in either the name-dropping or the control condition.

\section{Control Variables}

The control variables were aggregated to form two scales, "General quality of the lecture" $(\alpha=.47)$ and "Subject's ability to follow the lecture" $(\alpha=.62)$. In addition, the item "The lecturer gives practical examples" was used as a control. A MANOVA yielded no differences between the name-dropping conditions for any of the control variables. As expected, subjects' ability to follow the lecture was high, and the lecture was generally considered good, although quite boring. Table 2 shows means and standard deviations of the control variables.

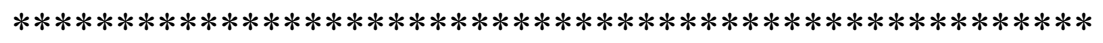

Table 2

Descriptive Statistics of Control Variables

$* * * * * * * * * * * * * * * * * * * * * * * * * * * * * * * * * * * * * * * * * * * * * * * * * * * *$

Also, no differences existed between the name-dropping conditions regarding biographical data of the subjects. That is, subjects were comparable in gender, age, year of study, and prior knowledge in the topic of the lecture, and both conditions had similar percentages of subjects with psychology as a major or minor.

\section{Structure of the Dependent Measures}

An explorative principal component analysis was calculated to compare the postulated dimensions of competence and liking with the structure of the empirical data. Oblique rotation (direct oblimin) was used because I assumed that the dimensions are 
correlated. This assumption is valid for many psychological variables in general (Fabrigar, Wegener, MacCallum, \& Strahan, 1999) and for person perception in particular (e.g., Asch, 1946). Specifically, I assumed that students do not differentiate in a clear-cut way between their professors' research quality, teaching abilities, and general competence. ${ }^{2}$ Exploratory analysis was used as opposed to Confirmatory Factor Analysis because little is known about person perception dimensions in the lecture setting I used, and because sample size is too small (Fabrigar et al., 1999).

To retain an appropriate number of factors, I used the Kaiser criterion (eigenvalues > 1; Kaiser, 1960) and verified it with a scree test (Cattell, 1966). Table 3 shows the threefactor solution. Analysis of the pattern matrix suggest the dimensions Research Competence, Liking, and General Competence. However, three of the postulated variables of General Competence load strongly on the Research Competence factor, namely the items "I think the lecturer is very intelligent", "The lecturer has good general knowledge", and "The lecturer is an expert in his field." Factor 3 comprises four heterogeneous variables, from which two were theoretically attributed to Teaching Competence and two were attributed to General Competence. Therefore, I named Factor 1 "Research and General Competence", Factor 2 "Liking", and I considered Factor 3 a residual factor that can not be interpreted.

$* * * * * * * * * * * * * * * * * * * * * * * * * * * * * * * * * * * * * * * * * * * * * * * * * * * *$

Table 3

Rotated Factors and Item Loadings

$* * * * * * * * * * * * * * * * * * * * * * * * * * * * * * * * * * * * * * * * * * * * * * * * * * * *$ 
Factor loadings are satisfying and all but one item are clearly attributable to one of the factors, namely, the item "The lecturer imparts knowledge very well" loads strongly on both Liking and the residual factor. To sum, the structure diverts from the theoretical dimensions in that Teaching Competence is not found as a separate factor but is split over the dimensions Liking (two items) and the residual factor (one item). Also, one of the Teaching Competence items loads on two factors to very similar degrees, and this item is disregarded in all further analyses. The factor Research Competence is found in the empirical data with all postulated items but also includes items from the postulated factor General Competence.

I repeated the principal component analysis without the ambivalent item and confirmed the structure for the remaining 14 items. The three factors account for $67.09 \%$ of the total item variance. The coefficient alpha reliabilities are $\alpha=.87$ for Research and General Competence (seven items), $\alpha=.88$ for Liking (four items), and $\alpha=.78$ for the residual factor (three items). The correlations between the factors are moderate: Research and General Competence correlates with Liking with $r=.36$ and with the residual factor with $r=-.38$; Liking correlates with the residual factor with $r=-.32$. This indicates that the three factors can be clearly distinguished from one another. The following analyses and result reports will use the factor scores of the empirically found dimensions as dependent measures.

Several biographical data could influence the perception of the lecturer because they bring with them different backgrounds and different degrees of experience with lectures, namely age, prior knowledge, and year of study. Therefore, the three factors and their means were correlated with these variables. Correlations were all low and not significant, and no biographical data were included as covariates in the analyses. 


\section{Effect of Name-Dropping on the Dependent Measures}

To test the effect of name-dropping on students' perception of the lecturer, a multivariate analysis of variance (MANOVA) was performed with name-dropping as independent variable and the three empirically found factors as dependent variables. The results are shown in Table 4.

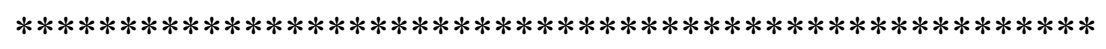

Table 4

MANOVA with Factor Scores as Dependent Measures

The subjects confronted with name-dropping rated the lecturer more favorably on the factor Research and General Competence than did subjects not confronted with namedropping $(F=3.33, p=.04)$. In MANOVA, eta-squared $\left(\eta^{2}\right)$ can be interpreted as an effect size that estimates the proportion of variance accounted for by the factor (Cohen, Cohen, West, \& Aiken, 2003). Here, the effect is $\eta^{2}=.02$, which is considered small (Cohen, 1988). The lecturer using name-dropping was also perceived as more likeable, however, for the factor Liking the results do not reach statistical significance $(F=1.03$, $p=.16$.

As explained in the introduction, there has been no prior research on the concept of name-dropping and its effects on an audience. Therefore, it is possible that at least some subjects respond negatively. Included in the questionnaire with the dependent measures was a final open question, "Do you have any more remarks on the lecturer or on the 
lecture?" From all the subjects who filled in remarks, 12 explicitly stated that the names, references, and/or publications mentioned (all of which were part of the name-dropping manipulation) annoyed them. Because there is an overall tendency toward a positive effect of name-dropping that might be impaired by a minority of subjects who respond very negatively to name-dropping, I used such annoyance by name-dropping as a covariate. The results of the multivariate analysis of covariance (MANCOVA) are shown in Table 5. They support the hypothesis: The positive effect of name-dropping on competence evaluation of the lecturer increased if annoyance with name-dropping was controlled for $(F=4.18, p=.02)$. The effect size estimate rose to $\eta^{2}=.03$. Also, the factor Liking showed an effect size of $\eta^{2}=.02$ and reached statistical significance $(F=$ $2.97, p=.04)$. Thus, both competence and liking perceptions improved in the namedropping condition if annoyance was controlled for.

$* * * * * * * * * * * * * * * * * * * * * * * * * * * * * * * * * * * * * * * * * * * * * * * * * * * *$

Table 5

MANCOVA with Factor Scores as Dependent Measures

\section{Additional Analyses}

As an additional analysis, I grouped items that load strongly on the same factor as scales and repeated the calculations with scale means instead of factor scores as dependent measures. Results are very similar: Without the covariate annoyance, no factor reaches significance. In the MANCOVA, both Research and General Competence 
$(F=3.65, p=.03)$ and Liking $(F=3.98, p=.02)$ are rated more favorably in the namedropping condition. The MANCOVA results are shown in Table 6.

$* * * * * * * * * * * * * * * * * * * * * * * * * * * * * * * * * * * * * * * * * * * * * * * * * * * *$

Table 6

MANCOVA with Scale Means as Dependent Measures

Table 7 and 8 present the means of the items of the two factors, distinguishing between the two name-dropping conditions, the name-dropping subsample that stated annoyance with the manipulation, and the name-dropping subsample that did not state such annoyance. Without exception, all items show the tendency for a positive namedropping effect: Means are higher (i.e., ratings are more positive) in the total namedropping sample and in the subsample that was not annoyed, than in the control condition.

$* * * * * * * * * * * * * * * * * * * * * * * * * * * * * * * * * * * * * * * * * * * * * * * * * * * *$

Table 7

Means of Items Loading on Factor 1

$* * * * * * * * * * * * * * * * * * * * * * * * * * * * * * * * * * * * * * * * * * * * * * * * * * * *$

$* * * * * * * * * * * * * * * * * * * * * * * * * * * * * * * * * * * * * * * * * * * * * * * * * * * *$

Table 8

Means of Items Loading on Factor 2

$* * * * * * * * * * * * * * * * * * * * * * * * * * * * * * * * * * * * * * * * * * * * * * * * * * * *$ 


\section{Discussion}

My data support the hypothesis: Using name-dropping in a lecture can improve the impression the lecturer makes on the student audience. The effect has been shown on two empirically established factors, Research and General Competence and Liking, and all items of the factors showed the hypothesized direction of the effect. That is, the lecturer who mentioned colleagues was perceived as a more highly qualified researcher and of greater general competence than the lecturer who did not mention others. This factor includes the lecturer's reputation and recognition by other researchers, the quality of his research, his expertise, intelligence, and general knowledge. The effect on liking showed if scale means were used as dependent measures, i.e., the name-dropping lecturer was perceived more likeable and agreeable. No moderating variables were found for these effects.

Despite the positive main effect, name-dropping might be a double-edged sword. Many other impression management tactics have been found backfiring. For example, if ingratiation is very transparent (Gordon, 1997) or if self-presentation in resume and cover letter is too blatant (Knouse, Giacolone, \& Pollard, 1988), the actor is evaluated negatively. In my study, several subjects explicitly stated that the names mentioned in the lecture annoyed them. Those subjects' feelings of annoyance had a direct influence on their perception of the lecturer; when annoyance was entered as a covariate, the overall positive effect of name-dropping in the total sample increased. Also, competence and liking ratings were lower in the annoyed subsample than in the condition without name-dropping, thus clearly indicating a backfiring effect. However, only 12 subjects (15\% of the name-dropping subsample) stated their annoyance, therefore, no tests could 
be run on these mean differences.

Thus, it seems that name-dropping is a tactic that may polarize the audience toward positive as well as toward negative perceptions of the lecturer. Although the negatively affected subjects made less than $15 \%$ of the sample, this number might indeed be far larger because some subjects may have been annoyed to a lesser degree and may not have explicitly commented on the reasons. At this point, I can merely speculate which variables mediate the polarizing effects of name-dropping. A closer look at the 12 subjects yielded no distinctive features with regard to gender (five were female, seven male), age, mother tongue, nationality, or year of study. However, 11 out of the 12 subjects are neither psychology majors nor minors, and 8 of the 12 are business students. This is disproportionate to the $3: 2$ ratio of psychology and business majors in the sample. It is possible that the lecture on the tape was held in a style more familiar to psychology students because the author of the lecture is a psychologist. Even if I give credit to sampling, I can only speculate whether the positive effect would have been increased in a typical sample of $100 \%$ psychology students. Also, the amount of variance explained by sampling is probably small, otherwise I would not have found the effect in a mixed sample like the one used. Further research on mediating person characteristics should focus on cognitive variables such as need for cognition or selfmonitoring, which might influence the way people process names and references in the context of a first impression. People with high need for cognition might recognize namedropping more easily as a deliberate tactic than people with low need of cognition, and high self-monitors might have a tendency to use the tactic themselves.

The manipulation of name-dropping comprised three domains, namely "research" (colleagues' names), "teaching" (colleagues' names), and "general knowledge" (e.g., 
journalist's name), with three names each. On the one hand, this ensured the broad operationalization appropriate for a new construct. On the other hand, I can hardly draw conclusions about the origins of the name-dropping effect. Is it possible that the effect is due to only one (or two) of the domains applied? The empirically found factor structure argues that all domains contributed to the overall effect: Factor 1 consists of both research and general competence items, thus it is likely that subjects drew on both domains of name-dropping to develop an impression of the lecturer's competence.

I conclude from my data that name-dropping has an overall positive effect on the first impression a person makes. I also conclude that its effect is small, that it can backfire in some parts of the audience, and that we know little yet about the process of its influence.

Missing links to the process of the name-dropping effect, i.e., by what means namedropping affects person perception, is definitely the most important limitation of this study. My aim was to establish the name-dropping effect, and I made a point for the highly specific operationalization. I think that a first study can offer only that much. There are, however, additional limitations to consider. First, the lecturer on the recording was in truth a German doctoral student. Future studies on Swiss samples should record a Swiss person to acknowledge the distinct Swiss accent in spoken German.

Second, the number of items that comprised the dependent measure of competence turned out suboptimal for factor analysis. Especially in small samples, overdetermination of factors is important, i.e. each (assumed) factor should be represented by at least four items (Fabrigar et al., 1999).

Third, and most important, the manipulation of name-dropping included not only names but also additional information such as the university affiliations of the people mentioned. It is possible that such information is regarded as additional content, thus 
adding value and quality to the lecture. Future studies need to use name-dropping manipulations that strictly separate names from information and systematically look for differential effects. Also, different domains of name-dropping should be applied separately in a between-subjects design in order to calculate the relative effects of the teaching, research, and general knowledge domains.

Fourth, the manipulation of name-dropping was rather weak because the names mentioned were unknown to the students and bore no valence to them. The effect might be increased by names that provide a strong positive association.

Last, the questionnaire did not ask subjects for possible negative reactions on the recording. Due to this, I only know of 12 subjects who explicitly commented that they were annoyed by the names and references. Future studies should include questions on negative impressions and open questions on how subjects form their impressions, as information on why and when name-dropping polarizes an audience.

Study 2

The aim of Study 2 is to replicate the name-dropping effect established in Study 1 in another German-speaking country. Furthermore, I postulate that students assume that the name-dropping lecturer knows personally the individuals he mentions and that he has particularly broad interests and knowledge, and that these assumptions mediate the positive effects of name-dropping on students' impressions of the lecturer.

I discarded the factors motivation and focus used in Study 1, for one because the manipulations failed in Study 1, for another because the name-dropping effect proved small and needs large samples to show. I therefore decided to use only two conditions, a name-dropping condition and a control group. Nevertheless, I controlled for subjects' 
motivation and focus by including the manipulation check items of Study 1.

Method

\section{Experimental Design}

The experiment is a between-subjects design with two conditions, manipulating name-dropping applied by the lecturer (name-dropping vs. no name-dropping). As in

Study 1, the dependent variables of interest are perceived competence with regard to teaching and research, perceived general competence, and liking of the lecturer.

\section{Sample}

240 students of the University of Tuebingen participated in this study. Seven subjects (3\%) did not indicate their gender; of the remaining subjects, $48 \%$ were female, $52 \%$ were male. Subjects were more heterogeneous with regard to their study majors than the Swiss sample, with $10.4 \%$ business majors, $10 \%$ law majors, $8.3 \%$ history majors, $7.1 \%$ psychology majors, and 5\% geography majors. Seventeen subjects $(7.1 \%)$ did not indicate their major. The remaining $57.1 \%$ of subjects split into a variety of subjects from the Humanities, Fine Arts, Social and Behavioral Sciences. Only ten subjects (4\%) studied Natural Sciences. Four students were psychology minors.

The mean age was 23.7 years, with a median of 23 years. Seventeen $(7.1 \%)$ did not indicate their age. The 223 students who indicated their semester of study had been studying for 6 semesters, with a median of 5 and a standard deviation of 4.3. The high standard deviation is caused by one student who had been studying for 28 semesters; apart from that, number of semesters ranged from 1 to 16 . Students were recruited on campus and participated voluntarily. To provide an incentive to participate, I raffled $4 \mathrm{x}$ EUR 50 amongst all subjects. Psychology majors received additional credit towards research credit requirement. All students were randomly assigned to one of the two 
conditions.

\section{Procedure}

Up to four subjects were present at the same time. Subjects were welcomed and asked to choose one of four work stations, each supplied with an MP3-player, head phones, written instructions, and the questionnaires. They were then asked to read the instruction and were told that the proceeding was described in there.

In the instruction they read that they would now listen to a tape recording of a lecture on the MP3-player, then work through the four folders in front of them in the prepared order, and that the experiment would take approx. 30 minutes. As a cover story I told subjects during recruitment and in the instruction that I was doing a study on didactics in higher education and therefore looking for students' opinion on courses. The instruction is provided in Appendix D-1.

The end of the tape recording was indicated by a female voice who asked the subjects to open folder 1 . Folder 1 contained the dependent measures in Likert scales, some free space for possible comment on the tape recording, and the request to close folder 1 and move on to folder 2. Folder 2 contained the manipulation check items in Likert scales and the request to close folder 2 and open folder 3 . Folder 3 asked about subjects' familiarity with and prior knowledge on the lecture topic, work organization. They were also asked what they thought was the research goal of the experiment. On a second sheet, subjects provided information about their study subjects, study year, gender, age, and nationality. They were requested to open folder 4 , which contained my thanks for participation and the written debriefing. Before the students left, they were offered to receive notice of the experiment's results. Interested students left their email address and were later contacted with information on the results by the author. 


\section{Manipulation of Name-Dropping}

The same manipulation material as in Study 1 was used: There were two versions of the recording. Transcripts of the tape recordings are provided in Appendix B-1. In the condition without name-dropping, subjects listened to an alleged section of a lecture on work organization. As in Study 1, the male lecturer defined and explaind the terms job enlargement, job enrichment, and job rotation for about seven minutes. In the condition with name-dropping I used the same tape, but the lecturer added a total of nine references during his lecture: three each regarding teaching aspects, research aspects, and general knowledge on the topic of work organization.

\section{Measures}

\section{Dependent Measures}

The same 7-point Likert scales were used as in Study 1. Several new items were included in the dependent measures questionnaire and used as information on potential mediators. Table 9 provides a list of all new items. However, for the replication I used exactly the same items as dependent variables as in the original study.

$* * * * * * * * * * * * * * * * * * * * * * * * * * * * * * * * * * * * * * * * * * * * * * * * * * * *$

Table 9

Descriptive Statistics of Additional Variables

\section{Manipulation Check}

The manipulation check questionnaire contained 17 items (including control variables) and is shown in Appendix C-2. Six 7-point Likert scales checked on the 
name-dropping manipulation (including two additional items to those in Study 1) to test the three domains teaching competence, research, and general competence with two items each. Three 7-point Likert scales checked on subjects' motivation to follow the lecture (including one additional item to those in Study 1). One of the previous dichotomous items checked whether subjects focused more on teaching or more on research, namely "While listening to the tape, I focused primarily on a) how the lecturer explains and conveys knowledge, b) how the lecturer presents research".

\section{Control Variables}

Several items were included as control variables and are listed in Table 10: Three items measured the general quality of the lecture, and no differences between the experimental conditions were expected on these. Two items measured the subjects' ability to understand the lecture and three items the subject's motivation to follow the lecture, and high scores were expected on ability and motivation items for all conditions. As in Study 1, one variable controlled for the possibility that the name-dropping manipulation was interpreted as additional information by the subjects. All control variables were part of the second questionnaire, which can be found in Appendix C-2.

In addition, several biographical data were included to ensure that the conditions do not differ systematically with regard to subjects' gender, age, year of study, prior knowledge in the topic of the lecture, and having psychology as a major or minor.

Results

\section{Manipulation Check}

Cronbach's $\alpha$ reliability was $\alpha=.80$ for the six name-dropping items and the items were thus interpreted as a homogeneous scale. A t-test for independent samples with the mean of the name-dropping scale as dependent variable shows that the manipulation was 
successful $(t=-18.86, p<.001)$ : Subjects in the name-dropping condition were more likely to affirm that names were mentioned on the tape.

\section{Control Variables}

The control variables were aggregated to form three scales, "General quality of the lecture" $(\alpha=.52)$, "Subject's ability to follow the lecture" $(\alpha=.62)$ and "Subject's motivation to follow the lecture" $(\alpha=.62)$. Also, the item "The lecturer gives practical examples" was used as a control. T-tests for independent samples yielded no differences between the two conditions for any of the control variables. The means were very similar to those obtained in Study 1: Subjects' ability to follow the lecture was high, and the lecture was generally considered good, although quite boring. Table 10 shows means and standard deviations of the control variables.

$* * * * * * * * * * * * * * * * * * * * * * * * * * * * * * * * * * * * * * * * * * * * * * * * * * * *$

Table 10

Descriptive Statistics of Control Variables

Also, no differences existed between the name-dropping conditions regarding biographical data of the subjects. That is, subjects are comparable in gender, age, year of study, and both conditions have similar percentages of subjects with psychology as a major or minor. With regard to prior knowledge, there was a significant difference on the ordinal item "Have you been familiar with the concepts production team, job enrichment, job enlargement, and job rotation prior to your participation in this study?" in that subjects in the no name-dropping condition were more familiar with the concepts 
explained during the lecture (Mann-Witney U-test, $Z=-2.09, p=.04$, two-sided).

Therefore, this item was included as a covariate in all further analyses.

Structure of the Dependent Measures

An explorative principal component analysis with oblique rotation was calculated to examine the structure of the empirical data. The Kaiser criterion suggests two factors in this replication sample. Table 11 shows the rotated factors and the respective item loadings. As in Study 1, one item is discarded because it loads equally strongly on both factors. In this data set, the first factor is again "Research and General Competence". The second factor includes all items originally considered to measure Liking and Teaching Competence and is therefore named "Liking and Teaching Competence".

$* * * * * * * * * * * * * * * * * * * * * * * * * * * * * * * * * * * * * * * * * * * * * * * * * * * *$

Table 11

Rotated Factors and Item Loadings

$* * * * * * * * * * * * * * * * * * * * * * * * * * * * * * * * * * * * * * * * * * * * * * * * * * * *$

The two factors account for $58.63 \%$ of the total item variance. The coefficient alpha reliabilities are $\alpha=.88$ for both Research and General Competence (eight items) and Liking and Teaching competence (six items). The two factors correlate with $r=-.53$. The following analyses and result reports will use the factor scores of the empirically found dimensions as dependent measures.

Besides prior knowledge, differences between subjects with regard to age and year of study could influence the impressions formed of the lecturer. Therefore, the two factors and their means were correlated with these variables. Correlations were all low and not 
significant, and biographical variables were not included as covariates.

\section{Effect of Name-Dropping on the Dependent Measures}

To test the effect of name-dropping on students' perception of the lecturer, a multivariate analysis of covariance (MANCOVA) was performed with name-dropping as independent variable, the two empirically found factors as dependent variables, and the prior knowledge item as covariate. Due to the directional hypotheses, one-sided testing was used. The difference between the two name-dropping conditions did not reach significance; however, for the first factor, there was only a $6 \%$-probability to receive this mean difference if the null hypothesis is true $(F=2.32, p=.06)$. The results are summarized in Table 12.

$* * * * * * * * * * * * * * * * * * * * * * * * * * * * * * * * * * * * * * * * * * * * * * * * * * * *$

Table 12

MANOVA with Factor Scores as Dependent Measures

$* * * * * * * * * * * * * * * * * * * * * * * * * * * * * * * * * * * * * * * * * * * * * * * * * * * *$

The effect on the Research and General Competence ratings was in the hypothesized direction, however, it did not reach significance, and, more importantly, the effect was smaller than in the original study $\left(\eta^{2}=.01\right)$. No effect existed on the Liking and Teaching Competence ratings.

Again, I tested whether controlling for explicit annoyance with the name-dropping manipulation increased the effect. From all the subjects who filled in remarks in the open question, “Do you have any more remarks on the lecturer or on the lecture?", 14 
subjects ( $11 \%$ of the experimental condition) explicitly stated that the names, references, and/or publications mentioned (all of which were part of the name-dropping manipulation) annoyed them. However, controlling for annoyance did not change the results of the first MANCOVA $(F=2.19, p=.07)$.

\section{Additional analyses}

As in Study 1, I grouped items that load strongly on the same factor as scales and repeated the calculations with scale means instead of factor scores as dependent measures. Results are again very similar: With the covariate prior knowledge, the factor "Research and General knowledge" just fails to reach significance $(F=2.53, p=.06)$, whereas no effect is found for the factor "Liking and Teaching Competence".

In this replication study, two additional items of interest were included in the dependent measure questionnaire (see Table 9): one to measure assumed personal acquaintance of the lecturer with colleagues in the field ("I believe that the lecturer knows personally many people in his area of expertise"), the other to measure the assumed breadth of interests and knowledge ("The lecturer has interests and knowledge beyond his area of expertise"). I used these items as potential mediators in an analysis described by Baron and Kenny (1989). For each mediator, three regressions were calculated. First, the hypothesized mediator was regressed on the name-dropping condition. Second, competence perception (Factor 1) was regressed on the namedropping condition. Third, competence perception was regressed on both name-dropping condition and mediator item in the same regression analysis.

For the hypothesized mediator "assumed personal acquaintance", the first regression equation was significant: The name-dropping condition affected assumed personal acquaintance $(t=3.77, p<.001$, two-sided, $\beta=.24)$. The second equation shows that the 
name-dropping condition affected competence perception $(t=1.55, p=.12$, two-sided, $\beta$ $=.10$ ), although the effect was only marginally significant as in the MANCOVA stated above. The third equation shows that assumed personal acquaintance affected competence perception $(t=9.04, p<.001$, two-sided, $\beta=.53)$, and that the experimental condition lost its predictive power once assumed personal acquaintance was entered into the analysis $(t=-.48, p=.63$, two-sided, $\beta=-.03)$. Thus, assumed personal acquaintance is a mediator for the relationship between the name-dropping manipulation as independent variable and the perceived research and general competence as dependent variable. The results of the mediation analysis are very similar when the control variable, i.e., the prior knowledge item, is included in the equations.

For the second hypothesized mediator, "interests and knowledge beyond his area of expertise", the same procedure was applied. However, the first equation, which regressed the mediator on the independent variable, was not significant.

Thus, I conclude that subjects in the name-dropping condition assume that the lecturer knows many people of his field personally, probably including those people he mentions in his lecture, and that this assumption then improves their impression of the lecturer's research and general competence.

\section{Discussion}

The second study intended to replicate the results of the first study. This is of special importance with regard to the name-dropping effect because it has never been investigated before. In order to replicate and generalize the results, I used a more heterogeneous sample from a different country. Conveniently, the standard German used in the audio manipulation is understood in both countries, which allowed for the identical manipulation and items in the original and in the replication study. The results 
are marginally significant; although the sample was substantially larger, the namedropping effect showed on only the first of two dependent measures: Name-dropping affected research and general competence ratings. The finding from Study 1 that namedropping positively affects students' liking ratings is not confirmed, which might go with the slightly different items that comprise this factor.

Besides the replication and the generalization to a different sample and a second country, I tried to give first answers to the question what mediates the effect of namedropping on competence perception. I found that subjects' rating on whether the lecturer knows many people in his field personally fully mediates the name-dropping effect. This is a variable that comes to mind easily as a potential mediator, in fact, it is part of the definition of name-dropping as found in encyclopedias such as the Oxford English Dictionary or the German Duden: mentioning other people to foster the impression that one knows these people personally. Thus, a first step has been made toward the processes of impression management via name-dropping. I suggest that the names mentioned in the lecture are interpreted as personal acquaintances of the lecturer, that this assumption establishes that the lecturer is included in and an integral part of the (scientific) community, and thus leads to a higher regard of his research and general competence.

So far, operationalisation of name-dropping included three domains: names of researchers, names of teaching professors, and names of people of the general public. The effect, however, was stronger on perceived research and general competence than on teaching competence. The question addressed in the third experiment is thus whether differential effects are induced by different domains of people mentioned. Such differences might further our understanding of the nature of the impression formation 
process: Is the name-dropping effect a general, halo effect, is it used as a heuristic for those domains in which impressions are otherwise hard to form, or is it used as information and processed as domain-specific arguments for competence?

\section{Study 3}

The aim of the study is twofold: First, to replicate the name-dropping effect with another German sample, second, to extend our knowledge on what causes the effect, i.e., to answer the question if it is names per se or rather names of a specific domain such as teaching or general knowledge that influences competence and liking perceptions. Therefore, I used the original two conditions (name-dropping vs. no name-dropping) to replicate the previous findings. In addition, I used two new name-dropping versions, name-dropping teaching (nd-t) with names of teaching colleagues only, and namedropping general knowledge (nd-gk) with names of the general knowledge domain only, to investigate their specific effects as opposed to the more general names effect established in the previous studies.

I hypothesize that the data replicate the previously shown name-dropping effect and I assume that name-dropping positively affects both competence and liking perceptions. I also assume that the new condition nd-t only affects the teaching dimension of competence, whereas the condition nd-gk only affects the general knowledge dimension of competence. As the new conditions are more focused on a specific competence dimension and, therefore, manipulating name-dropping more intensely, the effect might be larger on the respective competence dimension than the overall name-dropping effect in the original conditions. Due to the directional hypotheses, one-sided testing is used in all analyses. 


\section{Method}

\section{Experimental Design}

The experiment is a between-subjects design with four conditions, manipulating name-dropping applied by the lecturer. Two conditions are the same as in Studies 1 and 2. The other two conditions are name-dropping conditions with nine name-dropping sequences, one focuses exclusively on teaching (nd-t), the other focuses exclusively on general knowledge (nd-gk). The dependent variables of interest are perceived competence with regard to teaching and research, perceived general competence, and liking of the lecturer.

\section{Sample}

232 students of the University of Heidelberg participated in this study. Two subjects $(0.9 \%)$ did not indicate their gender; from the remaining subjects, $55.7 \%$ were female, $44.3 \%$ were male. The sample included a number of psychology students comparable to that of the Swiss sample, but more natural science students and less liberal arts students: $29.3 \%$ were psychology majors, $14.7 \%$ medical science majors, $8.2 \%$ physics majors, $6.0 \%$ biology majors, $5.6 \%$ mathematics majors, and $4.7 \%$ pharmacy majors. ${ }^{3}$ Six subjects (2.6\%) did not indicate their major. From the remaining 31.5\% of subjects, less than ten studied the same major, including the subjects languages/translation, law, chemistry, politics, and business.

The mean age was 23.36 years, with a median of 23 years. Four students (1.7\%) did not indicate their age. The 226 students who indicated their semester of study had on average been studying for 4.75 semesters, with a median of 4 and a standard deviation of 3.4. Semesters range from 1 to 13. Students were recruited on campus and participated voluntarily. To provide an incentive to participate, I raffled 4 x EUR 50 amongst all 
subjects. All students were randomly assigned to one of the four conditions.

\section{Procedure}

Up to four subjects were present at the same time. Subjects were welcomed and asked to choose one of four work stations, each supplied with an MP3-player, head phones, written instructions, and the questionnaires. They were then asked to read the instruction and were told that the proceeding was described in there.

In the instruction they read that they would now listen to a tape recording of a lecture on the MP3-player, then work through the four folders in front of them in the prepared order, and that the experiment would take approx. 30 minutes. As a cover story I told subjects during recruitment and in the instruction that I was doing a study on didactics in higher education and therefore looking for students' opinion on courses.

The end of the tape recording was indicated by a female voice who asked the subjects to open folder 1. Folder 1 contained the dependent measures in Likert scales, some free space for voluntary comment on the tape recording, and the request to close folder 1 and move on to folder 2. Folder 2 contained the manipulation check items in Likert scales and the request to close folder 2 and open folder 3. Folder 3 asked about subjects' familiarity with and prior knowledge on the lecture topic, work organization. They were also asked what they thought was the research goal of the experiment. On a second sheet, subjects provided information about their study subjects, study year, gender, age, and nationality. They were requested to open folder 4 , which contained my thanks for participation and the written debriefing. Before the students left, they were offered to receive notice of the experiment's results. Interested students left their email address and were later contacted with information on the results by the author. 


\section{Manipulation of Name-Dropping}

For the name-dropping (nd) and no name-dropping (no-nd) conditions I used the same material as in Studies 1 and 2: In the no name-dropping control condition, subjects listened to an alleged section of a lecture on work organization. As in Study 1, the male lecturer defined and explained the terms job enlargement, job enrichment, and job rotation for about seven minutes. In the name-dropping condition, the identical tape was used, but the lecturer added a total of nine references during his lecture, three each regarding teaching aspects, research aspects, and general knowledge on the topic of work organization.

For the conditions "name-dropping research (nd-r)" and "name-dropping general knowledge (nd-gk)", I created two new versions of the recording. Whereas the original name-dropping recording had nine name-dropping sequences with three each for teaching, research, and general knowledge, the nd-r condition contained nine research sequences, and the nd-gk nine general knowledge sequences. I kept the three original research and general knowledge sequences, respectively, and used the names of the six other sequences to adapt the wording to a research or general knowledge context, respectively. I then pretested the new sequences by asking 24 subjects to indicate for every sequence the context they saw in it. The pretest questionnaire is shown in Appendix E-1. Sequences that were assigned to another context than intended by 8 $(30 \%)$ or more of the subjects were rephrased. Translations of the final nine nd-r and nine nd-gk sequences are provided in Table 13 (nd-r) and Table 14 (nd-gk). 
$* * * * * * * * * * * * * * * * * * * * * * * * * * * * * * * * * * * * * * * * * * * * * * * * * * * *$

Table 13

Name-Dropping Sequences in the Condition nd-r

$* * * * * * * * * * * * * * * * * * * * * * * * * * * * * * * * * * * * * * * * * * * * * * * * * * * *$

$* * * * * * * * * * * * * * * * * * * * * * * * * * * * * * * * * * * * * * * * * * * * * * * * * * * *$

Table 14

Name-Dropping Sequences in the Condition nd-gk

$* * * * * * * * * * * * * * * * * * * * * * * * * * * * * * * * * * * * * * * * * * * * * * * * * * * *$

\section{Measures}

\section{Dependent Measures}

The same 7-point Likert scales were used as in Studies 1 and 2, except that scale endpoints were changed from "not at all true" and "absolutely true" to "not true" and "true". I hoped to induce more variance in the ratings by using less extreme endpoints. The items included in the dependent measures questionnaire of Study 2 that were used as information on potential mediators were again included, and Table 15 provides a list of all new items and their descriptive statistics in Study 3. However, just as in Study 2, the dependent variables for the replication were exactly the same as in Study 1. 
$* * * * * * * * * * * * * * * * * * * * * * * * * * * * * * * * * * * * * * * * * * * * * * * * * * * * * * *$

Table 15

Descriptive Statistics of Additional Variables

\section{Manipulation Check}

The manipulation check questionnaire was identical to the one used in Study 2 and contained 17 items (including control variables), as shown in Appendix C-3. Six 7-point Likert scales checked on the name-dropping manipulation, three 7-point Likert scales checked on subjects' motivation, and one of the previous dichotomous items checked on subjects' focus, namely "While listening to the tape, I focused primarily on a) how the lecturer explains and conveys knowledge, b) how the lecturer presents research".

\section{Control Variables}

Control variables were the same as in Study 2 (see Table 10): Three items measured the general quality of the lecture, and no differences between experimental conditions were expected on these. Two items measured the subjects' ability to understand the lecture and three items the subject's motivation to follow the lecture, and high scores were expected on ability and motivation items for all conditions. As in Studies 1 and 2, one variable controlled for the possibility that the name-dropping manipulation was interpreted by the subjects as additional information. All control variables were part of the second questionnaire, which can be found in Appendix C-3.

In addition, several biographical data were included to ensure that the conditions do not differ systematically with regard to subjects' gender, age, year of study, prior 
knowledge in the topic of the lecture, and having psychology as a major or minor.

Results

\section{Manipulation Check}

A MANOVA and post-hoc tests (LSD) showed that the manipulation was successful. The six manipulation check items were entered as single item dependent measures. The multivariate test was significant (Wilks's $\lambda=.22, F=7.23, p<.001$; all tests on the manipulation are run two-sided), and univariate tests were significant for all dependent measures (all six $p \leq .02$ ). Pairwise comparisons show that subjects in the control condition were significantly less inclined to affirm four of the six manipulation check items than subjects of any of the name-dropping conditions (all four $p<.001$ ). The difference between nd-r and nd-gk was tested with two items: First, subjects in the nd-r condition should be less likely than subjects in the nd-gk condition to acquiesce to the statement "The lecturer mentions newspaper articles". The difference is significant in the predicted direction $(p<.001)$. Second, subjects in the nd-gk condition should be less likely than subjects in the nd-r condition to acquiesce to the statement "The lecturer is familiar with his colleagues and their research projects". The difference is significant in the predicted direction $(p<.001)$.

The difference between the nd condition and the single-context conditions nd-r and nd-gk is more difficult to establish because nd contains both research and general knowledge sequences, only fewer than nd-r and nd-gk. However, it is only nd that contains teaching sequences, and pairwise comparisons show that the subjects in the nd condition were significantly more inclined to acquiesce to the teaching item "The lecturer mentions his colleagues' textbooks" than were subjects in nd-r and nd-gk (both $p<.001$ ), and significantly more inclined to acquiesce to "The lecturer knows much 
about his colleagues' teaching activities" than subjects in the nd-gk condition $(p=.02)$. Therefore, I consider the manipulation successful.

\section{Control Variables}

The control variables were aggregated to form three scales, "General quality of the lecture" $(\alpha=.50)$, "Subject's ability to follow the lecture" $(\alpha=.70)$ and "Subject's motivation to follow the lecture" $(\alpha=.58)$. Also, the item "The lecturer gives practical examples" was used as a control. A MANOVA yielded no differences between the four conditions for any of the control variables. The means were very similar to those obtained in Study 1 und 2: Subjects' ability to follow the lecture was high, and the lecture was generally considered good, although quite boring. Table 16 shows means and standard deviations of the control variables.

$* * * * * * * * * * * * * * * * * * * * * * * * * * * * * * * * * * * * * * * * * * * * * * * * * * * *$

Table 16

Descriptive Statistics of Control Variables

Also, no differences were found between the name-dropping conditions regarding biographical data of the subjects. That is, subjects are comparable in gender, age, year of study, prior knowledge, and both conditions have similar percentages of subjects with psychology as a major.

Structure of the Dependent Measures

An explorative principal component analysis with oblique rotation was calculated to examine the structure of the empirical data. According to the Kaiser criterion, three 
factors can be distinguished in this replication sample. However, two items were discarded because they load equally strongly on two factors. The re-run with the remaining 13 items shows only two factors. Thus, as in Study 2, the first factor is "Research and General Competence", the second factor is "Liking and Teaching Competence". Table 17 shows the rotated factors and the respective item loadings.

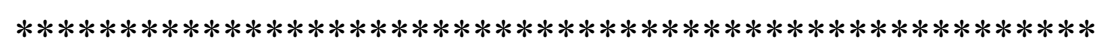

Table 17

Rotated Factors and Item Loadings

The two factors account for $57.66 \%$ of the total item variance. The coefficient alpha reliabilities are $\alpha=.87$ for Research and General Competence (eight items) and $\alpha=.85$ for Liking and Teaching Competence (five items). The two factors correlate with $r=.44$. The following analyses and result reports will use the factor scores of the empirically found dimensions as dependent measures.

Several biographical data could influence the perception of the lecturer in terms of different backgrounds and experience with lecturers, namely age, prior knowledge, and year of study. Therefore, the two factors were correlated with these variables.

Correlations were all low and not significant, and no biographical data were included as covariates in the analyses.

Effect of Name-Dropping on the Dependent Measures

A multivariate analysis of variance (MANOVA) was performed with name-dropping as independent variable and the two empirically found factors as dependent variables. 
The difference between the name-dropping conditions did not reach significance. However, for the Liking and Teaching Competence factor, there was only a $6 \%$ probability to receive this mean difference when the null hypothesis is true $(F=2.00, p$ $=.06$; all tests are run one-sided). However, as opposed to Study 1 and 2, the multivariate test failed to reach significance (Wilks's $\lambda=.96, F=1.63, p=.07$ ). The results are shown in Table 18.

$* * * * * * * * * * * * * * * * * * * * * * * * * * * * * * * * * * * * * * * * * * * * * * * * * * * *$

Table 18

MANOVA with Factor Scores as Dependent Measures

The effect on the factor Liking and Teaching Competence occurred in the hypothesized direction, however, it just failed to reach significance. The effect is smaller than in Study 1 but larger than in Study $2\left(\eta^{2}=.03\right)$. No effect was found for the factor Research and General Competence. Post-hoc tests (LSD) show that there was no difference between nd and no-nd condition as found in the previous two studies. Instead, the effect of name-dropping on Liking and Teaching Competence is that subjects in the nd-gk condition were significantly more taken by the lecturer than were subjects in the original nd condition $(F=5.46 ; p=.01)$. The effect is small with $\eta^{2}=.05$. In addition, the $95 \%$-confidence interval around the mean difference $(\Delta=.53)$ does not include zero $(.81 ; .07)$

Again, I tested whether controlling for explicit annoyance with the name-dropping 
manipulation increased the effect. In the open-ended question, "Do you have any more remarks on the lecturer or on the lecture?" 25 subjects $(11 \%, n=9$ in the nd condition, $n$ $=8$ each in nd-r and nd-gk) explicitly stated that the names, references, and/or publications mentioned by the lecturer annoyed them. A multivariate analysis of covariance (MANCOVA), however, showed that the results on Liking and Teaching Competence were equal to those obtained in the MANOVA $(F=2.03, p=.06)$.

\section{Additional analyses}

When items that load strongly on the same factor are grouped as scales and calculations are repeated with scale means instead of factor scores as dependent measures, results are very similar: The factor Liking and Teaching Competence is affected significantly $(F=2.24, p=.04)$, whereas the factor Research and General Competence is not. Again, the multivariate test is only marginally significant (Wilks's $\lambda$ $=.96, F=1.57, p=.08)$. When annoyance is controlled for, the effect on Liking and Teaching Competence is very similar $(F=2.29, p=.04)$, with a marginally significant multivariate test (Wilks's $\lambda=.96, F=1.58, p=.07$ ).

As in Study 2, two additional items of interest were included in the dependent measure questionnaire (see Table 9): one to measure assumed personal acquaintance of the lecturer with colleagues in the field ("I believe that the lecturer knows personally many people in his area of expertise"), the other to measure the assumed breadth of interests and knowledge ("The lecturer has interests and knowledge beyond his area of expertise"). I wanted to use these items as potential mediators in an analysis described by Baron and Kenny (1989), following the same procedure as described in Study 2 . However, for both items the first regression equation did not reach significance, and the mediation analysis was not pursued any further. 


\section{Discussion}

I hypothesized that the name-dropping effect is replicated a second time on another German student sample and that different name-dropping foci, namely teaching and general knowledge, would have differential impact on teaching vs. general knowledge dimensions. Both hypotheses were only marginally supported. Although there was a positive name-dropping effect, it was not the original name-dropping condition that differed from the no name-dropping condition but the newly created general knowledge (nd-gk) condition: It improved the lecturer's teaching competence and likeability in the eyes of the students. Also, the overall multivariate effect for name-dropping did not reach statistical significance. No differential effects were found in that the teaching (ndt) condition affected teaching competence or in that the general knowledge (nd-gk) condition affected research and general competence. As in Study 2, effects were small and prone to just fail the significance criterion. Due to this, I was unable to replicate the mediation analysis of Study 2, where students' impression that the lecturer knows many people in his field personally fully mediated the name-dropping effect.

\section{General Discussion}

Three studies confirm that there is a positive effect of name-dropping if a lecturer mentions names unknown to a student audience. Thus, Cialdini's concept of BIRG can not only be shown in actors, but also in targets in that the use of BIRG positively affects targets' impressions during first encounters. The effect is small in terms of effect size and explained variance, and not all analyses reached statistical analysis. However, I expected the effect to be small because name-dropping is a rather subtle selfpresentation tactic, and even more so because the names bore no valence to the audience. 
Whereas Studies 1 and 2 showed highly similar results, Study 3 did not fully replicate the original effect, but instead showed a related effect: The lecturer who mentioned many (but exclusively) journalists and public characters was liked more and rated higher on teaching competence than the lecturer in the original nd condition of Studies 1 and 2. There is a different quality to the results of Study 3: First, it was not primarily competence ratings that were affected, but liking and teaching. Second, the replication of the original effect failed in that the control condition and the original name-dropping condition did not differ significantly.

Sample composition might be one explanation for the diverging results. Although I used student samples in all studies, Study 3 was different in that medical and natural science students made up 35\% of the subjects. Both majors were underrepresented in Studies 1 and 2. Moreover, these majors have a culture with regard to lectures and didactics that is very different from the liberal arts and humanities majors who participated in Studies 1 and 2. Medical and natural science majors might be less accustomed to scientific referencing, i.e., the mentioning of researchers to indicate authorship and intellectual property. For one reason, references might occur less often. For another reason, lectures form a less important part of studying to begin with because medical science majors spend parts of their time in practice, natural science majors spend time in exercise courses, and both have to spend time in laboratory classes.

Although I do not consider my name-dropping manipulation scientific referencing, being used to names during lectures might be stronger among the samples of Studies 1 and 2. In Study 3, students appreciated names of journalists and public figures, and they appreciated them in terms of teaching competences. Thus, this sample might not have deemed names of researchers and colleagues (in the original name-dropping condition) 
relevant for competence judgments.

Although the underlying process of assumed personal acquaintance could not be tested in Study 3, I conclude from the missing replication effect that personal acquaintance was probably not the mediator in Study 3. Instead, students might have appreciated the lecturer's references to current events in terms of newspaper articles and publications as a didactic means to make students relate to the lecture topic. This, of course, is mere speculation and needs further research.

Also, scale endpoints were rephrased in Study 3. We know from research by Schwarz and colleagues (e.g., Schwarz, 1999; Schwarz \& Oyserman, 2001) that item phrasing and scales can have strong impacts on study results. However, despite the rephrased scale endpoints, control variables showed that the audio tape was perceived very similarly in all studies, and descriptive statistics on ratings of the general quality of the lecture are basically identical. Therefore, I do not think that scale endpoints had a crucial impact on the dependent measures.

Due to the small effect size found in all studies, power is a central issue, and, thus, large samples are crucial in the study of name-dropping. Also due to small effect sizes, error variance such as induced by varying sample composition looms large on significance testing.

In sum, the research presented here shows that name-dropping can positively influence ratings of competence and liking. Some individuals are annoyed by the names mentioned, and they merit separate analyses. I have also shown that the underlying process of the effect is the audience's assumption that the name-dropping person knows personally the individuals he mentions, and the effect disappears if we control for this assumption by way of mediation analysis. 
Name-dropping has been shown to influence a student audience. Future research should use large samples to investigate the effects of name-dropping in different settings and on populations other than students. Impression management research claims that some settings qualify more for self-presentational efforts than others. For example, job interviews not only elicit many tactics in applicant behavior, their outcomes are also highly influenced by such behaviour. Most of the time, self-presentational efforts during job interviews are beneficial for applicants (e.g., Higgins, Judge, \& Ferris, 2003; Kacmar \& Carlson, 1999). Recently, McFarland, Yun, Harold, Viera, and Moore (2005) showed positive effects of self-presentation in assessment centers. Thus, the research on how name-dropping affects first encounters should be extended to other areas of selfpresentation, preferably to the context of job application. 


\section{References}

Asch, S. E. (1946). Forming impressions of personality. Journal of Abnormal and Social Psychology, 41, 258-290.

Baron, R. M., \& Kenny, D. A. (1986). The moderator-mediator variable distinction in social psychological research: Conceptual, strategic, and statistical considerations. Journal of Personality and Social Psychology, 51, 1173-1182.

Cattell, R. B. (1966). The scree test for the number of factors. Multivariate Behavioral Research, 1, 245-276.

Cialdini, R. B., \& de Nicholas, M. E. (1989). Self-presentation by association. Journal of Personality and Social Psychology, 57, 626-631.

Cialdini, R. B., Finch, J. F., \& De Nicholas, M. E. (1990). Strategic self-presentation: The indirect route. In M. J. Cody (Ed.), The psychology of tactical communication. Monographs in social psychology of language (Vol. 2, pp. 194-206). Clevedon: Multilingual Matters.

Cialdini, R. B., \& Richardson, K. D. (1980). Two indirect tactics of image management: Basking and blasting. Journal of Personality and Social Psychology, 39, 406-415.

Cohen, J. (1988). Statistical power analysis for the behavioral sciences $\left(2^{\text {nd }}\right.$ ed.). Hillsdale, NJ: Lawrence Erlbaum.

Cohen, J., Cohen, P., West, S. G., \& Aiken, L. (2003). Applied multiple regression/correlation analysis for the behavioral sciences. Mahwah, NJ: Lawrence Erlbaum.

Ellis, A. P. J., West, B. J., Ryan, A. M., \& DeShon, R. P. (2002). The use of impression management tactics in structured interviews: A function of question type? Journal of 
Applied Psychology, 87, 1200-1208.

Fabrigar, L. R., Wegener, D. T., MacCallum, R. C., \& Strahan, E. J. (1999). Evaluating the use of exploratory factor analysis in psychological research. Psychological Methods, 4, 272-299.

Goffman, E. (1959). The presentation of self in everyday life. New York, NY: Doubleday.

Gordon, R. A. (1996). Impact of ingratiation on judgments and evaluations: A metaanalytic investigation. Journal of Personality and Social Psychology, 71, 54-70.

Higgins, C. A., Judge, T. A., \& Ferris, G. R. (2003). Influence tactics and work outcomes: A meta-analysis. Journal of Organizational Behavior, 24, 89-106.

Jones, E.E. \& Pittman, T.S. (1980). Toward a general theory of strategic selfpresentation, In S. Suls (Ed.), Psychological perspectives of the self(Vol. 1, pp. 231262), Hillsdale, NJ: Erlbaum.

Kacmar, K. M., \& Carlson, D. S. (1999). Effectiveness of impression management tactics across human resource situations. Journal of Applied Social Psychology, $29,1293-1315$.

Kacmar, K. M., Delery, J. E., \& Ferris, G. R. (1992). Differential effectiveness of applicant impression management tactics on employment interview decisions. Journal of Applied Social Psychology, 22, 1250-1272.

Kaiser, H. F. (1960). The application of electronic computers to factor analysis. Educational and Psychological Measurement, 20, 141-151.

Knouse, S. B., Giacalone, R. A., \& Pollard, H. (1988). Impression management in the resume and its cover letter. Journal of Business and Psychology, 3, 242-249.

McFarland, L. A., Yun, G., Harold, C. M., Viera, L. J., \& Moore, L. G. (2005). An 
examination of impression management use and effectiveness across assessment center exercises: The role of competency demands. Personnel Psychology, 58, 949-980.

Rosenberg, S., Nelson, C., \& Vivekananthan, P. S. (1968). A multidimensional approach to the structure of personality impressions. Journal of Personality and Social Psychology, 9, 283-294.

Rosenberg, S., \& Olshan, K. (1970). Evaluative and descriptive aspects in personality perception. Journal of Personality and Social Psychology, 16, 619-626.

Schlenker, B. R., \& Wowra, S. A. (2003). Carryover effects of feeling socially transparent or impenetrable on strategic self-presentation. Journal of Personality and Social Psychology, 85, 871-880.

Schwarz, N. (1999). Self-reports: How the questions shape the answers. American Psychologist, 54, 93-105.

Schwarz, N., \& Oyserman, D. (2001). Asking questions about behaviour: Cognition, communication, and questionnaire construction. American Journal of Evaluation, $22,127-160$.

Stevens, C. K., \& Kristof, A. L. (1995). Making the right impression: A field study of applicant impression management during job interviews. Journal of Applied Psychology, 80, 587-606. 
Author Note

Carmen Lebherz, Department of Psychology, University of Zurich, Switzerland; Correspondence concerning this article should be addressed to Carmen Lebherz, University of Zurich, Department of Psychology, Social and Business Psychology, Binzmuehlestrasse 14, box 13, 8050 Zurich, Switzerland.

Study 1 was partly presented at the meetings of the EAESP at Wuerzburg, Germany, 2005 and of the Fachgruppe Sozialpsychologie at Jena, Germany, 2005. I am grateful to the Psychology Departments of Tuebingen and Heidelberg, Germany, for the possibility of conducting Studies 2 and 3 on campus.

I would like to thank Monika Stoll, Nathalie Schröder, Stoilka Krasteva, Barbara Tomljenovic, and Caspar Coninx who assisted in conducting the research. 


\section{Footnotes}

${ }^{1}$ Switzerland has three official languages, German, French, and Italian. Although courses at the University of Zurich are done in German, some subjects might have French or Italian as mother tongue, depending on the area they grew up in.

${ }^{2}$ Varimax rotation shows a very similar factor solution and similar results with regard to the effects found.

${ }^{3}$ Subjects with two majors were assigned to the subject they mentioned first. 
Table 1

Study 1: Suggested Dimensions of the Dependent Measure

\begin{tabular}{|c|c|c|c|c|c|c|c|c|c|c|}
\hline $\begin{array}{l}\text { Factor } \\
\text { Name }\end{array}$ & Item & $\begin{array}{l}\text { Item } \\
\text { No. }\end{array}$ & $N$ & Min & Max & $M$ & $S D$ & $\alpha$ & $\begin{array}{c}\text { Item-total } \\
\text { correlation } \\
\text { in dependent } \\
\text { measure subscale }\end{array}$ & $\begin{array}{c}\text { Item-total } \\
\text { correlation } \\
\text { in total scale }\end{array}$ \\
\hline \multirow{6}{*}{1} & $\begin{array}{c}\text { Total scale } \\
\text { (15 variables) }\end{array}$ & & 164 & & & 4.48 & .90 & .91 & & \\
\hline & Teaching Competence & & & & & 4.42 & 1.23 & .85 & & \\
\hline & The speaker explains very well. & 1 & 167 & 1 & 7 & 5.28 & 1.16 & & .58 & .54 \\
\hline & $\begin{array}{l}\text { The speaker imparts knowledge } \\
\text { very well. }\end{array}$ & 6 & 167 & 1 & 7 & 4.74 & 1.51 & & .76 & .68 \\
\hline & $\begin{array}{l}\text { I would recommend this lecture } \\
\text { to other students. }\end{array}$ & 13 & 166 & 1 & 7 & 3.98 & 1.66 & & .73 & .67 \\
\hline & $\begin{array}{l}\text { I think the speaker enjoys a } \\
\text { good reputation among students. }\end{array}$ & 5 & 167 & 1 & 7 & 3.68 & 1.55 & & .73 & .69 \\
\hline \multirow[t]{5}{*}{2} & Research Competence & & & & & 4.22 & 1.08 & .83 & & \\
\hline & $\begin{array}{l}\text { I think the speaker is one of the } \\
\text { leading researchers in his field. }\end{array}$ & 11 & 167 & 1 & 7 & 3.65 & 1.36 & & .67 & .63 \\
\hline & $\begin{array}{l}\text { I think the speaker is recognized } \\
\text { by other researchers. }\end{array}$ & 3 & 167 & 1 & 7 & 4.65 & 1.26 & & .62 & .61 \\
\hline & $\begin{array}{l}\text { I think the speaker publishes his } \\
\text { work in important professional } \\
\text { journals. }\end{array}$ & 15 & 164 & 1 & 7 & 4.43 & 1.39 & & .62 & .54 \\
\hline & $\begin{array}{l}\text { I think the speaker is known for } \\
\text { his good research. }\end{array}$ & 8 & 167 & 1 & 7 & 4.16 & 1.26 & & .74 & .61 \\
\hline \multirow[t]{6}{*}{3} & General Competence & & & & & 5.07 & .88 & .81 & & \\
\hline & $\begin{array}{l}\text { The speaker knows what he is } \\
\text { talking about. }\end{array}$ & 7 & 167 & 2 & 7 & 5.84 & 1.14 & & .64 & .59 \\
\hline & The speaker appears competent. & 4 & 167 & 1 & 7 & 5.38 & 1.20 & & .58 & .61 \\
\hline & $\begin{array}{l}\text { The speaker is an expert in his } \\
\text { field. }\end{array}$ & 14 & 166 & 2 & 7 & 4.90 & 1.19 & & .70 & .70 \\
\hline & $\begin{array}{l}\text { I think the speaker is very } \\
\text { intelligent. }\end{array}$ & 12 & 167 & 1 & 7 & 4.62 & 1.16 & & .56 & .56 \\
\hline & $\begin{array}{l}\text { The speaker has good general } \\
\text { knowledge. }\end{array}$ & 9 & 167 & 1 & 7 & 4.61 & 1.20 & & .49 & .48 \\
\hline \multirow[t]{3}{*}{4} & Liking & & & & & 3.65 & 1.43 & .87 & & \\
\hline & The speaker is a likeable person. & 10 & 167 & 1 & 7 & 3.34 & 1.59 & & .78 & .57 \\
\hline & $\begin{array}{l}\text { The speaker is an agreeable } \\
\text { person. }\end{array}$ & 2 & 167 & 1 & 7 & 3.95 & 1.44 & & .78 & .60 \\
\hline
\end{tabular}

Note. Item No. denotes the item's original position in the questionnaire. 
Table 2

Study 1: Descriptive Statistics of Control Variables

\begin{tabular}{lrrr}
\hline & $n$ & $M$ & $S D$ \\
\hline $\begin{array}{l}\text { General quality of the lecture } \\
\text { The speaker explains in a very precise way. }\end{array}$ & 167 & 5.68 & 1.20 \\
The speaker's wording is clear and exact. & 167 & 5.75 & 1.23 \\
$\quad$ & 167 & 3.78 & 1.90 \\
The lecture is boring.* & & & \\
$\begin{array}{l}\text { Subject's ability to follow the lecture } \\
\text { There were parts in the lecture that I did not understand.* }\end{array}$ & 167 & 5.28 & 1.77 \\
$\quad \begin{array}{l}\text { I have understood the differences between job } \\
\text { enlargement, job enrichment, and job rotation.** }\end{array}$ & 167 & 5.93 & 1.08 \\
The speaker gives practical examples. & 166 & 4.75 & 2.05 \\
\hline
\end{tabular}

Notes. All items were rated on 7-point Likert scales from 1 ("not at all true”) to 7 ("absolutely true”). * Item is reverse coded. ** The lecture was on work organization, and the speaker explained the three concepts job enlargement, job enrichment, and job rotation. 
Table 3

Study 1: Rotated Factors and Item Loadings

\begin{tabular}{|c|c|c|c|c|c|c|c|c|c|}
\hline & \multirow[b]{2}{*}{$\begin{array}{l}\text { Factor } \\
\text { Name }\end{array}$} & \multirow[b]{2}{*}{ Item } & \multicolumn{3}{|c|}{ Factor } & \multirow{2}{*}{$\begin{array}{l}\text { Initial } \\
\text { Eigen- } \\
\text { value }\end{array}$} & \multirow{2}{*}{$\begin{array}{c}\% \text { of } \\
\text { Total } \\
\text { Variance } \\
\text { (unrotated) }\end{array}$} & \multirow[t]{2}{*}{$\alpha$} & \multirow{2}{*}{$\begin{array}{l}\text { Corrected } \\
\text { Item- } \\
\text { Total } \\
\text { Correlation }\end{array}$} \\
\hline & & & 1 & 2 & 3 & & & & \\
\hline \multirow[t]{8}{*}{1} & \multicolumn{2}{|c|}{ Research and General Competence } & & & & 6.23 & $44.98 \%$ & .87 & \\
\hline & & $\begin{array}{l}\text { I think the speaker publishes his } \\
\text { work in important professional } \\
\text { journals. }\end{array}$ & .86 & .01 & .14 & & & & .67 \\
\hline & & $\begin{array}{l}\text { I think the speaker is known for his } \\
\text { good research. }\end{array}$ & .82 & -.11 & -.13 & & & & .74 \\
\hline & & $\begin{array}{l}\text { I think the speaker is one of the } \\
\text { leading researchers in his field. }\end{array}$ & .71 & .17 & .02 & & & & .68 \\
\hline & & $\begin{array}{l}\text { The speaker has good general } \\
\text { knowledge. }\end{array}$ & .70 & .00 & .05 & & & & .55 \\
\hline & & The speaker is an expert in his field. & .63 & .03 & -.31 & & & & .71 \\
\hline & & $\begin{array}{l}\text { I think the speaker is very } \\
\text { intelligent. }\end{array}$ & .62 & .11 & -.53 & & & & .58 \\
\hline & & $\begin{array}{l}\text { I think the speaker is recognized by } \\
\text { other researchers. }\end{array}$ & .50 & .14 & -.32 & & & & .63 \\
\hline \multirow[t]{5}{*}{2} & Liking & & & & & 1.86 & $13.28 \%$ & .88 & \\
\hline & & The speaker is a likeable person. & .10 & .92 & .05 & & & & .77 \\
\hline & & The speaker is an agreeable person. & .05 & .90 & .08 & & & & .77 \\
\hline & & $\begin{array}{l}\text { I think the speaker enjoys a good } \\
\text { reputation among students. }\end{array}$ & -.02 & .78 & -.23 & & & & .76 \\
\hline & & $\begin{array}{l}\text { I would recommend this lecture to } \\
\text { other students. }\end{array}$ & .01 & .72 & -.25 & & & & .70 \\
\hline \multirow[t]{6}{*}{3} & Residual Factor & & & & & 1.26 & $9.0 \%$ & .78 & \\
\hline & & The speaker explains very well. & -.17 & .22 & -.82 & & & & .57 \\
\hline & & The speaker appears competent. & .18 & -.03 & -.79 & & & & .67 \\
\hline & & $\begin{array}{l}\text { The speaker knows what he is } \\
\text { talking about. }\end{array}$ & .30 & -.08 & -.67 & & & & .61 \\
\hline & Ambivalent item & & & & & & & & \\
\hline & & $\begin{array}{l}\text { The speaker imparts knowledge } \\
\text { very well.* }\end{array}$ & .56 & .14 & .62 & & & & \\
\hline
\end{tabular}

Note. $N=164,14$ variables. ${ }^{*}$ Loadings derived from the first analysis before the item was discarded. 
Table 4

Study 1: Multivariate Analysis of Variance with Factor Scores as Dependent Measures

\begin{tabular}{|c|c|c|c|c|}
\hline & $d f$ & $F$ & $\eta^{2}$ & $p$ \\
\hline \multicolumn{5}{|c|}{ Factor 1 Research and General Competence } \\
\hline Name-Dropping & 1 & 3.33 & .02 & $.04 *$ \\
\hline \multicolumn{5}{|c|}{ Factor 2 Liking } \\
\hline Name-Dropping & 1 & 1.03 & .00 & .16 \\
\hline \multicolumn{5}{|c|}{ Factor 3 Residual } \\
\hline Name-Dropping & 1 & .04 & .00 & .43 \\
\hline
\end{tabular}

Notes. ${ }^{*} p \leq .05$, one-sided. 
Table 5

Study 1: Multivariate Analysis of Covariance with Factor Scores as Dependent Measures

\begin{tabular}{|c|c|c|c|c|}
\hline & $d f$ & $F$ & $\eta^{2}$ & $p$ \\
\hline \multicolumn{5}{|c|}{ Factor 1 Research and General Competence } \\
\hline Name-Dropping & 1 & 4.18 & .03 & $.02 *$ \\
\hline \multicolumn{5}{|c|}{ Factor 2 Liking } \\
\hline Name-Dropping & 1 & 2.97 & .02 & $.04^{*}$ \\
\hline \multicolumn{5}{|c|}{ Factor 3 Residual } \\
\hline Name-Dropping & 1 & .05 & .00 & .41 \\
\hline
\end{tabular}

Notes. ${ }^{*} p \leq .05$, one-sided. Annoyance with the name-dropping manipulation was used as covariate. 
Table 6

Study 1: Multivariate Analysis of Covariance with Scale Means as Dependent Measures

\begin{tabular}{|c|c|c|c|c|}
\hline & $\overline{d f}$ & $F$ & $\eta^{2}$ & $p$ \\
\hline \multicolumn{5}{|c|}{ Factor 1 Research and General Competence } \\
\hline Name-Dropping & 1 & 3.65 & .02 & $.03^{*}$ \\
\hline \multicolumn{5}{|c|}{ Factor 2 Liking } \\
\hline Name-Dropping & 1 & 3.98 & .02 & $.02 *$ \\
\hline \multicolumn{5}{|c|}{ Factor 3 Residual } \\
\hline Name-Dropping & 1 & .42 & .00 & .30 \\
\hline
\end{tabular}

Notes. ${ }^{*} p \leq .05$, one-sided. Annoyance with the name-dropping manipulation was used as covariate. 
Table 7

Study 1: Means of Items Loading on Factor 1 Research and General Competence

\begin{tabular}{|c|c|c|c|c|}
\hline & \multicolumn{3}{|c|}{ Name-dropping } & \multirow{2}{*}{$\begin{array}{l}\text { No name- } \\
\text { dropping }\end{array}$} \\
\hline & Total sample & Annoyance & No Annoyance & \\
\hline $\begin{array}{l}\text { I think the speaker is recognized by other } \\
\text { researchers. }\end{array}$ & 4.67 & 4.33 & 4.72 & 4.63 \\
\hline $\begin{array}{l}\text { I think the speaker is known for his good } \\
\text { research. }\end{array}$ & 4.28 & 4.00 & 4.33 & 4.05 \\
\hline The speaker has good general knowledge. & 4.80 & 5.00 & 4.77 & 4.43 \\
\hline $\begin{array}{l}\text { I think the speaker is one of the leading } \\
\text { researchers in his field. }\end{array}$ & 3.72 & 2.92 & 3.86 & 3.58 \\
\hline I think the speaker is very intelligent. & 4.83 & 4.58 & 4.87 & 4.43 \\
\hline The speaker is an expert in his field. & 4.96 & 4.42 & 5.06 & 4.84 \\
\hline $\begin{array}{l}\text { I think the speaker publishes his work in } \\
\text { important professional journals. }\end{array}$ & 4.58 & 4.00 & 4.69 & 4.28 \\
\hline
\end{tabular}

Notes. Higher means indicate more favorable ratings. Sample sizes vary between 78 and 81 in the column "total sample", between 67 and 69 in the column "no annoyance", and between 85 and 86 in the column "no name-dropping". Sample size in the column "annoyance" is 12. 
Table 8

Study 1: Means of Items Loading on Factor 2 Liking

\begin{tabular}{|c|c|c|c|c|}
\hline & \multicolumn{3}{|c|}{ Name-dropping } & \multirow{2}{*}{$\begin{array}{c}\text { No } \\
\text { name- } \\
\text { dropping }\end{array}$} \\
\hline & $\begin{array}{c}\text { Total } \\
\text { sample }\end{array}$ & Annoyance & $\begin{array}{c}\text { No } \\
\text { Annoyance }\end{array}$ & \\
\hline $\begin{array}{l}\text { I would recommend this lecture to } \\
\text { other students. }\end{array}$ & 4.10 & 3.25 & 4.25 & 3.86 \\
\hline The speaker is a likeable person. & 3.52 & 2.67 & 3.67 & 3.17 \\
\hline $\begin{array}{l}\text { I think the speaker enjoys a good } \\
\text { reputation among students. }\end{array}$ & 3.90 & 3.08 & 4.04 & 3.47 \\
\hline $\begin{array}{l}\text { The speaker is an agreeable } \\
\text { person. }\end{array}$ & 4.00 & 3.17 & 4.14 & 3.91 \\
\hline
\end{tabular}

Notes. Sample sizes vary between 80 and 81 in the column "total sample" and between 68 and 69 in the column "no annoyance". Sample size in the column "annoyance" is 12. Sample size in the column "no name-dropping" is 86. 
Table 9

Study 2: Descriptive Statistics of Additional Variables

\begin{tabular}{lccc}
\hline & $n$ & $M$ & $S D$ \\
\hline $\begin{array}{l}\text { The speaker gave a very good lecture. } \\
\begin{array}{l}\text { The speaker makes an effort to correctly convey the information } \\
\text { on this topic. }\end{array}\end{array}$ & 240 & 4.42 & 1.42 \\
$\begin{array}{l}\text { The speaker has the skills necessary to correctly convey the } \\
\text { information on this topic. }\end{array}$ & 237 & 4.98 & 1.04 \\
$\begin{array}{l}\text { I believe that the speaker knows personally many people in his } \\
\text { area of expertise. }\end{array}$ & 235 & 4.36 & 1.52 \\
$\begin{array}{l}\text { The speaker has interests and knowledge beyond his area of } \\
\text { expertise. }\end{array}$ & 238 & 3.97 & 1.32 \\
I am impressed by the speaker's knowledge. & 240 & 2.90 & 1.48 \\
\hline
\end{tabular}

Notes. All items were rated on 7-point Likert scales from 1 ("not at all true”) to 7 ("absolutely true"). 
Table 10

Study 2: Descriptive Statistics of Control Variables

\begin{tabular}{llll}
\hline & $n$ & $M$ & $S D$ \\
\hline General quality of the lecture & & & \\
$\quad$ The speaker explains in a very precise way. & 240 & 5.43 & 1.22 \\
The speaker's wording is clear and exact. & 240 & 5.76 & 1.17 \\
$\quad$ The lecture is boring.* & 240 & 3.63 & 1.94 \\
Subject's ability to follow the lecture & & & \\
$\quad$ There were parts in the lecture that I did not understand.* & 240 & 5.32 & 1.71 \\
$\quad$ I have understood the differences between job enlargement, & 239 & 5.64 & 1.34 \\
$\quad$ job enrichment, and job rotation.** & & & \\
Subject's motivation to follow the lecture & & & \\
$\quad$ While listening, I zoned out from time to time* & 238 & 3.27 & 1.70 \\
$\quad$ I made an effort to understand the content of the lecture. & 240 & 5.77 & 1.39 \\
$\quad$ During the lecture, I was highly motivated to listen. & 239 & 4.09 & 1.65 \\
The speaker gives practical examples. & 239 & 4.96 & 1.73 \\
\hline
\end{tabular}

Notes. All items were rated on 7-point Likert scales from 1 ("not at all true”) to 7 ("absolutely true”). *Item is reverse coded. ** The lecture was on work organization, and the speaker explained the three concepts job enlargement, job enrichment, and job rotation. 
Table 11

Study 2: Rotated Factors and Item Loadings

\begin{tabular}{|c|c|c|c|c|c|c|c|c|}
\hline & \multirow[b]{2}{*}{ Factor Name } & \multirow[b]{2}{*}{ Item } & \multicolumn{2}{|c|}{ Factor } & \multirow{2}{*}{$\begin{array}{l}\text { Initial } \\
\text { Eigen- } \\
\text { value }\end{array}$} & \multirow{2}{*}{$\begin{array}{l}\% \text { of Total } \\
\text { Variance } \\
\text { (unrotated) }\end{array}$} & \multirow[t]{2}{*}{$\alpha$} & \multirow{2}{*}{$\begin{array}{l}\text { Corrected } \\
\text { Item- } \\
\text { Total } \\
\text { Correlation }\end{array}$} \\
\hline & & & 1 & 2 & & & & \\
\hline \multirow[t]{9}{*}{1} & \multicolumn{2}{|c|}{ Research and General Competence } & & & 6.61 & $47.20 \%$ & .88 & \\
\hline & & $\begin{array}{l}\text { I think the speaker is known for his } \\
\text { good research. }\end{array}$ & .86 & .09 & & & & .71 \\
\hline & & The speaker is an expert in his field. & .83 & .09 & & & & .68 \\
\hline & & $\begin{array}{l}\text { I think the speaker is very } \\
\text { intelligent. }\end{array}$ & .81 & .02 & & & & .70 \\
\hline & & $\begin{array}{l}\text { I think the speaker publishes his } \\
\text { work in important professional } \\
\text { journals. }\end{array}$ & .72 & .06 & & & & .59 \\
\hline & & $\begin{array}{l}\text { I think the speaker is one of the } \\
\text { leading researchers in his field. }\end{array}$ & .71 & -.12 & & & & .67 \\
\hline & & $\begin{array}{l}\text { I think the speaker is recognized by } \\
\text { other researchers. }\end{array}$ & .61 & -.19 & & & & .63 \\
\hline & & $\begin{array}{l}\text { The speaker knows what he is } \\
\text { talking about. }\end{array}$ & .55 & -.30 & & & & .65 \\
\hline & & $\begin{array}{l}\text { The speaker has good general } \\
\text { knowledge. }\end{array}$ & .40 & -.23 & & & & .46 \\
\hline \multirow[t]{9}{*}{2} & \multicolumn{2}{|c|}{ Liking and Teaching } & & & 1.60 & $11.43 \%$ & .88 & \\
\hline & & The speaker is a likeable person. & -.07 & -.85 & & & & .69 \\
\hline & & The speaker is an agreeable person. & -.11 & -.81 & & & & .60 \\
\hline & & $\begin{array}{l}\text { The speaker imparts knowledge } \\
\text { very well. }\end{array}$ & .04 & -.78 & & & & .71 \\
\hline & & The speaker explains very well. & .03 & -.74 & & & & .64 \\
\hline & & $\begin{array}{l}\text { I would recommend this lecture to } \\
\text { other students. }\end{array}$ & .18 & -.70 & & & & .72 \\
\hline & & $\begin{array}{l}\text { I think the speaker enjoys a good } \\
\text { reputation among students. }\end{array}$ & .22 & -.70 & & & & .74 \\
\hline & \multirow[t]{2}{*}{$\begin{array}{l}\text { Ambivalent } \\
\text { item }\end{array}$} & & & & & & & \\
\hline & & The speaker appears competent.* & .47 & -.39 & & & & \\
\hline
\end{tabular}

Notes. $N=240,14$ variables. * Loadings derived from the first analysis before the item was discarded. 
Table 12

Study 2: Multivariate Analysis of Covariance with Factor Scores as Dependent Measures

\begin{tabular}{lcccc}
\hline & \multicolumn{1}{c}{$d f$} & $F$ & $\eta^{2}$ & $p$ \\
\hline & \multicolumn{4}{l}{ Factor 1 Research and General Competence } \\
Name-Dropping & 1 & 2.32 & .01 & .06 \\
& Factor 2 Liking and Teaching Competence & & \\
Name-Dropping & 1 & .06 & .00 & .40 \\
\hline
\end{tabular}

Notes. p-values are one-sided. Prior knowledge was used as covariate. 
Table 13

Study 3: Name-Dropping Sequences in the Condition nd-r

\begin{tabular}{cl}
\hline $\begin{array}{c}\text { Position } \\
\text { in the lecture }\end{array}$ & \multicolumn{1}{c}{ Wording } \\
\hline 1 & $\begin{array}{l}\text { You might be familiar with the research articles of Conny Antoni. He } \\
\text { described these aspects quite nicely. }\end{array}$ \\
3 & $\begin{array}{l}\text { I agree with researchers such as Ansfried Weinert... } \\
\text { My colleague Alexandra Hey and other researchers would give the same } \\
\text { answer in their publications. }\end{array}$ \\
2 & $\begin{array}{l}\text { Also, I recommend you research done by Ekkehart Frieling and his group at } \\
\text { the Institute for Industrial Science in Kassel. }\end{array}$ \\
4 & $\begin{array}{l}\text { Sabine Pietruschka, too, postulates this in a recent research article in the } \\
\text { Journal of Organizational Research }\end{array}$ \\
6 & $\begin{array}{l}\text { I recommend you research done by Klaus Giersiepen and his colleagues at } \\
\text { the Institute for Prevention Research and Social Medicine in Bremen. }\end{array}$ \\
5 & $\begin{array}{l}\text { You probably heard of Frederic Winslow Taylor's research on Scientific } \\
\text { Sonagement before, in another context. } \\
\text { concept strongly influenced by the work of Michael Schumann. }\end{array}$ \\
9 & $\begin{array}{l}\text { The scientist Dieter E. Zimmer took up this aspect in a recent congress } \\
\text { presentation. }\end{array}$ \\
\hline
\end{tabular}


Table 14

Study 3: Name-Dropping Sequences in the Condition nd-gk

\begin{tabular}{cl}
\hline $\begin{array}{c}\text { Position } \\
\text { in the lecture }\end{array}$ & \multicolumn{1}{c}{ Wording } \\
\hline 1 & $\begin{array}{l}\text { You might be familiar with the newspaper articles of Conny Antoni. He } \\
\text { described these aspects quite nicely. }\end{array}$ \\
I agree with Ansfried Weinert, a business consultant well-known for his \\
management guidebooks... \\
Alexandra Hey gave the same answer recently in a reportage on work \\
organization at DaimlerChrysler. \\
Also, I recommend you articles written by Ekkehart Frieling and published, \\
for example, in ManagerMagazin. \\
4 & $\begin{array}{l}\text { Siemens manager Sabine Pietruschka, too, postulates this in the current issue } \\
\text { of the weekly magazine DER SPIEGEL. }\end{array}$ \\
6 & $\begin{array}{l}\text { With regard to this I have recently listened to an interview on channel ZDF } \\
\text { in which Klaus Giersiepen said something very similar. }\end{array}$ \\
& $\begin{array}{l}\text { You probably heard of Frederic Winslow Taylor's research on Scientific } \\
\text { Management before, in another context. } \\
\text { So, for this you wouldn’t even need the much-cited reprofessionalization } \\
\text { about which you can learn in the business sections of „DIE ZEIT“ or „NZZ“. } \\
\text { The journalist Dieter E. Zimmer took up this aspect in a recent article. }\end{array}$ \\
\hline
\end{tabular}


Table 15

Study 3: Descriptive Statistics of Additional Variables

\begin{tabular}{lccc}
\hline & $n$ & $M$ & $S D$ \\
\hline $\begin{array}{l}\text { The speaker gave a very good lecture. } \\
\begin{array}{l}\text { The speaker makes an effort to correctly convey the information } \\
\text { on this topic. }\end{array}\end{array}$ & 232 & 4.53 & 1.39 \\
$\begin{array}{l}\text { The speaker has the skills necessary to correctly convey the } \\
\text { information on this topic. }\end{array}$ & 231 & 5.13 & 1.01 \\
$\begin{array}{l}\text { I believe that the speaker knows personally many people in his } \\
\text { area of expertise. }\end{array}$ & 230 & 4.56 & 1.41 \\
$\begin{array}{l}\text { The speaker has interests and knowledge beyond his area of } \\
\text { expertise. }\end{array}$ & 229 & 4.07 & 1.27 \\
I am impressed by the speaker's knowledge. & 231 & 2.81 & 1.55 \\
\hline
\end{tabular}

Note. All items were rated on 7-point Likert scales from 1 ("not true”) to 7 (“true”). 
Table 16

Study 3: Descriptive Statistics of Control Variables

\begin{tabular}{|c|c|c|c|}
\hline & $n$ & $M$ & $S D$ \\
\hline \multicolumn{4}{|l|}{ General quality of the lecture } \\
\hline The speaker explains in a very precise way. & 228 & 5.67 & 1.20 \\
\hline The speaker's wording is clear and exact. & 228 & 6.00 & 1.92 \\
\hline The lecture is boring.* & 228 & 5.25 & 1.92 \\
\hline \multicolumn{4}{|l|}{ Subject's ability to follow the lecture } \\
\hline There were parts in the lecture that I did not understand.* & 228 & 5.25 & 1.92 \\
\hline $\begin{array}{l}\text { I have understood the differences between job enlargement, } \\
\text { job enrichment, and job rotation.** }\end{array}$ & 228 & 5.80 & 1.45 \\
\hline \multicolumn{4}{|l|}{ Subject's motivation to follow the lecture } \\
\hline While listening, I zoned out from time to time* & 228 & 3.27 & 1.70 \\
\hline I made an effort to understand the content of the lecture. & 228 & 6.08 & 1.39 \\
\hline During the lecture, I was highly motivated to listen. & 228 & 4.30 & 1.61 \\
\hline The speaker gives practical examples. & 232 & 5.32 & 1.76 \\
\hline
\end{tabular}

Notes. All items were rated on 7-point Likert scales from 1 ("not true") to 7 ("true"). *Item is reverse coded. ** The lecture was on work organization, and the speaker explained the three concepts job enlargement, job enrichment, and job rotation. 
Table 17

Study 3: Rotated Factors and Item Loadings

\begin{tabular}{|c|c|c|c|c|c|c|c|c|}
\hline & \multirow[b]{2}{*}{$\begin{array}{l}\text { Factor } \\
\text { Name }\end{array}$} & \multirow[b]{2}{*}{ Item } & \multicolumn{2}{|c|}{ Factor } & \multirow{2}{*}{$\begin{array}{c}\text { Initial } \\
\text { Eigen- } \\
\text { value }\end{array}$} & \multirow{2}{*}{$\begin{array}{l}\% \text { of Total } \\
\text { Variance } \\
\text { (unrotated) }\end{array}$} & \multirow[t]{2}{*}{$\alpha$} & \multirow{2}{*}{$\begin{array}{c}\text { Corrected Item } \\
\text { Total } \\
\text { Correlation }\end{array}$} \\
\hline & & & 1 & 2 & & & & \\
\hline \multirow[t]{9}{*}{1} & Research & General Competence & & & 5.61 & 43.16 & .87 & \\
\hline & & $\begin{array}{l}\text { I think the speaker is known for his } \\
\text { good research. }\end{array}$ & .90 & -.14 & & & & .73 \\
\hline & & $\begin{array}{l}\text { I think the speaker is recognized by } \\
\text { other researchers. }\end{array}$ & .82 & -.06 & & & & .70 \\
\hline & & $\begin{array}{l}\text { I think the speaker is one of the leading } \\
\text { researchers in his field. }\end{array}$ & .76 & -.03 & & & & .64 \\
\hline & & $\begin{array}{l}\text { I think the speaker publishes his work } \\
\text { in important professional journals. }\end{array}$ & .74 & -.08 & & & & .58 \\
\hline & & The speaker is an expert in his field. & .65 & .05 & & & & .58 \\
\hline & & The speaker appears competent. & .62 & .28 & & & & .68 \\
\hline & & $\begin{array}{l}\text { The speaker knows what he is talking } \\
\text { about. }\end{array}$ & .58 & .18 & & & & .58 \\
\hline & & I think the speaker is very intelligent. & .49 & .29 & & & & .55 \\
\hline \multirow[t]{10}{*}{2} & Liking anc & aching Competence & & & 1.88 & 14.49 & .85 & \\
\hline & & $\begin{array}{l}\text { The speaker imparts knowledge very } \\
\text { well. }\end{array}$ & -.05 & .85 & & & & .69 \\
\hline & & $\begin{array}{l}\text { I would recommend this lecture to } \\
\text { other students. }\end{array}$ & .05 & .79 & & & & .69 \\
\hline & & The speaker explains very well. & -.02 & .78 & & & & .64 \\
\hline & & The speaker is a likeable person. & .02 & .75 & & & & .65 \\
\hline & & The speaker is an agreeable person. & .03 & .75 & & & & .63 \\
\hline & Ambivale & $\mathrm{ms}$ & & & & & & \\
\hline & & & 1 & 2 & 3 & & & \\
\hline & & $\begin{array}{l}\text { I think the speaker enjoys a good } \\
\text { reputation among students.* }\end{array}$ & -.00 & -.51 & .53 & & & \\
\hline & & $\begin{array}{l}\text { The speaker has good general } \\
\text { knowledge.* }\end{array}$ & .31 & .09 & .36 & & & \\
\hline
\end{tabular}

Notes. $N=232,13$ variables. * Loadings derived from the first analysis before the item was discarded. 
Table 18

Study 3: Multivariate Analysis of Variance with Factor Scores as Dependent Measures

\begin{tabular}{lcccc}
\hline & \multicolumn{1}{c}{$d f$} & $F$ & $\eta^{2}$ & $p$ \\
\hline & \multicolumn{4}{l}{ Factor 1 Research and General Competence } \\
Name-Dropping & 3 & .61 & .01 & .31 \\
& Factor 2 Liking and Teaching Competence & & \\
Name-Dropping & 3 & 2.00 & .03 & .06 \\
\hline
\end{tabular}

Note. p-values are one-sided. 


\section{Running Head: TWO APPLICATIONS OF NAME-DROPPING}

Two Applications of Name-Dropping and Their Effects in First Encounters:

Job Interview and Get-Acquainted Conversation

Carmen Lebherz \& Barbara Tomljenovic

University of Zurich 


\begin{abstract}
This paper investigates the effects of name-dropping on first impressions in two different settings: In Study 1, an applicant mentions former supervisors during job interview, in Study 2, an alleged student and future co-operation partner mentions his personal association with tennis professional Roger Federer (RF) during an informal getacquainted conversation. In Study 1, name-dropping does not affect competence and hireability ratings but the name-dropping applicant is perceived as less modest, less shy, more discursive, and is liked less than the applicant in the control condition. In Study 2, the partner is liked less and perceived as more manipulative when he associates himself with $\mathrm{RF}$ as friend or as friend and sports partner compared to when he states that he is a fan or does not mention RF at all. Perceived manipulativeness mediates the negative effect of name-dropping on liking.
\end{abstract}


Two Applications of Name-Dropping and Their Effects in First Encounters: Job Interview and Get-Acquainted Conversations

If we learned that somebody knows Ralph Nader personally, would we perceive her as more environmentalist than if we had not learned this detail? If somebody told us that he shoots some hoots with Dirk Nowitzki from time to time, would we perceive him as more sportive than if he did the same thing with just anybody?

Cialdini, Borden, Thorne, Walker, Freeman, and Sloan (1976) coined the term "Basking in Reflected Glory", or BIRG, for people's endeavor to associate themselves openly with famous groups and individuals. A prior study and its replications (Lebherz \& Jonas, 2005, see also Paper 1) have shown that students view a university lecturer as more competent and more likeable if he mentions his colleagues in a positive way and if he associates himself very subtly with these persons, than if he does not mention them. We discussed this finding in terms of successful BIRG, and we showed that the effect of such name-dropping on impressions is mediated by subjects' understanding that the lecturer knows personally the individuals he mentions.

With the present studies we build on these results. In Study 1 we investigate whether name-dropping is also beneficial in job interviews. As opposed to subjects in the previous studies who rated a university lecturer, subjects in Study 1 have a more powerful standing relative to the name-dropping individual: They observe an applicant of their own status (as a student) during his job interview and are asked to evaluate his performance and hireability. In Study 2, we look at yet another constellation of roles and power between the name-dropping individual and the audience: We investigate whether there is a name-dropping effect in coequal student-student dyads as opposed to the 
hierarchical lecturer-student and interviewer-applicant dyads. Study 2 also differs from previous studies in that the mentioned name is famous and easily recognized and bears a strong (positive) valence, and in that the association with that famous person is clearly stated instead of subtly implied.

Thus, these studies address the question: How do people react if a new acquaintance mentions his/her association with another person during the very first encounter, and what difference does it make how name-dropping individual and the audience relate to each other with regard to status or roles? Both studies apply the BIRG phenomenon in line with Cialdini, Finch, and De Nicholas' (1990) suggestion that a simple friendship connection might lead the audience to make "personality attributions that are independent of a person's true traits" (p. 194).

\section{Study 1: Name-Dropping in the Job Interview}

For the context of job interviews, we can derive hypotheses on the effects of namedropping on interview outcome from the ample research on impression management in job interviews. Field studies with Human Resource professionals and real job interviews showed that applicant self-presentation tactics such as self-promotion and ingratiation are an integral and expected part of job interviews. Indeed, the majority of research, both experimental and correlational, has found medium to strong positive effects of selfpresentation use on interviewers' evaluation and perceived hireability of applicants (e.g., Kacmar \& Carlson, 1999; Stevens \& Kristof, 1999).

Higgins, Judge, and Ferris (2003) performed a meta-analysis on the influence of impression management tactics on performance in organizational selection processes. With regard to job interviews, they found a strong positive effect of self-promotion on 
interviewers' assessments of the applicant with an averaged corrected correlation of $r=$ .60 , and a similarly strong effect of ingratiation with a correlation of $r=.58$.

We assume that name-dropping is a self-presentational tactic and, as such, more powerful in settings that allow for assertive and promotional self-presentation, such as the job interview, than in settings in which self-presentation is less expected, such as in a university lecture. Indeed, Fletcher (1989) suggested that claiming association with prestigious figures might be beneficial for an applicant during employment interviews. However, to our knowledge, this hypothesis has not been tested to date.

In our study, the job involved is a fundraiser position for a student-run theater. We picked this job, its description and its requirements on job candidates in order to further strengthen the appropriateness of self-presentation. Previous research has shown interactive effects of certain self-presentation tactics and job types on hireability in that assertive tactics generated more favorable hireability ratings for applicants in sales/marketing than in accounting (e.g., Buttner \& McEnally, 1996). We think that, as a fundraiser, the candidate would need to get in touch and stay in touch with new people, to network, and to be persuasive in order to be successful, and we felt that the appropriateness of self-promotion in general and name-dropping in particular might be further enhanced in this job context. Therefore, we hypothesize that the candidate who associates himself with several individuals during the interview is found more suitable for the fundraising job than the candidate who does not mention other individuals, and we investigate whether this effect is due to evaluators' attribution of interpersonal skills, networking ability, and the like.

We differentiate two forms of name-dropping in Study 1. One experimental condition employs the mentioning of former supervisors. This is similar to the manipulation in 
Paper 1: The applicant mentions individuals without having been asked for it. Another experimental condition, which we will call BIRG, employs a sequence during the interview in which the applicant does not merely mention an individual but describe his relationship with a famous professor in detail. Contrary to previous manipulations, this sequence is initiated by the interviewer who explicitly asks the applicant about the professor. Differentiating between elicited and spontaneous name-dropping seems important to us because research by Coupland, Coupland, and Giles (1991) as well as Bangerter (1999) has shown that audiences react differently to these forms of selfpresentations during general conversation and during job interview.

To sum, self-presentational efforts have proven successful in the context of job interviews. As we assume name-dropping a self-presentational tactic and as we use a fundraising job position, we hypothesize that name-dropping positively affects hireability ratings as well as job-specific competence perceptions. Besides the original name-dropping manipulation, i.e., mentioning names of other individuals and subtly associating oneself with them, this study also uses a BIRG manipulation to test whether more blatant association with a specific person and that person's openly stated merits have differential effects on the audience. We hypothesize that the BIRG manipulation has stronger impact because it establishes a clear valence for the mentioned person and is less subtle than the name-dropping manipulation.

We know from our own prior research that ratings of competence and liking are not perfectly correlated in the dependent measures. Moreover, distinguishing between competence traits and social traits has a long history in person perception, going back to Heider's (1958) ideas and Rosenberg, Nelson, and Vivekananthan's (1968) multidimensional scaling study. Therefore, we formulate separate hypotheses for liking 
and competence perception, assuming that liking is reduced by some forms of namedropping because they violate social norms of modesty, whereas competence ratings might nevertheless increase.

Besides the liking and competence ratings, we also ask subjects to evaluate the applicant's personality. We do not have directional hypotheses with regard to these ratings because there is no prior research on how name-dropping affects, for example, extraversion or enthusiasm ratings. Therefore, all tests concerning competence and liking are run one-sided, whereas all tests concerning personality inferences are run twosided.

\section{Method}

\section{Experimental Design}

The experiment is a $2 \times 2$-factorial design, manipulating that an applicant in a job interview either uses name-dropping as a self-presentational tactic (W/ND) or does not (W/OND), and that the applicant either basks in the reflected glory of a famous professor (W/BIRG) or does not (W/OBIRG).

\section{Pretest}

We did a pretest on a sample of 42 subjects to show, first, that the manipulation of both name-dropping and BIRG is successful and, second, that the four conditions are comparable on all other dimensions that might be relevant for interview outcome and applicant evaluation. The pretest subjects did not participate in the main study.

We know from person perception research that facial expression and gesture influence our evaluation of others. Specifically, research on what influences employment interview outcome has given ample evidence for the importance of nonverbal cues. For example, smiling and eye contact have both been associated with 
positive impressions (e.g., Gifford, Hg, \& Wilkinson, 1985; Kacmar, Delery, \& Ferris, 1992), whereas stuttering, fidgeting, and very slow or very fast speech have a negative impact on the perception of the actor (DeGroot \& Motowidlo, 1999; see also Hollandsworth, Kazelskis, Stevens, \& Dressel, 1979; Imada \& Hakel, 1977). Physical attractiveness and appearance of the applicant also influence hireability ratings (Cable \& Judge, 1997; Kinicki \& Lockwood, 1985; Marlowe, Schneider, \& Nelson, 1996; Riggio $\&$ Throckmorton, 1988). Therefore, our conditions need to be comparable with regard to these dimensions.

We shot the approx. seven-minute video showing the alleged job interview with a professional actor. Also, we shot segments of about two minutes instead of the whole video in a row, and we made sure that the actor took turns in starting with the namedropping and the no name-dropping conditions, to prevent a routine bias in the actor's behavior. The actor made efforts to use the exact same gesture, amount of smiling and laughing, nodding, and motion in general. A second, non-professional actor was involved in the video. He acted as the interviewer and was not shown in the video, as the camera was constantly focused on the professional actor. Subjects only heard the interviewer ask questions and reply to the applicant. This non-professional actor read his lines from a transcript, using the exact same phrases in all conditions. A transcript of the job interview is provided in Appendix F-1.

\section{Pretest of the Name-Dropping Manipulation}

Subjects stated for each name in the interview and for five distractor names whether or not that name was mentioned during the interview. The manipulation check questionnaire is provided in Appendix G-1. The manipulation was successful. The 
recognition test showed that subjects in the W/ND condition acquiesced more frequently to all six critical names than subjects in the W/OND condition. The Pearson Chi-Square Test was significant on one-sided tests for five of the six names (all $\chi^{2}>6$, all $p \leq .02$ ), One name was recognized correctly by only five of twenty W/ND subjects $\left(\chi^{2}=2.69, p\right.$ $=.12$ ). It is very likely that this part of the video tape was difficult to understand acoustically. ${ }^{1}$ At the same time, no differences between the two groups existed with regard to any of the five distractor names.

\section{Pretest of the BIRG Manipulation}

The name that was used for the BIRG manipulation was the only name that was mentioned in all four conditions: The interviewer ties in the mentioned name of the professor, indicating his fame. He thus either initiates the BIRG sequence (W/BIRG) or moves on to other questions (W/OBIRG).

The manipulation check showed that the BIRG name was indeed equally well recognized in both W/BIRG and W/OBIRG condition. However, one item asked the subjects to indicate the kind of information that they received about the BIRG name, whether it was positive, negative, or no information at all. On this item, subjects in the W/BIRG condition were more likely to affirm positive information about the BIRG name than in the W/OBIRG condition. This confirms our manipulation because the BIRG name is supposed to have a clearly positive valence. The name was not once considered negative; however, eight out of 20 subjects in the W/OBIRG condition also found that the BIRG name was mentioned in a positive manner. Therefore, the item was re-phrased more restrictively for the main study, changing "he is a well-known expert in his field" into "he is a famous expert in his field". By doing so, we hoped to enlarge the 
difficulty of the item and to receive agreement only from subjects who actually heard about, as opposed to inferred, the fame of the BIRG name. Additionally, the "no information"- answer option was changed from "the interview contains no information" into "the interview contains no information about the quality of his work". Thus, we expect those subjects who in the pretest merely inferred the BIRG professor's fame to be more likely to choose this third option.

In the BIRG sequence, the applicant showed very obviously that he was pleased to be associated with the famous BIRG professor: The actor leaned back in a rather complacent way, changing posture significantly, which he did not throughout the rest of the interview. We were concerned about whether this obviousness might make the applicant too boastful in the eye of some subjects. This was indeed the case in the pretest. As subjects stated in open-ended questions that they found the applicant boastful due to the motion that accompanied his words, we used a more modest version of the BIRG sequence for the main study. In this modest version, the actor merely smiled contently when he was associated with the famous professor, and he did not change posture at all.

\section{Pretest of Control Variables}

As noted above, we wanted to ensure that the actor was personating the applicant in very similar ways in all four conditions with regard to everything but the experimental factors. Therefore, several descriptors of the applicant's behavior were given to the subjects, and they indicated on a seven-point Likert scale the degree to which the applicant showed the behavior. ${ }^{2}$ The two-factorial MANOVA (two-sided testing) revealed no main effect for name-dropping or BIRG on any dimension. There was a 
significant interaction effect on the dimension "[the applicant] talks very fast", in that subjects in the W/ND condition agreed more with this statement than did W/OND subjects, but only if they were in the W/OBIRG condition $(F=4.25, p=.05)$. Because we could not find any plausible reason for this effect when comparing the versions of the video, we decided to interpret the effect as a likely sampling error. Nevertheless, we included these dimensions in the main study as a safeguard.

In sum, the applicant's behavior during the interview was perceived very similarly in the four conditions with regard to fidgeting, frequency of smiling, stuttering, appropriateness of clothing, volume of voice, clarity of speech, attractiveness, and eye contact.

We also wanted to make sure that subjects read the instruction very carefully and that they learned three characteristics desired of a successful candidate: relevant work experience, agreeable manner of appearance, and relevant interests. With regard to subjects' ability to learn this information, the pretest showed that experience was correctly recalled by $81 \%$, manner of appearance by $91 \%$, and interests by $95 \%$ of the subjects.

\section{Main Study}

\section{Sample}

Subjects were recruited on campus. From 253 subjects in the main study, one was discarded from all analyses because he or she failed to fill in one of the questionnaires, and three were discarded because they knew personally either the professional actor or the non-professional actor. From the remaining 249 subjects, $68.7 \%$ were female, $31.3 \%$ male. Seven subjects did not indicate their major or minor. From the others, $68.2 \%$ had 
psychology as either major or minor, $6 \%(n=14)$ were law majors, $6 \%(n=14)$ were business majors, and the remaining $19.8 \%$ split over a variety of subjects, with less than ten subjects from the same subject. Four subjects did not pursue any study.

\section{Procedure}

Subjects who were present at one time (up to five subjects per session) received the same manipulation, i.e., they watched one of the four video versions projected against the wall. They were welcomed and asked to take a seat. Each was supplied with written instructions and the questionnaires. They were then asked to read the instruction and were told that the proceeding was described in there.

In the instruction they read that they would first receive a job description for the position of a fundraiser at a student theater and a profile of what a successful candidate should be like, then watch a video projection of a job interview for the position, and finally state their opinion of the applicant. They were told that the study would take approx. 40 minutes. The full version of the instruction is provided in Appendix H-1.

After subjects read the candidate profile, they were asked on a separate sheet to identify on a multiple choice item the three characteristics that the candidate should have. Although the pretest had shown that the profile was generally understood and learned easily, we wanted to ensure that each subject read the profile carefully. Also, after that, we again presented the profile to provide the correct answer to the profile question.

\section{Manipulations}

Name-dropping and BIRG were manipulated using the video projection of the job interview as described in the pretest section. The original BIRG sequence used in the pretest was replaced by a more moderate version that we also described in the pretest 
section.

\section{Measures}

\section{Dependent Measures}

First, subjects stated the probability (in percent) that they would hire the applicant on the basis of his performance in the interview if they had to make a decision without seeing other applicants. Second, subjects rated the applicant on 17 seven-point Likert scales ("not true" to "true") with regard to competence and likeability.

Among the list of control variables were some person descriptors that can not be considered control variables in a strict sense because they are indeed personality inferences and, thus, dependent measures. This is true for the dimensions/adjectives polite, enthusiastic, self-confident, modest, extraverted, motivated, shy, eloquent, discursive, and arrogant. However, because subjects rated these dimensions only after the manipulation check, we decided to analyze them apart from the other dependent measures and not include them in the factor analysis of the dependent variables.

\section{Manipulation Check}

The name-dropping manipulation check was identical to the one used in the pretest: Subjects stated for each name in the interview and for five distractor names whether or not that name was mentioned during the interview. We expected subjects in the W/ND condition to correctly identify more of the critical names that were used in the video tape than subjects in the W/OND condition.

To test the BIRG manipulation, one item asked subjects to indicate the kind of information that they received about the BIRG name, whether it was positive, negative, or no information at all. We expected subjects in the W/BIRG condition to choose the positive option, namely "He is a famous expert in his field", subjects in the W/OBIRG 
condition to choose the neutral option, namely "The interview contains no information about the quality of his work".

\section{Control Variables}

Ten control variables were used to ensure that the four versions of the video were comparable with regard to everything but the manipulation (see pretest section). Also, two variables controlled for subjects' influences on applicant evaluation, namely subjects' prior experience in fundraising or personnel recruitment (e.g., "Do you have experience with fundraising?", answered yes/no), interest in theater (one variable, “Are you interested in theater?" rated on a 7-point Likert scale), motivation (two variables, see Table 3), biographical data (age, gender, and year of study), memory of job-relevant facts about the applicant (four variables, e.g., "The applicant has experience with fundraising", answered yes/no), and self-rated similarity to the applicant (six variables, see Table 3). The latter was included because previous research has established pervasive similar-to-self biases during interview evaluation, i.e., interviewers' applicant evaluation correlates up to $r=.50$ with interviewers' self-rated similarity to the applicant (e.g., Anderson \& Shackleton, 1990; Graves \& Powell, 1988).

Results

\section{Manipulation Check}

The name-dropping manipulation was successful: The recognition test showed that subjects in the W/ND condition affirmed all six critical names more frequently than subjects in the W/OND condition. The Pearson Chi-Square Test was significant on onesided tests for all six names (all $\chi^{2}>15.00$, all $p \leq .02$ ). At the same time, no differences between the two groups existed with regard to four of the five distractor names, only one distractor was subject to a false positive error and chosen more often by subjects in the 
name-dropping condition $\left(\chi^{2}>6.00 ; p=.02\right)$.

The BIRG manipulation was successful: Subjects in the W/BIRG condition more frequently chose the positive option to describe the BIRG person, namely "He is a famous expert in his field", subjects in the W/OBIRG condition more frequently chose the neutral option, namely "The interview contains no information about the quality of his work". The Pearson Chi-Square Test was significant in the predicted direction $\left(\chi^{2}>\right.$ $85.63 ; p<.001)$. No such difference was found for the name-dropping conditions.

\section{Control Variables}

Ten variables tested whether the applicant was similarly personated in the four experimental conditions. Table 1 shows the descriptive statistics. A multivariate test (MANOVA) showed significant differences as an interaction of name-dropping and BIRG (Wilks' $\lambda=.93, F=1.94, p=.05$ ). According to univariate tests, these differences are marginally significant for ratings of applicant attractiveness $(F=3.06, p=.08)$, appropriateness of clothing $(F=3.43, p=.07)$, the interviewer's reaction to the applicant $(F=3.54, p=.06)$, and the perceived similarity between interviewer and applicant $(F=3.61, p=.06)$. These variables were included as covariates in all further analyses. Furthermore, univariate tests showed significant differences between the name-dropping conditions with regard to volume of voice $(F=3.86, p=.05)$ and between the BIRG conditions with regard to fidgeting $(F=4.22, p=.04)$, talking speed $(F=6.11, p=.01)$, and, marginally, volume of voice $(F=3.70, p=.06)$ Therefore, these variables were also included as covariates in all further analyses.

As we have found in previous studies that gender, age (see Paper 1), and study year correlate with dependent measures of person perception, we included them as control variables, even though the conditions did not differ in these regards. Also, prior 
experience with fundraising and personnel recruitment, interest in theater, motivation, and the self-rated degree of similarity between subject and applicant were used as control variables. The six similarity ratings were taken as a homogeneous similarity scale (Cronbach's $\alpha=.61$ ), and the two motivation items were taken as a homogeneous motivation scale $(\alpha=.88)$. The exact wordings of the similarity and motivation items are given in Table 1.

$* * * * * * * * * * * * * * * * * * * * * * * * * * * * * * * * * * * * * * * * * * * * * * * * * * * *$

Table 1

Descriptive Statistics of Control Variables

With regard to the subjects' ability to learn the characteristics desired of a successful candidate (prior work experience, interest in theater), the pretest had shown that memory for the characteristics was generally high $(76 \%$ answered all three questions correctly, additional $21 \%$ answered two questions correctly) and did not differ between the conditions. In the main study, we asked subjects in the manipulation check questionnaire whether the applicant fulfilled these and other job relevant characteristics (e.g., having studied a year abroad), and subjects of the four conditions did not differ in their ratings. Structure of the Dependent Measures

The item asking for hireability (in per cent) was used as a single item measure. The other 17 dependent measure items were factor analyzed with a principal component analysis and oblique rotation. To decide on the number of factors, I used the Kaiser criterion (eigenvalues $>1$; Kaiser, 1960) and the scree test (Cattell, 1966). Three items 
do not load clearly on one of the three factors and were discarded from the analysis. The remaining 14 items clearly form three empirical factors that can be interpreted as JobSpecific Competence, Liking, and Interpersonal Competence. Together they explain $73.01 \%$ of variance in the dependent measure. The factors have high internal consistency (Cronbach's $\alpha$ ), and only one item shows low item-total correlation, namely "The applicant knows his way around culture" on the Liking factor. The factor analyzed dependent measure items and their empirical structure are shown in Table 2.

$* * * * * * * * * * * * * * * * * * * * * * * * * * * * * * * * * * * * * * * * * * * * * * * * * * * *$

Table 2

Rotated Factors and Item Loadings

The dependent measures that asked for inferences regarding the applicant's personality (e.g., "extraverted", "arrogant") and that were included in the list of control variables were analyzed separately due to their late appearance in the questionnaire. They were included as single item measures in the analyses and are shown in Table 3.

$* * * * * * * * * * * * * * * * * * * * * * * * * * * * * * * * * * * * * * * * * * * * * * * * * * * *$

Table 3

Personality Inferences as Additional Dependent Measures

$* * * * * * * * * * * * * * * * * * * * * * * * * * * * * * * * * * * * * * * * * * * * * * * * * * * *$ 


\section{Effect of Name-Dropping on the Dependent Measures}

A MANCOVA was calculated with all of the above mentioned control variables as covariates and the three empirical factors Job-Specific Competence, Liking, and Interpersonal Competence, as well as hireability ratings and the personality inferences as dependent measures.

Multivariate tests were significant for the name-dropping manipulation (Wilks' $\lambda=$ $.87, F=1.95, p=.02$, two-sided) but not for the BIRG manipulation. Table 4 shows the univariate tests for name-dropping: If the applicant used name-dropping in the job interview, he was perceived as more discursive $\left(F=9.67, p=.002, \eta^{2}=.05\right)$, less shy $(F$ $\left.=5.13, p=.03, \eta^{2}=.03\right)$, and less modest $\left(F=4.76, p=.03, \eta^{2}=.02\right)$. No effects were found on the empirical factors or the hireability rating.

$* * * * * * * * * * * * * * * * * * * * * * * * * * * * * * * * * * * * * * * * * * * * * * * * * * * *$

Table 4

MANCOVA with Factor Scores as Dependent Measures

Results were very similar when we built scales of the items loading strongly on the same factor and used scale means instead of factor scores as dependent measures. Again, multivariate tests were significant only for the name-dropping factor (Wilks' $\lambda=.85, F$ $=2.29, p=.01)$. Table 5 shows the results of the univariate tests: The Liking scale reached significance $\left(F=3.50 p=.03, \eta^{2}=.02\right.$, one-sided $)$, i.e., the W/ND candidate was perceived less likeable than the W/OND candidate. Also, the personality inferences 
on discursiveness $\left(\eta^{2}=.05\right)$, shyness $\left(\eta^{2}=.03\right)$, and modesty $\left(\eta^{2}=.02\right)$ differed significantly. In addition, inferred applicant enthusiasm was marginally significant $(F=$ $3.12, p=.08, \eta^{2}=.01$, two-sided), i.e., the W/ND candidate was perceived as slightly more enthusiastic.

We would have liked to use explicit annoyance with the mentioned names as a covariate and asked subjects whether they were annoyed by anything in the video tape and/or the applicant. We have done that before (Lebherz \& Jonas, 2005) and thereby have shown that the positive effect of name-dropping increases overall if annoyed subjects are controlled for. In this sample, however, only five subjects in the W/ND condition commented on the names, four of which where at the same time part of the W/OBIRG condition. Therefore, we could not run tests on annoyance.

$* * * * * * * * * * * * * * * * * * * * * * * * * * * * * * * * * * * * * * * * * * * * * * * * * * * *$

Table 5

MANCOVA with Scale Means as Dependent Measures

\section{Discussion}

\section{Discussion of Results}

The hypotheses are partially confirmed: Name-dropping did affect some of the personality inferences, i. e., the applicant who mentions others was perceived as more discursive, less shy, and less modest. He was also liked less by the evaluators. However, the most central dependent measure, the student evaluators' hiring decision, was not affected by name-dropping in any direction: Subjects in our study tended to hire both 
applicants with chances around $60 \%$ and believed both candidates to be equally capable of doing the fundraiser job.

Furthermore, and again contrary to our hypothesis, BIRG affected neither hiring decision nor ratings of personality, competence, or liking. Although we would have expected the BIRG manipulation to be a much more blatant self-presentation tactic than name-dropping, the multivariate test did not reach significance.

Interestingly, only five subjects commented on the names mentioned, as opposed to up to $15 \%$ of name-dropping subsamples of previous studies (see Paper 1). This might indicate that name-dropping is indeed regarded appropriate during employment interview. Nevertheless, personality inferences and liking ratings were negatively affected, and it did not have any positive impact on competence perception and hireability. We do not think that the manipulation was too weak and would be more influential when including more names. Indeed, the applicant mentioned seven names, six of which were unique to the name-dropping condition, and the interview lasted only about seven minutes. Rather, we think that subjects deemed the names mentioned sufficiently appropriate but that they did not feel increased trust in the applicant's potential as a fundraiser.

\section{Limitations and Future Research}

The major limitation of this study is that subjects rated the applicant's personality after the other dependent measures and after the manipulation check. Thus, we can not be sure to what degree the manipulation check items influenced the personality inferences. As subjects stated for each name and several distractor names whether or not it was mentioned in the video tape, they might have become aware of the manipulation, study purpose, and/or ulterior motives underlying the applicant's name-dropping. 
Replication studies should ensure that subjects provide personality inferences right after the manipulation has ended. However, our trust in the results is enhanced by the fact that there is an effect of name-dropping on the liking ratings, which subjects provided before the manipulation check. This suggests that there is, indeed, a negative effect of namedropping on applicant evaluation.

Study 2: Name-Dropping in Get-Acquainted Conversations

The purpose of Study 2 is to apply name-dropping to yet another context, that of a get-acquainted email conversation between two students. Contrary to the ample research relevant to Study 1, research on self-presentation effects on competence and liking in get-acquainted conversations is rare. Therefore, we consult two theories that allow predictions, Heider's Balance Theory and Tesser's Self-Evaluation Maintenance Model (SEM).

Heider's Balance Theory states that our liking of another individual depends on the information $(\mathrm{O})$ we $(\mathrm{P})$ have about that individual $(\mathrm{X})$ and on the three relationships ("relatedness") that exist between O, P, and X. With regard to the present study, Heider's Balance Theory predicts that we $(\mathrm{P})$ should have a positive impression of a person $(\mathrm{X})$ who mentions a famous other $(\mathrm{O})$ if the relationship between $\mathrm{X}$ and $\mathrm{O}$ is positive (i.e., if $\mathrm{X}$ associates himself in a positive way with $\mathrm{O}$, by admiring $\mathrm{O}$ or by showing any positive attitude toward $\mathrm{O}$ ) and if the relationship between $\mathrm{P}$ and $\mathrm{O}$ is positive (i.e., if we perceive that famous person as likeable, competent, or in any way positive). Put in a different way, if two individuals share the same attitude toward a third entity (if their evaluations of $\mathrm{O}$ are in balance), they will evaluate each other more positively than if they disagree on their attitude toward that third entity. Theoretical as 
Heider's suggestions are, there is indeed empirical evidence that attitude similarity is a strong predictor of reciprocal liking (Berscheid, 1985; Byrne, 1971).

From a balance theory point of view, it should make no difference how strong, intimate, or important the relationship between the three entities of $\mathrm{P}, \mathrm{O}$, and $\mathrm{X}$ is. Heider (1958) states that even the slightest relationships, which he called unit relatedness, produce either balance or imbalance in the entity triad and consequently cause either positive or negative reactions in $\mathrm{P}$.

Tesser's Self-Evaluation Maintenance Model (SEM) roots in Festinger's (1954) work. Festinger assumes in his Social Comparison Theory that our self-evaluations are not absolute, but relative to our perceptions of others. For example, if we want to know how well we perform, we consult similar others, compare our performance with their performance, and then draw conclusions about our performance from the result of that comparison (Festinger, 1954). In general, we prefer to compare ourselves with similar others. Often we can choose whether we compare ourselves with individuals who perform worse than ourselves (downward comparison) or with individuals who perform better (upward comparison). Upward comparisons have been shown to threaten selfesteem.

However, Tesser's SEM model states that meeting a more successful individual does not necessarily lead to negative impressions. He brings into the equation the two additional aspects self-relevance and closeness. Closeness means the psychological connection we have to the successful individual. Tesser's (1991) understanding of psychological closeness is in line with Heider's (1958) unit relatedness; it is induced by physical or psychological similarity and spatial contiguity (see also Tesser, 1988). Selfrelevance regards how important the domain is for our self-concept. If a friend of ours is 
a successful pianist, we should not experience lowered self-esteem due to outperformance, as long as we are not headed for a career as pianist ourselves. Instead, we might be proud to know personally such a successful individual, and the closer we are to her, the more positive is the affect we receive from that acquaintance.

According to the SEM model, meeting a superior individual triggers either a reflection process or a comparison process. The reflection process is triggered if the domain in question is irrelevant to our self-concept. In the reflection process, outperformance is no threat to self-esteem. Quite to the contrary: We can bask in the reflected glory of the other's successes - and even more so if we are close to the superior individual. We can also enhance the basking (and, therefore, our self-esteem) by increasing the perceived closeness. In the case of our pianist friend, we could stress that we like to jam together, and that we have known each other for years.

The comparison process is triggered if the domain in question is relevant to our selfconcept. If we strive to be a pianist and we get to know another pianist, we are likely to compare our abilities, previous concerts, and critique in order to conclude who is the better pianist. If we are outperformed by the other, our self-esteem is threatened. Closeness can then enhance the negative feelings. In order to restore our self-esteem, we might downgrade the other pianist's accomplishments or search for dissimilarities between the two of us; for example, we could focus on the fact that we are still a couple of years younger than the other pianist.

In line with the SEM model, Pleban and Tesser (1981) found that subjects claimed less interpersonal closeness with a rival, and Salovey and Rodin (1984) reported that subjects felt negative affect (jealousy), that they were likely to disparage the rival after being outperformed in a comparison process, and that they stated little desire to be 
friends with the rival. Thus, closeness harbors a potential for both pleasure and pain, depending on the kind of process that is triggered (Tesser, Millar, \& Moore, 1988).

Whereas we can apply Balance Theory directly to name-dropping by defining as unit $\mathrm{O}$ the person who is mentioned, we have to make some additional assumptions about the SEM model. The SEM model has thus far been concerned with the situation that another individual directly outperforms us, and how we react to that situation. In our namedropping manipulation in Study 2, the name-dropping individual does not directly outperform their counterpart, but associates himself with Roger Federer, who is the current Number One Tennis player in the world and who clearly outperforms any of our subjects in the sports domain. We assume that the SEM does apply to such indirect outperformance.

As we are interested in the effects of name-dropping on person perception, we made sure that there is a certain degree of closeness between our subjects and the namedropping individual in order to measure how subjects' social judgments of the namedropping individual change compared to judgments of an individual who does not use name-dropping.

Balance Theory and the SEM model arrive at different hypotheses with regard to the social judgments made in this study. Balance Theory is primarily concerned with liking between individuals. Subjects $(\mathrm{P})$ should like a new acquaintance $(\mathrm{X})$ if he or she claims to be a fan of Roger Federer's $(\mathrm{O})$, because the P-O-X triad is balanced. As the theory does not make predictions about how different strengths of the relatedness between $\mathrm{X}$ and $\mathrm{O}$ influence the relatedness between $\mathrm{P}$ and $\mathrm{O}$, the effect should be the same whether the new acquaintance claims to be a friend of Roger Federer's or claims to work out with Roger Federer. As the theory does not make predictions about how self-relevance 
of the comparison domain plays a role in the triad, the effect should not be influenced by the subjects' own sportiveness.

By contrast, the SEM model is concerned with both liking and competence perceptions, and it allows for more differentiated hypotheses. It predicts that subjects who consider themselves sportive and for whom sport is self-relevant should like the new acquaintance better if he is a fan of Roger Federer's than if he does not mention Roger Federer (reflection process), but that they should find him less likeable, less close, and less similar to themselves if he claims to be friends with Roger Federer and/or working out with him (comparison process).

It also predicts that subjects who consider themselves not sportive and for whom sport is irrelevant should like the acquaintance better if he mentions Roger Federer, regardless of whether he is a fan, friend, or sports partner (reflection process). Sportive subjects, on the contrary, might like the acquaintance less if he/she is a friend or sports partner of Roger Federer's because they are envious (comparison process).

With regard to competence perceptions, we assume that sportive subjects process systematically and understand the strength of the relationship as an argument for the acquaintance's sportiveness. Specifically, sportive subjects should acknowledge that their acquaintance works out with Roger Federer and view him significantly more sportive than if he is only a friend. We assume that less sportive subjects process heuristically and view the association as friend as a cue that the acquaintance is sportive.

As the two theories we build on come to divergent conclusions concerning the quality of the name-dropping effect (positive vs. negative) in the four name-dropping conditions we manipulate, we do not specify directional hypotheses and we will run all tests twosided. 
Method

\section{Experimental Design}

The experiment is a $4 \times 2$-factorial between-subjects design. We manipulated four name-dropping conditions: The "fan" condition, in which the bogus email sender mentions Roger Federer and states his/her" admiration for him; the "friends" condition, in which the sender mentions Roger Federer and states that they have been friends for a long time; and the "friends and sports" condition, in which the sender mentions Roger Federer and states that they are friends and working out together. In the control condition, the sender does not mention Roger Federer at all.

As a second, quasi-experimental factor, subjects' reported their sportiveness before the manipulation of name-dropping, and a median-split provided the conditions "sportive" and "not sportive". The dependent measures of interest are the sender's perceived general competence, sport-related competence, sociability, and manipulativeness; liking of sender; and perceived similarity between oneself and the sender.

\section{Pretest}

We used a pretest to ensure that Roger Federer is as unequivocally liked and perceived competent as we think he is. A sample of 34 student subjects rated Roger Federer and five other prominent Swiss individuals on five 7-point Likert scales: liking ("not likeable" to "very likeable"), success ("not at all successful" to "very successful"), competence ("incompetent" to "very competent"), regard ("I do not think much of this person" to "I think much of this person"), performance ("I find the performance of this person poor" to "I find the performance of this person very good"). The pretest subjects did not participate in the main study. 
The scores of all items were summed for each subject and a mean sum score was calculated for each prominent person. As expected, Roger Federer achieved the highest rank, with a mean of $M=30.64$ and a median of $M d=31(S D=3.21)$. Lowest in the rank order was the conservative politician Christoph Blocher with $M=17.82(S D=$ $5.63)$.

Also, the ratings of Roger Federer varied less than any of the others' ratings. Thus, Roger Federer is perceived as highly successful, competent, and likeable and is in fact the unequivocally, very strongly positively associated name that we wanted for this experiment.

\section{Main Study}

\section{Sample}

183 students of the University of Zurich participated in this study. From these, 71 subjects were dropped due to one or several of these problems: received email from bogus partner with other gender than self; guessed correctly that the study was about name-dropping; was suspicious that the bogus email was not authentic; did not fulfill manipulation check criteria. From the final sample of 112 subjects, $49 \%$ were female, $51 \%$ male. $51 \%$ were psychology majors, $8.9 \%$ political science majors, $9 \%$ history majors and $7.1 \%$ economics majors. The remaining $25 \%$ of the subjects split into a variety of subjects from the Humanities, Fine Arts, Social and Behavioral Sciences, and Natural Sciences.

The mean age was 22.9 years, with a median of 22 years. Students were recruited on campus and participated voluntarily. To provide an incentive to participate, we raffled 4 x CHF 50 amongst all subjects. Psychology majors received additional credit towards 
research credit requirement. All students were randomly assigned to one of the four name-dropping conditions.

\section{Procedure}

The procedure was implemented as part of a master thesis by the second author. She received assistance in recruiting and conducting the study by four other female graduate students. During recruitment, participating students provided their email address and proposed an appointment for the experiment. We told them that they were to do the experiment together with another student, that the experimenter would assign them a partner depending on the proposed appointment, and that they should introduce themselves via email to their partner before the experiment in order to get acquainted. The cover story was "work-life balance", and we told subjects that we were specifically interested in student's sports training strategies (as part of their work-life balance). We used this topic because Roger Federer stands for the sports domain and we therefore wanted to include subjects' sportiveness as a quasi-experimental factor: With the sports training strategy topic we were able to ask students about their individual sportiveness without raising suspicion, and with the extension on work-life balance we were able to avoid the obvious connection between the study topic (sports) and the mentioned person (Roger Federer) which could have led to suspicion about the authenticity of the email.

Subjects were then contacted by the experimenter via email. The email confirmed the requested appointment and contained the full name and email address of the alleged partner. Different names and different addresses from several free email providers were used in case some students talked to each other about the experiment. ${ }^{4}$ The email also told subjects that their partner had been chosen to send an email introduction first and would do so soon, that they should then reply to the partner and introduce themselves, 
and we asked them to return the email questionnaire as soon as possible.

The questionnaire contained control variables, namely biographical data on gender, age, and study major. Additionally, questions on subjects' studying and leisure time behavior were included, three of which were on subjects' sports behavior and were used to generate the quasi-experimental factor "sportiveness". Similarly phrased items on music-related leisure time behavior were included to distract subjects and to support the cover story of work-life balance. This email questionnaire is provided in Appendix I-1.

Once a subject had returned the questionnaire via email, the experimenter sent out the email from the alleged partner's email account which contained the manipulation according to one of the four name-dropping conditions. Alleged partners were of the same gender as the subjects. The four full versions of the manipulation emails are provided in Appendix J-1. Subjects were instructed to print the email they receive and bring it with them to the experiment appointment.

The dependent measures were gathered on the proposed appointment. Up to five subjects were scheduled for the same time. Subjects were welcomed, told that their partner for the study had not yet arrived, and asked to take a seat. The experimenter had a large, colorful spreadsheet which she consulted for every subject as though looking for the respective partner. This was done to convince subjects that they had a specific partner (the one who had introduced him-/herself via email and to whom they had responded and introduced themselves) who just happened to be late.

The experimenter asked the subjects to read their partner's email once more. When subjects had not brought the email printout, the experimenter sent them to a nearby computer lab to check their accounts and re-read the email. However, 17 subjects (15.2\%) did not read the email once more right before the experiment for different 
reasons. ${ }^{5}$ This was noted and statistically controlled for in all subsequent analyses. The experimenter then told subjects that they could start with a paper-pencil questionnaire until their partners' arrivals because questionnaires were to be filled out independently anyway. She told them to start with Folder 1 and afterwards move on to Folder 2. Folder 1 contained the dependent measures and manipulation check items. Folder 2 contained our thanks and the debriefing. The paper-pencil questionnaire containing the dependent measures and the manipulation check is provided in Appendix K-1.

Before the students left, they were offered to receive notice of the study's results. Because all subjects were interested, the second author later emailed information on the results to all subjects.

\section{Manipulations}

The factor name-dropping was manipulated by means of the email which the subjects received, ostensibly by their partner. The four versions of the email are shown in Appendix J-1. In the control condition, the alleged partner wrote about his/her age, studies, part-time job, and leisure time behavior (sports). In the "fan" condition, the leisure time behavior (sports) section was followed by additional sentences that praised Roger Federer as an admirable sportsman. In the "friends" condition, the sports section was followed by additional sentences in which the partner described his friendship with Roger Federer and praised him as a friend and sportsman. In the "friends and sports" condition, the partner used the additional sentences to described his friendship with Roger Federer, praised him as a friend and sportsman, and additionally stated that he and Roger Federer occasionally went to fitness training together or jogged together. Thus, the three experimental conditions increase in strength of association between the partner and Roger Federer from "fan" to "friends" to "friends and sports" condition. 


\section{Measures}

\section{Dependent Measures}

Seventeen items measured six dimensions of person impression: three items each for general competence, sport-related competence, liking, manipulativeness, and similarity between partner and subject, and two items for sociability. All items were rated on 7point Likert scales ranging from 1 ("not true)" to 7 ("true"). General competence and liking items were taken from previous experiments (Lebherz \& Jonas, 2005; see also Paper 1) and sport-related competence items were generated for the purpose of this study. Sociability and manipulativeness items were translated from Gurevitch (1985, see also Tal-Or, Philosoph, Shapira, \& Malca, 2005). Table 6 lists the dimensions and their items, descriptive statistics, Cronbach's $\alpha$, and item-total correlations in this sample. The manipulativeness items were reverse coded.

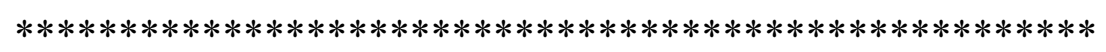

Table 6

Suggested Dimensions of the Dependent Measure

\section{Manipulation Check}

Two items tested whether subjects remembered the association between the partner and Roger Federer correctly. The first item was a multiple choice item ("My partner mentioned in his email...”) with five options (Bruce Willis/Kofi Annan/Roger Federer/Pete Sampras/none of these). Subjects were asked to choose one option. The second item was a multiple choice item ("If your partner mentioned one of these 
individuals: How does he relate to that individual?") that allowed for more than one choice (dislikes him/admires him/is a friend of his/they do fitness training together). Multiple choices were allowed because the name-dropping conditions increased in association strength between the partner and Roger Federer, and more intense conditions included associations that existed also in the less intense conditions. For example, the "friends" condition also included the admiration statement of the "fan" condition. Thus, this item was considered as rank ordered.

One item tested whether subjects remembered the cover story correctly. Subjects chose to the item "Today's study is about..." one of four options: study strategies at university/music/sports training strategies. ${ }^{6}$

\section{Quasi-Experimental Factor}

As Roger Federer is a professional tennis player, it is important to control for subjects' self-evaluation with regard to sports, importance assigned to sports, and sports behavior. These variables were measured by self-report at the point when the experiment appointment was confirmed, i.e., before the name-dropping manipulation and before the dependent measure. The respective items were "I am very sportive" (7-point Likert scale), "Sports are important to me" (7-point Likert scale), and free answers on how

many hours per week the subjects spend doing sports and what kinds of sports they did. ${ }^{7}$

Averaged z-transformations of the three variables were used as a composite "sportiveness" score $(\alpha=.87)$, and a median split provided the quasi-experimental between-subjects factor subject sportiveness, assigning each subject to either the sportive or the non-sportive condition.

\section{Control Variables}

Several biographical data were included to ensure that the conditions do not differ 
systematically with regard to gender, age, and having psychology as a major. Filler items were included in the questionnaire to support the cover story of work-life balance: They were phrased similarly to the sports items, three asked for study behavior, three for music-related leisure time activities.

\section{Results}

\section{Manipulation Check}

Each case was checked with regard to the three manipulation check items, and cases were only accepted in the final sample if Roger Federer was chosen in the first item, if the highest answer option chosen from the rank order item corresponded to the assigned name-dropping condition, and if subjects recalled the study topic, i.e., training strategies in leisure time (non-professional) sports. 133 subjects fulfilled all manipulation check criteria. Of these, 11 subjects were discarded due to other problems (e.g., because they questioned the authenticity of their partner's email, see section Sample).

\section{Control Variables}

Table 7 shows means and standard deviations of the control variables for the final sample of 112 subjects. The subjects in the four conditions did not differ with regard to sports self-evaluation, importance assigned to sports, or self-reported hours spent on sports.

$* * * * * * * * * * * * * * * * * * * * * * * * * * * * * * * * * * * * * * * * * * * * * * * * * * * *$

Table 7

Descriptive Statistics of Control Variables

$* * * * * * * * * * * * * * * * * * * * * * * * * * * * * * * * * * * * * * * * * * * * * * * * * * * *$ 
Also, no differences were found between the name-dropping conditions regarding biographical data of the subjects. That is, subjects in the four conditions are comparable in gender and age, and all conditions have similar percentages of subjects majoring in psychology.

\section{Structure of the Dependent Measures}

An explorative principal component analysis was calculated on the final sample of 112 subjects $^{8}$ to compare the postulated dimensions of competence with the structure of the empirical data. Oblique rotation (direct oblimin) was used because it is assumed that the dimensions are intercorrelated. This assumption is valid for many psychological variables (Fabrigar, Wegener, MacCallum, \& Strahan, 1999). ${ }^{9}$ Exploratory analysis was used as opposed to Confirmatory Factor Analysis due to the small sample size (Fabrigar et al., 1999).

Table 8 shows the three-factor solution according to the Kaiser criterion. Manipulativeness and Liking comprise the strongest factor, with two items of each of the postulated factors. Sport-Related Competence is the second strongest factor, comprising all three postulated items. Similarity is also found as postulated, however, it additionally includes a fourth item that was postulated to load on Liking, namely "I think my partner and I will get along very well”. General Competence is found as the fourth factor, however, it comprises only two of the postulated items as well as a third item that was postulated to load on Manipulativeness, namely "I find my partner manipulative". Sociability is the fifth factor, comprising two of the postulated items and the item "I think my partner is very intelligent" that was meant to measure general competence. Thus, five of six postulated factors are clearly found in the empirical data; however, three items are astray, one each on the factors Similarity, General Competence, and 
Sociability. Factor loadings are satisfying and all items are clearly attributable to one of the factors.

$* * * * * * * * * * * * * * * * * * * * * * * * * * * * * * * * * * * * * * * * * * * * * * * * * * * *$

Table 8

Rotated Factors and Item Loadings

The five factors account for $68.22 \%$ of the total item variance. The coefficient alpha reliabilities are $\alpha=.79$ for Manipulativeness and Liking (four items), $\alpha=.75$ for SportRelated Competence (three items), $\alpha=.77$ for Similarity (four items), $\alpha=.56$ for General Competence (three items), and $\alpha=.72$ for Sociability (three items). Due to its ambiguous loading structure and its low Cronbach's $\alpha$, General Competence should not be interpreted as a homogeneous scale. One of the three originally postulated general competence items loads clearly on Sociability. The other two items, namely "My partner's email has given me a competent impression" and "I think my partner succeeds in what he strives for", are included as single item measures in the following analyses.

The correlations between the factors are low to moderate, indicating that the four factors can be clearly distinguished from one another. Table 9 shows the correlations between the factors, the control variables, and the composite sportiveness score: Age correlates with the factor Sociability $(r=-.20)$, and the sportiveness composite correlates with the factor Similarity $(r=.45)$. Therefore, age is included as covariate in all further analyses. Sportiveness will be used as a quasi-experimental factor.

The following analyses and result reports will use the factor scores of the four 
empirically found dimensions as well as the two single item measures of general competence as dependent measures.

********************************************************

Table 9

Intercorrelations of Dependent Measures and Control Variables

\section{Effects of Name-Dropping on the Dependent Measures}

To test the effect of name-dropping on person perception in get-acquainted conversations, a multivariate analysis of covariance (MANCOVA) was performed with name-dropping and subjects' sportiveness as independent variables and the empirically found factors as dependent measures. Age and the dichotomous variable "read partner's email again before participating yes/no" were used as covariates. All tests were run twosided.

The multivariate test was significant for both name-dropping (Wilks's $\lambda=.58, F=$ $3.12, p<.001$ ) and sportiveness (Wilks's $\lambda=.77, F=4.50, p<.001$ ). There were no significant interaction effects of name-dropping and sportiveness, although Figure 1 shows a tendency in that the name-dropping conditions differentially affected perceived Sport-Related Competence in the sportive subjects ("Friend and Sports" caused the highest ratings, "Fan" caused the lowest ratings), but identically affected those subjects who did not consider themselves sportive.

Univariate tests showed that name-dropping significantly affected ratings of Manipulativeness and Liking $(F=13.61, p<.001)$, whereas sportiveness affected 
ratings of Similarity $(F=21.25, p<.001)$ in that sportive subjects felt more similar to their partner. Effect sizes are $\eta^{2}=.18$, which corresponds to a large effect of namedropping on Manipulativeness and Liking (see also Figure 2), and $\eta^{2}=.29$, which corresponds to a large effect of sportiveness on Perceived Similarity (Cohen, 1988, see also Figure 3). Univariate test results are shown in Table 10.

$* * * * * * * * * * * * * * * * * * * * * * * * * * * * * * * * * * * * * * * * * * * * * * * * * * * *$

Figures 1 to 3

Effects of name-dropping and subjects' Sportiveness

$* * * * * * * * * * * * * * * * * * * * * * * * * * * * * * * * * * * * * * * * * * * * * * * * * * * *$

Table 10

MANCOVA with Factor Scores as Dependent Measures

Table 11 shows the pairwise comparisons for the significant main effects. The stronger the association with Roger Federer, the more manipulative and the less likeable subjects perceived their partner. Figure 2 depicts this effect. Pairwise comparisons showed significant differences between the strongest name-dropping condition ("friend and sports") and each of the other conditions. To avoid the danger of alpha inflation that comes with several t-tests, we used an adjusted Bonferroni correction ("H” by Holm, 1979; see also Seaman, Levin, and Serlin, 1991). 
$* * * * * * * * * * * * * * * * * * * * * * * * * * * * * * * * * * * * * * * * * * * * * * * * * * * * * *$

Table 11

Pairwise Comparisons for Significant Main Effects of Name-Dropping and Subjects' Sportiveness

A marginally significant difference existed between the "fan" and the "friends" condition: The partner was perceived as more manipulative and was liked less when he was friends with Roger Federer than when he was a fan. No difference in perception existed between the subjects who were confronted with a fan of Roger Federer's and those who were not confronted with Roger Federer at all.

Similarly, MANCOVAs were run for the empirically found factors Sport-Related Competence, Similarity, and Sociability. The name-dropping conditions caused a tendency to more negative perceptions on all factors but Sport-Related Competence, which improved. However, with the Bonferroni H correction, none of the pairwise comparisons reached significance. Control condition vs. "fan" condition did not cause any difference in impressions. Thus, mentioning one's admiration toward Roger Federer did not affect impressions compared to the control condition. Personal association with Roger Federer ("friend" and "friend and sports"), however, exerted an influence on perceptions that increased with the strength of that association. Again, these results reached significance only on the Manipulativeness and Liking factor.

\section{Additional Analyses}

Two additional analyses were run. First, subjects' annoyance with name-dropping 
was investigated. Second, a mediation analysis was done to investigate the explanatory role of manipulativeness.

With regard to subjects' annoyance, we had included a final open question in the dependent measures questionnaire, “Did anything about your partner's email annoy you?" The second author coded whether or not subjects found it annoying or weird that Roger Federer was mentioned. Table 12 shows how annoyance was distributed over the three name-dropping conditions. The stronger the association, the more subjects felt annoyed; in the "fan and friend" condition, $60 \%(n=15)$ found the name-dropping annoying or weird.

$* * * * * * * * * * * * * * * * * * * * * * * * * * * * * * * * * * * * * * * * * * * * * * * * * * * * *$

Table 12

Observed Frequencies of Subjects’ Mentioning of Annoyance With Name-Dropping

$* * * * * * * * * * * * * * * * * * * * * * * * * * * * * * * * * * * * * * * * * * * * * * * * * * * * *$

With regard to the explanatory role of manipulativeness, we wanted to know whether the partner's imputed manipulativeness mediates the effects of name-dropping on liking. To answer this, we performed a three-step mediation analysis similar to that suggested by Baron and Kenny (1986). If manipulativeness mediates the effect of name-dropping on liking, the effect of name-dropping on liking should be confirmed if the manipulativeness items are removed from the Manipulativeness and Liking factor, but should disappear or significantly decrease if manipulativeness is controlled for.

To separate liking from manipulativeness items, we performed an additional oblique 
factor analysis with 14 of the 17 original dependent measures, omitting the three manipulativeness items. The resulting factors explain $73.66 \%$ of the variance. The factor structure is similar to the postulated five-factor structure and depicted in Table 13.

$* * * * * * * * * * * * * * * * * * * * * * * * * * * * * * * * * * * * * * * * * * * * * * * * * * * *$

Table 13

Rotated Factors and Item Loadings on the 14 Dependent Measures, Omitting the Three Manipulativeness Items

Most importantly, we receive a clear Liking factor on which two of the three liking items load strongly. This Liking factor was then used for the mediation analysis. The three manipulativeness items were averaged because Cronbach's Alpha is $\alpha=.76$, indicating a sufficiently homogenous scale.

For the mediation analysis, ANCOVAs with age and the dichotomous variable "read partner's email again before participating yes/no" as covariates were performed: Step 1 showed the expected significant effects of name-dropping on the Liking scale $(F=5.23$, $p<.001)$ and on the Manipulativeness scale $(F=12.86, p<.001)$. Step 2 showed that Liking and Manipulativeness scales were significantly correlated by $r=-.52$. Step 3 showed that the effect of name-dropping disappeared if an ANCOVA was performed with Liking as dependent measure and Manipulativeness as the third covariate $(F=0.74$, $p=.53)$. The effect of Manipulativeness on Liking remained strong $(F=21.16, p<$ .001). Thus, Manipulativeness completely mediated the effect of name-dropping on Liking. 


\section{Discussion}

\section{Discussion of Results}

Contrary to our hypotheses, the fan condition did not differ significantly from the control condition. Also contrary to our hypotheses, name-dropping and subjects' sportiveness did not interact in their effects on competence or liking. Thus, neither Heider's Balance Theory nor Tesser's SEM apply to these data. Instead, a mediator analysis showed that the significant negative effect of name-dropping on perceptions of liking was fully mediated by perceived manipulativeness. If manipulativeness was controlled for, liking was not affected by name-dropping. Inman, McDonald, and Ruch (2004) reported similar results with regard to the so-called teller-listener extremity effect: A target who directly (i.e., firsthand) listens to an actor speaking about her accomplishments evaluates the actor less favorably than does a target who indirectly (secondhand) listens to the same accomplishments, i.e., who listens to somebody else speaking about the actor's accomplishments. Thus, firsthand perceivers evaluate the same actor less favorably than secondhand perceivers. Inman et al. (2004) showed that firsthand perceivers thought the targets were boasting about their accomplishments. When the effects of boasting were removed by means of mediation analysis, firsthand perceivers evaluated the actor as favorably as did secondhand perceivers.

Manipulativeness and boasting are similar concepts in that the target presumes that the actor actively and consciously engages in impression management. An additional analysis of an open-ended question showed that some subjects commented negatively on their partner's mentioning of Roger Federer. Thus, subjects did not appreciate it that their new acquaintance mentioned their association with Roger Federer during the getacquainted conversation. We know from several areas of research, e.g., on-line person 
judgment (Hastie \& Park, 1986), control theory (e.g., Klein, 1989), and attribution theory (e.g., Kelley, 1971), that inconsistent, or unexpected, information about an individual elicits causal reasoning: Targets try to understand the motivation behind the unexpected behaviors, and they are likely to attribute such behaviors internally, i.e., they see the reason in the individuals himself. Given that perceived manipulativeness mediated the effects of name-dropping on liking ratings, we think that subjects imputed that their partner intentionally tried to manipulate their impression by means of namedropping, that they interpreted this as inappropriate for get-acquainted conversations, and that they therefore liked their partner less than if that partner did not engage in name-dropping. According to Abelson (1959), relations such as the ones that constitute Heider's balanced triads are "readily denied when the external evidence for the relation is remote, ambiguous, under suspicion of bias, or dependent upon specific circumstances which can readily be perceived as inapplicable in general" (p. 349). Thus, subjects might not have applied cognitively balanced relations between Roger Federer and the alleged partner due to suspicion.

These thoughts on the mediating effects of appropriateness are also in line with research on social disclosure, i.e., about the information about oneself that we verbally communicate to others (Collins \& Miller, 1994). The degree of disclosure that researchers assign to an information depends on its quality, i.e., the intimacy level, and on its quantity, i.e., the amount of information shared. Although social disclosure has been found attractive in the way that a disclosing individual is perceived as more likeable, trusting, friendly, warm, and open (see Collins \& Miller, 1994, for a metaanalysis), the effect is mediated by the appropriateness of the disclosure. Derlega and Grzelak (1979) stated that there exist strict social rules about what information is 
appropriate to reveal and in which contexts, and Altman and Taylor (1973) hypothesized with regard to first encounters that disclosing personal information at the earliest stage of a relationship might be too much, too soon. When violating this norm of appropriateness, the actor is evaluated unfavorably as a sanction.

Wyer, Budesheim, Lambert, and Swan (1994) showed in line with Gurevich's (1985) hypotheses that individuals take into account not only the information that a person conveys but also the reason why this information is conveyed. Wyer et al. (1994) called this "pragmatic implications of the information". Vonk (1999) examined a similar concept which she called "ulterior motives" and showed that perceivers take into account the self-presentational motives of an actor. By manipulating whether a claimed performance could or could not be verified by others, Vonk (1999) found that perceivers regarded the actor's performance claims as less indicative of the actor's ability and more strongly driven by self-promotion motives when the claims could not be verified by others. She argued that inferences about an actor's motives mediate trait judgment. Similarly, we found in our study that perceptions of manipulativeness mediated liking judgments. As Vonk further stated, "we have little empirical knowledge of the different circumstances in which self-presentational behavior is identified as such and in which it is judged as acceptable or even appropriate" (p. 410). Although we have not explicitly asked our subjects about ulterior motives, we assume that in this study, mentioning one's association with Roger Federer was considered inappropriate, leading to inferences of ulterior motives of manipulativeness and boasting, and, thus, to unfavorable evaluations of liking.

Why were the liking ratings nevertheless on the positive end of the scale, even in the strongest name-dropping manipulation (see also Figure 2)? We assume that subjects 
gave credit to the ambiguous social situation during the process of impression formation: They did not like their future partner very much, but assumed that they were about to get to know that partner personally and to work together. Similarly, Neuberg and Fiske (1987) showed that outcome dependency has a strong impact on impression formation: In their study, subjects who expected to interact with another person and felt that taskoutcome was dependent on that person abandoned categorical thinking for the benefit of more individuating processing. Thus, dependency changes how person information is processed from categorical to more sophisticated thinking. We think that our subjects tried to avoid any hard feelings and, therefore, did not weigh the manipulative aspects of the email too strongly. Thus, dependency might have led subjects to form a less extreme, more sophisticated picture of the alleged partner, which resulted in the relatively more negative ratings that are nevertheless positive in absolute terms, i.e., with regard to the rating scale.

We did not find the detrimental effects of name-dropping on competence vs. liking that have been reported by others in the field of self-presentation. For example, Gurevitch (1984) found that self-promotion generated positive impressions in ability, but negative impressions in manipulativeness. In our sample, name-dropping also generated negative impressions in manipulativeness, but ability impressions similar to that in the control condition. This is in line with Vonk's (1999) finding that boasting leads to ulterior motives attribution more than to ability attribution. Similarly, Godfrey, Jones, and Lord (1986) as well as Holtgraves and Srull (1989) found that the content of an actor's self-presentation (e.g., "I have an IQ of 140") does not affect the equivalent target's judgments (i.e., about the actor's intelligence) once the self-presentational behavior has been labeled as such and found to be inappropriate. As Godfrey et al. 
(1986) summarized, self-presentation attempts are successful only if they are subtle and contingent on the response of the target person (see also Baron, 1986; Gurevitch, 1985). Contrary to the research of Godfrey et al. (1986) and Holtgraves and Srull (1989), our study did not offer a back-and-forth communication, because the actor, i.e., the partner, sent the email first and thus started the conversation. We think, however, that the contingency of the response was violated because subjects did not expect (and did not find appropriate) such blatant self-presentation in a first encounter.

Another possible reason for our results is that Roger Federer as name-dropping manipulation was too strong. Indeed, Roger Federer scored high not only on success and performance in the pretest ratings, but also on liking. He seems to stand for more than a single (sports) dimension, maybe he even represents a current Swiss national symbol. This might explain the lack of interaction effects of subjects' sportiveness and namedropping.

\section{Strengths}

The central strength of this study is that it did not employ vignettes or mere trait descriptions as previous research (e.g., Holtgraves \& Srull, 1989), but "real” email communication. It has been repeatedly discussed and shown that person perception processes are different in direct interactions in a social context vs. in laboratory manipulations in which subjects are fed bits and pieces of person information, e.g., via trait descriptions on a monitor (Wyer et al., 1994; Wyer, Swan, \& Gruenfeld, 1995). Also, we were strict in including only those cases in the analyses that did not show any suspicion as to the bogus email and the cover story. Thus, we ensured a realistic setting and high ecological validity. 


\section{Limitations and Future Research}

One limitation to the study is that many data points did not enter the analyses due to procedural problems and that, thus, the sample is rather small for the $4 \times 2$-factorial design. Nevertheless, the negative effects on perceived manipulativeness and liking proved strong.

Future studies should look at interactions of subject gender and partner gender. In our study, subjects received emails only by same-gender partner, and we reasoned that social comparison might follow different processes when the actor/comparison person is of the same vs. of the opposite gender as the target. Thus, holding gender pairs constant seemed a reasonable way to control for gender effects. Due to this design, however, possible interactions between actor gender and target gender could not immerge. For example, research by Miller, Cooke, Tsang, and Morgan (1992) suggested that personal statements ("disclosures") activate person perception dimensions that are tied to stereotypical judgments of men and women (see also Neuberg \& Fiske, 1987). . Furthermore, some of these dimensions are more readily accessible for females (namely liking/sociability), whereas others are more readily accessible for males (namely competence). If this is the case, interactions should be found between actor gender and target gender.

Also, one could criticize that our self-report measures of sportiveness do not capture the importance of sports-related success for subjects' self-concept. Therefore, future studies should use professional athletes in their samples to strengthen the linkage between the name-dropping content (Roger Federer) and subjects' self-concept (as an athlete). 


\section{General Discussion}

\section{Synopsis of Results}

Two studies in two different contexts found negative effects of name-dropping on the impression an audiences establishes of the actor: In the job interview study, the applicant was liked less and found more discursive and less modest when he mentioned prior supervisors compared to when he did not mention them. In a bogus get-acquainted email conversation between students, a name-dropping student was less liked by other students if he or she claimed to be a friend or sports partner of Roger Federer's compared to when he or she merely claimed to be a fan.

Both studies show that the actor who employed name-dropping as a tactic did not benefit in any regard compared to the control group who did not mention other individuals. More specifically, the actor did not benefit in the most important regard, in assumed competence: Name-dropping did not improve hiring chances and did not increase sportiveness ratings. Instead, name-dropping led to less liking, fully mediated, in Study 2, by the audience's impression of actor manipulativeness. Whereas Lebherz and Jonas (2005) found that a lecturer who mentioned colleagues and public personalities was perceived more competent and liked better by students than a lecturer who did not mention others, and that this effect was mediated by assumed personal acquaintance with the mentioned individuals, the studies described here document quite the opposite effect for the job interview and get-acquainted context.

The BIRG manipulation employed in Study 1 and the name-dropping manipulation using Roger Federer in Study 2 have in common that the actor mentions a specific individual whose merits are known (or made explicit), and very specifically associates 
himself with that individual, i.e., individuals are not merely mentioned, but the relationship is described in some detail. It is in this regard that the manipulations differ from the name-dropping manipulations used in Lebherz and Jonas (2005) and in the W/ND condition in Study 1. Despite the similarities of the manipulations, the effects have not been the same: BIRG did not show any effect whatsoever on the audience's evaluation of the job applicant, whereas the student associating with Roger Federer as a friend or sports partner faced less favorable ratings than the student merely identifying himself as a fan. Clearly, there is a difference in the person used as association. Whereas the BIRG individual in Study 1 was a (bogus) Australian professor of marketing unknown to our subjects, Roger Federer elicits a clear impression as a complex, positive attitude object in our Swiss student sample.

We know from social cognition research on comparison processes that exemplars tend to elicit contrast effects if they are sufficiently extreme (e.g., Herr, 1986; Schwarz \& Bless, 1992; Stapel \& Schwarz, 1998). Thus, if association with another individual yields comparison processes as described in the introduction, the exemplar Roger Federer makes the actor pale in comparison. However, we would have expected and hypothesized that the job applicant is able to bask in the reflected glory of the professor, which equals a reflection process as opposed to the comparison process of Study 2.

\section{Limitations and Future Research}

Unfortunately, our results do not allow for clear answers on the molecular, social cognitive level of analysis that is represented by the above-mentioned studies of Schwarz and Bless (1992) or Stapel and Schwarz (1998) on assimilation and contrast effects. Instead, we took to more molar, social psychological explanations of appropriateness and ulterior motives to discuss the results. Future studies should try to 
combine these levels of analyses and thus strengthen our knowledge about the specific cognitive processes of person evaluation and how social psychological models such as Tesser's SEM on the one hand, and social cognitive models such as Schwarz and Bless's (1992) inclusion/exclusion model of assimilation and contrast on the other hand, come together to explain the effects of exemplars (and, thus, name-dropping) on person evaluation.

The studies presented here did not systematically vary actor gender. In Study 1, the applicant was male throughout the experimental conditions and impersonated by the very same professional actor. In Study 2, subjects received emails from a bogus student of the same gender as themselves. Although this can be regarded a limitation, we did this very much by purpose. There is not only evidence for gender main effects on hireability ratings (e.g., Marlowe, Schneider, \& Nelson, 1996) and with regard to engagement in self-presentation during job application (e.g., Dipboye \& Wiley, 1977; Lee, Quigley, Nesler, Corbett, \& Tedeschi, 1999), there is also evidence for interactive effects of applicant gender and behavior on evaluation by interviewers: Both nonverbal and verbal skills affect interviewer ratings differently for male versus female applicants (Goldberg \& Cohen, 2004), female applicants are judged more favorably than male applicants with regard to nonverbal interview behaviors such as posture and eye contact (Parsons \& Liden, 1984) but less favorably with regard to their paper credentials (e.g., Arvey, 1979).

Furthermore, with regard to Study 2, comparison processes depend on perceived similarity (e.g., Anderson \& Shackleton, 1990), especially on similarity of social categories (e.g., Mussweiler \& Bodenhausen, 2002) and especially if subjects' self is involved. As sport-related competence perceptions are likely to be influenced by gender, we thought same-gender couples of actor and target the easiest way to control for gender 
effects without complicating the experimental design. Future research should look systematically at applicant gender main effects as well as at interaction effects of actor gender and target gender, by using a factorial design.

Similarly, we limited this very first job interview study on name-dropping to the position of fundraiser because prior research suggests that applicant evaluation is affected differently by self-presentation tactics, depending on the type of job that is at stake (Buttner \& McEnally, 1996). Future studies should vary job type and thereby extent our knowledge about such interaction effects to the specific self-presentation tactic name-dropping. 


\section{References}

Abelson, R. P. (1959). Modes of resolution of belief dilemmas. The Journal of Conflict Resolution, 3, 343-352.

Altman, I., \& Taylor, D. (1973). Social penetration: The development of interpersonal relationships. New York, NY: Holt, Rinehart and Winston.

Anderson, N., \& Shackleton, V. (1990). Decision making in the graduate selection interview: A field study. Journal of Occupational Psychology, 63, 63-76.

Arvey, R. (1979). Unfair discrimination in the employment interview: Legal and psychological aspects. Psychological Bulletin, 86, 736-765.

Bangerter, A. (2000). Self-representation: Conversational implementation of selfpresentational goals in research interviews. Journal of Language and Social Psychology, 19, 436-462.

Baron, R. A. (1988). Perfume as a tactic of impression management in social and organizational settings. In S. Van Toller, \& G. H. Dodd (Eds.), Perfumery: The psychology and biology of fragrance (pp. 91-104). London, UK: Chapman \& Hall/CRC.

Baron, R. M., \& Kenny, D. A. (1986). The moderator-mediator variable distinction in social psychological research: Conceptual, strategic, and statistical considerations. Journal of Personality and Social Psychology, 51, 1173-1182.

Berscheid, E. (1985). Interpersonal attraction. In G. Lindzey \& E. Aronson (Eds.), Handbook of social psychology ( $3^{\text {rd }}$ ed., Vol. 2, pp. 413-484). New York, NY: Random House.

Buttner, E. H., \& McEnally, M. (1996). The interactive effect of influence tactic, 
applicant gender, and type of job on hiring recommendations. Gender Roles, 34, $581-591$.

Byrne, D. (1971). The attraction paradigm. New York, NY: Academic Press.

Cable, D. M., \& Judge, T. A. (1997). Interviewers' perceptions of person-organization fit and organizational selection decision. Journal of Applied Psychology, 82, 546-561.

Cattell, R. B. (1966). The scree test for the number of factors. Multivariate Behavioral Research, 1, 245-276.

Cialdini, R. B., Borden, R. J., Thorne, A., Walker, M. R., Freeman, S., \& Sloan, L. R. (1976). Basking in reflected glory: Three (football) field studies. Journal of Personality and Social Psychology, 34, 366-375.

Cialdini, R. B., Finch, J. F., \& De Nicholas, M. E. (1990). Strategic self-presentation: The indirect route. In M. J. Cody (Ed.), The psychology of tactical communication. Monographs in social psychology of language (Vol. 2, pp. 194-206). Clevedon: Multilingual Matters.

Cohen, J. (1988). Statistical power analysis for the behavioral sciences $\left(2^{\mathrm{nd}}\right.$ ed.). Hillsdale, NJ: Lawrence Erlbaum.

Collins, N. L., \& Miller, L. C. (1994). Self-disclosure and liking: A meta-analytic review. Psychological Bulletin, 116, 457-475.

Coupland, N., Coupland, J., \& Giles, H. (1991). Language, society, and the elderly. Oxford, UK: Basil Blackwell.

DeGroot, T., \& Motowidlo, S. J. (1999). Why visual and vocal interview cues can affect interviewers' judgments and predict job performance. Journal of Applied Psychology, 84, 986-993.

Derlega, V., \& Grzelak, J. (1979). Appropriateness of self-disclosure. In G. Chelune 
(Ed.), Self-disclosure: Origins, patterns and implications of openness in interpersonal relationships (pp. 151-176). San Francisco, CA: Jossey-Bass.

Dipboye, R. L., \& Wiley, J. W. (1977). Reactions of college recruiters to interviewee sex and self-presentation style. Journal of Vocational Behavior, 10, 1-12.

Fabrigar, L. R., Wegener, D. T., MacCallum, R. C., \& Strahan, E. J. (1999). Evaluating the use of exploratory factor analysis in psychological research. Psychological Methods, 4(3), 272-299.

Festinger, L. (1954). A theory of social comparison processes. Human Relations, 7, 117140.

Fletcher, C. (1989). Impression management in the selection interview. In R. A. Giacalone, \& P. Rosenfeld (Eds.), Impression management in the organization (pp. 269-281). Hillsdale, NJ: Lawrence Erlbaum.

Gifford, R., Ng, F. C., \& Wilkinson, M. (1985). Nonverbal cues in the employment interview: Links between applicant qualities and interviewer judgments. Journal of Applied Psychology, 70, 729-736.

Godfrey, D. K., Jones, E. E., \& Lord, C. G. (1986). Self-promotion is not ingratiation. Journal of Personality and Social Psychology, 50, 206-115.

Goldberg, C., \& Cohen, D. J. (2004). Walking the walk and talking the talk. Group and Organization Management, 29, 369-384.

Graves, L. M., \& Powell, G. N. (1988). An investigation of sex discrimination in recruiters' evaluations of actual applicants. Journal of Applied Psychology, 73, 2029.

Gurevitch, Z. D. (1984). Impression formation during tactical self-presentation. Social Psychology Quarterly, 47, 262-270. 
Gurevitch, Z. D. (1985). The receiver's dilemma: Impressions formed in response to impression management. Basic and Applied Social Psychology, 6, 145-157.

Hastie, R. \& Park, B. (1986). The relationship between memory and judgment depends on whether the judgment task is memory-based or on-line. Psychological Review, $83,258-268$.

Heider, F. (1958). The psychology of interpersonal relations. New York, NY: John Wiley.

Herr, P. M. (1986). Consequences of priming: Judgment and behavior. Journal of Personality and Social Psychology, 51, 1106-1115.

Higgins, C. A., Judge, T. A., \& Ferris, G. R. (2003). Influence tactics and work outcomes: A meta-analysis. Journal of Organizational Behavior, 24, 89-106.

Hollandsworth, J. G. Jr., Kazelskis, R., Stevens, J., \& Dressel, M. E. (1979). Relative contributions of verbal, articulative, and nonverbal communication to employment decisions in the job interview setting. Personnel Psychology, 32, 359-367.

Holm, S. (1979). A simple sequentially rejective multiple test procedure. Scandinavian Journal of Statistics, 6, 65-70.

Holtgraves, T., \& Srull, T. K. (1989). The effects of positive self-descriptions on impressions: General principles and individual differences. Personality and Social Psychology Bulletin, 15, 452-462.

Imada, A. S., \& Hakel, M. D. (1977). Influence of nonverbal communication and rater proximity on impressions and decisions in simulated employment interviews. Journal of Applied Psychology, 62, 295-300.

Inman, M. L., McDonald, N., \& Ruch, A. (2004). Boasting and firsthand and secondhand impressions: A new explanation for the positive teller-listener extremity 
effect. Basic and Applied Social Psychology, 26, 59-75.

Kacmar, K. M., \& Carlson, D. S. (1999). Effectiveness of impression management tactics across human resource situations. Journal of Applied Social Psychology, 29, 1293-1315.

Kacmar, K. M., Delery, J. E., \& Ferris, G. R. (1992). Differential effectiveness of applicant impression management tactics on employment interview decisions. Journal of Applied Social Psychology, 22, 1250-1272.

Kaiser, H. F. (1960). The application of electronic computers to factor analysis. Educational and Psychological Measurement, 20, 141-151.

Kelley, H. H. (1971). Attribution in social interaction. Morristown, NJ: General Learning.

Kinicki, A. J., \& Lockwood, C. A. (1985). The interview process: An examination of factors recruiters use in evaluating job applicants. Journal of Vocational Behavior, $26,117-125$.

Klein, H. J. (1989). An integrated control theory model of work motivation. Academy of Management Review, 13, 150-172.

Lebherz, C. \& Jonas, K. (2005, July). Name-dropping as a self-presentational tactic: Does it work? Paper presented at the meeting of the European Association of Experimental Social Psychology, Wuerzburg, Germany.

Lee, S. J., Quigley, B. M., Nesler, M. S., Corbett, A. B., \& Tedeschi, J. T. (1999). Development of a self-presentation tactics scale. Personality and Individual Differences, 26, 701-722.

Marlowe, C. M., Schneider, S. L., \& Nelson, C. E. (1996). Gender and attractiveness biases in hiring decisions: Are more experienced managers less biased? Journal of 
Applied Psychology, 81, 11-21.

Miller, L. C., Cooke, L. L., Tsang, J., \& Morgan, F. (1992). Should I brag?: Nature and impact of positive and boastful disclosures for women and men. Human Communications Research, 18, 364-399.

Mussweiler, T., \& Bodenhausen, G. V. (2002). I know you are, but what am I? Selfevaluative consequences of judging in-group and out-group members. Journal of Personality and Social Psychology, 82, 19-32.

Neuberg, S. L., \& Fiske, S. T. (1987). Motivational influences on impression formation: Outcome dependency, accuracy-driven attention, and individuating processing. Journal of Personality and Social Psychology, 53, 431-444.

Parsons, C. K., \& Liden, R. C. (1984). Interviewer perceptions of applicant qualifications: A multivariate field study of demographic characteristics and nonverbal cues. Journal of Applied Psychology, 69, 557-568.

Pleban, R., \& Tesser, A. (1981). The effects of relevance and quality of another's performance on interpersonal closeness. Social Psychology Quarterly, 44, 278285.

Riggio, R. E., \& Throckmorton, B. (1988). The relative effects of verbal and nonverbal behavior, appearance, and social skills on evaluations made in hiring interviews. Journal of Applied Social Psychology, 18, 331-348.

Rosenberg, S., Nelson, C., \& Vivekananthan, P. S. (1968). A multidimensional approach to the structure of personality impressions. Journal of Personality and Social Psychology, 9, 283-294.

Salovey, P., \& Rodin, J. (1984). Some antecedents and consequences of socialcomparison jealousy. Journal of Personality and Social Psychology, 47, 780-792. 
Schwarz, N., \& Bless, H. (1992). Constructing reality and its alternatives: An inclusion/exclusion model of assimilation and contrast effects in social judgment. In L. L. Martin \& A. Tesser (Eds.), The construction of social judgments (pp. 217-245). Hillsdale, NJ: Lawrence Erlbaum.

Seaman, M.A. Levin, J.R., \& Serlin, R.C. (1991). New developments in pairwise multiple comparisons: Some powerful and practicable procedures. Psychological Bulletin, 110, 577-586.

Stapel, D. A., \& Schwarz, N. (1998). The republican who did not want to become president: Colin Powell's impact on evaluations of the Republican Party and Bob Dole. Personality and Social Psychology Bulletin, 24, 690-698.

Stevens, C. K., \& Kristof, A. L. (1995). Making the right impression: A field study of applicant impression management during job interviews. Journal of Applied Psychology, 80, 587-606.

Tal-Or, N., Philosoph, M., Shapira, N., \& Malca, G. (2005). Impressions formed in response to public self-evaluation maintenance strategies. Journal of Experimental Social Psychology, 41, 388-395.

Tesser, A. (1988). Toward a self-evaluation maintenance model of social behavior. In L. Berkowitz (Ed.), Advances in experimental social psychology (Vol. 21, pp. 181-227). New York: Academic Press.

Tesser, A. (1991). Emotion in social comparison and reflection processes. In J. Suls \& T. A. Wills (Eds.), Social comparison: Contemporary theory and research (pp. 115145). Hillsdale, NJ: Lawrence Erlbaum.

Tesser, A., Millar, M., \& Moore, J. (1988). Some affective consequences of social comparison and reflection processes: The pain and pleasure of being close. Journal of 
Personality and Social Psychology, 54, 49-61.

Vonk, R. (1999). Effects of outcome dependency on correspondence bias. Personality and Social Psychology Bulletin, 25, 382-389.

Wyer, R. S., Budesheim, T. L., Lambert, A. J., \& Swan, S. (1994). Person memory and judgment: Pragmatic influences on impressions formed in a social context. Journal of Personality and Social Psychology, 66, 254-267.

Wyer, R. S., Swan, S., \& Gruenfeld, D. H. (1995). Impression formation in informal conversations. Social Cognition, 13, 243-272. 
Author Note

Carmen Lebherz, Department of Psychology, University of Zurich, Switzerland; Barbara Tomljenovic, Zurich, Switzerland.

Correspondence concerning this article should be addressed to Carmen Lebherz, University of Zurich, Department of Psychology, Social and Business Psychology, Binzmuehlestrasse 14, box 13, 8050 Zurich, Switzerland.

Study 1 was conducted as part of the doctoral thesis of the first author, Study 2 is the second author's master thesis, supervised by the first author. We are grateful for research assistance by Ursina Minder, Bettina Keller, Jeannette Oostlander, Lea Brägger, Michèle Nägeli, Isabelle Ehlers, Selina Lauber, Yeshi Ngingthatshang, Christian Schmid, Sandra DePasquale, Olivia Santella, Olivier Meyenhofer, Susan van Schie, Patrick Meier, and Anna Vonhoff. 


\section{Footnotes}

${ }^{1}$ The video tape was acoustically difficult to understand in several parts. Pretest subjects complained about load side noises, mumbling, and parts where the actor's voice faded toward the end of sentences. We improved the quality of the recording technically after the pretest and added control items about the technical quality to the manipulation check questionnaire in the main study.

${ }^{2}$ In the pretest, scale endpoints were labeled "not at all true" and "absolutely true"; For the main study they were changed to "not true" and "true".

${ }^{3}$ The email sender was of the same gender as the respective subject who received the email. Thus, both male and female senders existed.

${ }^{4}$ The names and addresses were not unique for each subject. However, we used combinations of about 30 different name-and-address combinations for the 183 subjects, assuming that it was thus unlikely that two subjects share this information and recognize that they have been emailed by the same person.

${ }^{5}$ For example, some did not have the email available on an online-accessible email account.

${ }^{6}$ The first version of this manipulation check item included „health consciousness“ instead of „music“. This proved too similar to the cover story and was thus incorrectly chosen by some subjects. If these subjects mentioned the sports topic in one of the openended questions, they remained in the sample, otherwise they were excluded.

${ }^{7}$ We coded whether subjects did tennis in particular. However, there were too few to run separate analyses on this subsample. 
${ }^{8}$ The same procedure was applied to the original sample of 183 subjects. However, the factor structure was different, and therefore only the final sample was used to generate factors.

${ }^{9}$ Varimax rotation showed a similar, but less clear, factor solution. 
Table 1

Study 1: Descriptive Statistics of Control Variables

\begin{tabular}{lccc}
\hline & $n$ & $M$ & $S D$ \\
\hline Descriptors of the applicant & & & \\
fidgets & 248 & 2.63 & 1.53 \\
smiles frequently & 247 & 3.76 & 1.61 \\
stutters & 249 & 1.55 & .96 \\
nervous & 249 & 3.22 & 1.57 \\
appropriately dressed & 249 & 4.92 & 1.76 \\
speaks clearly & 244 & 4.61 & 1.61 \\
attractive & 248 & 3.40 & 1.48 \\
talks very low & 249 & 2.59 & 1.45 \\
keeps eye-contact & 245 & 5.15 & 1.45 \\
talks very fast & 249 & 2.93 & 1.42 \\
Subjects' similarity to the applicant & 249 & 2.59 & .81 \\
I would act similarly in a job interview. & 249 & 3.96 & 1.58 \\
The applicant reminds me of myself. & 249 & 2.57 & 1.39 \\
I have done similar internships. & 249 & 1.52 & 1.14 \\
I have similar job experience. & 249 & 1.65 & 1.22 \\
I have similar interests. & 249 & 2.89 & 1.58 \\
I have similar attitudes. & 246 & 2.93 & 1.35 \\
Subjects' motivation to follow the interview. & 249 & 5.64 & 1.25 \\
I listened closely throughout the interview. & 248 & 5.97 & 1.21 \\
While listening, I zoned out from time to time.* & 249 & 5.31 & 1.71 \\
\hline
\end{tabular}

Notes. All items were rated on 7-point Likert scales from 1 ("not true”) to 7 ("true”). * Item is reverse coded. 
Table 2

Study 1: Rotated Factors and Item Loadings

\begin{tabular}{|c|c|c|c|c|c|c|c|c|c|c|}
\hline & \multirow[b]{2}{*}{$\begin{array}{l}\text { Factor } \\
\text { Name }\end{array}$} & \multirow[b]{2}{*}{ Item } & \multirow[b]{2}{*}{$\begin{array}{l}\text { Item } \\
\text { No. }\end{array}$} & \multicolumn{3}{|c|}{ Factor } & \multirow[t]{2}{*}{$\begin{array}{c}\text { Initial } \\
\text { Eigen- } \\
\text { value }\end{array}$} & \multirow{2}{*}{$\begin{array}{c}\% \text { of } \\
\text { Total } \\
\text { Variance } \\
\text { (unrotated) }\end{array}$} & \multirow[t]{2}{*}{$\alpha$} & \multirow{2}{*}{$\begin{array}{c}\text { Corrected } \\
\text { Item- } \\
\text { Total } \\
\text { Correlation }\end{array}$} \\
\hline & & & & 1 & 2 & 3 & & & & \\
\hline \multirow[t]{6}{*}{1} & Job-Spe & ific Competence & & & & & 7.36 & 52.56 & .88 & \\
\hline & & $\begin{array}{l}\text { The applicant has the necessary } \\
\text { knowledge for the job. }\end{array}$ & 8 & .90 & -.02 & .07 & & & & .74 \\
\hline & & $\begin{array}{l}\text { The applicant has experience that is } \\
\text { instrumental in the job. }\end{array}$ & 5 & .80 & -.12 & -.00 & & & & .56 \\
\hline & & $\begin{array}{l}\text { I think the applicant will excel in } \\
\text { all tasks. }\end{array}$ & 3 & .75 & .17 & -.07 & & & & .74 \\
\hline & & $\begin{array}{l}\text { I think the applicant strongly } \\
\text { qualifies for the job. }\end{array}$ & 1 & .74 & .24 & .04 & & & & .78 \\
\hline & & $\begin{array}{l}\text { The applicant made a competent } \\
\text { impression in the interview. }\end{array}$ & 2 & .63 & .08 & -.26 & & & & .75 \\
\hline \multirow[t]{5}{*}{2} & Liking & & & & & & 1.64 & 11.71 & .83 & \\
\hline & & The applicant is likeable. & 12 & -.05 & .94 & -.02 & & & & .79 \\
\hline & & $\begin{array}{l}\text { The applicant is an agreeable } \\
\text { person. }\end{array}$ & 14 & .01 & .93 & .03 & & & & .78 \\
\hline & & The applicant is friendly. & 4 & .03 & .87 & .01 & & & & .70 \\
\hline & & $\begin{array}{l}\text { The applicant knows his way } \\
\text { around culture. }\end{array}$ & 11 & .22 & .39 & -.10 & & & & .42 \\
\hline \multirow[t]{10}{*}{3} & Interpe & onal Competence & & & & & 1.22 & 8.74 & .92 & \\
\hline & & $\begin{array}{l}\text { The applicant handles language } \\
\text { very well. }\end{array}$ & 9 & -.09 & -.04 & -.10 & & & & .82 \\
\hline & & $\begin{array}{l}\text { The applicant knows very well how } \\
\text { to express himself. }\end{array}$ & 6 & -.03 & -.05 & -.95 & & & & .81 \\
\hline & & $\begin{array}{l}\text { The applicant can put his ideas into } \\
\text { words. }\end{array}$ & 15 & .06 & .05 & -.82 & & & & .83 \\
\hline & & $\begin{array}{l}\text { The applicant is good at } \\
\text { approaching others. }\end{array}$ & 17 & .11 & .21 & -.64 & & & & .75 \\
\hline & & $\begin{array}{l}\text { The applicant is good at convincing } \\
\text { potential sponsors of his ideas. }\end{array}$ & 10 & .29 & .05 & -.58 & & & & .72 \\
\hline & Ambiva & nt Items* & & & & & & & & \\
\hline & & $\begin{array}{l}\text { The applicant is good at } \\
\text { networking with organizations. }\end{array}$ & 7 & .48 & -.09 & -.43 & & & & \\
\hline & & $\begin{array}{l}\text { I think that the applicant is very } \\
\text { intelligent. }\end{array}$ & 16 & -.03 & .40 & -.40 & & & & \\
\hline & & $\begin{array}{l}\text { The applicant makes a professional } \\
\text { impression on potential sponsors. }\end{array}$ & 13 & .34 & .18 & -.38 & & & & \\
\hline
\end{tabular}

Notes. $N=249,17$ variables. ${ }^{*}$ Loadings derived from the first analysis before the items were discarded. 
186

Table 3

Study 1: Personality Inferences as Additional Dependent Variables

\begin{tabular}{lccc}
\hline & $n$ & $M$ & $S D$ \\
\hline & & & \\
Polite & 249 & 6.08 & .97 \\
Enthusiastic & 249 & 3.99 & 1.58 \\
Self-confident & 249 & 5.04 & 1.54 \\
Modest & 248 & 3.51 & 1.63 \\
Extraverted & 249 & 3.94 & 1.53 \\
Motivated & 249 & 4.94 & 1.45 \\
Shy & 249 & 2.84 & 1.51 \\
Eloquent & 249 & 4.43 & 1.43 \\
Discursive & 249 & 3.02 & 1.73 \\
Arrogant & 249 & 2.76 & 1.65 \\
\hline
\end{tabular}

Note. All items were rated on 7-point Likert scales from 1 ("not true”) to 7 ("true”). 
Table 4

Study 1: Multivariate Analysis of Covariance with Factor Scores as Dependent Measures

\begin{tabular}{lcccc}
\hline & $d f$ & $F$ & $\eta^{2}$ & $p$ \\
\hline Name-Dropping & & & & \\
Hireability & 1 & .01 & .00 & .46 \\
Factor 1 Job-Specific Competence & 1 & .78 & .00 & .19. \\
Factor 2 Liking & 1 & 1.79 & .01 & .09 \\
Factor 3 Interpersonal Competence & 1 & .71 & .00 & .20 \\
Discursive & 1 & 9.67 & .05 & $.002^{*}$ \\
Shy & 1 & 5.13 & .03 & $.03 *$ \\
Modest & 1 & 4.76 & .02 & $.03 *$ \\
\hline
\end{tabular}

Notes. ${ }^{*}$ p-values are two-sided. Covariates are listed in the text. $\eta^{2}=$ eta-squared, an effect size estimate. 
Table 5

Study 1: Multivariate Analysis of Covariance with Scale Means as Dependent Measures

\begin{tabular}{lcccc}
\hline & $d f$ & $F$ & $\eta^{2}$ & $p$ \\
\hline Name-Dropping & & & & \\
Hireability & 1 & .14 & .00 & .36 \\
Factor 1 Job-Specific Competence & 1 & .79 & .00 & .19 \\
Factor 2 Liking & 1 & 3.50 & .02 & .03 \\
Factor 3 Interpersonal Competence & 1 & .18 & .34 & .00 \\
Discursive & 1 & 9.96 & .05 & $.002^{*}$ \\
Shy & 1 & 6.85 & .03 & $.01 *$ \\
Enthusiastic & 1 & 3.12 & .01 & $.08^{*}$ \\
Modest & 1 & 5.28 & .02 & $.02 *$ \\
\hline
\end{tabular}

Notes. ${ }^{*}$ p-values are two-sided. Covariates are listed in the text. $\eta^{2}=$ eta-squared, an effect size estimate. 
Table 6

Study 2: Suggested Dimensions of the Dependent Measure

\begin{tabular}{|c|c|c|c|c|c|c|c|c|c|c|}
\hline Factor & Item & $\begin{array}{l}\text { Item } \\
\text { No. }\end{array}$ & $N$ & Min & Max & $M$ & $S D$ & $\alpha$ & $\begin{array}{c}\text { Item-total } \\
\text { correlation } \\
\text { in dependent } \\
\text { measure } \\
\text { subscale }\end{array}$ & $\begin{array}{c}\text { Item-total } \\
\text { correlation } \\
\text { in total } \\
\text { scale }\end{array}$ \\
\hline & $\begin{array}{c}\text { Total scale } \\
\text { (17 variables) }\end{array}$ & & 110 & & & & & .81 & & \\
\hline \multirow[t]{4}{*}{1} & General Competence & & & & & & & .59 & & \\
\hline & $\begin{array}{l}\text { I think my partner succeeds in what he } \\
\text { strives for. }\end{array}$ & 7 & 112 & 2 & 7 & 4.86 & .96 & & .44 & .39 \\
\hline & I think my partner is very intelligent. & 13 & 112 & 2 & 7 & 4.79 & .93 & & .40 & .45 \\
\hline & $\begin{array}{l}\text { My partner's email has given me a } \\
\text { competent impression. }\end{array}$ & 17 & 112 & 1 & 7 & 5.09 & 1.20 & & .38 & .36 \\
\hline \multirow[t]{4}{*}{2} & Sport-Related Competence & & & & & & & .75 & & \\
\hline & I think my partner is very sportive. & 3 & 111 & 2 & 7 & 5.23 & .91 & & .62 & .22 \\
\hline & $\begin{array}{l}\text { I think my partner knows very } \\
\text { efficient sports training strategies. }\end{array}$ & 5 & 111 & 2 & 7 & .4 .06 & 1.35 & & .58 & .09 \\
\hline & $\begin{array}{l}\text { I think my partner is sportier than } \\
\text { most students. }\end{array}$ & 15 & 112 & 2 & 7 & 4.72 & 1.11 & & .56 & .19 \\
\hline \multirow[t]{4}{*}{3} & Liking & & & & & & & .80 & & \\
\hline & $\begin{array}{l}\text { My partner's email has given me a } \\
\text { positive impression. }\end{array}$ & 1 & 111 & 2 & 7 & 5.90 & 1.04 & & .66 & .62 \\
\hline & $\begin{array}{l}\text { I think my partner and I will get along } \\
\text { very well. }\end{array}$ & 8 & 112 & 2 & 7 & 4.89 & 1.10 & & .55 & .61 \\
\hline & I find my partner very likeable. & 2 & 110 & 2 & 7 & 5.55 & 1.00 & & .75 & .63 \\
\hline \multirow[t]{4}{*}{4} & Manipulativeness & & & & & & & .76 & & \\
\hline & I find my partner conceited. & 6 & 112 & 2 & 7 & 5.76 & 1.41 & & .68 & .50 \\
\hline & I find my partner manipulative. & 12 & 112 & 1 & 7 & 5.33 & 1.45 & & .45 & .19 \\
\hline & I find my partner very self-centered. & 16 & 112 & 1 & 7 & 5.25 & 1.45 & & .67 & .43 \\
\hline \multirow[t]{4}{*}{5} & Similarity & & & & & & & .75 & & \\
\hline & $\begin{array}{l}\text { My partner and I are similarly } \\
\text { sportive. }\end{array}$ & 4 & 110 & 1 & 7 & 3.81 & 1.53 & & .44 & .11 \\
\hline & My partner and I are alike. & 9 & 112 & 1 & 7 & 3.67 & 1.32 & & .65 & .51 \\
\hline & $\begin{array}{l}\text { I have interests that are similar to my } \\
\text { partner's interests. }\end{array}$ & 11 & 112 & 1 & 7 & 3.88 & 1.40 & & .67 & .45 \\
\hline \multirow[t]{3}{*}{6} & Sociability & & & & & & & .66 & & \\
\hline & I think my partner is an honest person. & 10 & 112 & 3 & 7 & 5.51 & 1.04 & & .50 & .51 \\
\hline & $\begin{array}{l}\text { I think my partner is a warm-hearted } \\
\text { person. }\end{array}$ & 14 & 111 & 2 & 7 & 5.60 & .97 & & .50 & .45 \\
\hline
\end{tabular}

Note. Item No. denotes the item's original position in the questionnaire. 
Table 7

Study 2: Descriptive Statistics of Control Variables

\begin{tabular}{lccc}
\hline & $n$ & $M$ & $S D$ \\
\hline Self-evaluation with regard to sports (“I am very sportive.”) & 112 & 3.90 & 1.48 \\
Importance assigned to sports ("Sport is very important to me.”) & 112 & 4.35 & 1.73 \\
Sports behaviour ("I spend approx. _ hours on sports per week”.) & 112 & 3.80 & 3.13 \\
\hline
\end{tabular}

Notes. The self-evaluation and importance items were rated on 7-point Likert scales from 1 ("not true") to 7 ("true"). In the sports behaviour item, participants filled in the number of hours per week they spend on sports. 
Table 8

Study 2: Rotated Factors and Item Loadings

\begin{tabular}{|c|c|c|c|c|c|c|c|c|c|c|}
\hline & \multirow[b]{2}{*}{$\begin{array}{l}\text { Factor } \\
\text { Name }\end{array}$} & \multicolumn{5}{|c|}{ Factor } & \multirow{2}{*}{$\begin{array}{l}\text { Initial } \\
\text { Eigen- } \\
\text { value }\end{array}$} & \multirow{2}{*}{$\begin{array}{c}\% \text { of } \\
\text { Total } \\
\text { Variance } \\
\text { (unrotated) }\end{array}$} & \multirow[t]{2}{*}{$\alpha$} & \multirow{2}{*}{$\begin{array}{c}\text { Corrected } \\
\text { Item- } \\
\text { Total } \\
\text { Correlation }\end{array}$} \\
\hline & & 1 & 2 & 3 & 4 & 5 & & & & \\
\hline \multirow[t]{5}{*}{1} & Manipulativeness and Liking & & & & & & 4.93 & 29.00 & .79 & \\
\hline & I find my partner conceited.* & .81 & .03 & .04 & .03 & .10 & & & & .68 \\
\hline & $\begin{array}{l}\text { I find my partner very self- } \\
\text { centered.* }\end{array}$ & .73 & -.07 & -.05 & .15 & .31 & & & & .60 \\
\hline & $\begin{array}{l}\text { My partner's email has given me a } \\
\text { positive impression. }\end{array}$ & .62 & .10 & .30 & -.42 & -.18 & & & & .57 \\
\hline & I find my partner very likeable. & .46 & .06 & .33 & -.21 & .19 & & & & .57 \\
\hline \multirow[t]{4}{*}{2} & Sport-Related Competence & & & & & & 2.39 & 14.06 & .75 & \\
\hline & $\begin{array}{l}\text { I think my partner is sportier than } \\
\text { most students. }\end{array}$ & .04 & .86 & .01 & .13 & .08 & & & & .60 \\
\hline & I think my partner is very sportive. & .19 & .84 & -.12 & -.14 & -.16 & & & & .62 \\
\hline & $\begin{array}{l}\text { I think my partner knows very } \\
\text { efficient sports training strategies. }\end{array}$ & -.27 & .75 & .03 & -.06 & .09 & & & & .58 \\
\hline \multirow[t]{5}{*}{3} & Similarity & & & & & & 1.97 & 11.56 & .77 & \\
\hline & My partner and I are alike. & .15 & .19 & .86 & .16 & .06 & & & & .71 \\
\hline & $\begin{array}{l}\text { I have interests that are similar to } \\
\text { my partner's interests. }\end{array}$ & .16 & -.06 & .82 & -.05 & -.06 & & & & .68 \\
\hline & $\begin{array}{l}\text { My partner and I are similarly } \\
\text { sportive. }\end{array}$ & -.22 & -.17 & .74 & -.01 & .09 & & & & .43 \\
\hline & $\begin{array}{l}\text { I think my partner and I will get } \\
\text { along very well. }\end{array}$ & .02 & -.02 & .57 & -.12 & .45 & & & & .48 \\
\hline \multirow[t]{4}{*}{4} & General Competence & & & & & & 1.21 & 7.12 & .56 & \\
\hline & $\begin{array}{l}\text { My partner's email has given me a } \\
\text { competent impression. }\end{array}$ & .10 & .04 & -.08 & -.73 & -.02 & & & & .40 \\
\hline & $\begin{array}{l}\text { I think my partner succeeds in what } \\
\text { he strives for. }\end{array}$ & -.28 & .15 & .12 & -.67 & .18 & & & & .37 \\
\hline & I find my partner manipulative.* & .40 & -.18 & -.07 & -.50 & .17 & & & & .36 \\
\hline \multirow[t]{4}{*}{5} & Sociability & & & & & & 1.10 & 6.47 & .72 & \\
\hline & $\begin{array}{l}\text { I think my partner is a warm- } \\
\text { hearted person. }\end{array}$ & .19 & .02 & .01 & .23 & .82 & & & & .53 \\
\hline & $\begin{array}{l}\text { I think my partner is very } \\
\text { intelligent. }\end{array}$ & -.07 & .15 & .03 & -.28 & .68 & & & & .51 \\
\hline & $\begin{array}{l}\text { I think my partner is an honest } \\
\text { person. }\end{array}$ & .12 & -.09 & -.06 & -.30 & .64 & & & & .58 \\
\hline
\end{tabular}

Notes. $N=112,17$ variables. * Item is reverse coded. 
Table 9

Study 2: Intercorrelations of Dependent Measures and Control Variables

\begin{tabular}{|c|c|c|c|c|c|c|c|c|c|c|}
\hline & & 1 & 2 & 3 & 4 & 5 & 6 & 7 & 8 & 9 \\
\hline 1 & $\begin{array}{l}\text { Factor } 1 \\
\text { Manipulativeness } \\
\text { and Liking }\end{array}$ & 1 & & & & & & & & \\
\hline 2 & $\begin{array}{l}\text { Factor } 2 \\
\text { Sport-Related } \\
\text { Competence }\end{array}$ & -.03 & 1 & & & & & & & \\
\hline 3 & $\begin{array}{l}\text { Factor } 3 \\
\text { Similarity }\end{array}$ & .14 & -.01 & 1 & & & & & & \\
\hline 4 & $\begin{array}{l}\text { Factor } 4 \\
\text { General Competence }\end{array}$ & $-.19 *$ & -.16 & -.16 & 1 & & & & & \\
\hline 5 & $\begin{array}{l}\text { Factor } 5 \\
\text { Sociability }\end{array}$ & $.31 * *$ & .09 & .15 & $-.25 * *$ & 1 & & & & \\
\hline 6 & Age & -.08 & .10 & .02 & .11 & $-.20 *$ & 1 & & & \\
\hline 7 & $\begin{array}{l}\text { Self-evaluation with } \\
\text { regard to sports }\end{array}$ & -.04 & -.10 & $.46^{* *}$ & -.00 & .12 & .02 & 1 & & \\
\hline 8 & $\begin{array}{l}\text { Importance assigned } \\
\text { to sports }\end{array}$ & -.01 & -.07 & .45 & .04 & .10 & .12 & $.80 * *$ & 1 & \\
\hline 9 & Sports behavior & .03 & .03 & .29 & .06 & .18 & .03 & $.60 *$ & $.67 * *$ & 1 \\
\hline
\end{tabular}

Notes. ${ }^{*} p \leq .05,{ }^{* *} p \leq .01$, two-sided. Sample sizes vary between 108 and 112 . 
Figure 1. Study 2: Effects of name-dropping and subjects' sportiveness on perceived Sport-related Competence.
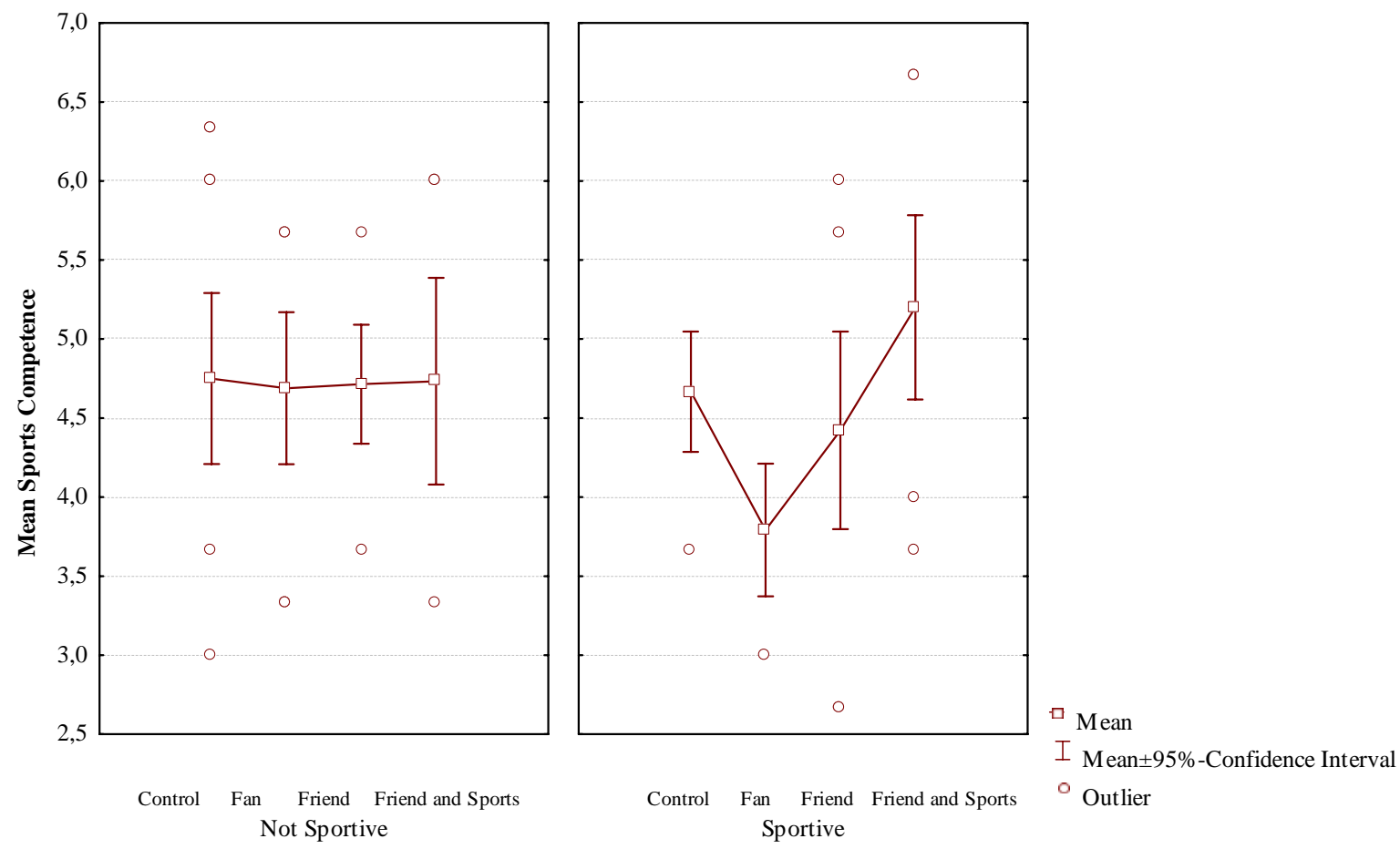
Figure 2. Study 2: Effects of name-dropping on perceived Manipulativeness and Liking.

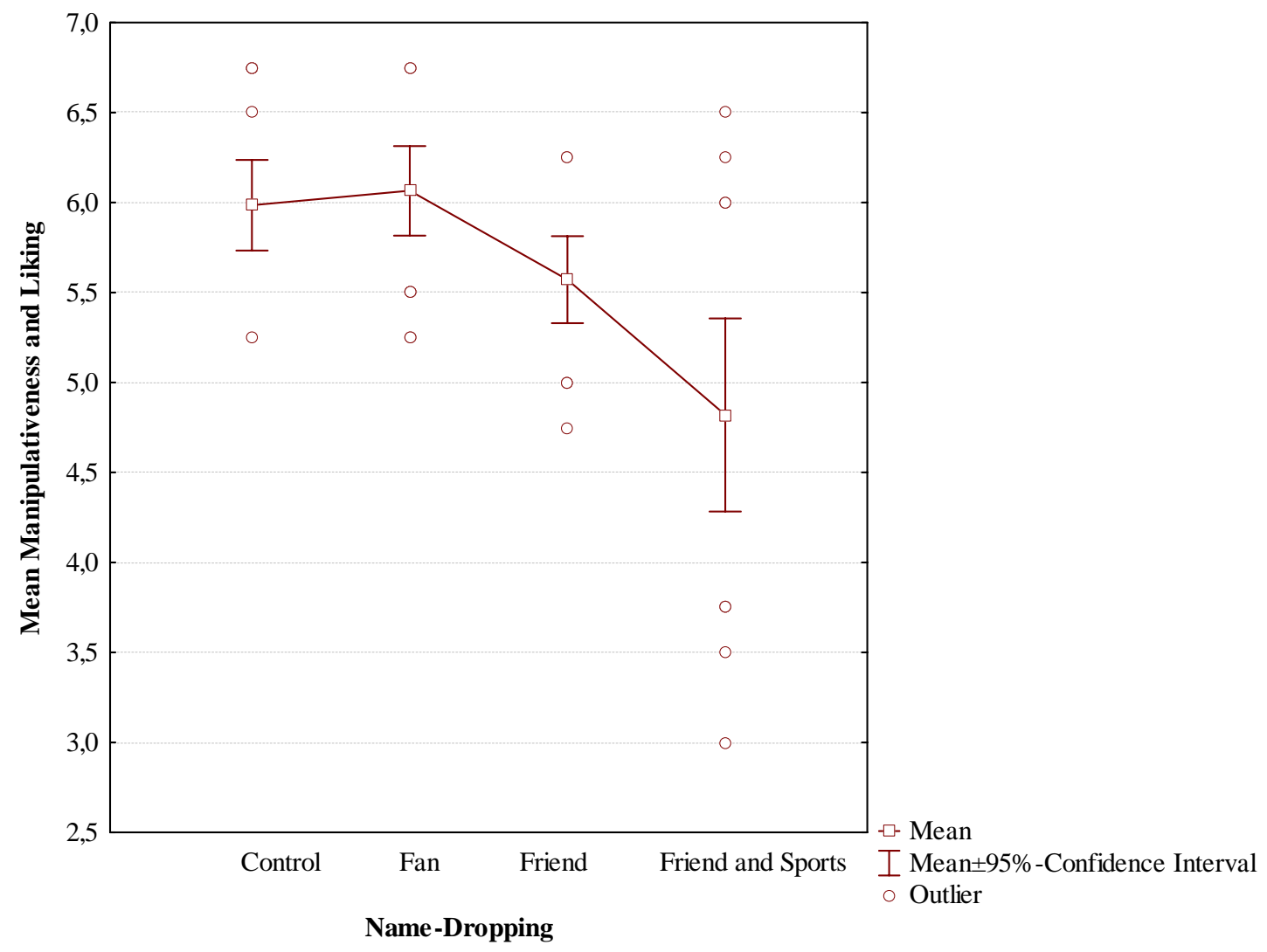


Figure 3. Study 2: Effects of subjects' sportiveness on Perceived Similarity.

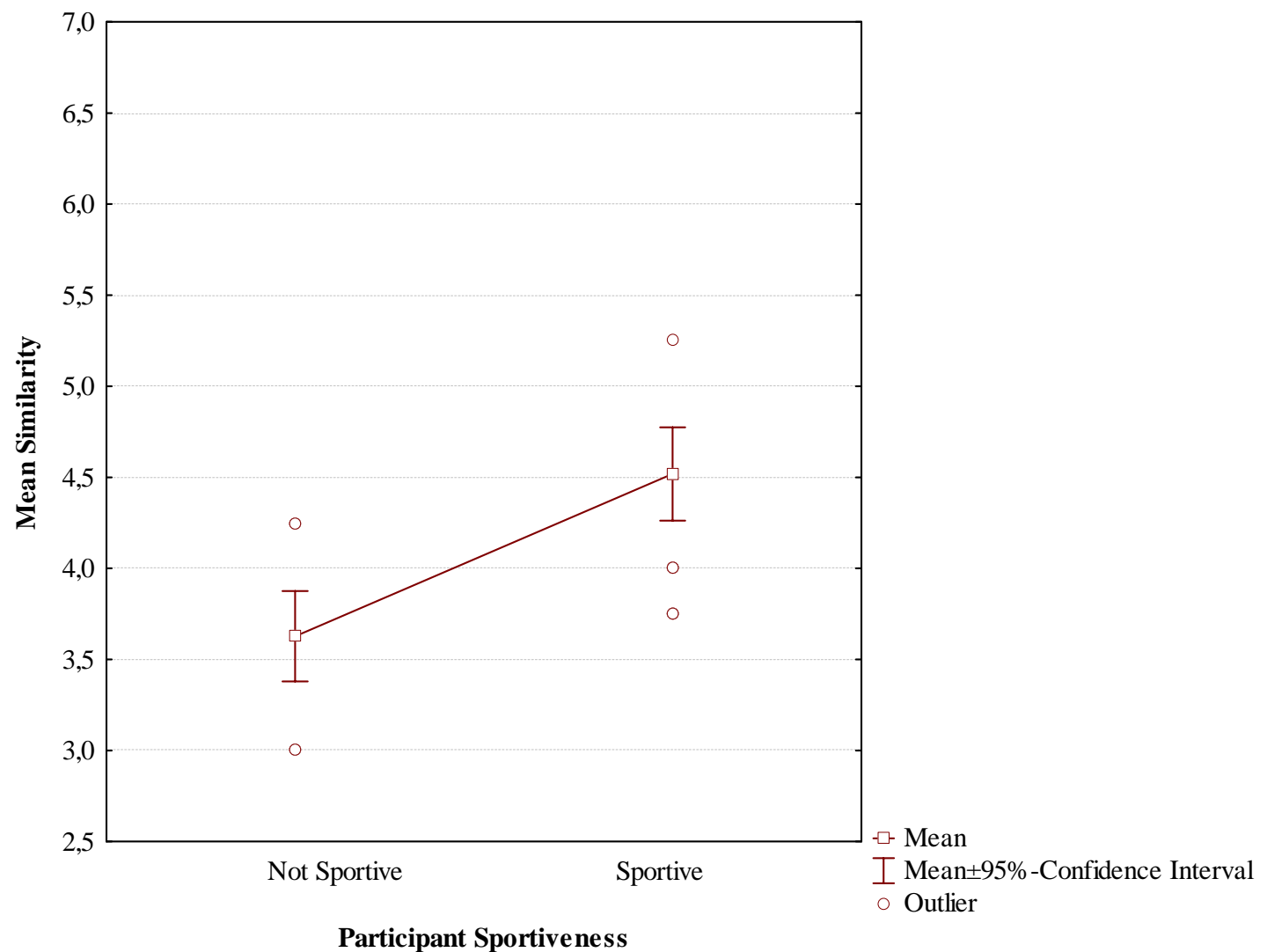

Participant Sportiveness 
Table 10

Study 2: Multivariate Analysis of Covariance with Factor Scores as Dependent Measures

\begin{tabular}{lllll}
\hline$d f$ & $F$ & $\eta^{2}$ & $p$ \\
\hline
\end{tabular}

Factor 1 Manipulativeness and Liking

Name-Dropping

Participant Sportiveness

Name-Dropping

Participant Sportiveness

ame-Dropping

Participant Sportiveness

Name-Dropping

Participant Sportiveness
3

1

13.61

.34

.18

$<.001$

.56

Factor 2 Sport-Related Competence

$3 \quad 1.82$

$1 \quad 1.15$

Factor 3 Similarity

3

0.22
21.25

.88

1

.29

$<.001$

Factor 4 Sociability

3.05

13.33

Notes. All p-values are two-sided. Age and whether participants had read the partner's email a second time were used as covariates. $\eta^{2}=$ eta-squared, an effect size estimate. 
Table 11

Study 2: Pairwise Comparisons for Significant Main Effects of Name-Dropping and Sportiveness

\begin{tabular}{|c|c|c|c|c|c|c|}
\hline & Pairwise & Comparisons & $p$ & $\alpha$ & $\alpha_{\mathrm{H}}$ & $\begin{array}{c}\text { Statistical } \\
\text { Significance } \\
\text { after } \\
\text { Adjusted } \\
\text { Bonferroni } \\
\text { Correction }\end{array}$ \\
\hline \multirow{6}{*}{$\begin{array}{l}\text { Manipulativeness } \\
\text { and Liking }\end{array}$} & Control & "Fan" & .424086 & .05 & .0500 & $\mathrm{~ns}$ \\
\hline & & "Friend & .028742 & .05 & .0250 & ns \\
\hline & & $\begin{array}{l}\text { "Friend and } \\
\text { Sports" }\end{array}$ & .000001 & .05 & .0100 & $\mathrm{~s}$ \\
\hline & "Fan" & "Friend" & .006184 & .05 & .0167 & $\mathrm{~s}$ \\
\hline & & $\begin{array}{l}\text { "Friend and } \\
\text { Sports" }\end{array}$ & .000000 & .05 & .0083 & $\mathrm{~s}$ \\
\hline & "Friend" & $\begin{array}{l}\text { "Friend and } \\
\text { Sports" }\end{array}$ & .005150 & .05 & .0125 & $\mathrm{~s}$ \\
\hline Similarity & Sportive & $\begin{array}{c}\text { Not } \\
\text { Sportive }\end{array}$ & .000 & .05 & - & $\mathrm{s}$ \\
\hline
\end{tabular}

Notes. $\alpha=$ type 1 error; $\alpha_{\mathrm{H}}=$ type 1 error after the adjusted Bonferroni correction according to $\operatorname{Holm}(1979$; “H”). 
Table 12

Study 2: Observed Frequencies of Subjects' Mentioning of Annoyance with Name-Dropping in the four Name-Dropping Conditions

\begin{tabular}{lccc}
\hline & Not Annnoyed & Annoyed & „Weird“ \\
\hline No name-dropping (control) & 34 & 0 & 0 \\
"Fan” & 18 & 5 & 1 \\
"Friend” & 17 & 12 & 0 \\
"Friend and Sports” & 10 & 14 & 1 \\
\hline
\end{tabular}


Table 13

Study 2: Rotated Factors and Item Loadings Omitting Manipulativeness Items

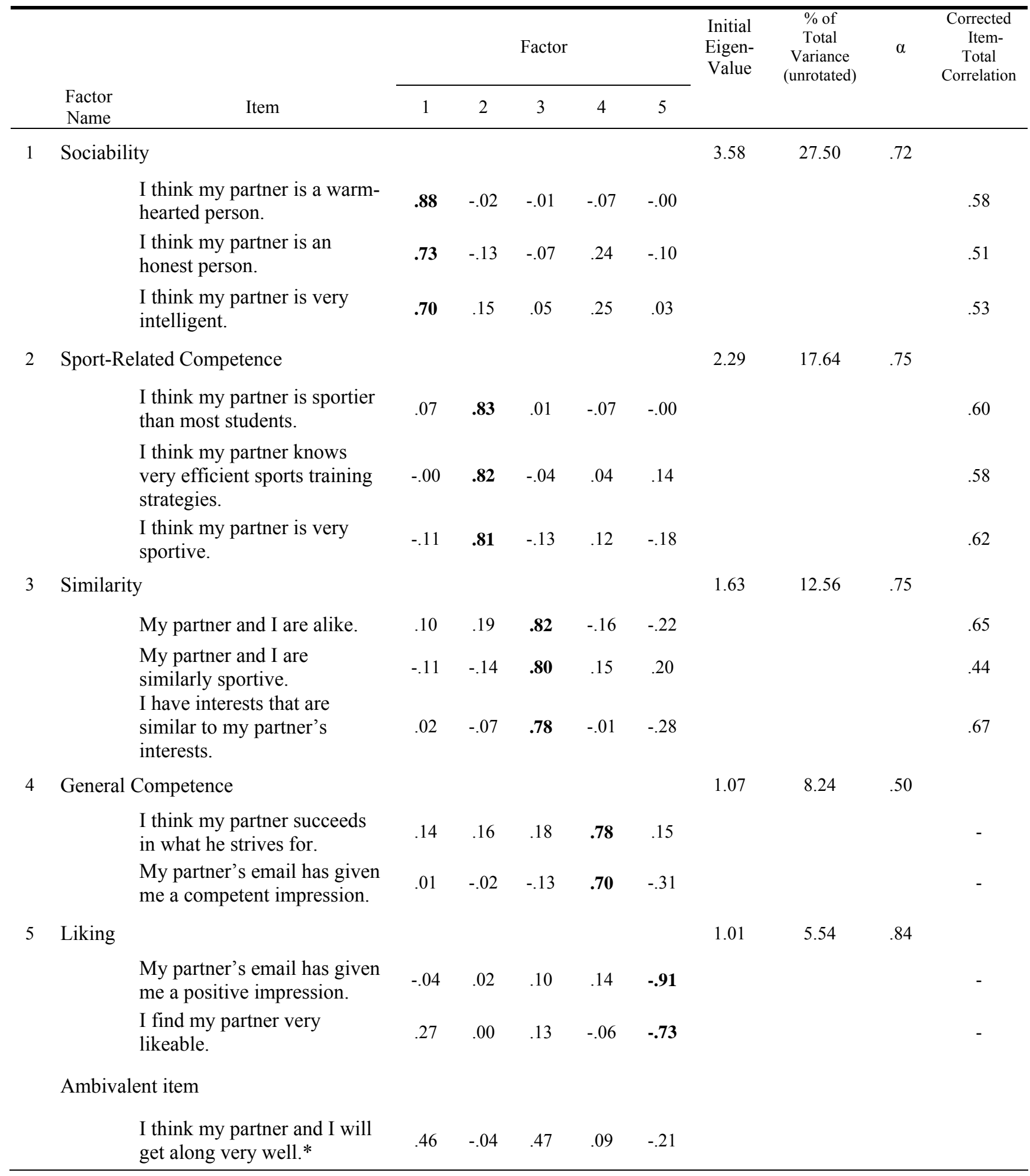

Notes. $N=112,14$ variables. ${ }^{*}$ Loadings derived from the first analysis before the item was discarded. 


\section{General Discussion}




\subsection{Summary of Papers}

The research described in Paper 1 shows positive effects of name-dropping when implemented by a university lecturer: Students who listen to the lecturer find him more competent, in general and with regard to his research abilities, and more likeable as a person. I also show that a minority of students reacts decidedly negatively to the manipulation and that the positive effect increases in the total sample if the negative reaction is controlled for. Thus, a potential for both positive and negative reactions on name-dropping is established. Furthermore, Paper 1 tells us more about the processes involved: Students assume that the lecturer knows the mentioned individuals personally, and this assumed personal acquaintance mediates the positive effect of name-dropping on actor evaluation.

The research described in Paper 2 shows negative effects of name-dropping when implemented by actors who are the study subjects' equals with regard to status: A student job applicant and a student acquaintance both elicit negative reactions in our student sample. Again, some insights into the processes exist: Subjects rate the actor manipulative, and this imputed manipulativeness mediates the negative effect of name-dropping on actor evaluation.

In the following section I will give a synopsis of the constituents of the namedropping effect, including all previously presented data.

\subsection{Synopsis: Effects of Name-Dropping on First Impressions}

\subsubsection{Status Differences}

One factor that seems to influence how name-dropping affects first impressions and whether the effect is of positive or negative direction is the relationship between the actor who implements name-dropping and the target who forms an impression of the actor. Specifically, it seems a question of status differences, i.e., hierarchical standing and relative power. In the original study in which a lecturer uses namedropping and students evaluate the lecturer, there is a clear hierarchy between actor and target, both in social norms and in assumed thematic knowledge. Thus, if student subjects rate a lecturer who is, regardless of whether he uses name-dropping or not, quite clear and precise in his wording and structuring, they assume him to be the 
expert on the topic and evaluate him positively. If he mentions colleagues and public characters, they assume that he, as an expert, knows these individuals personally, which further increases his status within the expert community and thereby improves research and general competence ratings. Thus, we can regard the positive effect of name-dropping an extension of an already positive judgment of expertise, a judgment provided by members of an inferior, non-expert, outgroup.

This relative hierarchical standing is different in Paper 2, where both actor and target are students and, thus, equals. Especially in the study using a get-acquainted situation as context, actor and target are very much alike: They are (ostensibly) of the same gender and expected to work together as partners in an experiment. The email sent out by the actor does not contain much information about qualification, and no information at all about expertise with regard to participation in the experiment. In the study using a job interview as context, the relative standing of actor and target depends on the prior job experience and experience in job application of the respective targets. However, these variables were controlled for in the study.

Evaluating an equal as opposed to a superior might result in harsher judgments. For one, there is no general expertise assumption and comparison with oneself and one's own qualifications are more readily accessible. For another, personal acquaintance with professors, CEOs, and sports world champions is not as readily believed or assumed.

Social cognition research on extreme exemplars (such as Roger Federer) and their effect on associated actors suggests that status differences between the actor and the associated person also play a role. Status is a social category that either both or only one can be a member of. Wänke, Bless, and Igou (2001) showed that an actor only benefits from associations with extreme exemplars if he shares a social category with that exemplar, a so-called "super-ordinate category" of which both individuals are members. A professor who shares his status (as professor) or his alma mater with a Nobel prize winner might be able to bask in the reflected glory of the successful colleague because the super-ordinate categories "professor" and/or "Stanford alumni” cause assimilation effects. However, a student who associates himself with Roger Federer does not share such super-ordinate categories with the tennis professional and, therefore, looks pale in comparison. 


\subsubsection{Appropriateness}

Two aspects of appropriateness need to be considered. First, it might be more appropriate for university lecturers than for students to mention other individuals as associates or references. This is in line with the status differences between professorstudent dyads discussed above. Second, it might be more appropriate to mention other individuals during a lecture or in a scientific/university context than in the context of get-acquainted conversations or job interview. With regard to university lectures, there is not doubt that students are used to their professors citing, referencing, and acknowledging the work of other researchers. This is especially true for the population of humanities and social science students that constituted the majority of subjects in my lecturer studies 1 and 2.

With regard to contextual appropriateness, previous work on impression management argued that job interviews are indeed highly appropriate settings for self-presentational efforts (Fletcher, 1989; Knouse, 1994). Therefore, I hypothesized that the use of name-dropping positively affects job interview outcome. Although this did not hold in our study, the results presented in Paper 2 do not necessarily argue for inappropriateness of name-dropping because we did not explicitly ask subjects for their opinion on appropriateness. Name-dropping negatively affected liking and perceived modesty, however, the job applicant was also perceived less shy if he used name-dropping, a rating that is usually considered favorable in the job interview. Thus, I might not be able to argue whether or not name-dropping is appropriate in the job interview context. I can, however, show that it is perceived as manipulative during get-acquainted conversations, which strongly suggests that participants felt this kind of behavior inappropriate.

\subsubsection{Target's Assumptions about Ulterior Motives}

Although this aspect is intertwined with the previous two sections, I would like to point out that a target's thoughts about the causes of name-dropping as behavior might be central to understanding both positive and negative effects of namedropping. Kammrath, Mendoza-Denton, and Mischel (2005) showed that dispositional inferences are mediated by an audience's inferences about the actor's motivation, or desire, to impress. Furthermore, Vonk $(1998,1999)$ found that impression management backfires if the audience perceives such behavior as self- 
serving, considering possible underlying intentions of the actor. In those of my studies that elicit positive effects, subjects were not only confronted with a lecturer of higher status and stronger expertise than themselves, they also had very little reason to suspect impression management motives in the lecturer. Instead, they could have considered benevolent motives in the name-dropping behavior, e.g., the lecturer's wish to provide references for further reading (see also section 4.2.5), or to stress the relevance of the lecture topic by putting it into a bigger picture of related research fields and current newspaper articles. Due to the lecturer's status as professor and expert, impression management might not be the first that comes to mind when student subjects listen to name-dropping.

In the get-acquainted conversation setting, however, things are different. Many subjects explicitly stated their annoyance with the mentioning of a sports champion in the very first email conversation with an unknown student. Indeed, annoyance increased proportionally the stronger the manipulation, i.e., the stronger the acclaimed association with Roger Federer was. Also, ratings were influenced by name-dropping only with regard to increased dislike, not with regard to any competence dimension. Together with the complete mediation of the effect by perceived manipulativeness, this indicates that a social norm of how to behave in such encounters was violated and that participants considered that the actor actively tried to manipulate the impression he/she makes by means of the email.

A line of research on attitude and persuasion has explored the role of elaboration on attitude change. Recently, Tormala and Petty (2002, 2004) showed that elaboration is crucial in reaction to persuasive attacks: Unsuccessful attacks lead to increased attitude certainty only when elaboration is high. If we consider impression management an effort to persuade an audience of our qualities, awareness of the audience might also be the necessary conditions for impression management tactics to backfire on the actor. This is in line with Gordon's (1996) meta-analytical finding that ingratiation in organizations only works as long as the tactic is not transparent to the target. Thus, several different lines of reasoning support my preliminary empirical findings: Intentional considerations on the side of the target moderate the effects of name-dropping on first impressions. 


\subsubsection{Name Valence and Exemplar Extremity}

The studies described in this dissertation employed identical definitions of namedropping. However, manipulations varied slightly in phrasing and use as I needed to adapt the name-dropping sequences to different contexts. One major variation is the strength of valence that comes with the name of the mentioned individual. In the studies of Paper 1, I used names of professors and public characters that are, most likely, unknown to participants (and I controlled for prior knowledge of the lecture topic because it might cause familiarity with the names). In the job interview study, the name-dropping condition included professors and CEOs, all of them fictitious. Thus, these manipulations have in common that the names are unknown, that they share a mildly positive valence due to status (professor, CEO, public character), and that there are several sequences (nine and six, respectively) throughout the audio/video tape.

The BIRG condition of the job interview study is different in that only one name was mentioned, an unfamiliar name that nevertheless had a strong valence attached to it due to the information included in the sequence that the individual is a wellknown professor with an excellent reputation in his field.

Yet another manipulation was used in the get-acquainted study, with Roger Federer as the probably most extreme exemplar of several social categories, among them the categories "sportsman", "celebrity", and "Swiss". Interestingly, it is this study that elicits the clearest negative effects and the largest effect sizes of all studies. Although only one name appears as opposed to several, name recognition and the social categories associated with it enlarged the impact of the manipulation considerably. The comparable one-name BIRG condition in the job interview study did not elicit any effects whatsoever. Although the studies and conditions differ on several other dimensions, some of which I have discussed in previous sections, the extremity dimension merits some thoughts.

We know from social cognition research that extreme exemplars of a category are likely to cause contrast effects, i.e., whatever other exemplar of the same category is compared to it, will be contrasted against the extreme example. An actor using namedropping would want to achieve an assimilation effect, i.e., he would like to be assimilated into the social category of successful, likeable, Swiss sportsmen for which Roger Federer stands, he would like to be perceived as more successful, more 
sportive, and/or more likeable than without the association with Roger Federer. However, ample research suggests that extreme exemplars will cause the opposite: He will seem pale compared to the champion and be perceived less successful, less sportive, and/or less likeable than without this association to famous Roger Federer (e.g., Stapel \& Koomen, 2001). Thus, although extremity and familiarity of a name enlarge the impact as I suggested in the introduction, the direction of the effect is likely to counteract the actor's impression management intentions (see also Martin, Seta, \& Crelia, 1990).

From the studies described in this dissertation, I can not conclude that the getacquainted study caused a contrast effect because the nature of the manipulation and the dependant measure are not in line with social cognitive methodological standards and, therefore, do not allow for the data to be interpreted on such molecular level. However, it seems reasonable to conclude that the reliable and well-established finding of social cognitive research, that extreme exemplars cause contrast rather than assimilation, does apply to name-dropping (e.g., Herr, 1986; Schwarz \& Bless, 1992; Stapel \& Schwarz, 1998). Future research should try to bridge the gap between the classic social psychological designs used in this dissertation and the processoriented methods used in social cognition to specify how an audience processes name-dropping and how exactly person judgments are formed as a result.

\subsubsection{Name-Dropping as Referencing}

Does name-dropping only work for the actor because it is considered referencing? I can not give a final answer to this question based on my data. It is true that a positive name-dropping effect has been found only for the university lecturer, and that the manipulation used in these studies is close to the scientific referencing considered common and even necessary in academia, a fact that the Swiss and German student subjects should be familiar with.

However, there are several arguments against the interpretation that the namedropping effect is based solely on correct referencing in an academic setting. First, of the names mentioned in the lecturer studies, one third was non-academic, i.e., taken from newspaper articles and the area of general knowledge. One replication study that was extended to a new name-dropping condition in which all names were taken from the area of general knowledge (the nd-gk condition) showed that students liked the lecturer better and rated him higher on teaching competence when he used 
exclusively names of the general knowledge area (mainly names of journalists and CEOs) compared to when he used a mixture of areas (the original nd condition). Thus, students seem to place even greater importance on general knowledge sequences than on scientific referencing.

Second, mediation analysis showed for the original name-dropping condition that students assume personal acquaintance between the lecturer and the mentioned individuals and, therefore, rate him more competent. I consider this finding the most central argument against a mere referencing effect because personal acquaintance suggests a closer relationship between the lecturer and the mentioned individual than referencing.

Third, if referencing was the major explanatory factor, I would expect that students rated the lecturer who mentions references not only more competent, but a better teacher. However, teaching competence was less strongly affected by namedropping than research and general competence.

Thus, although referencing might be considered a qualitative aspect of teaching and might have added to the positive effect of name-dropping, I do not consider it central to the process of self-presentation by name-dropping. Future research should look at this possible alternative explanation systematically, e.g., by using samples that are unfamiliar with academia's demand for scientific referencing (see also section 4.3.1), or by contrasting name-dropping manipulations that are nothing but scientific references with manipulations that can not in any case be regarded references.

\subsection{Methodological Issues}

\subsubsection{Samples}

Participants in all studies were students. In the studies of Paper 1 and the getacquainted study, this was essential for the manipulation. I made an effort to include a wide variety of majors and to extend the Swiss data by including samples from two German universities. Therefore, the lecture study and its two replication studies show rather different sample compositions: Study 1 and 3 contain one third psychology majors, whereas study 2 is very heterogeneous, containing as largest subsamples business and law majors (10\% each). Whereas study 1 contains primarily economics, law, and liberal arts majors, in study 3 about $15 \%$ of subjects were medical science 
majors and over $20 \%$ were in natural science. Thus, within the student population, replication is possible in rather diverse areas. Nevertheless, restriction to the student population remains problematic. This is especially true for the job interview study, because students can not be considered experts on job candidates and hiring decisions. Indeed, Barr and Hitt (1986) compared managers' and students' evaluations of applicants for managerial positions in a video manipulation similar to ours. They found that managers and students used different criteria in selection, and that students used more criteria and rated applicants more favorably. Thus, real managers process applicant information differently. Although not all authors question the generalizability of student sample data in job application research (e.g., Dipboye, Fromkin, \& Wiback, 1975), I agree with the general criticism of student samples (Rosenthal \& Rosnow, 1969) as well as the specific criticism concerning job interview research.

For the matter of name-dropping in general, future studies should move on to a broader population. For example, I have observed negative correlations between participant age and person judgments (regardless of name-dropping) in some samples. Thus, it seems that participants become more critical in their judgments, probably due to more experience with person judgment in general and with regard to specific contexts such as job interviews in particular. I have not found systematic age differences between participants who explicitly mentioned their annoyance with name-dropping and those who did not mention it. However, age variance in student samples is low. A wider variety of age groups is necessary to determine whether individuals become aware of name-dropping during their life or career, and whether that rather facilitates positive reactions (i.e., met expectations) or negative reactions (i.e., annoyance).

Furthermore, future studies should move beyond student samples because appropriateness (see section 4.2.2) will always depend on the population asked. Social norms vary between populations as much as between contexts. For example, managers are less used to scientific referencing than lawyers because it is not a central part of their education. As socialization within a study or business always forms expectations about social norms and their fulfillment in behavioral scripts, different businesses should react differently to scientific referencing.

In general, I think that the degree of expertise in an audience strongly determines how name-dropping is processed. For one, a set of specific names might have a 
completely different valence to experts vs. novices. For another, expertise comes with experience, and both sharpen expectations. For example, a personnel recruiter who has seen it all during her 20 years of job experience brings a much more complex set of expectations to a job interview, and is likely to react very different to self-presentation tactics than a novice to recruitment. An expert in one field, however, is a novice in another field. Therefore, name-dropping should be looked at in different fields, using samples from different populations.

\subsubsection{Effect Size}

The name-dropping effect is small throughout the studies, with the result that some analyses barely reach the conventional significance criterion. For illustration, between-group differences in the lecture studies equal less than one scale point on the seven-point Likert scale used. However, this is hardly surprising. Given that there is more to person perception in lectures and job interviews than self-presentation, relatively little variance should be explained by a specific self-presentational tactic like name-dropping. Also, of the many self-presentational tactics proposed in the literature (for an overview see McFarland et al., 2005), only ingratiation and selfpromotion have been repeatedly found to have substantial impact on person perception, and even those depend, to some degree, on contextual variables (Higgins \& Judge, 2004; Ferris et al., 1994). Many other, more specific tactics failed to elicit strong effects (Ellis et al. 2002) and/or had very low power because actors employ them rarely (e.g., Ellis et al., 2002; Stevens \& Kristof, 1995).

Effect sizes are substantially larger in the get-acquainted conversation study, probably enhanced by the extreme exemplar used in the manipulation and the fact that the very short email contained little more than the extreme exemplar.

Effect sizes of name-dropping will always depend on the specific manipulation used and the context in which it is employed. I do not think I can conclude from my studies that negative effects are larger and, therefore, easier to produce than the positive effects in the lecture studies. I am unaware of a general finding in the impression management literature that negative effects prevail, or that negative effects are easier to obtain. If there is evidence at all, it rather supports the contrary: Most studies took place in the realm of organizational recruitment and evaluation, where ingratiation and self-promotion tend to be beneficial (Gilmore \& Ferris, 1989; Howard \& Ferris, 1996; Kacmar et al., 1992). 


\subsection{Critique}

This dissertation project is the first, to the best of my knowledge, to empirically examine target effects of name-dropping as a self-presentation tactic. It is also one of few studies that look at target effects per se, as previous research has focused more on the actor's choices than on the target's responses.

Being first to examine an effect brings with it the responsibility to build a solid basis and enhance our trust in the true existence and nature of the effect. I have provided two replication studies that show that name-dropping works similarly in different student samples, at different universities, and in two German-speaking countries.

I consider an asset of the present research that it not only established the effect but also indicated that the effect can adopt both a positive and a negative direction, and that the underlying processes involve assumed personal acquaintance with the individuals mentioned, or assumed manipulativeness of the actor, respectively.

In a further step, the present research went beyond the original university lecture setting and showed that name-dropping also affects person perception during job interviews and during get-acquainted conversations. Thereby, I generalized the effect to more than one context and beyond a specific name-dropping manipulation and, by applying name-dropping to the job interview, tied it in with the well-established research on impression management during job application processes. I also varied the nature of the stimuli in that I used written, acoustic, and visual material.

The major limitations of the present research have been discussed in detail in previous sections and are only summarized at this point: Sampling was limited to the population of university students, which is problematic especially with regard to the job interview study. As the effects of name-dropping have proven small on most occasions, statistical power was curtailed by sample sizes between 15 and 80 per cell. As a result, some of the results barely reach statistical significance.

A limitation that is, at the same time, a proposal for the future research agenda on namedropping concerns the relative explanatory value of social psychological experimental design and social cognitive theories. During my work at this dissertation project, I became increasingly aware that the classic audio and video tape manipulations and the traditional Likert-type questionnaire measures I was using are 
perfectly able to show that name-dropping affects person perception, but that it is a methodology rather unable to show how it affects person processing and based on precisely which cognitive mechanisms. At the same time, I found myself drawing increasingly on social cognitive theories of how individuals process person information, specifically how they compare exemplars of same and different categories, gauge contradictory information, integrate sequential input, and retrieve prior knowledge from memory. However, the research underlying these theories uses very different paradigms than I did in my studies. As a result, my explanations of results along social cognitive processes might seem, in part, distant to my empirical data.

From this I conclude that future research both on impression management in general and on name-dropping in particular should make a strong effort to bridge the gap between the classic social psychological designs and measures that have constituted the literature on impression management until now, and the state of the art manipulations and measures of social cognition research. For example, Cialdini's et al. (1976) studies on Basking in Reflected Glory are classics that have inspired many theoretical publications as well as some empirical replications (e.g., End et al., 2002) and are omnipresent in all current publications on self-presentational efforts. Yet, little do they explain how BIRG works and why basking individuals assume that it works.

Despite in-depth theoretical analyses (e.g., Cialdini et al., 1990), we have still no empirical answers on the question why individuals assume that the glory of a distant, successful other enhances their own standing in the eyes of an audience. And yet there is evidence from social cognitive research that individuals sometimes assign one person's traits to another person, based on temporal or spatial association in perception (what has become known as trait transference). This, on the other hand, allows for systematic hypotheses about the underlying processes both in the actor and the target. Furthermore, process-oriented dependent measures such as reaction time and systematic memory errors are more precise descriptors of what is going on and how it affects person judgment than mediation analysis of questionnaire data.

Therefore, the obvious next question on the research agenda is: By what means does name-dropping influence person perception and person judgment? 


\section{References}


Ambady, N., \& Rosenthal, R. (1992). Thin slices of expressive behavior as predictors of interpersonal consequences: A meta-analysis. Psychological Bulletin, 111, 256274.

Ambady, N., \& Rosenthal, R. (1993). Half a minute: Predicting teacher evaluations from thin slices of nonverbal behavior and physical attractiveness. Journal of Personality and Social Psychology, 64, 431-441.

Andersen, S. M., \& Cole, S. W. (1990). "Do I know you?": The role of significant others in general social perception. Journal of Personality and Social Psychology, 59, 384-399.

Andersen, S. M., \& Glassman, N. S. (1996). Responding to significant others when they are not there: Effects on interpersonal inference, motivation, and affect. In R. M. Sorrentino \& E. T. Higgins (Eds.), Handbook of motivation and cognition: Vol. 3. The interpersonal context (pp. 262-321). New York, NY: Guilford Press.

Andrews, M. C., \& Kacmar, K. M. (2001). Impression management by association: Construction and validation of a scale. Journal of Vocational Behavior, 58, 142161.

Arkin, R. (1981). Self-presentation styles. In J. T. Tedeschi (Ed.), Impression management and social psychological research. New York, NY: Academic Press.

Arvey, R., \& Campion, M. (1982). The employment interview: A summary of recent research. Personnel Psychology, 35, 281-322.

Asch, S. E. (1946). Forming impressions of personality. Journal of Abnormal and Social Psychology, 41, 258-290.

Bales, R. F. (1970). Personality and interpersonal behavior. New York, NY: Holt, Rinehart, and Winston.

Bangerter, A. (2000). Self-representation: Conversational implementation of selfpresentational goals in research interviews. Journal of Language and Social Psychology, 19, 436-462.

Bargh, J. A. (1994). The four horsemen of automaticity: Awareness, intention, efficiency, and control in social cognition. In R. S. J. Wyer, \& T. K. Srull (Eds.), Handbook of social cognition: Vol. 1. Basic processes ( $2^{\text {nd }}$ ed., pp. 1-40). Hillsdale, NJ: Erlbaum.

Bargh, J.A., Chaiken, S., Govender, R., \& Pratto, F. (1992). The generality of the automatic attitude activation effect. Journal of Personality and Social Psychology, 62, 893-912.

Bargh, J. A., Chen, M., \& Burrows, L. (1996). Automaticity of social behavior: Direct effects of trait construct and stereotype activation on action. Journal of Personality and Social Psychology, 71, 230-244.

Baron, R. A. (1986). Self-presentation in job interviews: When there can be "too much of a good thing." Journal of Applied Social Psychology, 16, 16-28.

Baron, R. A., Fortin, S. P., Frei, R. L., Hauver, L. A., \& Shack, M. L. (1990). Reducing organizational conflict: The role of socially-induced positive affect. International Journal of Conflict Management, 1, 133-152.

Berscheid, E. (1985). Interpersonal attraction. In G. Lindzey, \& E. Aronson (Eds.), Handbook of social psychology ( $3^{\text {rd }}$ ed., Vol. 2, pp. 413-484). New York, NY: Random House.

Birnbaum, I. M. (1973). Retroactive inhibition in two paradigms of negative transfer. Journal of Experimental Psychology, 100, 116-121. 
Bizman, A., \& Yinon, Y. (2002). Engaging in distancing tactics among sport fans: Effects on self-esteem and emotional responses. Journal of Social Psychology, 142, 381-392.

Blakeney, R. N. \& MacNaughton, J. F. (1971). Effects of temporal placement of unfavourable information on decision making during the selection interview. Journal of Applied Psychology, 55, 138-142.

Blumberg, H. H. (1972). Communication of interpersonal evaluations. Journal of Personality and Social Psychology, 23, 157-162.

Boen, F., Vanbeselaere, N., Pandelaere, M., Dewitte, S., Duriez, B., Snauwaert, B., et al. (2002). Politics and basking-in-reflected-glory: A field study in Flanders. Basic and Applied Social Psychology, 24, 205-214.

Bolino, M. C., \& Turnley, W. H. (2003). More than one way to make an impression: Exploring profiles of impression management. Journal of Management, 29, 141 160.

Bond, M. H., Leung, K., \& Wan, K. (1982). The social impact of self-effacing attributions: The Chinese case. The Journal of Social Psychology, 118, 157-166.

Brewer, M. B. (1988). A dual process model of impression formation. In T. K. Srull, \& R. S. Wyer (Eds.), Advances in social cognition (Vol. 1, pp. 1-36). Hillsdale, NJ: Erlbaum.

Brewer, M. B. (1991). The social self: On being the same and different at the same time. Personality and Social Psychology Bulletin, 17, 475-482.

Brown, D. R. (1953). Stimulus-similarity and the anchoring of subjective scales. The American Journal of Psychology, 66, 199-214.

Brown, R. D., \& Bassili, J. N. (2002). Spontaneous trait associations and the case of the superstitious banana. Journal of Experimental Social Psychology, 38, 87-92.

Bruner, J. S. (1957). On perceptual readiness. Psychological Review, 64, 123-152.

Bruner, J. S., \& Tagiuri, R. (1954). The perception of people. In G. Lindzey (Ed.), Handbook of social psychology (Vol. 2, pp. 634-654). Cambridge, MA: Addison Wesley.

Byrne, D. (1961). Interpersonal attraction and attitude similarity. Journal of Abnormal and Social Psychology, 62, 713-715.

Byrne, D. (1971). The attraction paradigm. New York: Academic Press.

Carlston, D. E., \& Skowronski, J. J. (1994). Savings in the relearning of trait information as evidence for spontaneous inference generation. Journal of Personality and Social Psychology, 66, 840-856.

Chaiken, S. (1980). Heuristic versus systematic information processing and the use of source versus message cues in persuasion. Journal of Personality and Social Psychology, 39, 752-756.

Chen, S. (2001). The role of theories in mental representation and their use in social perception: A theory-based approach to significant-other representations and transference. In G. B. Moskowitz (Ed.), Cognitive social psychology: The Princeton Symposium on the Legacy and Future of Social Cognition (pp. 125-142). Mahwah, NJ: Erlbaum.

Chen, S. (2003). Psychological-state theories about significant others: Implications for the content and structure of significant-other representations. Personality and Social Psychology Bulletin, 29, 1285-1302. 
Chen, S. \& Andersen, S. M. (1999). Relationships from the past in the present: Significant-other representations and transference in interpersonal life. In M. P. Zanna (Ed.), Advances in experimental social psychology (Vol. 31, pp. 123-190). San Diego, CA: Academic Press.

Chen, S., Andersen, S. M., \& Hinkley, K. (1999). Triggering transference: Examining the role of applicability in the activation and use of significant-other representations in social perception. Social Cognition, 17, 332-385.

Chaiken, S. (1980). Heuristic versus systematic information processing and the use of source versus message cues in persuasion. Journal of Personality and Social Psychology, 39, 752-766.

Cialdini, R. B. (1989). Indirect tactics of image management: Beyond basking. In R. A. Giacalone (Ed.), Impression management in the organization (pp. 45-56). Hillsdale, NJ: Lawrence Erlbaum.

Cialdini, R. B., Borden, R. J., Thorne, A., Walker, M. R., Freeman, S., \& Sloan, L. R. (1976). Basking in reflected glory: Three (football) field studies. Journal of Personality and Social Psychology, 34, 366-375.

Cialdini, R. B., \& de Nicholas, M. E. (1989). Self-presentation by association. Journal of Personality and Social Psychology, 57, 626-631.

Cialdini, R. B., Finch, J. F., \& De Nicholas, M. E. (1990). Strategic self-presentation: The indirect route. In M. J. Cody (Ed.), The psychology of tactical communication. Monographs in social psychology of language (Vol. 2, pp. 194-206). Clevedon: Multilingual Matters.

Cialdini, R. B., \& Richardson, K. D. (1980). Two indirect tactics of image management: Basking and blasting. Journal of Personality and Social Psychology, 39, 406- 415.

Coupland, N., Coupland, J., \& Giles, H. (1991). Language, society, and the elderly. Oxford, UK: Basil Blackwell.

Crant, J. M. (1996). Doing more harm than good: When is impression management likely to evoke a negative response? Journal of Applied Social Psychology, 26, 1454-1471.

De Bruin, E. N. M., \& Van Lange, P. A. M. (2000). What people look for in others: Influences of the perceiver and the perceived in information selection. Personality and Social Psychology Bulletin, 26, 206-219.

De Houwer, J., Thomas, S., \& Baeyens, F. (2001). Association learning of likes and dislikes: A review of 25 years of research on human evaluative conditioning. Psychological Bulletin, 127, 853-869.

Denrell, J. (2005). Why most people disapprove of me: Experience sampling in impression formation. Psychological Review, 112, 951-978.

DePaulo, B. M. (1992). Nonverbal behavior and self-presentation. Psychological Bulletin, 111, 203-243.

Dijksterhuis, A., Spears, R., Postmes, T., Stapel, D. A., Koomen, W., van Knippenberg, A., et al. (1998). Seeing one thing and doing another: Contrast effects in automatic behavior. Journal of Personality and Social Psychology, 75, 862-871.

Dijksterhuis, A., \& van Knippenberg, A. (1998). The relation between perception and behavior, or how to win a game of Trivial Pursuit. Journal of Personality and Social Psychology, 74, 865-877. 
Dipboye, R. L., Fromkin, H. L., \& Wiback, K. (1975). Relative importance of applicant sex, attractiveness, and scholastic standing in evaluation of job applicant resumés. Journal of Applied Psychology, 60, 39-43.

Dipboye, R. L., \& Gaugler, B. B. (1993). Cognitive and behavioral processes in the selection interview. In N. Schmitt \& W. C. Borman (Eds.), Personnel selection in organizations (pp. 135-171). San Francisco, CA: Jossey-Bass.

Dougherty, T. W., Turban, D. B., \& Callender, J. C. (1994). Confirming first impressions in the employment interview: A field study of interviewer behaviour. Journal of Applied Psychology, 79, 659-665.

Eagly, A. H., Ashmore, R. D., Makhijani, M. G., \& Longo, L. C. (1991). What is beautiful is good, but...: A meta-analytic review of research on the physical attractiveness stereotype. Psychological Bulletin, 110, 109-128.

Ellis, A. P. J., West, B. J., Ryan, A. M., \& DeShon, R. P. (2002). The use of impression management tactics in structured interviews: A function of question type? Journal of Applied Psychology, 87, 1200-1208.

End, C. M., Dietz-Uhler, B., Harrick, E. A., \& Jacquemotte, L. (2002). Identifying with winners: A reexamination of sport fans' tendency to BIRG. Journal of Applied Social Psychology, 32, 1017-1030.

Fandt, P. M., \& Ferris, G. R. (1990). The management of information and impressions: When employees behave opportunistically. Organizational Behavior and Human Decision Processes, 45, 140-158.

Farr, J.L. (1973). Response requirements and primacy-recency effects in a simulated selection interview. Journal of Applied Psychology, 57, 228-233.

Fazio, R. H., Sanbonmatsu, D. M., Powell, M. C., \& Kardes, F. R. (1986). On the automatic activation of attitudes. Journal of Personality and Social Psychology, 50, 229-238.

Fein, S., Hilton, J. L., \& Miller, D. T. (1990). Suspicion of ulterior motivation and the correspondence bias. Journal of Personality and Social Psychology, 58, 753-764.

Ferris, G. R., Bhawuk, D. P. S., Fedor, D. F., \& Judge, T. A. (1995). Organizational politics and citizenship: Attributions of intentionality and construct definition. In $\mathrm{M}$. J. Martinko (Ed.), Attribution theory: An organizational perspective (pp. 231-251). Delray Beach, FL: St. Lucie.

Ferris, G. R., \& Judge, T. A. (1991). Personnel/human resources management: A political influence perspective. Journal of Management, 19, 447-488.

Ferris, G. R., Judge, T. A., Rowland, K. M., \& Fitzgibbons, D. E. (1994). Subordinate influence and the performance evaluation process: Test of a model. Organizational Behavior and Human Decision Processes, 58, 101-135.

Festinger, L. (1954). A theory of social comparison processes. Human Relations, 7, 117140.

Finch, J. F., \& Cialdini, R. B. (1989). Another indirect tactic of (self-) image management: Boosting. Personality and Social Psychology Bulletin, 15, 222-232.

Fiske, S. T. (1982). Schema-triggered affect: Applications to social perception. In M. S. Clark \& S. T. Fiske (Eds.), Affect and cognition: The 17th Annual Carnegie Symposium on Cognition. Hillsdale, NJ: Erlbaum.

Fiske, S. T. (2004). Social beings: A core motives approach to social psychology. Hoboken, NJ: John Wiley. 
Fiske, S. T., Cuddy, A. J., Glick, P., \& Xu, J. (2002). A model of (often mixed) stereotype content: Competence and warmth respectively follow from perceived status and competition. Journal of Personality and Social Psychology, 82, 878-902.

Fiske, S. T., \& Neuberg, S. L. (1990). A continuum model of impression formation, from category based to individuating processes: Influences of information and motivation on attention and interpretation. In M. P. Zanna (Ed.), Advances in experimental social psychology (Vol. 23, pp. 1-74). New York, NY: Academic Press.

Fletcher, C. (1989). Impression management in the selection interview. In R. A. Giacalone, \& P. Rosenfeld (Eds.), Impression Management in the Organization (pp. 269-281). Hillsdale, NJ: Lawrence Erlbaum.

Foppa, K. (1990). Topic progression and intention. In I. Markovà \& K. Foppa (Eds.), The dynamics of dialogue (pp. 178-200). Hemel Hempstead, UK: Harvester Wheatsheaf.

Forsyth, D. R., Berger, R. E., \& Mitchell, T. (1981). The effects of self-serving vs. other-serving claims of responsibility on attraction and attribution in groups. Social Psychology Quarterly, 44, 59-64.

Gardner, W. L. (1992). Lessons in organizational dramaturgy: The art of impression management. Organizational Dynamics, 21, 33-46.

Gardner, W. L., \& Martinko, M. J. (1988). Impression management in organizations. Journal of Management, 14, 321-338.

Giacalone, R. A. (1985). On slipping when you thought you had put your best foot forward: Self-promotion, self-destruction, and entitlements. Group and Organization Studies, 10, 61-80.

Gilbert, D. T. (1989). Thinking lightly about others: Automatic components of the social inference process. In J. S. Uleman, \& J. A. Bargh (Eds.), Unintended thought (pp. 189-211). New York, NY: Guilford Press.

Gilbert, D. T. (1998). Ordinary personology. In D. T. Gilbert, S. T. Fiske, \& G. Lindzey (Eds.), The handbook of social psychology ( $4^{\text {th }}$ ed., Vol. 2, pp. 89-150). Boston, MA: McGraw-Hill.

Gilbert, D. T., \& Malone, P. S. (1995). The correspondence bias. Psychological Bulletin, 117, 21-38.

Gilmore, D. C., \& Ferris, G. R. (1989). The effects of applicant impression management tactics on interviewer judgments. Journal of Management, 15, 557-564.

Gilmore, D. C., Stevens, C. K., Harrel-Cook, G., \& Ferris, G. R. (1989). Impression management tactics. In R. W. Eder, \& M. M. Harris (Eds.), The employment interview handbook (pp. 321-336). Thousand Oaks, CA: Sage.

Gilovitch, T. (1981). Seeing the past in the present: The effect of associations to familiar events on judgments and decisions. Journal of Personality and Social Psychology, 40, 797-808.

Godfrey, D. K., Jones, E. E., \& Lord, C. G. (1986). Self-promotion is not ingratiation. Journal of Personality and Social Psychology, 50, 206-115.

Goffman, E. (1959). The presentation of self in everyday life. New York, NY: Doubleday.

Gordon, R. A. (1996). Impact of ingratiation on judgments and evaluations: A metaanalytic investigation. Journal of Personality and Social Psychology, 71, 54-70. 
Gurevitch, Z. D. (1984). Impression formation during tactical self-presentation. Social Psychology Quarterly, 47, 262-270.

Gurevitch, Z. D. (1985). The receiver's dilemma: impressions formed in response to impression management. Basic and Applied Social Psychology, 6, 145-157.

Ham, J., \& Vonk, R. (2003). Smart and easy: Co-occurring activation of spontaneous trait inferences and spontaneous situational inferences. Journal of Experimental Social Psychology, 39, 434-447.

Harrel-Cook, G., Ferris, G. R., \& Dulebohn, J. H. (1999). Political behaviors as moderators of the perceptions of organizational politics - work outcomes relationships. Journal of Organizational Behavior, 20, 1093-1105.

Hastie, R. \& Park, B. (1986). The relationship between memory and judgment depends on whether the judgment task is memory-based or on-line. Psychological Review, 83, 258-268.

Heider, F. (1944). Social perception and phenomenal causality. Psychological Review, $51,358-374$.

Heider, F. (1958). The psychology of interpersonal relations. New York, NY: John Wiley.

Herr, P. M. (1986). Consequences of priming: Judgment and behavior. Journal of Personality and Social Psychology, 51, 1106-1115.

Higgins, C. A., \& Judge, T. A. (2004). The effect of applicant influence tactics on recruiter perceptions of fit and hiring recommendations: A field study. Journal of Applied Psychology, 89, 622-632.

Higgins, C. A., Judge, T. A., \& Ferris, G. R. (2003). Influence tactics and work outcomes: A meta-analysis. Journal of Organizational Behavior, 24, 89-106.

Higgins, E. T., \& Brendl, C. M. (1995). Accessibility and applicability: Some "activation rules" influencing judgment. Journal of Experimental Social Psychology, 31, 218-243.

Higgins, E. T., Rholes, W. S., \& Jones, C. R. (1977). Category accessibility and impression formation. Journal of Experimental Social Psychology, 13, 141-154.

Higgins, R. L., \& Snyder, C. R. (1989). The business of excuses. In R. A. Giacalone \& P. Rosenfeld (Eds.), Impression management in the organization. Hillsdale, NJ: Lawrence Erlbaum Associates.

Holtgraves, T., \& Srull, T. K. (1989). The effects of positive self-descriptions on impressions: General principles and individual differences. Personality and Social Psychology Bulletin, 15, 452-462.

Ichheiser, G. (1943). Misinterpretations of personality in everyday life. Character and Personality, 11, 145-160.

Johnson, M. K., Hashtroudi, S., \& Lindsay, D. S. (1993). Source monitoring. Psychological Bulletin, 114, 3-28.

Jones, E. E. (1964). Ingratiation. New York, NY: Appleton-Century-Crofts.

Jones, E. E., \& Harris, V. A. (1967). The attribution of attitudes. Journal of Experimental Social Psychology, 3, 1-24.

Jones, E.E., \& Pittman, T.S. (1980). Toward a general theory of strategic self presentation, in: S. Suls (Ed.), Psychological perspectives of the self (Vol. 1, pp. 231-262), Hillsdale, NJ: Erlbaum.

Jones, E. E., \& Wortman, C. (1973). Ingratiation: An attributional approach. NJ: General Learning Press. 
Judge, T. A., \& Bretz, R. D., Jr. (1994). Political influence behavior and career success. Journal of Management, 20, 43-65.

Judge, T. A., \& Ferris, G. R. (1993). Social context of performance evaluation decisions. Academy of Management Journal, 36, 80-105.

Kacmar, K. M., \& Carlson, D. S. (1999). Effectiveness of impression management tactics across human resource situations. Journal of Applied Social Psychology, 29, 1293-1315.

Kacmar, K. M., Delery, J. E., \& Ferris, G. R. (1992). Differential effectiveness of applicant impression management tactics on employment interview decisions. Journal of Applied Social Psychology, 22, 1250-1272.

Kammrath, L. K., Mendoza-Denton, R., \& Mischel, W. (2005). Incorporating if... then... personality signatures in person perception: Beyond the person-situation dichotomy. Journal of Personality and Social Psychology, 88, 605-618.

Kassin, S. M., \& Sukel, H. (1997). Coerced confessions and the jury: An experimental test of the "harmless error" rule. Law and Human Behavior, 21, 27-46.

Kernis, M. H., \& Wheeler, L. (1981). Beautiful friends and ugly strangers: Radiation and contrast effects in perceptions of same-sex pairs. Personality and Social Psychology Bulletin, 7, 617-620.

Kipnis, D., \& Schmidt, S. M. (1988). Upward-influence styles: Relationship with performance evaluations, salary, and stress. Administrative Science Quarterly, 33, 528-542.

Knouse, S. B. (1994). Impressions of the resume: The effects of applicant education, experience, and impression management. Journal of Business and Psychology, 9, 33-45.

Knouse, S. B., Giacalone, R. A., \& Pollard, H. (1988). Impression management in the resume and its cover letter. Journal of Business and Psychology, 3, 242-249.

Kristof-Brown, A. L., Barrick, M. R., \& Franke, M. (2002). Applicant impression management: Dispositional influences and consequences for recruiter perceptions of fit and similarity. Journal of Management, 28, 27-46.

Krull, D. S. (2001). On partitioning the fundamental attribution error: Dispositionalism and the correspondence bias. In G. B. Moskowitz (Ed.), Cognitive social psychology: The Princeton Symposium on the Legacy and Future of Social Cognition (pp. 211-227). Mahwah, NJ: Erlbaum.

Krull, D. S., \& Erickson, D. J. (1995). Inferential hopscotch: How people draw social inferences from behavior. Current Directions in Psychology Science, 4(2), 35-38.

Leary, M. R., \& Kowalski, R. M. (1990). Impression management: A literature review and two-component model. Psychological Bulletin, 107, 34-47.

Lebherz, C., \& Jonas, K. (2005, July). Name-dropping as a self-presentational tactic: Does it work? Paper presented at the General Meeting of the European Association of Experimental Social Psychology, Wuerzburg, Germany.

Lippa, R. (1967). Expressive control, expressive consistency, and the correspondence between expressive behavior and personality. Journal of Personality, 44, 541-559.

Macrae, C. N., \& Bodenhausen, G. V. (2000). Social cognition: Thinking categorically about others. Annual Review of Psychology, 51, 93-120.

Macrae, C. N., Bodenhausen, G. V., Milne, A. B., Castelli, L., Schloerscheidt, A. M., \& Greco, S. (1998). On activating exemplars. Journal of Experimental Social Psychology, 34, 330-354. 
Manis, M., Cornell, S. D., \& Moore, J. C. (1974). The transmission of attitude-relevant information through a communication chain. Journal of Personality and Social Psychology, 30, 81-94.

Martin, L. L. (1986). Set/reset: Use and disuse of concepts in impression formation. Journal of Personality and Social Psychology, 51, 493-505.

Martin, L. L., Seta, J. J., \& Crelia, R. A. (1990). Assimilation and contrast as a function of people's willingness and ability to expend effort in forming an impression. Journal of Personality and Social Psychology, 59, 27-37.

McFarland, L. A., Yun, G., Harold, C. M., Viera, L. J., \& Moore, L. G. (2005). An examination of impression management use and effectiveness across assessment center exercises: The role of competency demands. Personnel Psychology, 58, 949-980.

McGraw, K. M. (2003). Political impressions: Formation and management. In D. O. Sears, L. Huddy \& R. Jervis (Eds.), Handbook of political psychology (pp. 394432). New York, NY: Oxford University Press.

Merton, R. K. (1948). The bearing of empirical research upon the development of social theory. American Sociological Review, 13, 505-515.

Miller, N., Campbell, D. T., Twedt, H., \& O'Connell, E. J. (1966). Similarity, contrast and complementarity in friendship choice. Journal of Personality and Social Psychology, 3, 1-24.

Moskowitz, G. B. (2005). Social cognition: Understanding self and others. New York, NY: The Guilford Press.

Moskowitz, G. B., \& Roman, R. J. (1992). Spontaneous trait inferences as self generated primes: Implications for conscious social judgment. Journal of Personality and Social Psychology, 62, 728-738.

Moskowitz, G. B., \& Skurnik, I. W. (1999). Contrast effects as determined by the type of prime: Trait versus exemplar primes initiate processing strategies that differ in how accessible constructs are used. Journal of Personality and Social Psychology, 76, 911-927.

Mussweiler, T. (2003a). Everything is relative: Comparison processes in social judgment. The 2002 Jaspars lecture. European Journal of Social Psychology, 33, 719-733.

Mussweiler, T. (2003b). Comparison processes in social judgment: Mechanisms and consequences. Psychological Review, 110, 472-489.

Niedenthal, P. M., Halberstadt, J. B., \& Setterlund, M. B. (1997). Being happy and seeing "happy": Emotional state facilitates visual encoding. Cognition and Emotion, 11, 403-432.

Noffsinger, E. B., Pellegrini, R. J., \& Burnell, G. M. (1983). The effect of associated persons upon the formation and modifiability of first impressions. The Journal of Social Psychology, 120, 183-195.

Parsons, C. K., Liden, R. C., \& Bauer, T. N. (2001). Person perception in employment interviews. In M. London (Ed.), How people evaluate others in organizations (pp. 67-90). Mahwah, NJ: Lawrence Erlbaum.

Peters, L. H., \& Terborg, J. R. (1975). The effects of temporal placement of unfavorable information and attitude similarity on personnel selection decisions. Organizational Behavior and Human Performance, 13, 279-293. 
Petty, R. E., \& Cacioppo, J. T. (1981). Attitudes and persuasion: Classic and contemporary approaches. Dubuque, IA: William C. Brown.

Powers, T. A., \& Zuroff, D. C. (1988). Interpersonal consequences of overt selfcriticism: A comparison with neutral and self-enhancing presentations of self. Journal of Personality and Social Psychology, 54, 1054-1062.

Pratkanis, A. R., Greenwald, A. G., Leippe, M. R., \& Baumgardner, M. H. (1988). In search of reliable persuasion effects: III. The sleeper effect is dead. Long live the sleeper effect. Journal of Personality and Social Psychology, 54, 203-218.

Pratto, F., \& John, O. P. (1991). Automatic vigilance: The attention-grabbing power of negative social information. Journal of Personality and Social Psychology, 61, 380391.

Prentice, D. A. (1990). Familiarity and differences in self- and other-representations. Journal of Personality and Social Psychology, 59, 369-383.

Rao, A., Schmidt, S. M., \& Murray, L. H. (1995). Upward impression management: Goals, influence strategies, and consequences. Human Relations, 48, 147-167.

Richardson, K. D., \& Cialdini, R. B. (1981). Basking and blasting: Tactics of indirects self-presentation. In J. T. Tedeschi (Ed.), Impression Management Theory and Social Psychological Research (pp. 41-53). Albany, NY: Academic Press.

Robinson, M. D., Johnson, J. T., \& Shields, S. A. (1995). On the advantages of modesty: The benefits of a balanced self-presentation. Communication Research, 22, 575591.

Rosenberg, S., Nelson, C., \& Vivekananthan, P. S. (1968). A multidimensional approach to the structure of personality impressions. Journal of Personality and Social Psychology, 9, 283-294.

Rosenberg, S., \& Olshan, K. (1970). Evaluative and descriptive aspects in personality perception. Journal of Personality and Social Psychology, 16, 619-626.

Rosenfeld, P., Giacolone, R.A., \& Riordan, C.A. (1995). Impression management in organizations. New York, NY: Routledge.

Rosenthal, R., \& Rosnow, R. L. (1969). The volunteer subject. In R. Rosenthal, \& R. L. Rosnow (Eds.), Artifact in behavioral research. New York, NY: Academic Press.

Roskos-Ewoldsen, D. R., \& Fazio, R. H. (1992). On the orienting value of attitudes: Attitude accessibility as a determinant of an object's attraction of visual attention. Journal of Personality and Social Psychology, 63, 198-211.

Ross, L. (1977). The intuitive psychologist and his shortcomings: Distortions in the attribution process. In L. Berkowitz (Ed.), Advances in experimental social psychology (Vol. 10, pp. 174-221). New York, NY: Academic Press.

Ross, L., Amabile, T. M., \& Steinmetz, J. L. (1977). Social roles, social control, and biases in social-perception processes. Journal of Personality and Social Psychology, 35, 484-494.

Schlenker, B. R. (1980). Impression management: The self-concept, social identity, and interpersonal relations. Monterey, CA: Brooks/Cole.

Schlenker, B. R. (1985). Identity and self-identification. In B. R. Schlenker (Ed.), The self and social life (pp. 65-100). New York, NY: McGraw-Hill.

Schlenker, B. R. (2003). Self-presentation. In M. R. Leary (Ed.), (2003). Handbook of self and identity (pp. 492-518). New York, NY: Guilford.

Schlenker, B. R., Britt, T. W., \& Pennington, J. (1996). Impression regulation and management: Highlights of a theory of self-identification. In R. M. Sorrentino \& E. 
T. Higgins (Eds.), Handbook of motivation and cognition: Vol. 3. The interpersonal context (pp. 118-147). New York, NY: Guilford Press.

Schlenker, B. R., \& Leary, M. R. (1982a). Social anxiety and self-presentation: A conceptualization model. Psychological Bulletin, 92, 641-669.

Schlenker, B. R., \& Leary, M. R. (1982b). Audiences' reactions to self-enhancing, selfdenigrating, and accurate self-presentations. Journal of Experimental Social Psychology, 18, 89-104.

Schlenker, B. R., Pontari, B. A., \& Christopher, A. N. (2001). Excuses and character: Personal and social implications of excuses. Personality and Social Psychology Review, 5, 15-32.

Schlenker, B. R., \& Weigold, M. F. (1992). Interpersonal processes involving impression regulation and management. Annual Review of Psychology, 43, 133-168.

Schlenker, B. R., \& Wowra, S. A. (2003). Carryover effects of feeling socially transparent or impenetrable on strategic self-presentation. Journal of Personality and Social Psychology, 85, 871-880.

Schneider, D. J. (1981). Tactical self-presentations: Toward a broader conception. In J. T. Tedeschi (Ed.), Impression Management Theory and Social Psychological Research (pp. 23-40). Albany, NY: Academic Press.

Schwarz, N., \& Bless, H. (1992). Constructing reality and its alternatives: An inclusion/exclusion model of assimilation and contrast effects in social judgment. In L. L. Martin \& A. Tesser (Eds.), The construction of social judgments (pp. 217245). Hillsdale, NJ: Lawrence Erlbaum.

Sedikides, C., \& Skowronski, J. J. (1991). The law of cognitive structure activation. Psychological Inquiry, 2, 169-184.

Skowronski, J. J. (2002). Honesty and intelligence judgments of individuals and groups: The effects of entity-related behavior diagnosticity and implicit theories. Social Cognition, 20, 136-169.

Skowronski, J. J., \& Carlston, D. E. (1989). Negativity and extremity biases in impression formation: A review of explanations. Psychological Bulletin, 105, 131142.

Skowronski, J. J., Carlston, D. E., Mae, L., \& Crawford, M. T. (1998). Spontaneous trait transference: Communicators take on the qualities they describe in others. Journal of Personality and Social Psychology, 74, 837-848.

Sloan, L. R. (1989). The motives of sports fans. In J. H. Goldstein (Ed.), Sports, games and play: Social and psychological viewpoints ( $2^{\text {nd }}$ ed., pp. 175-240). Hillsdale, NJ: Lawrence Erlbaum.

Snyder, C. R., Lassegard, M., \& Ford, C. E. (1986). Distancing after group success and failure: Basking in reflected glory and cutting off reflected failure. Journal of Personality and Social Psychology, 51, 382-388.

Snyder, M. L., \& Frankel, A. (1976). Observer bias: A stringent test of behavior engulfing the field. Journal of Personality and Social Psychology, 34, 857-864.

Snyder, M., \& Swann, W. B. (1978). Hypothesis-testing processes in social interaction. Journal of Personality and Social Psychology, 36, 1202-1212.

Springbett, B. M. (1958). Factors affecting the final decision in the employment interview. Canadian Journal of Psychology, 12, 13-22.

Srull, T. K., \& Wyer, R. S. J. (1989). Person memory and judgment. Psychological Review, 96, 58-83. 
Stapel, D. A., \& Koomen, W. (2001). Let's not forget the past when we go to the future: On our knowledge of knowledge accessibility. In G. B. Moskowitz (Ed.), Cognitive social psychology: The Princeton Symposium on the Legacy and Future of Social Cognition (pp. 229-246). Mahwah, NJ: Erlbaum.

Stapel, D. A., Koomen, W., \& Van der Pligt, J. (1996). The referents of trait inferences: The impact of trait concepts versus actor-trait links on subsequent judgments. Journal of Personality and Social Psychology, 70, 437-450.

Stapel, D. A., Koomen, W., \& Van der Pligt, J. (1997). Categories of category accessibility: The impact of trait concept versus exemplar priming on person judgments. Journal of Experimental Social Psychology, 33, 47-76.

Stapel, D. A., \& Schwarz, N. (1998). The republican who did not want to become president: Colin Powell's impact on evaluations of the Republican Party and Bob Dole. Personality and Social Psychology Bulletin, 24, 690-698.

Stevens, C. K., \& Kristof, A. L. (1995). Making the right impression: A field study of applicant impression management during job interviews. Journal of Applied Psychology, 80, 587-606.

Strack, F., Schwarz, N., Bless, H., Kübler, A., \& Wänke, M. (1993). Awareness of the influence as a determinant of assimilation versus contrast. European Journal of Social Psychology, 23, 53-62.

Stroop, J. R. (1935). Studies of interference in serial verbal reactions. Journal of Experimental Psychology, 18, 643-662.

Sunnafrank, M., \& Ramirez, A. J. (2004). At first sight: Persistent relational effects of get-acquainted conversations. Journal of Social and Personal Relationships, 21, 361-379.

Tagiuri, R. (1958). Introduction. In R. Tagiuri \& L. Petrullo (Eds.), Person perception and interpersonal behavior (pp. xi-xvii). Stanford, CA: Stanford University Press.

Tajfel, H., \& Turner, J. C. (1986). An integrative theory of intergroup relations. In S. Worchel, \& W. G. Austin (Eds.), Psychology of intergroup relations ( $2^{\text {nd }}$ ed., pp. 724). Chicago, IL: Nelson-Hall.

Tedeschi, J. T., \& Melburg, V. (1984). Impression management and influence in the organization. Research in the Sociology of Organizations, 3, 31-58.

Tedeschi, J. T., \& Riess, M. (1981). Identities, the phenomenal self, and laboratory research. In J. T. Tedeschi (Ed.), Impression management theory and social psychological research (pp. 3-22). Albany, NY: Academic Press.

Tesser, A. (1988). Toward a self-evaluation maintenance model of social behavior. In L. Berkowitz (Ed.), Advances in experimental social psychology (Vol. 21, pp. 181227). New York, NY: Academic Press.

Tetlock, P. E. (1980). Explaining teacher explanations of pupil performance: An examination of the selfpresentation position. Social Psychology Quarterly, 43, 283290.

Tetlock, P. E. (1985). Accountability: The neglected social context of judgment and choice. Research in Organizational Behavior, 7, 297-332.

Thacker, R. A. (1999). Perceptions of trust, upward influence tactics, and performance ratings. Perceptual and Motor Skills, 88, 1059-1070.

Toris, C., \& DePaulo, B. M. (1984). Effects of actual deception and suspiciousness of deception on interpersonal perceptions. Journal of Personality and Social Psychology, 47, 1063-1073. 
Todorov, A., \& Uleman, J. S. (2002). Spontaneous trait inferences are bound to actors' faces: Evidence form a false recognition paradigm. Journal of Personality and Social Psychology, 83, 1051-1065.

Todorov, A., \& Uleman, J. S. (2003). The efficiency of binding spontaneous trait inferences to actors' faces. Journal of Experimental Social Psychology, 39, 549562.

Todorov, A., \& Uleman, J. S. (2004). The person reference process in spontaneous trait inferences. Journal of Personality and Social Psychology, 87, 482-493.

Tormala, Z. L., \& Petty, R. E. (2001). On-line versus memory-based processing: The role of "need to evaluate" in person perception. Personality and Social Psychology Bulletin, 27, 1599-1612.

Tormala, Z. L., \& Petty, R. E. (2004). Resistance to persuasion and attitude certainty: The moderating role of elaboration. Personality and Social Psychology Bulletin, 30, 1446-1457.

Trope, Y. (1986). Identification and inferential processes in dispositional attribution. Psychological Review, 93, 239-257.

Trope, Y., \& Liberman, N. (1996). Social hypothesis testing: Cognitive and motivation factors. In E. T. Higgins, \& A. W. Kruglanski (Eds.), Social psychology: Handbook of basic principles (pp. 239-270). New York, NY: Guilford Press.

Uleman, J. S., Newman, J., \& Winter, L. (1992). Can traits be inferred automatically? Spontaneous inferences require cognitive capacity at encoding. Consciousness and Cognition, 1, 77-90.

Uleman, J. S., Newman, L. S., \& Moskowitz, G. B. (1996). People as flexible interpreters: Evidence and issues from spontaneous trait inference. Advances in Experimental Social Psychology, 28, 211-279.

Vonk, R. (1998). The slime effect: Suspicion and dislike of likeable behavior toward superiors. Journal of Personality and Social Psychology, 74, 849-864.

Vonk, R. (1999). Effects of outcome dependency on correspondence bias. Personality and Social Psychology Bulletin, 25, 382-389.

Wänke, M., Bless, H., \& Igou, E. R. (2001). Next to a star: Paling, shining, or both? Turning interexemplar contrast into interexemplar assimilation. Personality and Social Psychology Bulletin, 27, 14-29.

Wayne, S. J., \& Ferris, G. R. (1990). Influence tactics, affect, and exchange quality in supervisor-subordinate interactions: A laboratory experiment and field study. Journal of Applied Psychology, 75, 487-499.

Wayne, S. J., \& Kacmar, K. M. (1991). The effects of impression management on the performance appraisal process. Organizational Behavior and Human Decision Processes, 48, 70-88.

Wayne, S. J., Kacmar, K. M., \& Ferris, G. R. (1995). Coworker responses to others' ingratiation attempts. Journal of Managerial Issues, 7, 277-289.

Wayne, S. J., \& Liden, R. C. (1995). Effects of impression management on performance ratings: A longitudinal study. Academy of Management Journal, 38, 232-260.

Wetzel, C. G., \& Insko, C. A. (1982). The similarity-attraction relationship: Is there an ideal one? Journal of Experimental Social Psychology, 18, 253-276.

Wigboldus, D. H. J., Dijksterhuis, A., \& van Knippenberg, A. (2003). When stereotypes get in the way: Stereotypes obstruct stereotype-inconsistent trait inferences. Journal of Personality and Social Psychology, 84, 470-484. 
Wigboldus, D. H. J., Sherman, J. W., Franzese, H. L., \& Van Knippenberg. (2004). Capacity and comprehension: Spontaneous stereotyping under cognitive load. Social Cognition, 22, 292-309.

Wojciszke, B. (1994). Multiple meanings of behavior: Construing actions in terms of competence and morality. Journal of Personality and Social Psychology, 67, 222232.

Wojciszke, B. (2005). Affective concomitants of information on morality and competence. European Psychologist, 10, 60-70.

Wortman, C., \& Linsenmeier, J. (1977). Interpersonal attraction and techniques of ingratiation in organizational settings. In B. M. Staw, \& G. Salancik (Eds.), New directions in organizational behavior (pp. 133-178). Chicago, IL: St. Clair's Press.

Wosinska, W., Dabul, A. J., Whetsone-Dion, R., \& Cialdini, R. B. (1996). Selfpresentational responses to success in the organization: The costs and benefits of modesty. Basic and Applied Social Psychology, 18, 229-242.

Yukl, G., \& Falbe, C. M. (1990). Influence tactics in upward, downward, and lateral influence attempts. Journal of Applied Psychology, 75, 132-140. 


\section{Appendix}


6.1 Appendix to Lebherz, C.: Name-Dropping as a Self-Presentational Tactic: Does It Work? 
6.1.1 Appendix A-1: Instruction Study 1(Four Versions) 
Version 1: Research Focus and High Motivation 
Liebe Teilnehmerin, lieber Teilnehmer,

zunächst vielen Dank für Ihre Bereitschaft, an unserer Untersuchung teilzunehmen!

Wir beschäftigen uns damit, wie Studierende die Qualität von Veranstaltungen beurteilen. Sie hören nun einen ca. siebenminütigen nachgestellten Auszug aus einem

\section{Forschungsvortrag}

zum Thema „Zentrale Konzepte der Arbeitsorganisation“. Ziel des Forschungsvortrags ist es, dass der Dozent den Zuhörern die Forschung zum Thema Arbeitsorganisation vorstellt.

Wenn die Aufnahme beendet ist, werden Sie aufgefordert, die Kopfhörer abzunehmen und den Fragebogen auszufüllen, der, verteilt auf verschiedene Mappen, vor Ihnen liegt. Bitte öffnen Sie die Mappen nicht vorher! Beginnen Sie mit Mappe 1 und öffnen Sie Mappe 2 erst, wenn Sie alle Fragen aus Mappe 1 bearbeitet haben. Schliessen Sie bearbeitete Mappen und legen Sie sie beiseite.

Der/die Versuchsleiter/in bringt Ihnen dann einen kurzen Multiple-ChoiceTest mit 5 Fragen zur Vorlesung. Wir wollen damit testen, was Sie aus dem Vortrag mitgenommen haben.

Sie haben ausreichend Zeit, die Fragen zu beantworten. Die Zeitplanung ist wie folgt:

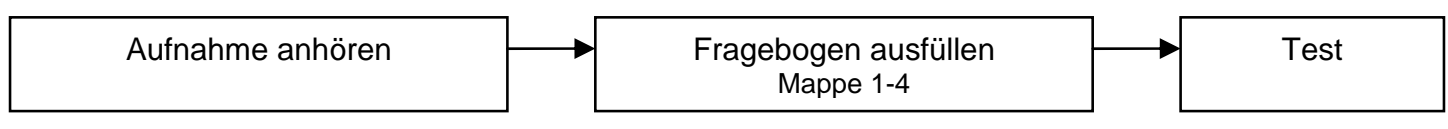

ca. 7 Min.

ca. 20 Min.

ca. 5 Min.

Bitte setzen Sie nun die Kopfhörer auf und starten Sie die Aufnahme! 
Version 2: Research Focus and Low Motivation 
Liebe Teilnehmerin, lieber Teilnehmer,

zunächst vielen Dank für Ihre Bereitschaft, an unserer Untersuchung teilzunehmen!

Wir beschäftigen uns damit, wie Studierende die Qualität von Veranstaltungen beurteilen. Sie hören nun einen ca. siebenminütigen nachgestellten Auszug aus einem

\section{Forschungsvortrag}

zum Thema „Zentrale Konzepte der Arbeitsorganisation“. Ziel des Forschungsvortrags ist es, dass der Dozent den Zuhörern die Forschung zum Thema Arbeitsorganisation vorstellt.

Wenn die Aufnahme beendet ist, werden Sie aufgefordert, die Kopfhörer abzunehmen und den Fragebogen auszufüllen, der, verteilt auf verschiedene Mappen, vor Ihnen liegt. Bitte öffnen Sie die Mappen nicht vorher! Beginnen Sie mit Mappe 1 und öffnen Sie Mappe 2 erst, wenn Sie alle Fragen aus Mappe 1 bearbeitet haben. Schliessen Sie bearbeitete Mappen und legen Sie sie beiseite.

Sie haben ausreichend Zeit, die Fragen zu beantworten. Die Zeitplanung ist wie folgt:

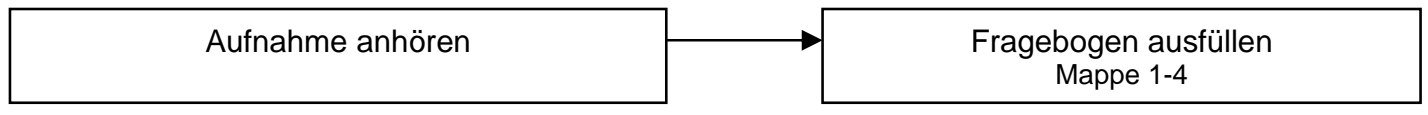

ca. 7 Minuten

ca. 20 Minuten

Bitte setzen Sie nun die Kopfhörer auf und starten Sie die Aufnahme! 
Version 3: Teaching Focus and High Motivation 
Liebe Teilnehmerin, lieber Teilnehmer,

zunächst vielen Dank für Ihre Bereitschaft, an unserer Untersuchung teilzunehmen!

Wir beschäftigen uns damit, wie Studierende die Qualität von Veranstaltungen beurteilen. Sie hören nun einen ca. siebenminütigen nachgestellten Auszug aus einem

\section{Lehrvortrag}

zum Thema „Zentrale Konzepte der Arbeitsorganisation“. Ziel des Lehrvortrags ist es, dass der Dozent seinen Zuhörern Wissen zum Thema Arbeitsorganisation vermittelt.

Wenn die Aufnahme beendet ist, werden Sie aufgefordert, die Kopfhörer abzunehmen und den Fragebogen auszufüllen, der, verteilt auf verschiedene Mappen, vor Ihnen liegt. Bitte öffnen Sie die Mappen nicht vorher! Beginnen Sie mit Mappe 1 und öffnen Sie Mappe 2 erst, wenn Sie alle Fragen aus Mappe 1 bearbeitet haben. Schliessen Sie bearbeitete Mappen und legen Sie sie beiseite.

Der/die Versuchsleiter/in bringt Ihnen dann einen kurzen Multiple-ChoiceTest mit 5 Fragen zur Vorlesung. Wir wollen damit testen, was Sie aus dem Vortrag mitgenommen haben.

Sie haben ausreichend Zeit, die Fragen zu beantworten. Die Zeitplanung ist wie folgt:

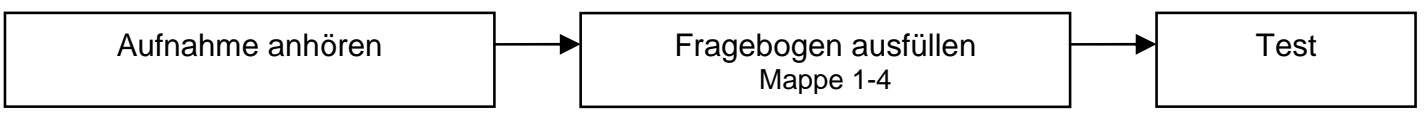

ca. 7 Min.

ca. 20 Min.

ca. 5 Min.

Bitte setzen Sie nun die Kopfhörer auf und starten Sie die Aufnahme! 
Version 4: Teaching Focus and Low Motivation 
Liebe Teilnehmerin, lieber Teilnehmer,

zunächst vielen Dank für Ihre Bereitschaft, an unserer Untersuchung teilzunehmen!

Wir beschäftigen uns damit, wie Studierende die Qualität von Veranstaltungen beurteilen. Sie hören nun einen ca. siebenminütigen nachgestellten Auszug aus einem

\section{Lehrvortrag}

zum Thema „Zentrale Konzepte der Arbeitsorganisation“. Ziel des Lehrvortrags ist es, dass der Dozent seinen Zuhörern Wissen zum Thema Arbeitsorganisation vermittelt.

Wenn die Aufnahme beendet ist, werden Sie aufgefordert, die Kopfhörer abzunehmen und den Fragebogen auszufüllen, der, verteilt auf verschiedene Mappen, vor Ihnen liegt. Bitte öffnen Sie die Mappen nicht vorher! Beginnen Sie mit Mappe 1 und öffnen Sie Mappe 2 erst, wenn Sie alle Fragen aus Mappe 1 bearbeitet haben. Schliessen Sie bearbeitete Mappen und legen Sie sie beiseite.

Sie haben ausreichend Zeit, die Fragen zu beantworten. Die Zeitplanung ist wie folgt:

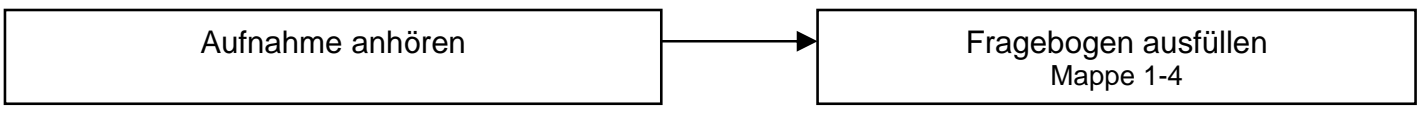

ca. 7 Minuten

ca. 20 Minuten

Bitte setzen Sie nun die Kopfhörer auf und starten Sie die Aufnahme! 
6.1.2 Appendix B-1: Transcript of Name-Dropping Manipulation on Audio Tape (Two Versions) 
Version 1: With Nine Name-Dropping Sequences 
Ich möchte einige zentrale Begrifflichkeiten der Arbeitsorganisation erläutern. Zunächst geht es um die Arbeitsorganisation im Fertigungsbereich. In den letzten Jahren ist es selbstverständlich geworden, dass die Arbeiter, die das Fahrzeug am Fließband zusammenmontieren, in Gruppen organisiert sind. Diese Fertigungsteams bestehen aus 8-12 Werkern. Sie bearbeiten einen bestimmten Fließbandabschnitt gemeinsam und organisieren sich ihr Arbeitsumfeld selbst. Vielleicht kennen Sie die Lehrbücher von Conny Antoni. $\mathrm{Er}$ hat diese Aspekte sehr anschaulich dargestellt. Ausserdem kann ich Ihnen die Forschung meines Kollegen Ekkehart Frieling und seiner Arbeitsgruppe am Kassler Institut für Arbeitswissenschaft empfehlen.

Bei der Arbeitsorganisation im Fertigungsbereich spielen drei Konzepte eine wichtige Rolle: job rotation, job enrichment und job enlargement. Die Klärung dieser Begriffe ist grundlegend für das Verständnis weiterer Punkte der Arbeitsorganisation. Darin stimme ich mit Lehrbuchautoren wie Ansfried Weinert überein. Deshalb gehe ich im Folgenden auf alle drei Begriffe ein.

Unter job rotation versteht man das systematische Wechseln der Arbeitsplätze in einem Fertigungsteam. Alle Teammitglieder beherrschen sämtliche Aufgaben innerhalb ihres Fertigungsbereichs und rotieren nach einem bestimmten Schema über die Arbeitsplätze. Häufig übernimmt das Team selbst die Organisation der Rotation. Manche Teams wechseln die Plätze nur in den Pausen, andere im Stundentakt.

Job enlargement bedeutet, dass sich der Aufgabenbereich eines Werkers vergrößert. Dieser Begriff ist stark an den Fertigungsbereich gekoppelt. Die Taktzeiten in der Montage sind sehr gering. Ich denke, dass das so bleiben wird. Der Trend geht eher zu kurzen statt längeren Arbeitseinheiten. Auch Sabine Pietruschka postuliert dies in einem aktuellen Forschungsartikel im Journal of Organization Research, Vergrößerung des Tätigkeitsspektrums ergibt sich bei job enlargement schon dadurch, dass ein Werker an mehreren Takten angelernt wird.

Job enrichment bedeutet, dass die neuen Tätigkeiten qualitativ anders sind als die bisherigen. Früher trennte man Kopf- und Handarbeit unter der Prämisse, dass es sich dabei um qualitativ unterschiedliche Arbeiten handelt. Sicherlich haben Sie auch in einem anderen Zusammenhang von Frederic Winslow Taylor und seiner Wissenschaftlichen Betriebsführung gehört. Im Fertigungsbereich dominierte lange die Idee, dass so unterschiedliche Aufgaben nur dann optimal ausgeführt werden können, wenn man sie auf verschiedene Personen verteilt. Damit war die starke Rolle des Meisters geboren, der den Werkern die Kopfarbeit abnahm und ihre Tätigkeit auf die reine Montage von Fahrzeugteilen reduzierte.

Durch job enrichment wurde die ursprüngliche Idee der Trennung von Kopf und Hand also aufgehoben. Werker sollen nun, zusätzlich zu ihrer Montagetätigkeit, auch wieder kognitive Aufgaben der Planung und Koordination übernehmen. 
Job rotation und job enlargement verfolgen das Ziel, körperliche Belastungen zu verringern, indem Bewegungsabläufe variiert werden. Überkopfarbeit kann schädlich für den Rücken sein, wenn man eine solche Arbeit über mehrere Stunden ausführt. Wenn sich die Teammitglieder abwechseln, reduziert sich diese Gefahr für den einzelnen, Muskulatur und Skelett werden entlastet. Ich verweise an dieser Stelle auf die Forschung von Klaus Giersiepen und seiner Arbeitsgruppe am Bremer Institut für Präventionsforschung und Sozialmedizin.

Also: Job enrichment verlangt den Werkern wieder Kopfarbeit ab, was bislang dem Meister überlassen war. Aber wie kann man verlangen, dass ein Werker teilweise diese Aufgaben übernimmt, wo der Meister doch eine ganz andere Qualifikation hat als der Werker am Band? Meine Antwort lautet, dass die Werker keine fachlichen Denkaufgaben übernehmen, die ihre Ausbildung übersteigen würde. Es geht vielmehr um organisatorische Tätigkeiten, die bislang der Meister übernommen hat. Die gleiche Antwort würden Sie auch von meiner Kollegin Alexandra Hey oder anderen Dozenten in ihren Vorlesungen erhalten.

Außerdem kommen Tätigkeiten hinzu, die bislang anderen Bereichen übertragen waren. Insbesondere bei der Instandhaltung von Maschinen geht man davon aus, dass die Werker ihre Maschinen sehr gut kennen, so dass sie auch ohne eine entsprechende Ausbildung kleine Reparaturen selbst vornehmen können. Dazu braucht es also noch nicht einmal die viel zitierte Reprofessionalisierung, von der Sie in den Wirtschaftsressorts der Zeit oder der NZZ lesen können.

Ich möchte jetzt zu den erhofften Vorteilen kommen. Einige haben wir bereits aufgegriffen: Job enlargement in Form von job rotation, verteilt die körperliche Belastung auf mehrere Schultern. Das verringert die Anzahl von Krankmeldungen und Ausfällen. Damit reduzieren sich auch die Kosten, die einem Betrieb durch Krankmeldungen entstehen. Fällt ein Teammitglied aus, können die anderen den Kollegen rein quantitativ nicht auffangen. Die Takte sind zu kurz, und personaler Puffer ist nicht eingeplant. Dann müssen Leiharbeiter eingestellt, bezahlt und eingelernt werden.

Ein weiterer Grund für job rotation ist, dass Unternehmen verpflichtet sind, Arbeitsplätze so zu gestalten, dass möglichst wenige Unfälle passieren. Ausserdem kann man sich vorstellen, dass es rufschädigend ist, wenn ein Unternehmen zu viele Krankmeldungen hat. Der Journalist Dieter E. Zimmer hat das erst neulich in einem Zeitungsartikel aufgegriffen.

Gehen wir zum Abschluss zu den Vorteilen des job enrichment. Es zielt auf das Menschenbild des motivierten Werkers ab, der durch die Montagearbeiten gelangweilt und unterfordert ist. Man geht heute davon aus, dass gerade die Werker am besten wissen, wie das Team funktioniert und was organisiert werden muss. Die Teams werden deshalb zunehmend systematisch zur Ideengenerierung aufgefordert. Das ist eine Arbeitsbereicherung im eigentlichen Sinne.

Damit möchte ich schliessen. Ich bedanke mich für Ihre Aufmerksamkeit. 
Version 2: Without Name-Dropping Sequences 
Ich möchte einige zentrale Begrifflichkeiten der Arbeitsorganisation erläutern. Zunächst geht es um die Arbeitsorganisation im Fertigungsbereich. In den letzten Jahren ist es selbstverständlich geworden, dass die Arbeiter, die das Fahrzeug am Fließband zusammenmontieren, in Gruppen organisiert sind. Diese Fertigungsteams bestehen aus 8-12 Werkern. Sie bearbeiten einen bestimmten Fließbandabschnitt gemeinsam und organisieren sich ihr Arbeitsumfeld selbst.

Bei der Arbeitsorganisation im Fertigungsbereich spielen drei Konzepte eine wichtige Rolle: job rotation, job enrichment und job enlargement. Die Klärung dieser Begriffe ist grundlegend für das Verständnis weiterer Punkte der Arbeitsorganisation. Deshalb gehe ich im Folgenden auf alle drei Begriffe ein.

Unter job rotation versteht man das systematische Wechseln der Arbeitsplätze in einem Fertigungsteam. Alle Teammitglieder beherrschen sämtliche Aufgaben innerhalb ihres Fertigungsbereichs und rotieren nach einem bestimmten Schema über die Arbeitsplätze. Häufig übernimmt das Team selbst die Organisation der Rotation. Manche Teams wechseln die Plätze nur in den Pausen, andere im Stundentakt.

Job enlargement bedeutet, dass sich der Aufgabenbereich eines Werkers vergrößert. Dieser Begriff ist stark an den Fertigungsbereich gekoppelt. Die Taktzeiten in der Montage sind sehr gering. Ich denke, dass das so bleiben wird. Der Trend geht eher zu kurzen statt längeren Arbeitseinheiten. Vergrößerung des Tätigkeitsspektrums ergibt sich bei job enlargement schon dadurch, dass ein Werker an mehreren Takten angelernt wird.

Job enrichment bedeutet, dass die neuen Tätigkeiten qualitativ anders sind als die bisherigen. Früher trennte man Kopf- und Handarbeit unter der Prämisse, dass es sich dabei um qualitativ unterschiedliche Arbeiten handelt. Im Fertigungsbereich dominierte lange die Idee, dass so unterschiedliche Aufgaben nur dann optimal ausgeführt werden können, wenn man sie auf verschiedene Personen verteilt. Damit war die starke Rolle des Meisters geboren, der den Werkern die Kopfarbeit abnahm und ihre Tätigkeit auf die reine Montage von Fahrzeugteilen reduzierte.

Durch job enrichment wurde die ursprüngliche Idee der Trennung von Kopf und Hand also aufgehoben. Werker sollen nun, zusätzlich zu ihrer Montagetätigkeit, auch wieder kognitive Aufgaben der Planung und Koordination übernehmen.

Job rotation und job enlargement verfolgen das Ziel, körperliche Belastungen zu verringern, indem Bewegungsabläufe variiert werden. Überkopfarbeit kann schädlich für den Rücken sein, wenn man eine solche Arbeit über mehrere Stunden ausführt. Wenn sich die Teammitglieder abwechseln, reduziert sich diese Gefahr für den einzelnen, Muskulatur und Skelett werden entlastet.

Also: Job enrichment verlangt den Werkern wieder Kopfarbeit ab, was bislang dem Meister überlassen war. Aber wie kann man verlangen, dass ein Werker teilweise diese Aufgaben übernimmt, wo der Meister doch eine ganz 
andere Qualifikation hat als der Werker am Band? Meine Antwort lautet, dass die Werker keine fachlichen Denkaufgaben übernehmen, die ihre Ausbildung übersteigen würde. Es geht vielmehr um organisatorische Tätigkeiten, die bislang der Meister übernommen hat.

Außerdem kommen Tätigkeiten hinzu, die bislang anderen Bereichen übertragen waren. Insbesondere bei der Instandhaltung von Maschinen geht man davon aus, dass die Werker ihre Maschinen sehr gut kennen, so dass sie auch ohne eine entsprechende Ausbildung kleine Reparaturen selbst vornehmen können.

Ich möchte jetzt zu den erhofften Vorteilen kommen. Einige haben wir bereits aufgegriffen: Job enlargement in Form von job rotation, verteilt die körperliche Belastung auf mehrere Schultern. Das verringert die Anzahl von Krankmeldungen und Ausfällen. Damit reduzieren sich auch die Kosten, die einem Betrieb durch Krankmeldungen entstehen. Fällt ein Teammitglied aus, können die anderen den Kollegen rein quantitativ nicht auffangen. Die Takte sind zu kurz, und personaler Puffer ist nicht eingeplant. Dann müssen Leiharbeiter eingestellt, bezahlt und eingelernt werden.

Ein weiterer Grund für job rotation ist, dass Unternehmen verpflichtet sind, Arbeitsplätze so zu gestalten, dass möglichst wenige Unfälle passieren. Ausserdem kann man sich vorstellen, dass es rufschädigend ist, wenn ein Unternehmen zu viele Krankmeldungen hat.

Gehen wir zum Abschluss zu den Vorteilen des job enrichment. Es zielt auf das Menschenbild des motivierten Werkers ab, der durch die Montagearbeiten gelangweilt und unterfordert ist. Man geht heute davon aus, dass gerade die Werker am besten wissen, wie das Team funktioniert und was organisiert werden muss. Die Teams werden deshalb zunehmend systematisch zur Ideengenerierung aufgefordert. Das ist eine Arbeitsbereicherung im eigentlichen Sinne.

Damit möchte ich schliessen. Ich bedanke mich für Ihre Aufmerksamkeit. 
6.1.3 Appendix C-1: Manipulation Check Questionnaire Study 1 


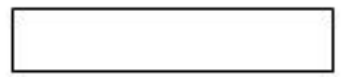

Im zweiten Teil des Fragebogens wollen wir wissen, wie Sie den Vortrag wahrgenommen haben. Auch hier interessieren uns Ihre persönlichen Eindrücke und Vermutungen. Bitte versuchen Sie, sich zu jeder Aussage eine Meinung zu bilden, auch wenn das manchmal schwierig ist.

Der Dozent erläutert sehr präzise.

$\begin{array}{ccccccl}1 & 2 & 3 & 4 & 5 & 6 & 7 \\ \begin{array}{l}\text { trifft gar } \\ \text { nicht zu }\end{array} & & & & & & \begin{array}{l}7 \text { trifft } \\ \text { völlig zu }\end{array}\end{array}$

Der Dozent kennt die Lehrtätigkeit seiner Kollegen genau.

$\begin{array}{rllllll}\begin{array}{rllll}1 \\ \text { trifft gar }\end{array} & 2 & 3 & 4 & 5 & 6 & 7 \\ \text { nicht zu } & & & & & & \text { trifft } \\ \text { völlig zu }\end{array}$

\begin{tabular}{|c|c|c|c|c|c|c|}
\hline Der Vortrag ist langweil & & & & & & \\
\hline $\begin{array}{l}1 \\
\text { trifft gar } \\
\text { nicht zu }\end{array}$ & 2 & 3 & 4 & 5 & 6 & $\begin{array}{l}7 \\
\text { trifitt } \\
\text { völlig zu }\end{array}$ \\
\hline
\end{tabular}

Der Dozent zitiert Autoren und Publikationen.

$\begin{array}{rllllll}1 & 2 & 3 & 4 & 5 & 6 & 7 \\ \text { trifft gar } & & & & & & \text { trifft } \\ \text { nicht zu } & & & & & & \\ \text { völlig zu }\end{array}$

Es gab Stellen im Vortrag, die ich nicht verstanden habe.

$\begin{array}{rllllll}\begin{array}{rllll}1 \\ \text { trifft gar }\end{array} & 2 & 3 & 4 & 5 & 6 & 7 \\ \text { nicht zu } & & & & & & \text { trifft } \\ \text { völlig zu }\end{array}$

Der Dozent kennt seine Forscherkollegen und deren Projekte genau.

$\begin{array}{rllllll}1 & 2 & 3 & 4 & 5 & 6 & 7 \\ \begin{array}{l}\text { trifft gar } \\ \text { nicht zu }\end{array} & & & & & & \begin{array}{l}7 \\ \text { trifft } \\ \text { vollig zu }\end{array}\end{array}$


Ich habe sehr darauf geachtet, wie gut der Dozent Wissen vermittelt.

\begin{tabular}{|c|c|c|c|c|c|c|}
\hline $\begin{array}{r}1 \\
\text { trifft gar } \\
\text { nicht zu }\end{array}$ & 2 & 3 & 4 & 5 & 6 & $\begin{array}{l}7 \\
\text { trifft } \\
\text { völlig zu }\end{array}$ \\
\hline
\end{tabular}

Der Dozent beschreibt Beispiele aus der Praxis.

$\begin{array}{rllllll}1 & 2 & 3 & 4 & 5 & 6 & \begin{array}{l}7 \\ \text { trifft } \\ \text { vifft gar } \\ \text { nicht zu }\end{array} \\ \text { vollig zu }\end{array}$

Ich habe mich bemüht, die Inhalte des Vortrags zu verstehen.

$\begin{array}{rllllll}1 & 2 & 3 & 4 & 5 & 6 & 7 \\ \text { trifft gar } & & & & & & \text { trifit } \\ \text { nicht zu } & & & & & & \\ \text { völlig zu }\end{array}$

Der Dozent kommt nie vom Thema ab.

$\begin{array}{rllllll}1 & 2 & 3 & 4 & 5 & 6 & \begin{array}{l}7 \\ \text { trifft gar } \\ \text { nicht zu }\end{array}\end{array}$

Ich habe sehr darauf geachtet, wie gut der Dozent Forschung vorstellt.

$\begin{array}{rllllll}1 & 2 & 3 & 4 & 5 & 6 & 7 \\ \begin{aligned} \text { trifft gar } \\ \text { nicht zu }\end{aligned} & & & & & & \text { trifft } \\ \text { völlig zu }\end{array}$

Die Formulierungen des Dozenten sind eindeutig und exakt.

$\begin{array}{rllllll}1 & 2 & 3 & 4 & 5 & 6 & 7 \\ \text { trifft gar } & & & & & & \text { trifft } \\ \text { nicht zu } & & & & & & \\ \text { völlig zu }\end{array}$

\section{Bitte wählen Sie eine der beiden Optionen: \\ Beim Zuhören habe ich stärker darauf geachtet,... \\ $\square$... wie der Dozent erklärt und Wissen vermittelt. \\ $\square$... wie der Dozent Forschung vorstellt.}


Beim Zuhören sind meine Gedanken von Zeit zu Zeit abgeschweift.

$\begin{array}{rlllllll}\begin{array}{rllll}1 \\ \text { trifft gar } \\ \text { nicht zu }\end{array} & 2 & 3 & 4 & 5 & 6 & \begin{array}{l}7 \\ \text { trifft } \\ \text { völlig zu }\end{array}\end{array}$

Der Dozent nimmt Bezug auf das aktuelle Zeitgeschehen.

$\begin{array}{lllllll}1 & 2 & 3 & 4 & 5 & 6 & 7 \\ \text { trifft gar } & & & & & & \begin{array}{l}\text { triffit } \\ \text { vicht zullig zu }\end{array}\end{array}$

Ich habe die Unterschiede zwischen Jab enlargement, Job enrichment und Jab rotation verstanden.

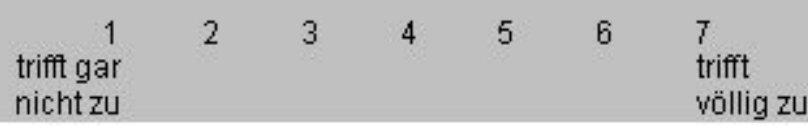

Bitte versuchen Sie sich zu erinnern, wie wir Ihnen den Vortrag angekündigt hatten. Wählen Sie eine der beiden Optionen:

Der Vortrag des Dozenten war als Lehrvortrag angekündigt.

$\square$ Der Vortrag des Dozenten war als Forschungswortrag angekündigt.

Bitte schliessen Sie diese Mappe und öfnen Sie Mappe 3! 
6.1.4 Appendix C-2: Manipulation Check Questionnaire Study 2 


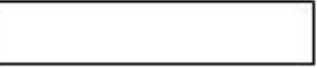

Im zweiten Teil des Fragebogens wollen wir wissen, wie Sie den Vortrag wahrgenommen haben. Auch hier interessieren uns Ihre persönlichen Eindrücke und Vermutungen. Bitte versuchen Sie, sich zu jeder Aussage eine Meinung zu bilden, auch wenn das manchmal schwierig ist.

Der Dozent erläutert sehr präzise.

$\begin{array}{llllllll}\begin{array}{l}\text { trifft gar } \\ \text { nicht zu }\end{array} & 2 & 3 & 4 & 5 & 6 & \begin{array}{l}7 \\ \text { trifft } \\ \text { völlig zu }\end{array}\end{array}$

Der Dozent kennt die Lehrtätigkeit seiner Kollegen genau.

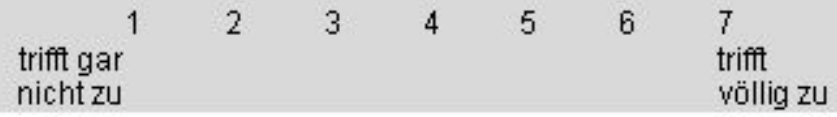

Der Vortrag ist langweilig.

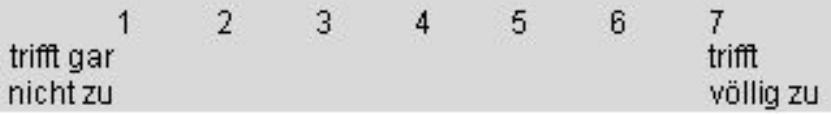

Der Dozent zitiert andere Forscher.

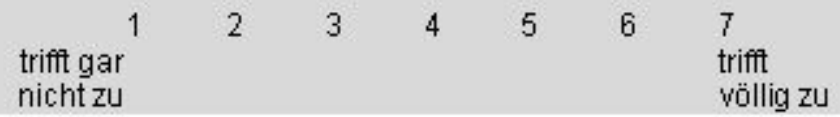

Es gab Stellen im Vortrag, die ich nicht verstanden habe.

\begin{tabular}{|c|c|c|c|c|c|}
\hline triftt gar ${ }^{1}$ & 2 & 3 & 4 & 5 & 6 \\
\hline
\end{tabular}

Der Dozent kennt seine Forscherkollegen und deren Projekte genau.

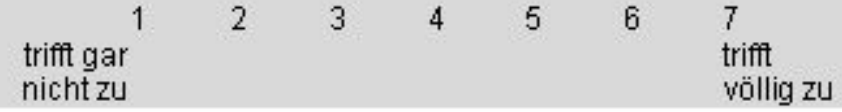


Der Dozent beschreibt Beispiele aus der Praxis.

$\begin{array}{lllllll}\begin{array}{l}\text { trifft gar } \\ \text { nicht zu }\end{array} & 2 & 3 & 4 & 5 & 6 & \begin{array}{l}7 \\ \text { trifft } \\ \text { völlig zu }\end{array}\end{array}$

Ich habe mich bemüht, die Inhalte des Vortrags zu verstehen.

$\begin{array}{llllllll}\begin{array}{l}\text { trifft gar } \\ \text { nicht zu }\end{array} & 2 & 3 & 4 & 5 & 6 & \begin{array}{l}7 \\ \text { trifft } \\ \text { völlig zu }\end{array}\end{array}$

Der Dozent kommt nie vom Thema ab.

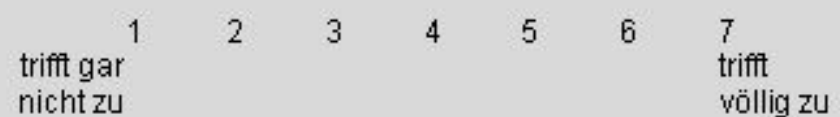

Die Formulierungen des Dozenten sind eindeutig und exakt.

$\begin{array}{lllllll}\begin{array}{l}\text { trifft gar } \\ \text { nicht zu }\end{array} & 2 & 3 & 4 & 5 & 6 & \begin{array}{l}7 \\ \text { trifft } \\ \text { völlig zu }\end{array}\end{array}$

Bitte wählen Sie eine der beiden Optionen:

Beim Zuhören habe ich stärker darauf geachtet, ...

$\square$... wie gut der Dozent erklären und Wissen vermitteln kann.

$\square$... was der Dozent zum Thema zu sagen hat.

Beim Zuhören sind meine Gedanken von Zeit zu Zeit abgeschweift.

$\begin{array}{llllllll}\begin{array}{l}\text { trifft gar } \\ \text { nicht zu }\end{array} & 2 & 3 & 4 & 5 & 6 & \begin{array}{l}7 \\ \text { trifft } \\ \text { völlig zu }\end{array} \\ & & & & & & & \end{array}$

Der Dozent erwähnt Artikel aus Tageszeitungen.

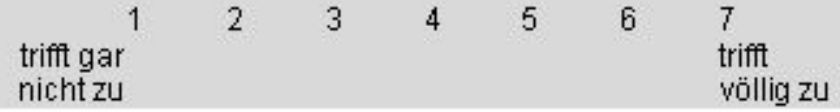


Ich habe die Unterschiede zwischen Jab enlargement, Job enrichment und Jab rotation verstanden.

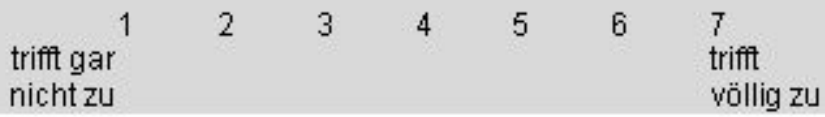

Der Dozent erwähnt die Lehrbücher seiner Kollegen.

$\begin{array}{llllllll} & 1 & 2 & 3 & 4 & 5 & 6 & 7 \\ \begin{array}{l}\text { trifft gar } \\ \text { nicht } z u\end{array} & & & & & & \text { trifft } \\ \text { völlig zu }\end{array}$

Während des Vortrags war meine Motivation zuzuhören sehr hoch.

$\begin{array}{lllllll}\text { trifft gar }_{\text {nicht zu }} & 2 & 3 & 4 & 5 & 6 & \begin{array}{l}7 \\ \text { trifft } \\ \text { völlig zu }\end{array}\end{array}$

Der Dozent nimmt Bezug auf das aktuelle Zeitgeschehen.

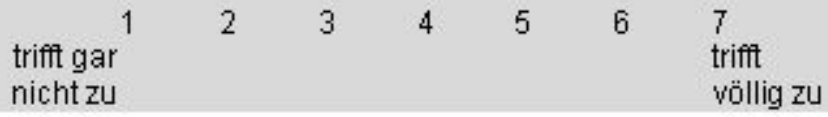

Hat Sie am Vortrag etwas gestört oder ist Ihnen etwas besonders negativ aufgefallen?

Bitte schließen Sie diese Mappe und öffnen Sie Mappe 3! 
6.1.5 Appendix C-3: Manipulation Check Questionnaire Study 3 


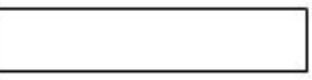

Im zweiten Teil des Fragebogens wollen wir wissen, wie Sie den Vortrag wahrgenommen haben. Auch hier interessieren uns lhre persönlichen Eindrücke und Vermutungen. Bitte versuchen Sie, sich zu jeder Aussage eine Meinung zu bilden, auch wenn das manchmal schwierig ist.

Der Dozent erläutert sehr präzise.

$\begin{array}{lllllll}1 & 2 & 3 & 4 & 5 & 6 & 7 \\ \text { trifft nicht zu } & & & & & & \text { trifft zu }\end{array}$

Der Dozent kennt die Lehrtätigkeit seiner Kollegen genau.

\begin{tabular}{|c|c|}
\hline iffit nicht zu & 2 \\
\hline
\end{tabular}

Der Vortrag ist langweilig.

$\begin{array}{ccccccc}\begin{array}{r}1 \\ \text { triffit nicht zu }\end{array} & 2 & 3 & 4 & 5 & 6 & 7_{\text {trifft zu }}\end{array}$

Der Dozent zitiert andere Forscher..

$\begin{array}{ccccccc}{ }_{\text {trifft nicht }}^{1} & 2 & 3 & 4 & 5 & 6 & 7_{\text {trifft zu }}\end{array}$

Es gab Stellen im Vortrag, die ich nicht verstanden habe.

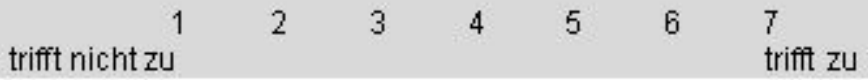

Der Dozent kennt seine Forscherkollegen und deren Projekte genau.

$\begin{array}{rrrrrrr}1 & 2 & 3 & 4 & 5 & 6 & 7 \\ \text { trifft nicht zu } & & & & & & \text { trifft zu }\end{array}$

Der Dozent beschreibt Beispiele aus der Praxis.

$\begin{array}{ccccccc}\begin{array}{r}1 \\ \text { trifft nicht zu }\end{array} & 2 & 3 & 4 & 5 & 6 & 7 \\ \text { trifft zu }\end{array}$


Ich habe mich bemüht, die Inhalte des Vortrags zu verstehen.

$\begin{array}{rllllll}1 & 2 & 3 & 4 & 5 & 6 & 7 \\ \text { triffit nicht zu } & & & & & & \text { trifft zu }\end{array}$

Der Dozent kommt nie vom Thema ab.

$\begin{array}{ccccccc}\begin{array}{r}1 \\ \text { trifft nicht zu }\end{array} & 2 & 3 & 4 & 5 & 6 & 7 \\ \text { trifft zu }\end{array}$

Die Formulierungen des Dozenten sind eindeutig und exakt.

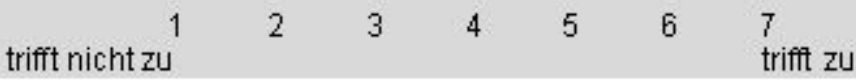

Bitte wählen Sie eine der beiden Optionen:

Beim Zuhören habe ich stärker darauf geachtet, ...

$\square$... wie gut der Dozent erklären und Wissen vermitteln kann.

$\square$... was der Dozent zum Thema zu sagen hat.

Beim Zuhören sind meine Gedanken von Zeit zu Zeit abgeschweift.

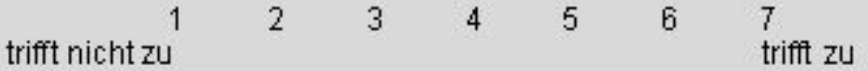

Der Dozent erwähnt Artikel aus Tageszeitungen.

$\begin{array}{rllllll}1 & 2 & 3 & 4 & 5 & 6 & 7 \\ \text { trifft nicht zu } & & & & & & \text { trifft zu }\end{array}$

Ich habe die Unterschiede zwischen Jab enlargement, Job enrichment und Jab rotation verstanden.

$\begin{array}{rrrrrrr}1 & 2 & 3 & 4 & 5 & 6 & 7 \\ \text { trifft nicht zu } & & & & & & \text { trifft zu }\end{array}$

Der Dozent erwähnt die Lehrbücher seiner Kollegen.

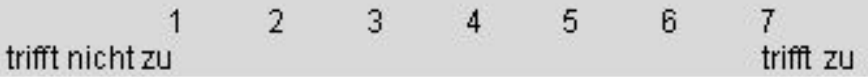


Während des Vortrags war meine Motivation zuzuhören sehr hoch.

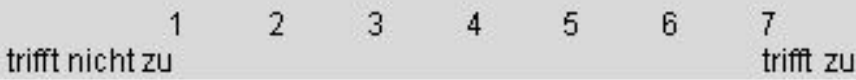

Der Dozent nimmt Bezug auf das aktuelle Zeitgeschehen.

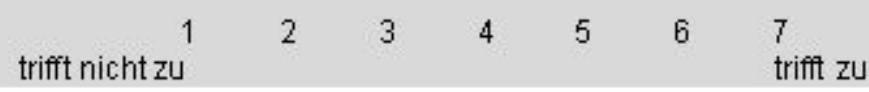

Hat Sie am Vortrag etwas gestört oder ist Ihnen etwas besonders negativ aufgefallen?

Bitte schließen Sie diese Mappe und öffnen Sie Mappe 3! 
6.1.6 Appendix D-1: Instruction Study 2 
Liebe Teilnehmerin, lieber Teilnehmer,

zunächst vielen Dank für Ihre Bereitschaft, an unserer Untersuchung teilzunehmen!

Wir beschäftigen uns damit, wie Studierende die Qualität von Veranstaltungen beurteilen. Sie hören nun einen ca. siebenminütigen nachgestellten Auszug aus einem

\section{Vortrag}

zum Thema „Zentrale Konzepte der Arbeitsorganisation“. Ziel des Vortrags ist es, dass der Dozent den Zuhörern zentrale Konzepte zum Thema Arbeitsorganisation vorstellt.

Wenn die Aufnahme beendet ist, werden Sie aufgefordert, die Kopfhörer abzunehmen und den Fragebogen auszufüllen, der, verteilt auf verschiedene Mappen, vor Ihnen liegt. Bitte öffnen Sie die Mappen nicht vorher! Beginnen Sie mit Mappe 1 und öffnen Sie Mappe 2 erst, wenn Sie alle Fragen aus Mappe 1 bearbeitet haben. Schließen Sie bearbeitete Mappen und legen Sie sie beiseite.

Sie haben ausreichend Zeit, die Fragen zu beantworten. Die Zeitplanung ist wie folgt:

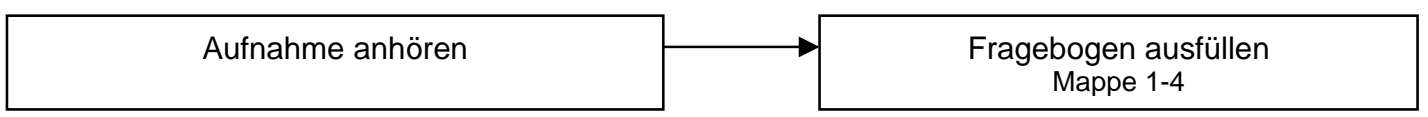

ca. 7 Minuten

ca. 20 Minuten

Bitte setzen Sie nun die Kopfhörer auf und starten Sie die Aufnahme! 
6.1.7 Appendix E-1: Pretest Questionnaire Study 3 


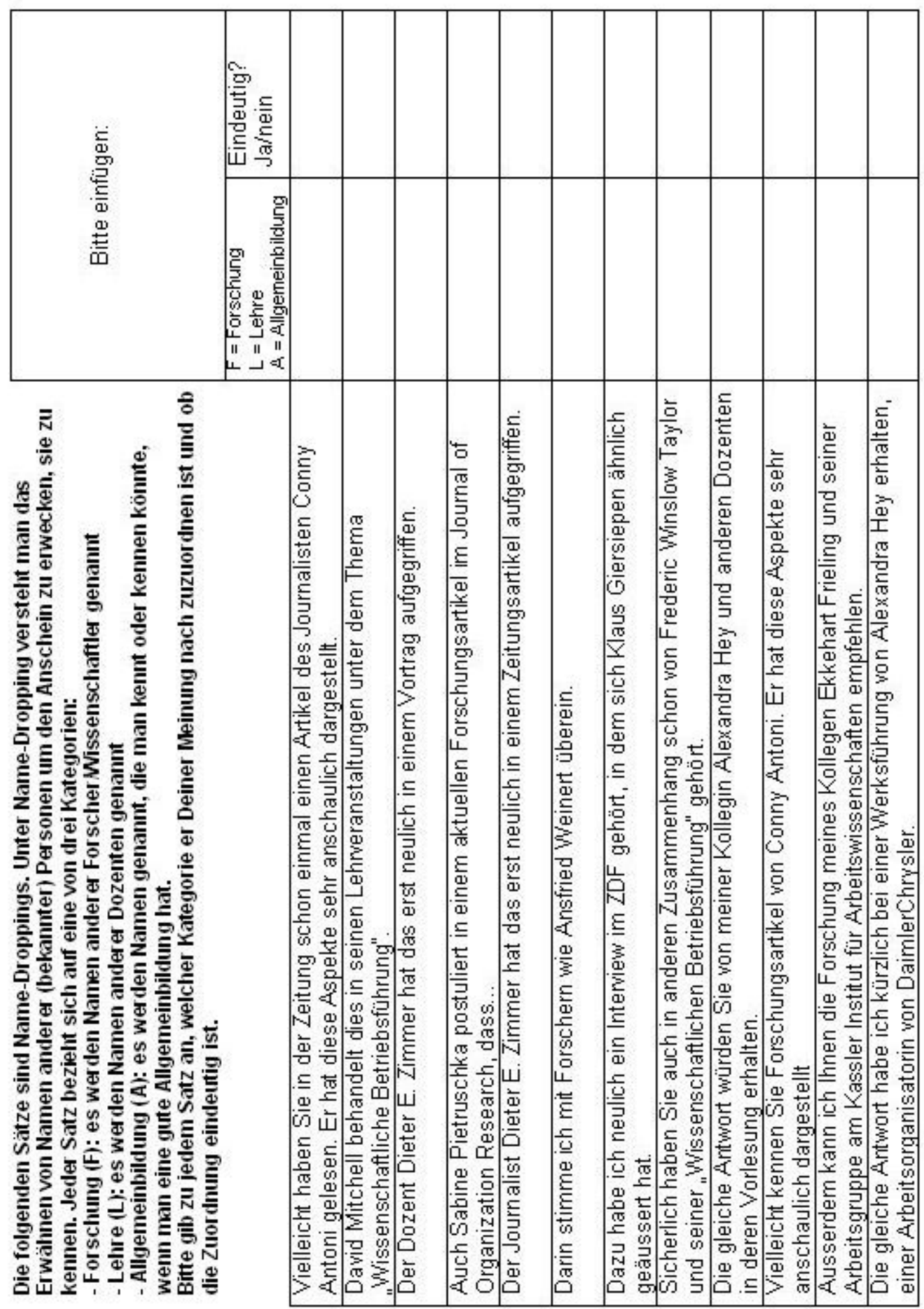




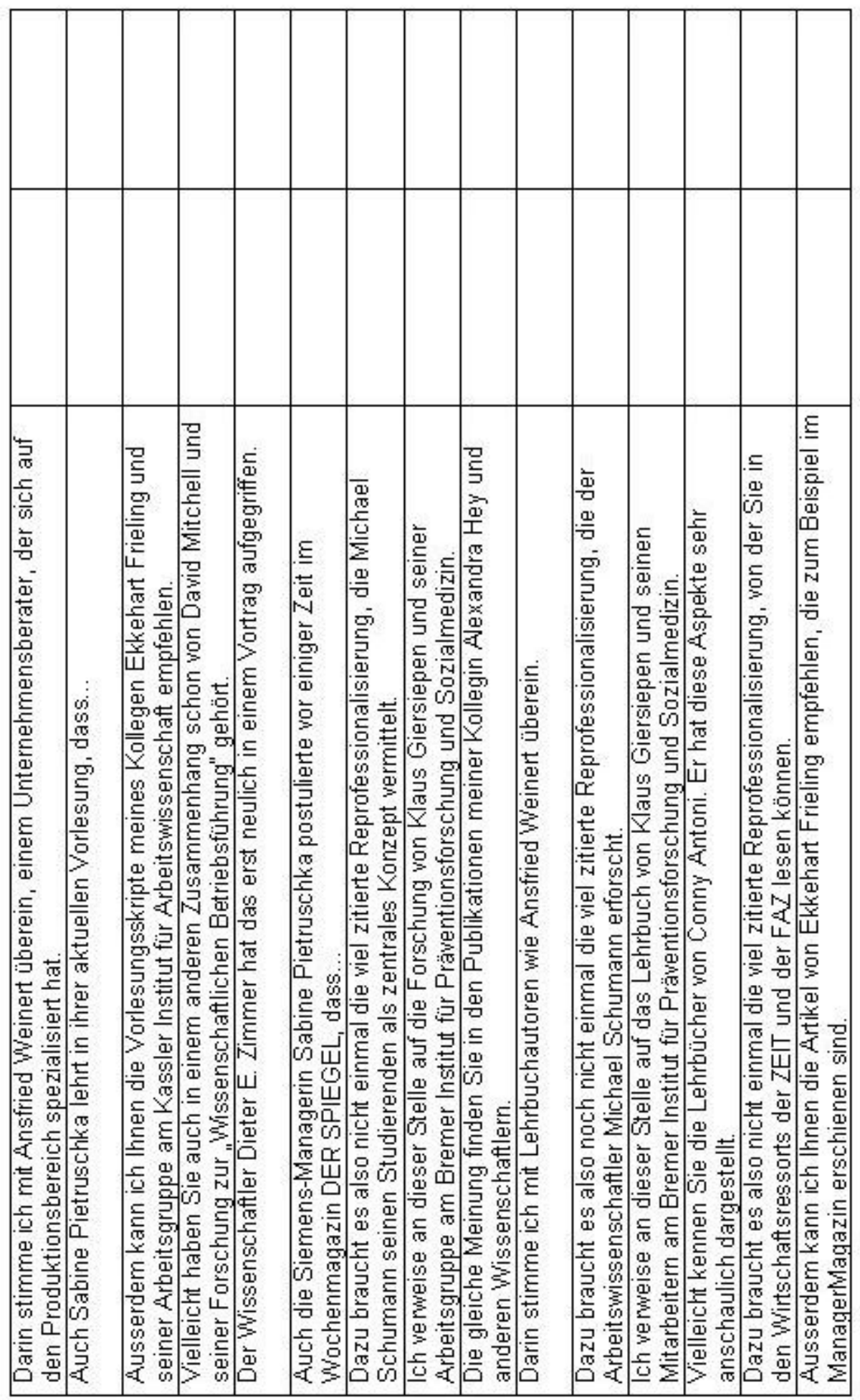


6.2 Appendix to Lebherz, C., \& Tomljenovic, B: Two Applications of Name-Dropping in First Encounters: Job Interview and GetAcquainted Conversation 
6.2.1 Appendix F-1: Transcript of Name-Dropping Manipulation on Video Tape (Four Versions) 
Version 1: With Name-Dropping Sequences and BIRG Sequence 
I: Hoi Stefan, danke für's Kommen.

B: Hoi Ruedi.

I: Du interessierst Dich also für die Stelle als Fundraiser für die „Tri-Bühne“. Der Vereinsvorstand hat beschlossen, dass unser Fundraising besser werden muss und deshalb diese Stelle geschaffen werden soll. Wir brauchen einen Profi auf dem Gebiet, weil keiner von uns Schauspielern das wirklich gut kann.

Ja, also, ich dachte, ich stelle Dir einfach ein paar Fragen: zu Dir und Deinen Erfahrungen, die für die Stelle wichtig sein könnten. Ist das gut?

B: Tiptop.

I: Hast Du in einem Praktikum oder in einem Job mal mit Fundraising, Kultursponsoring oder Marketing zu tun gehabt?

B: Ja, das Praktikum bei der UBS, das war im Marketing, da war ich im Hochschulmarketing tätig. Ich habe die Angebote für Praktika, Lizarbeiten und so ins richtige Layout gebracht und mich darum gekümmert, dass sie an den Lehrstühlen ausgehängt werden, also z.B. wenn wir einen Praktikanten im Controlling gebraucht haben, dann habe ich die Uni-Profs angemailt, z.B. Prof. Welti oder Prof. Baumberger, und innen die Aushänge geschickt. Und ich war auch auf einer Polymesse dabei, da haben mein Chef Beat Brunner und ich mit einem Messestand zwei Tage lang Mathe- und InformatikStudenten der ETH angeworben.

I: Okay, hmhm, Hochschulmarketing ist sicherlich nicht ganz so wie Fundraising, aber schon verwandt, man muss sein Unternehmen gut vertreten, Projekte vorstellen, Werbung machen und so. Ja, hast Du sonst noch einschlägige Erfahrung, vielleicht im Marketing, in der Werbung? Du studierst BWL, richtig? 
B: Ja, mit Schwerpunkt Marketing, vor allem am Lehrstuhl von Prof. Holzherr. Also, in der Werbung war ich noch nicht. Ich hab aber ein Jahr in Australien studiert, an der University of Sydney, und war da an einem Lehrstuhl für Marketing. Die Leute um den Prof, Professor Kozlowski (sprich: „Koslowski“), haben ein Projekt mit Werbefirmen gehabt, da hab ich mitgearbeitet. Ich habe die Fragebogen an die Firmen verteilt und organisiert, dass die ausgefüllten Fragebogen zurückgeschickt werden. Ich hab damals viel von meinen beiden Betreuern gelernt, vor allem von Richard Clark, über Kontakte zu Unternehmen, wie man seine Deadline durchsetzt ohne unhöflich zu werden, solche Sachen.

I: Aha, okay, das ist gut. Weil, wir haben ständig mit Unternehmen zu tun, und da braucht es viel Geduld und auch Frustrationstoleranz. Manchmal muss man sie mehrfach anschreiben oder anrufen, bis sich was tut, und wir wollen was von denen, nicht umgekehrt. Da muss man immer höflich bleiben, darf nicht aufgeben.

I: Der Name Kozlowski sagt mir was, das ist doch einer der ganz grossen in Sachen Marktforschung, oder? Ein Kumpel von mir macht auch Marketing, der hat sowas gesagt.

B: Ja, Bill Kozlowski ist ganz vorn mit dabei.

I: Hast Du ihn persönlich kennengelernt oder mal mit ihm gearbeitet?

$\mathrm{B}$ : Ja, klar, hab ich, in Australien ist das sowieso ungezwungener, mein Büro war auf dem gleichen Stockwerk wie seines, und meine beiden Betreuer waren bei ihm angestellt, es ist quasi sein Projekt gewesen.

I: Cool.

B: Hm. 
B: Ja, und wegen Nachhaken und so, das habe ich damals wirklich gelernt, weil, die Uni (in der Namedropping-Version steht statt „die Uni“ Richard und Tim, statt „hatte“ hatten und statt „wollte“ wollten) hatte das Projekt und wollte was von den Werbeleuten, und da war es ganz ähnlich: erst Akzeptanz schaffen, dann gut organisieren und keine Fragen offen lassen, immer wieder informieren, und wenn die Fragebogen nicht zurückkamen oder nicht viele, dann musste ich mir gut überlegen, wann ich jemanden in der Firma anrufe und nachfrage, und wen am besten.

$\mathrm{I}:$ Ja, Deine Erfahrung in der Wirtschaft, auch mit verschiedenen Unternehmen, das ist sicherlich gut, das würde helfen. Du hast aber keine direkte Erfahrung mit Fundraising, oder?

B: Nein.

I: Mit Kultursponsoring auch nicht?

B: Nein, leider nicht.

I: Wie würdest Du denn auf mögliche Sponsoren zugehen, was wäre Deine erste Strategie?

B: Also, ich würde erstmal die Kontakte in Unternehmen nutzen, die ich schon habe und versuchen, über die dann an die richtigen Ansprechpartner zu kommen, z.B. über Dr. Brunner oder den Abteilungsleiter der Oeffentlichkeitsarbeit, Damian Rohner. Ich hätte sicherlich keine Hemmungen, meine Connections auszuspielen. Und dann ist die Frage, ob es Stiftungen gibt, die Theater fördern.

I: Hmhm, genau.

I: Zu den Aufgaben des Fundraisers gehört auch viel Schriftliches:

Projektbeschreibungen für die Unternehmen, damit sie wissen, was sie 
sponsern sollen, Anträge für Gelder der öffentlichen Hand schreiben... Würdest Du von Dir selbst sagen, dass Du so was gut machen kannst?

$\mathrm{B}$ : Ja, ich denk schon. Was Formulierungen und Anschreiben angeht, bin ich durch meinen Job als Semesterassistenz geübt. Ich hatte am MarketingLehrstuhl die Vertretung für das Sekretariat von Prof. Holzherr gemacht, weil eine Sekretärin gekündigt hatte und es zwei Monate gedauert hat, bis die Stelle wieder besetzt war. Ich hab in der Zeit die Post und die Emails gesichtet und, soweit ich konnte, beantwortet, viele Briefe geschrieben, auch Sammelbriefe an die Studenten, und Prüfungstermine und Zeugnisse verschickt. Doch, ich denke, dass ich das gut kann.

I: Du hast als Hobbies unter anderem Kino und Theater angegeben. Kennst Du Dich in der Theaterlandschaft hier aus, gehst Du oft ins Theater?

B: Ja, also, ich hab meine Lieblingsstücke, vor allem mag ich Klassiker. Ja, ich bin schon recht regelmässig im Theater. In den letzten Monaten wurden einige Shakespeare-Stücke aufgeführt, z.B. Richard II. Gut gefallen haben mir auch die Tschechov-Inszenierungen letztes Jahr, „Die Möwe“ und die „Drei Schwestern“. Die fand ich beide sehr gelungen. Bei Euch in der TriBühne war „Leonce und Lena“ gut, wirklich sehr gut, ich war zweimal drin.

I: Hat's Dich nie gereizt, selbst mal zu schauspielern?

B: Nee, dafür wär' ich nicht begabt, das kommt nicht gut! Aber ich würd mich freuen, wenn ich über die Stelle ein bisschen hinter die Kulissen schauen könnte. Ich glaube, dass ich gut darin wäre, das Produkt zu vermarkten, sozusagen, Werbung zu machen und nach aussen zu repräsentieren. Ich mein, ich steh halt voll hinter dem Produkt, den Aufführungen, find's lässig, und wenn man davon überzeugt ist, kann man es auch anderen schmackhaft machen.

I: Ja, das stimmt, das kann ich mir auch gut vorstellen. 
Okay, dann würde ich sagen, wir bleiben in Kontakt und ich meld mich, wenn wir alle Bewerber da hatten und unsere Entscheidung gefallen ist. Ist das gut?

B: Ja, klar. Wär lässig, wenn's klappen würde! 
Version 2: With Name-Dropping Sequences without BIRG Sequence 
I: Hoi Stefan, danke für's Kommen.

B: Hoi Ruedi.

I: Du interessierst Dich also für die Stelle als Fundraiser für die „Tri-Bühne“. Der Vereinsvorstand hat beschlossen, dass unser Fundraising besser werden muss und deshalb diese Stelle geschaffen werden soll. Wir brauchen einen Profi auf dem Gebiet, weil keiner von uns Schauspielern das wirklich gut kann.

Ja, also, ich dachte, ich stelle Dir einfach ein paar Fragen: zu Dir und Deinen Erfahrungen, die für die Stelle wichtig sein könnten. Ist das gut?

B: Tiptop.

I: Hast Du in einem Praktikum oder in einem Job mal mit Fundraising, Kultursponsoring oder Marketing zu tun gehabt?

B: Ja, das Praktikum bei der UBS, das war im Marketing, da war ich im Hochschulmarketing tätig. Ich habe die Angebote für Praktika, Lizarbeiten und so ins richtige Layout gebracht und mich darum gekümmert, dass sie an den Lehrstühlen ausgehängt werden, also z.B. wenn wir einen Praktikanten im Controlling gebraucht haben, dann habe ich die Uni-Profs angemailt, z.B. Prof. Welti oder Prof. Baumberger, und innen die Aushänge geschickt. Und ich war auch auf einer Polymesse dabei, da haben mein Chef Beat Brunner und ich mit einem Messestand zwei Tage lang Mathe- und InformatikStudenten der ETH angeworben.

I: Okay, hmhm, Hochschulmarketing ist sicherlich nicht ganz so wie Fundraising, aber schon verwandt, man muss sein Unternehmen gut vertreten, Projekte vorstellen, Werbung machen und so. Ja, hast Du sonst noch einschlägige Erfahrung, vielleicht im Marketing, in der Werbung? Du studierst BWL, richtig? 
B: Ja, mit Schwerpunkt Marketing, vor allem am Lehrstuhl von Prof. Holzherr. Also, in der Werbung war ich noch nicht. Ich hab aber ein Jahr in Australien studiert, an der University of Sydney, und war da an einem Lehrstuhl für Marketing. Die Leute um den Prof, Professor Kozlowski (sprich: „Koslowski“), haben ein Projekt mit Werbefirmen gehabt, da hab ich mitgearbeitet. Ich habe die Fragebogen an die Firmen verteilt und organisiert, dass die ausgefüllten Fragebogen zurückgeschickt werden. Ich hab damals viel von meinen beiden Betreuern gelernt, vor allem von Richard Clark, über Kontakte zu Unternehmen, wie man seine Deadline durchsetzt ohne unhöflich zu werden, solche Sachen.

I: Aha, okay, das ist gut. Weil, wir haben ständig mit Unternehmen zu tun, und da braucht es viel Geduld und auch Frustrationstoleranz. Manchmal muss man sie mehrfach anschreiben oder anrufen, bis sich was tut, und wir wollen was von denen, nicht umgekehrt. Da muss man immer höflich bleiben, darf nicht aufgeben.

B: Ja, und wegen Nachhaken und so, das habe ich damals wirklich gelernt, weil, die Uni (in der Namedropping-Version steht statt "die Uni“ Richard und Tim, statt "hatte" hatten und statt "wollte" wollten) hatte das Projekt und wollte was von den Werbeleuten, und da war es ganz ähnlich: erst Akzeptanz schaffen, dann gut organisieren und keine Fragen offen lassen, immer wieder informieren, und wenn die Fragebogen nicht zurückkamen oder nicht viele, dann musste ich mir gut überlegen, wann ich jemanden in der Firma anrufe und nachfrage, und wen am besten.

I: Ja, Deine Erfahrung in der Wirtschaft, auch mit verschiedenen Unternehmen, das ist sicherlich gut, das würde helfen. Du hast aber keine direkte Erfahrung mit Fundraising, oder?

B: Nein.

I: Mit Kultursponsoring auch nicht? 
B: Nein, leider nicht.

I: Wie würdest Du denn auf mögliche Sponsoren zugehen, was wäre Deine erste Strategie?

B: Also, ich würde erstmal die Kontakte in Unternehmen nutzen, die ich schon habe und versuchen, über die dann an die richtigen Ansprechpartner zu kommen, z.B. über Dr. Brunner oder den Abteilungsleiter der Oeffentlichkeitsarbeit, Damian Rohner. Ich hätte sicherlich keine Hemmungen, meine Connections auszuspielen. Und dann ist die Frage, ob es Stiftungen gibt, die Theater fördern.

I: Hmhm, genau.

I: Zu den Aufgaben des Fundraisers gehört auch viel Schriftliches: Projektbeschreibungen für die Unternehmen, damit sie wissen, was sie sponsern sollen, Anträge für Gelder der öffentlichen Hand schreiben... Würdest Du von Dir selbst sagen, dass Du so was gut machen kannst?

B: Ja, ich denk schon. Was Formulierungen und Anschreiben angeht, bin ich durch meinen Job als Semesterassistenz geübt. Ich hatte am MarketingLehrstuhl die Vertretung für das Sekretariat von Prof. Holzherr gemacht, weil eine Sekretärin gekündigt hatte und es zwei Monate gedauert hat, bis die Stelle wieder besetzt war. Ich hab in der Zeit die Post und die Emails gesichtet und, soweit ich konnte, beantwortet, viele Briefe geschrieben, auch Sammelbriefe an die Studenten, und Prüfungstermine und Zeugnisse verschickt. Doch, ich denke, dass ich das gut kann.

I: Du hast als Hobbies unter anderem Kino und Theater angegeben. Kennst Du Dich in der Theaterlandschaft hier aus, gehst Du oft ins Theater?

B: Ja, also, ich hab meine Lieblingsstücke, vor allem mag ich Klassiker. Ja, ich bin schon recht regelmässig im Theater. In den letzten Monaten wurden 
einige Shakespeare-Stücke aufgeführt, z.B. Richard II. Gut gefallen haben mir auch die Tschechov-Inszenierungen letztes Jahr, „Die Möwe“ und die „Drei Schwestern“. Die fand ich beide sehr gelungen. Bei Euch in der TriBühne war „Leonce und Lena“ gut, wirklich sehr gut, ich war zweimal drin.

I: Hat's Dich nie gereizt, selbst mal zu schauspielern?

B: Nee, dafür wär' ich nicht begabt, das kommt nicht gut! Aber ich würd mich freuen, wenn ich über die Stelle ein bisschen hinter die Kulissen schauen könnte. Ich glaube, dass ich gut darin wäre, das Produkt zu vermarkten, sozusagen, Werbung zu machen und nach aussen zu repräsentieren. Ich mein, ich steh halt voll hinter dem Produkt, den Aufführungen, find's lässig, und wenn man davon überzeugt ist, kann man es auch anderen schmackhaft machen.

I: Ja, das stimmt, das kann ich mir auch gut vorstellen.

Okay, dann würde ich sagen, wir bleiben in Kontakt und ich meld mich, wenn wir alle Bewerber da hatten und unsere Entscheidung gefallen ist. Ist das gut?

B: Ja, klar. Wär lässig, wenn's klappen würde! 
Version 3: Without Name-Dropping Sequences with BIRG Sequence 
I: Hoi Stefan, danke für's Kommen.

B: Hoi Ruedi.

I: Du interessierst Dich also für die Stelle als Fundraiser für die „Tri-Bühne“.

Der Vereinsvorstand hat beschlossen, dass unser Fundraising besser

werden muss und deshalb diese Stelle geschaffen werden soll. Wir brauchen einen Profi auf dem Gebiet, weil keiner von uns Schauspielern das wirklich gut kann.

Ja, also, ich dachte, ich stelle Dir einfach ein paar Fragen: zu Dir und Deinen Erfahrungen, die für die Stelle wichtig sein könnten. Ist das gut?

B: Tiptop.

I: Hast Du in einem Praktikum oder in einem Job mal mit Fundraising, Kultursponsoring oder Marketing zu tun gehabt?

B: Ja, das Praktikum bei der UBS, das war im Marketing, da war ich im Hochschulmarketing tätig. Ich habe die Angebote für Praktika, Lizarbeiten und so ins richtige Layout gebracht und mich darum gekümmert, dass sie an den Lehrstühlen ausgehängt werden, also z.B. wenn wir einen Praktikanten im Controlling gebraucht haben, dann habe ich die Uni-Profs angemailt und ihnen die Aushänge geschickt. Und ich war auch auf einer Polymesse dabei, da haben mein Chef und ich mit einem Messestand zwei Tage lang Matheund Informatik-Studenten der ETH angeworben.

I: Okay, hmhm, Hochschulmarketing ist sicherlich nicht ganz so wie Fundraising, aber schon verwandt, man muss sein Unternehmen gut vertreten, Projekte vorstellen, Werbung machen und so. Ja, hast Du sonst noch einschlägige Erfahrung, vielleicht im Marketing, in der Werbung? Du studierst BWL, richtig? 
B: Ja, mit Schwerpunkt Marketing. Also, in der Werbung war ich noch nicht. Ich hab aber ein Jahr in Australien studiert, an der University of Sydney, und war da an einem Lehrstuhl für Marketing. Die Leute um den Prof, Professor Kozlowski (sprich: „Koslowski“), haben ein Projekt mit Werbefirmen gehabt, da hab ich mitgearbeitet. Ich habe die Fragebogen an die Firmen verteilt und organisiert, dass die ausgefüllten Fragebogen zurückgeschickt werden. Ich hab damals viel von meinen beiden Betreuern gelernt, über Kontakte zu Unternehmen, wie man seine Deadline durchsetzt ohne unhöflich zu werden, solche Sachen.

I: Aha, okay, das ist gut. Weil, wir haben ständig mit Unternehmen zu tun, und da braucht es viel Geduld und auch Frustrationstoleranz. Manchmal muss man sie mehrfach anschreiben oder anrufen, bis sich was tut, und wir wollen was von denen, nicht umgekehrt. Da muss man immer höflich bleiben, darf nicht aufgeben.

I: Der Name Kozlowski sagt mir was, das ist doch einer der ganz grossen in Sachen Marktforschung, oder? Ein Kumpel von mir macht auch Marketing, der hat sowas gesagt.

B: Ja, Bill Kozlowski ist ganz vorn mit dabei.

I: Hast Du ihn persönlich kennengelernt oder mal mit ihm gearbeitet?

$\mathrm{B}$ : Ja, klar, hab ich, in Australien ist das sowieso ungezwungener, mein Büro war auf dem gleichen Stockwerk wie seines, und meine beiden Betreuer waren bei ihm angestellt, es ist quasi sein Projekt gewesen.

I: Cool.

B: Hm.

B: Ja, und wegen Nachhaken und so, das habe ich damals wirklich gelernt, weil, die Uni hatte das Projekt und wollte was von den Werbeleuten, und da 
war es ganz ähnlich: erst Akzeptanz schaffen, dann gut organisieren und keine Fragen offen lassen, immer wieder informieren, und wenn die Fragebogen nicht zurückkamen oder nicht viele, dann musste ich mir gut überlegen, wann ich jemanden in der Firma anrufe und nachfrage, und wen am besten.

I: Ja, Deine Erfahrung in der Wirtschaft, auch mit verschiedenen Unternehmen, das ist sicherlich gut, das würde helfen. Du hast aber keine direkte Erfahrung mit Fundraising, oder?

B: Nein.

I: Mit Kultursponsoring auch nicht?

B: Nein, leider nicht.

I: Wie würdest Du denn auf mögliche Sponsoren zugehen, was wäre Deine erste Strategie?

B: Also, ich würde erstmal die Kontakte in Unternehmen nutzen, die ich schon habe und versuchen, über die dann an die richtigen Ansprechpartner zu kommen, z.B. über den Abteilungsleiter der Oeffentlichkeitsarbeit. Ich hätte sicherlich keine Hemmungen, meine Connections auszuspielen. Und dann ist die Frage, ob es Stiftungen gibt, die Theater fördern.

I: Hmhm, genau.

I: Zu den Aufgaben des Fundraisers gehört auch viel Schriftliches: Projektbeschreibungen für die Unternehmen, damit sie wissen, was sie sponsern sollen, Anträge für Gelder der öffentlichen Hand schreiben... Würdest Du von Dir selbst sagen, dass Du so was gut machen kannst? 
$\mathrm{B}$ : Ja, ich denk schon. Was Formulierungen und Anschreiben angeht, bin ich durch meinen Job als Semesterassistenz geübt. Ich hatte am MarketingLehrstuhl die Vertretung für das Sekretariat gemacht, weil eine Sekretärin gekündigt hatte und es zwei Monate gedauert hat, bis die Stelle wieder besetzt war. Ich hab in der Zeit die Post und die Emails gesichtet und, soweit ich konnte, beantwortet, viele Briefe geschrieben, auch Sammelbriefe an die Studenten, und Prüfungstermine und Zeugnisse verschickt. Doch, ich denke, dass ich das gut kann.

I: Du hast als Hobbies unter anderem Kino und Theater angegeben. Kennst Du Dich in der Theaterlandschaft hier aus, gehst Du oft ins Theater?

B: Ja, also, ich hab meine Lieblingsstücke, vor allem mag ich Klassiker. Ja, ich bin schon recht regelmässig im Theater. In den letzten Monaten wurden einige Shakespeare-Stücke aufgeführt, z.B. Richard II. Gut gefallen haben mir auch die Tschechov-Inszenierungen letztes Jahr, „Die Möwe“ und die „Drei Schwestern“. Die fand ich beide sehr gelungen. Bei Euch in der TriBühne war „Leonce und Lena“ gut, wirklich sehr gut, ich war zweimal drin.

I: Hat's Dich nie gereizt, selbst mal zu schauspielern?

B: Nee, dafür wär' ich nicht begabt, das kommt nicht gut! Aber ich würd mich freuen, wenn ich über die Stelle ein bisschen hinter die Kulissen schauen könnte. Ich glaube, dass ich gut darin wäre, das Produkt zu vermarkten, sozusagen, Werbung zu machen und nach aussen zu repräsentieren. Ich mein, ich steh halt voll hinter dem Produkt, den Aufführungen, find's lässig, und wenn man davon überzeugt ist, kann man es auch anderen schmackhaft machen.

I: Ja, das stimmt, das kann ich mir auch gut vorstellen.

Okay, dann würde ich sagen, wir bleiben in Kontakt und ich meld mich, wenn wir alle Bewerber da hatten und unsere Entscheidung gefallen ist. Ist das gut? 
B: Ja, klar. Wär lässig, wenn's klappen würde! 
Version 4: Without Name-Dropping Sequences without BIRG Sequence 
I: Hoi Stefan, danke für's Kommen.

B: Hoi Ruedi.

I: Du interessierst Dich also für die Stelle als Fundraiser für die „Tri-Bühne“.

Der Vereinsvorstand hat beschlossen, dass unser Fundraising besser

werden muss und deshalb diese Stelle geschaffen werden soll. Wir brauchen einen Profi auf dem Gebiet, weil keiner von uns Schauspielern das wirklich gut kann.

Ja, also, ich dachte, ich stelle Dir einfach ein paar Fragen: zu Dir und Deinen Erfahrungen, die für die Stelle wichtig sein könnten. Ist das gut?

B: Tiptop.

I: Hast Du in einem Praktikum oder in einem Job mal mit Fundraising, Kultursponsoring oder Marketing zu tun gehabt?

B: Ja, das Praktikum bei der UBS, das war im Marketing, da war ich im Hochschulmarketing tätig. Ich habe die Angebote für Praktika, Lizarbeiten und so ins richtige Layout gebracht und mich darum gekümmert, dass sie an den Lehrstühlen ausgehängt werden, also z.B. wenn wir einen Praktikanten im Controlling gebraucht haben, dann habe ich die Uni-Profs angemailt und ihnen die Aushänge geschickt. Und ich war auch auf einer Polymesse dabei, da haben mein Chef und ich mit einem Messestand zwei Tage lang Matheund Informatik-Studenten der ETH angeworben.

I: Okay, hmhm, Hochschulmarketing ist sicherlich nicht ganz so wie Fundraising, aber schon verwandt, man muss sein Unternehmen gut vertreten, Projekte vorstellen, Werbung machen und so. Ja, hast Du sonst noch einschlägige Erfahrung, vielleicht im Marketing, in der Werbung? Du studierst BWL, richtig? 
B: Ja, mit Schwerpunkt Marketing. Also, in der Werbung war ich noch nicht. Ich hab aber ein Jahr in Australien studiert, an der University of Sydney, und war da an einem Lehrstuhl für Marketing. Die Leute um den Prof, Professor Kozlowski (sprich: „Koslowski“), haben ein Projekt mit Werbefirmen gehabt, da hab ich mitgearbeitet. Ich habe die Fragebogen an die Firmen verteilt und organisiert, dass die ausgefüllten Fragebogen zurückgeschickt werden. Ich hab damals viel von meinen beiden Betreuern gelernt, über Kontakte zu Unternehmen, wie man seine Deadline durchsetzt ohne unhöflich zu werden, solche Sachen.

I: Aha, okay, das ist gut. Weil, wir haben ständig mit Unternehmen zu tun, und da braucht es viel Geduld und auch Frustrationstoleranz. Manchmal muss man sie mehrfach anschreiben oder anrufen, bis sich was tut, und wir wollen was von denen, nicht umgekehrt. Da muss man immer höflich bleiben, darf nicht aufgeben.

$\mathrm{B}$ : Ja, und wegen Nachhaken und so, das habe ich damals wirklich gelernt, weil, die Uni hatte das Projekt und wollte was von den Werbeleuten, und da war es ganz ähnlich: erst Akzeptanz schaffen, dann gut organisieren und keine Fragen offen lassen, immer wieder informieren, und wenn die Fragebogen nicht zurückkamen oder nicht viele, dann musste ich mir gut überlegen, wann ich jemanden in der Firma anrufe und nachfrage, und wen am besten.

I: Ja, Deine Erfahrung in der Wirtschaft, auch mit verschiedenen Unternehmen, das ist sicherlich gut, das würde helfen. Du hast aber keine direkte Erfahrung mit Fundraising, oder?

B: Nein.

I: Mit Kultursponsoring auch nicht?

B: Nein, leider nicht. 
I: Wie würdest Du denn auf mögliche Sponsoren zugehen, was wäre Deine erste Strategie?

B: Also, ich würde erstmal die Kontakte in Unternehmen nutzen, die ich schon habe und versuchen, über die dann an die richtigen Ansprechpartner zu kommen, z.B. über den Abteilungsleiter der Oeffentlichkeitsarbeit. Ich hätte sicherlich keine Hemmungen, meine Connections auszuspielen. Und dann ist die Frage, ob es Stiftungen gibt, die Theater fördern.

I: Hmhm, genau.

I: Zu den Aufgaben des Fundraisers gehört auch viel Schriftliches:

Projektbeschreibungen für die Unternehmen, damit sie wissen, was sie sponsern sollen, Anträge für Gelder der öffentlichen Hand schreiben... Würdest Du von Dir selbst sagen, dass Du so was gut machen kannst?

$\mathrm{B}$ : Ja, ich denk schon. Was Formulierungen und Anschreiben angeht, bin ich durch meinen Job als Semesterassistenz geübt. Ich hatte am MarketingLehrstuhl die Vertretung für das Sekretariat gemacht, weil eine Sekretärin gekündigt hatte und es zwei Monate gedauert hat, bis die Stelle wieder besetzt war. Ich hab in der Zeit die Post und die Emails gesichtet und, soweit ich konnte, beantwortet, viele Briefe geschrieben, auch Sammelbriefe an die Studenten, und Prüfungstermine und Zeugnisse verschickt. Doch, ich denke, dass ich das gut kann.

I: Du hast als Hobbies unter anderem Kino und Theater angegeben. Kennst Du Dich in der Theaterlandschaft hier aus, gehst Du oft ins Theater?

B: Ja, also, ich hab meine Lieblingsstücke, vor allem mag ich Klassiker. Ja, ich bin schon recht regelmässig im Theater. In den letzten Monaten wurden einige Shakespeare-Stücke aufgeführt, z.B. Richard II. Gut gefallen haben mir auch die Tschechov-Inszenierungen letztes Jahr, „Die Möwe“ und die 
„Drei Schwestern“. Die fand ich beide sehr gelungen. Bei Euch in der TriBühne war „Leonce und Lena“ gut, wirklich sehr gut, ich war zweimal drin.

I: Hat's Dich nie gereizt, selbst mal zu schauspielern?

B: Nee, dafür wär' ich nicht begabt, das kommt nicht gut! Aber ich würd mich freuen, wenn ich über die Stelle ein bisschen hinter die Kulissen schauen könnte. Ich glaube, dass ich gut darin wäre, das Produkt zu vermarkten, sozusagen, Werbung zu machen und nach aussen zu repräsentieren. Ich mein, ich steh halt voll hinter dem Produkt, den Aufführungen, find's lässig, und wenn man davon überzeugt ist, kann man es auch anderen schmackhaft machen.

I: Ja, das stimmt, das kann ich mir auch gut vorstellen.

Okay, dann würde ich sagen, wir bleiben in Kontakt und ich meld mich, wenn wir alle Bewerber da hatten und unsere Entscheidung gefallen ist. Ist das gut?

B: Ja, klar. Wär lässig, wenn's klappen würde! 
6.2.2 Appendix G-1: Manipulation Check Questionnaire Study 1 
Bitte vergleichen Sie den Bewerber Stefan mit sich selbst.

Ich würde mich in einem Einstellungsinterview ähnlich verhalten.

$\begin{array}{rrrrrrr}1 & 2 & 3 & 4 & 5 & 6 & 7 \\ \text { trifft nicht zu } & & & & & & \text { triffit zu }\end{array}$

Der Bewerber erinnert mich an mich.

$\begin{array}{rrrrrrr}1 & 2 & 3 & 4 & 5 & 6 & 7 \\ \text { trifft nicht zu } & & & & & & \text { trifft zu }\end{array}$

Ich habe ähnliche Praktika gemacht.

$\begin{array}{rrrrrrr}1 & 2 & 3 & 4 & 5 & 6 & 7 \\ \text { trifft nicht zu } & & & & & & \text { trifft zu }\end{array}$

Ich habe ähnliche Berufserfahrungen.

$\begin{array}{rrrrrrr}1 & 2 & 3 & 4 & 5 & 6 & 7 \\ \text { trifft nicht zu } & & & & & & \text { trifft zu }\end{array}$

Ich habe ähnliche Interessen.

$\begin{array}{rrrrrrr}1 & 2 & 3 & 4 & 5 & 6 & 7 \\ \text { trifft nicht zu } & & & & & & \text { trifft zu }\end{array}$

Ich habe ähnliche Einstellungen.

$\begin{array}{rrrrrrr}1 & 2 & 3 & 4 & 5 & 6 & 7 \\ \text { trifft nicht zu } & & & & & & \text { trifft zu }\end{array}$


In Einstellungsinterviews geben Bewerber viel Auskunft über sich selbst. In diesem Teil des Fragebogens möchten wir von lhnen erfahren, welche Informationen Sie zur Kenntnis genommen haben. Bitte versuchen Sie sich zu erinnern, ob die folgenden Aussagen zutreffen. Wenn Sie sich wöllig unsicher sind, wählen Sie die Option „ich erinnere mich nicht".

Der Bewerber hat Erfahrung mit Fundraising.

$\begin{array}{lcc}\square & \square & \square \\ \text { ja } & \square & \text { ich erinnere mich nicht }\end{array}$

Der Bewerber geht gerne ins Theater.

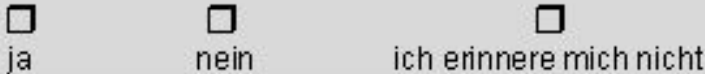

Der Bewerber hat ein Praktikum im Bereich Hochschulmarketing gemacht.

$\square_{\text {ja }}^{\square} \quad \square_{\text {nein }}^{\square}$ ich erinnere mich nicht

Der Bewerber hat ein Jahr im Ausland studiert.

$\square_{\text {ja }}^{\square} \quad \square_{\text {nein }}^{\square} \quad$ ich erinnere mich nicht

Der Bewerber hat Erfahrung mit Kultursponsoring.

$\square \quad \square_{\text {ja }}^{\square} \quad$ ich erinnere mich nicht

Welche der folgenden Personen wurden im Interview erwähnt?

(Mehrere Nennungen möglich.)

$\square$ Prof. Podsakoff $\square$ Dr. Beat Brunner $\square$ Prof. Holzherr $\square$ Prof. Walter

$\square$ Jonathan Smith $\square$ Prof. Koslowski $\square$ Dr. Silvan Maag $\square$ Richard Clark

$\square$ Prof. Welti $\square$ Prof. Baumberger $\square$ Philipp Kurz $\quad \square$ Damian Rohner

$\square$ Ich habe gehört, dass der Bewerber Personen enwähnt hat, habe aber die einzelnen Namen aufgrund der Tonqualität nicht alle verstanden.

\section{Bitte umblättem!}


Was geht aus dem Interview über Prof. Koslowski hervor? Wählen Sie eine der folgenden Optionen.

$\square$ Er ist ein berühmter Experte in seinem Fach.

$\square$ Er hat einen schlechten Ruf.

$\square$ Aus dem Interview geht nichts über die Qualität seiner Arbeit hervor.

Bitte schliessen Sie diese Mappe und offnen Sie Mappe 4! 
6.2.3 Appendix H-1: Instruction Study 1 
Liebe Teilnehmerin, lieber Teilnehmer,

zunächst vielen Dank für Ihre Bereitschaft, an unserer Studie teilzunehmen!

Im Folgenden geht es um ein Bewerbungsinterview. Der Bewerber Stefan interessiert sich für die Stelle als Fundraiser beim Studententheater „TriBühne“. Der Job wird auf Stundenbasis bezahlt.

Stellen Sie sich vor, Sie seien Mitglied des Studententheaters „Tri-Bühne“. Zunächst erhalten Sie eine Stellenbeschreibung für die Stelle als Fundraiser und ein Bewerber-Profil, das Ihnen zeigt, welche Eigenschaften und Kenntnisse der Bewerber haben sollte. Dann sehen Sie die Videoaufzeichnung eines Interviews, das der Vorstandsvorsitzende des Theaters, Ruedi, mit dem Bewerber Stefan geführt hat. Anschliessend bitten wir Sie, Ihre Meinung zum Bewerber abzugeben und zu entscheiden, ob er für die Stelle geeignet ist.

Der Ablauf ist wie folgt:

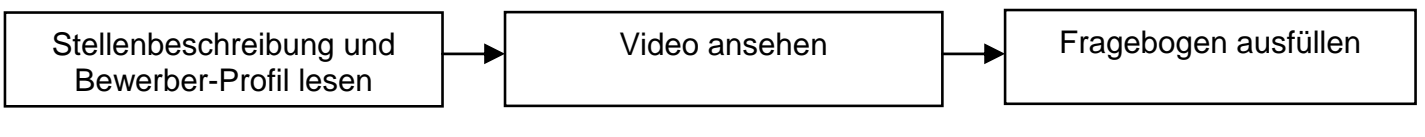

ca. 5 Minuten

ca. 10 Minuten

ca. 25 Minuten

Bitte öffnen Sie Mappe 1 und lesen Sie die Stellenbeschreibung und das Bewerber-Profil. 
6.2.4 Appendix I-1: Email Questionnaire Study 2 
Betreff: Work-Life-Balance/Sport Untersuchung

Von: work-life-balance@gmx.ch

Datum: Thu, 30 Mar 2006 22:09:15 +0200 (MEST)

An: c.lebherz@psychologie.unizh.ch

Liebe Carmen,

Wir freuen uns sehr, dass Du an unserer Untersuchung zur "Work-Life-Balance bei Studierenden" teilnimmst.

Als erstes brauchen wir ein paar Angaben zu Deiner Person. Damit dies so einfach wie möglich abläuft, haben wir den Fragebogen in diese Mail integriert (s. weiter unten). Bitte fülle den Fragebogen so schnell wie möglich aus, am besten gleich.

Die Untersuchung findet jeweils zu zweit statt (ca. 10-15 Minuten), deshalb haben wir Dir einen Partner zugelost,der Dich kontaktieren wird (wir haben uns entschieden, die Person zu bestimmen, die den Mailkontakt herstellt, um den Ablauf zu vereinfachen).

Wir interessieren uns insbesondere fur TRAININGSSTRATEGIEN IM FREIZEITSPORT.

Deshalb bitten wir Dich, in der Mail, in der Du Dich Deinem Partner

vorstellst, auf das Thema Sport Bezug zu nehmen, d.h. ein bisschen zu

erzählen, ob Du Sport treibst, wie oft und warum. Du musst auch nicht gross ausholen, ein paar Sätze genügen. Dies erleichtert später den Einstieg in die Untersuchung, an der Ihr gemeinsam teilnehmen werdet.

Bitte behandle alles, was Dir Dein Partner schreibt, vertraulich! Auch Dein Partner wird aufgefordert, nicht mit Dritten über Deine E-Mail zu sprechen.

DIE MAIL,DIE DU VON DEINEM PARTNER ERHĀLTST BITTE AUSDRUCKEN UND AN DIE UNTERSUCHUNG MITBRINGEN.

Wir freuen uns, Dich am DO, dem 9.2. um 13:00 im KOL-F-122 begrüssen zu dürfen!

Falls Du Fragen hast, schreibe uns einfach eine Mail.

Zum Ausfüllen des Fragebogen:
1. ZUERST REPLY/ANTWORTTASTE DRÜCKEN
2. FRAGEBOGEN IM ANTWORT-MAIL AUSFÜLLEN
3. MAIL ABSENDEN
Es folgt der Fragebogen:

Fragen zur Work-Life Balance bei Studierenden

Die Angaben, die Du in diesem Fragebogen machst, werden anonym behandelt. Sie werden nicht individuell ausgewertet, sondern statistisch zusammengefasst. Bitte gib bei jeder Aussage an, inwieweit Du diese als zutreffend bzW. nicht zutreffend empfindest. Wähle die Ziffer 7 , wenn Du völlig zustimmst, die Ziffer 1, wenn Du überhaupt nicht zustimmst, oder eine Ziffer dazwischen bei mittlerer Zustimmung. Ersetze die gewählte Zahl durch ein $x$. Bei offenen Fragen schreibe Deine Antwort auf die gestrichelte Linie. 
Beispiele:

Ich höre gerne Musik von Mozart.

$\begin{array}{lllllllll}\text { trifft nicht zu } & 1 & 2 & \times & 4 & 5 & 6 & 7 & \text { trifft zu }\end{array}$

Ich bin ......27 .....Jahre alt.

Persönliche Angaben:

Alter:. Jahre

Hauptfach:

Geschlecht:

[ ] weiblich

[ ] männlich

1. Ich übe

folgende

Sportart(en)

aus:

2. Ich bin sehr sportlich.

$\begin{array}{lllllllll}\text { trifft nicht zu } & 1 & 2 & 3 & 4 & 5 & 6 & 7 & \text { trifft zu }\end{array}$

3. Meinem Sport widme ich pro Woche ca. Stunden

4. Sport ist mir sehr wichtig.

$\begin{array}{lllllllll}\text { trifft nicht zu } & 1 & 2 & 3 & 4 & 5 & 6 & 7 & \text { trifft zu }\end{array}$

5. Meinem Studium widme ich pro Woche Stunden.

6. Mein Studium ist mir sehr wichtig.

$\begin{array}{lllllllll}\text { trifft nicht zu } & 1 & 2 & 3 & 4 & 5 & 6 & 7 & \text { trifft zu }\end{array}$

7. Es ist mir sehr wichtig, im Studium gute Noten zu erhalten.

$\begin{array}{lllllllll}\text { trifft nicht zu } & 1 & 2 & 3 & 4 & 5 & 6 & 7 & \text { trifft } z u\end{array}$ 
8. Ich

spiele

folgende(s)

Musikinstrument(e):

9. Ich bin sehr musikalisch.

$\begin{array}{lllllllll}\text { trifft nicht zu } & 1 & 2 & 3 & 4 & 5 & 6 & 7 & \text { trifft zu }\end{array}$

10. Musik widme ich pro Woche............Stunden.

11. Musik ist mir sehr wichtig.

$\begin{array}{lllllllll}\text { trifft nicht zu } & 1 & 2 & 3 & 4 & 5 & 6 & 7 & \text { trifft } z u\end{array}$

12. Ich habe

ausserdem

folgende

Hobbies:

VIELEN DANK! BITTE MAIL SENDEN! 
6.2.5 Appendix J-1: Email with Name-Dropping Manipulation (Four Versions) Study 2 
Version 1: „Friend and Sports“

Hoi [Name Teilnehmer],

ich habe mich für diese Untersuchung angemeldet, wo man ein Mail schreiben muss, um sich gegenseitig kennen zu lernen, bevor man dann gemeinsam an dieser Untersuchung teilnimmt, wo es um Sport gehen soll. Auf jeden Fall bin ich Dein Partner in dieser Untersuchung und stelle mich nun mal vor:

Ich heisse Michael, bin 24, wohne hier in Zürich mit meinen Kollegen aus dem Gymi in einer WG und habe soeben mit dem Psychologiestudium angefangen. Bis jetzt gefällt es mir eigentlich recht gut!

Nebenbei jobbe ich auch noch beim Flughafen, das heisst ich muss zum Beispiel Leute im Rollstuhl rumfahren, und Kinder auf ihren Flug bringen und so. Macht Spass!

Aber vielleicht komme ich mal zum Thema Hobbys und Sport, darum soll's ja gehen in der Untersuchung. Also, es ist mir schon wichtig, fit zu bleiben:-). Ich spiele gerne Badminton, fahre im Winter Snowboard und spiele im Sommer ab und zu Beachvolley in der Badi. Sonst verfolge ich natürlich die Sport Events in den Medien. Ausserdem habe ich das Glück mit Roger Federer befreundet zu sein (wir kennen uns schon ewig, seit der Primarschule), wir gehen zusammen in den Ausgang oder spielen Playstation, und ab uns zu gehe ich mit inm ins Konditionstraining, joggen und so - das heisst, falls er mal Zeit hat. Das ist ein ganz Flotter, der Roger. All die Auszeichnungen, die er kriegt, glaub mir, er hat alles alles verdient, denn er IST einfach eine überdurchschnittliche Persönlichkeit, auf dem Tennisplatz und ausserhalb! Dieses Jahr war wieder ganz toll für ihn und ich hoffe, dass sich das noch ein paar Jahre lang fortsetzen wird!

Freue mich Dich auch bald live kennen zu lernen, bis am [Datum]

Gruss

Michael 
Version 2: „Friend“

Hoi [Name Teilnehmer],

ich habe mich für diese Untersuchung angemeldet, wo man ein Mail schreiben muss, um sich gegenseitig kennen zu lernen, bevor man dann gemeinsam an dieser Untersuchung teilnimmt, wo es um Sport gehen soll. Auf jeden Fall bin ich Dein Partner in dieser Untersuchung und stelle mich nun mal vor:

Ich heisse Michael, bin 24, wohne hier in Zürich mit meinen Kollegen aus dem Gymi in einer WG und habe soeben mit dem Psychologiestudium angefangen. Bis jetzt gefällt es mir eigentlich recht gut!

Nebenbei jobbe ich auch noch beim Flughafen, das heisst ich muss zum Beispiel Leute im Rollstuhl rumfahren, und Kinder auf ihren Flug bringen und so. Macht Spass!

Aber vielleicht komme ich mal zum Thema Hobbys und Sport, darum soll's ja gehen in der Untersuchung. Also, es ist mir schon wichtig, fit zu bleiben:-). Ich spiele gerne Badminton, fahre im Winter Snowboard und spiele im Sommer ab und zu Beachvolley in der Badi. Ab und zu gehe ich ins Konditionstraining, joggen und so. Sonst verfolge ich natürlich die Sport Events in den Medien. Ausserdem habe ich das Glück mit Roger Federer befreundet zu sein (wir kennen uns schon ewig, seit der Primarschule), wir gehen zusammen in den Ausgang oder spielen Playstation, das heisst, falls er mal Zeit hat. Das ist ein ganz Flotter, der Roger. All die Auszeichnungen, die er kriegt, glaub mir, er hat alles alles verdient, denn er IST einfach eine überdurchschnittliche Persönlichkeit, auf dem Tennisplatz und ausserhalb! Dieses Jahr war wieder ganz toll für inn und ich hoffe, dass sich das noch ein paar Jahre lang fortsetzen wird!

Freue mich Dich auch bald live kennen zu lernen, bis am [Datum]

Gruss

Michael 
Version 3: „Fan“

Hoi [Name Teilnehmer],

ich habe mich für diese Untersuchung angemeldet, wo man ein Mail schreiben muss, um sich gegenseitig kennen zu lernen, bevor man dann gemeinsam an dieser Untersuchung teilnimmt, wo es um Sport gehen soll. Auf jeden Fall bin ich Dein Partner in dieser Untersuchung und stelle mich nun mal vor:

Ich heisse Michael, bin 24, wohne hier in Zürich mit meinen Kollegen aus dem Gymi in einer WG und habe soeben mit dem Psychologiestudium angefangen. Bis jetzt gefällt es mir eigentlich recht gut!

Nebenbei jobbe ich auch noch beim Flughafen, das heisst ich muss zum Beispiel Leute im Rollstuhl rumfahren, und Kinder auf ihren Flug bringen und so. Macht Spass!

Aber vielleicht komme ich mal zum Thema Hobbys und Sport, darum soll's ja gehen in der Untersuchung. Also, es ist mir schon wichtig, fit zu bleiben $\odot$. Ich spiele gerne Badminton, fahre im Winter Snowboard und spiele im Sommer ab und zu Beachvolley in der Badi. Ab und zu gehe ich ins Konditionstraining, joggen und so. Sonst verfolge ich natürlich die Sport Events in den Medien. Ja, zum Beispiel der Roger Federer, was der Rogi zustande bringt ist einfach genial! All die Auszeichnungen, die er kriegt, hat er alle alle verdient, finde ich. Dieses Jahr war wieder ganz toll für inn und ich hoffe, dass sich das noch ein paar Jahre lang fortsetzen wird!

$\mathrm{Hm}$, ich hoffe dies genügt fürs Erste!

Freue mich Dich auch bald live kennen zu lernen, bis am [Datum]

Gruss

Michael 
Version 4: Control (no Name-Dropping)

Hoi [Name Teilnehmer],

ich habe mich für diese Untersuchung angemeldet, wo man ein Mail schreiben muss, um sich gegenseitig kennen zu lernen, bevor man dann gemeinsam an dieser Untersuchung teilnimmt, wo es um Sport gehen soll. Auf jeden Fall bin ich Dein Partner in dieser Untersuchung und stelle mich nun mal vor:

Ich heisse Michael, bin 24, wohne hier in Zürich mit meinen Kollegen aus dem Gymi in einer WG und habe soeben mit dem Psychologiestudium angefangen. Bis jetzt gefällt es mir eigentlich recht gut!

Nebenbei jobbe ich auch noch beim Flughafen, das heisst ich muss zum Beispiel Leute im Rollstuhl rumfahren, und Kinder auf ihren Flug bringen und so. Macht Spass!

Aber vielleicht komme ich mal zum Thema Hobbys und Sport, darum soll's ja gehen in der Untersuchung. Also, es ist mir schon wichtig, fit zu bleiben:-). Ich spiele gerne Badminton, fahre im Winter Snowboard und spiele im Sommer ab und zu Beachvolley in der Badi. Ab und zu gehe ich ins Konditionstraining, joggen und so. Sonst verfolge ich natürlich die Sport Events in den Medien.

$\mathrm{Hm}$, ich hoffe dies genügt fürs Erste!

Freue mich Dich auch bald live kennen zu lernen, bis am [Datum]

Gruss

Michael 
6.2.6 Appendix K-1: Paper-Pencil Questionnaire Study 2 
Lieber Versuchsteilnehmer,

bevor wir zur Untersuchung kommen, interessiert uns noch, welchen Eindruck Du von Deinem Partner aufgrund der Email hast. Bitte gib bei jeder Aussage an, inwieweit Du diese als zutreffend bzw. nicht zutreffend empfindest. Nutze dazu die siebenstufige Skala, indem Du eine der Ziffern einkreist. Wähle die Ziffer 7, wenn Du völlig zustimmst, die 1, wenn Du überhaupt nicht zustimmst, oder eine Ziffer dazwischen bei mittlerer Zustimmung.

Bitte versuche Dir zu jeder Aussage eine Meinung zu bilden, auch wenn das manchmal schwierig ist. Es gibt keine richtigen oder falschen Antworten! Deine persönlichen Eindrücke interessieren uns!

\section{Beispiel:}

Ich höre gerne Musik von Mozart.

$\begin{array}{lllllll}1 & 2 & 3 & 4 & 5 & 6 & 7 \\ \text { trifft nicht zu } & (2 u\end{array}$

Bitte fasse Deinen Eindruck von Deinem Partner kurz zusammen!

Bitte umblättem! 
Die Email meines Partners hat einen angenehmen Eindruck bei mir hinterlassen.

$\begin{array}{rrrrrrr}1 & 2 & 3 & 4 & 5 & 6 & 7 \\ \text { trifft nicht zu } & & & & & & \text { trifft zu }\end{array}$

Ich finde meinen Partner sehr sympathisch.

$\begin{array}{rrrrrrr}1 & 2 & 3 & 4 & 5 & 6 & 7 \\ \text { trifft nicht zu } & & & & & & \text { trifft zu }\end{array}$

Wie kommst Du zu diesem Urteil?

Ich glaube, dass mein Partner sehr sportlich ist.

$\begin{array}{rrrrrrr}1 & 2 & 3 & 4 & 5 & 6 & 7 \\ \text { trifft nicht zu } & & & & & & \text { trifft zu }\end{array}$

Wie kommst Du zu diesem Urteil?

Mein Partner und ich sind ähnlich gut im Sport.

$\begin{array}{rrrrrrr}1 & 2 & 3 & 4 & 5 & 6 & 7 \\ \text { trifft nicht zu } & & & & & & \text { trifft zu }\end{array}$

Ich glaube, dass mein Partner sehr effiziente Trainingsstrategien im Sport kennt.

$\begin{array}{rrrrrrr}1 & 2 & 3 & 4 & 5 & 6 & 7 \\ \text { trifft nicht zu } & & & & & & \text { trifft zu }\end{array}$

\section{Bitte umblättem!}


Ich finde, dass mein Partner eingebildet ist.

$\begin{array}{rrrrrrr}1 & 2 & 3 & 4 & 5 & 6 & 7 \\ \text { trifft nicht zu } & & & & & & \text { trifft zu }\end{array}$

Ich glaube, dass mein Partner das, was er anpackt, erfolgreich abschliesst.

$\begin{array}{rrrrrrr}1 & 2 & 3 & 4 & 5 & 6 & 7_{\text {trifft zu }}\end{array}$

Ich glaube, dass mein Partner und ich sehr gut miteinander auskommen werden.

$\begin{array}{rrrrrrr}1 & 2 & 3 & 4 & 5 & 6 & 7 \\ \text { trifft nicht zu } & & & & & & \text { trifft zu }\end{array}$

Mein Partner und ich sind uns ähnlich.

$\begin{array}{rrrrrrr}1 & 2 & 3 & 4 & 5 & 6 & 7 \\ \text { trifft nicht zu } & & & & & & \text { trifft zu }\end{array}$

Ich glaube, dass mein Partner eine ehrliche Person ist.

$\begin{array}{rrrrrrr}\begin{array}{r}1 \\ \text { trifft nicht zu }\end{array} & 2 & 3 & 4 & 5 & 6 & 7 \\ \text { trifft zu }\end{array}$

Ich habe ähnliche Interessen wie mein Partner.

$\begin{array}{rrrrrrr}1 & 2 & 3 & 4 & 5 & 6 & 7 \\ \text { trifft nicht zu } & & & & & & \text { trifft zu }\end{array}$

Ich finde, dass mein Partner manipulativ ist.

$\begin{array}{rrrrrrr}1 & 2 & 3 & 4 & 5 & 6 & 7 \\ \text { trifft nicht zu } & & & & & & \text { trifft zu }\end{array}$

Ich glaube, dass mein Partner sehr intelligent ist.

$\begin{array}{rrrrrrr}1 & 2 & 3 & 4 & 5 & 6 & 7 \\ \text { trifft nicht zu } & & & & & & \text { trifft zu }\end{array}$

\section{Bitte umblättem!}


Ich glaube, dass die Zusammenarbeit zwischen mir und meinem Partner folgendermassen sein wird (bitte eine Option wählen):

$\square$ eher kooperativ

$\square$ eher kompetitiv

$\square \quad$ keines von beidem

Ich glaube, dass mein Partner eine warmherzige Person ist.

$\begin{array}{rrrrrrr}1 & 2 & 3 & 4 & 5 & 6 & 7 \\ \text { trifft nicht zu } & & & & & & \text { trifft zu }\end{array}$

Ich glaube, dass mein Partner sportlich fitter ist als die meisten Studierenden.

$\begin{array}{rllllll}1 & 2 & 3 & 4 & 5 & 6 & 7 \\ \text { trifft nicht zu } & & & & & & \text { trifft zu }\end{array}$

Ich finde, dass mein Partner sehr ichbezogen ist.

$\begin{array}{rrrrrrr}1 & 2 & 3 & 4 & 5 & 6 & 7 \\ \text { trifft nicht zu } & & & & & & \text { trifft zu }\end{array}$

Die Email meines Partners hat einen kompetenten Eindruck bei mir hinterlassen.

$\begin{array}{rrrrrrr}1 & 2 & 3 & 4 & 5 & 6 & 7 \\ \text { trifft nicht zu } & & & & & & \text { trifft zu }\end{array}$

Wer, glaubst Du, ist sportlich fitter, Du oder Dein Partner (bitte eine Option wählen):

$\square \quad$ eher mein Partner
$\square \quad$ eher ich
$\square \quad$ wir sind gleich fit

Was, glaubst Du, untersucht diese Studie?

Bitte umblättem! 
Ist Dir in der Email Deines Partners etwas negativ aufgefallen?

An dieser Stelle möchten wir noch von Dir wissen, an welche Informationen Du Dich erinnerst.

In der heutigen Untersuchung wird es um folgendes gehen (bitte eine Option wählen):

$\square \quad$ Lernstrategien im Studium

$\square \quad$ Musik

$\square \quad$ Trainingsstrategien im Freizeitsport

\section{Bitte umblättem!}


Mein Partner erwähnte in seiner Email (bitte eine Option wählen):

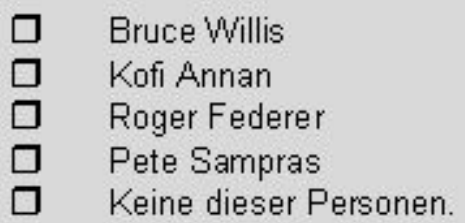

Falls Dein Partner eine dieser Personen erwähnt hat: Wie steht er zu dieser Person? (mehrere Optionen möglich)

$\square \quad$ Er kann sie nicht leiden.

$\square \quad$ Er bewundert sie.

$\square \quad$ Er ist mit ihr befreundet.

$\square \quad$ Er geht mit ihr ins Konditionstraining.

Hast Du weitere Anmerkungen?

Bitte schliesse diese Mappe und öfne Mappe 2! 


\section{CURRICULUM VitAE}

\section{Personal Data}

Name:

Lebherz

First Name:

Carmen

Date of Birth:

21 February 1978

Place of Birth:

Nationality:

Ludwigsburg, Germany

Marital status:

German

Address:

Email:

Single

Phone:

Rotbuchstrasse 8, 8006 Zurich, Switzerland

c.lebherz@web.de

Webpage:

+41 (0)43-233-9867

http://www.psychologie.unizh.ch/sowi/e/team/lebherz/index.html

\section{EDUCATION}

1997

Abitur (A-Level equivalent)

Christoph-Schrempf-Gymnasium Besigheim, Germany

Grade 1.3 (excellent)

1997-2000 Study of Psychology

University of Tuebingen, Germany

1999

Vordiplom (B.A. equivalent)

Grade 1.0 (excellent)

2000-2001 Study of Psychology and Human Resource Management,

University of Massachusetts, USA, Graduate Exchange Program

2001-2003 Study of Psychology

Technical University Chemnitz, Germany

$2003 \quad$ Diplom (M.A. equivalent)

Grade 1.1 (excellent)

Minor in Economics

Diplomarbeit (transl.): "Correlations of teamwork characteristics and

performance figures in vehicle assembly teams", a cooperation project with

Volkswagen (VW) Sachsen GmbH

Grade 1.0 (excellent)

2004-2006 PhD Project

University of Zurich, Switzerland

Title: "Are we known by the company we keep? Effects of name-dropping on first impressions"

summa cum laude

2004-2007 Teaching Skills Program

University of Zurich, Switzerland

Certified training and evaluation program for didactics that includes various coursework, peer observation and feedback, expert observation and feedback, and written reflection of own teaching

Certificate expected in April 2007 


\section{AWARDS AND HONORS}

1997

$1998 \quad$ Jugend musiziert: Second prize (singing, regional level)

2000-2003 Studienstiftung des deutschen Volkes: Scholarship

(German National Academic Foundation)

2000-2006 e-fellows.net: Scholarship

WORK EXPERIENCE

WORK EXPERIENCE AS A STUDENT

1997-2000 Vacation Jobs in Vehicle Parts Organization

DaimlerChrysler, Germany

Translated correspondence and instruction manuals (German, English,

French); worked independently on the development of instruction manuals

(German and English)

1998-2000 Research Assistant in Social Psychology

University of Tuebingen, Germany

Conducted experiments; managed and analyzed project data.

$2000 \quad$ Teaching Assistant in Methodology

University of Tuebingen, Germany

Taught introductory statistics

$2001 \quad$ Research Assistant in Educational Policy at the School of Education

University of Massachusetts, USA

Managed project data

2002 Research Assistant in Work, Organizational, and Social Psychology

Technical University Chemnitz, Germany

Analyzed data for a business cooperation partner

$2002 \quad$ Assistant at the Psychology Department

Technical University Chemnitz, Germany

Provided technical and organizational support during the congress "Tagung experimentell arbeitender Psychologen (TeaP)”

\section{INTERNSHIPS}

2001-2002 Internship in Work Organization (six months)

VW Sachsen GmbH, Germany

Worked in day-to-day business in the department for work organization and employee suggestion system in a vehicle production plant; developed, administered, and analyzed surveys

$2002 \quad$ Internship in Human Resource Marketing and Recruitment (three months)

AUDI AG, Germany

Conceptualized, created, and presented intranet site for the human resource marketing department; analyzed marketing research data; responded to customer requests via email and phone 


\section{Post-GraduATE WORK EXPERIENCE}

$2003 \quad$ Research Fellow (50\%)

Technical University Chemnitz, Work, Organizational, and Social Psychology

Department

Conducted research; taught classes; organized excursion; co-organized local congress with business partner

09/2003- $\quad$ Research Fellow and PhD candidate (70\%)

University of Zurich, Switzerland, Social and Business Psychology

Department

Conducted research in Switzerland and Germany; cooperated with business partners; taught classes; advised graduate students and interns; helped organize international congress; developed, organized, and evaluated exams; recruited and managed the department's research assistants; co-translated a bilingual textbook (English-German)

$2004 \quad$ Management Workshop

Speyer, Germany

Independently conceptualized and co-conducted a 2-day management workshop for leaders in public administration

2004-2005 Research Project on Management Development Center

Co-evaluated an existing development center of the department's business

partner Alstom AG, Switzerland

2005- $\quad$ Research Project on Sales Performance

Advised a research project on what differentiates top salesmen from average salesmen

2006- $\quad$ Research Project on Ethical Leadership and Values in Organizations

Cooperation with Prof. Dr. Carmen Tanner, University of Zurich

2005/2006 Visiting Lecturer

Technical University Chemnitz, Germany

Taught introductory research methodology for non-psychologists (5-day course)

\section{LANGUAGES}

Self-assessment according to the Europass Language Passport of the Council of Europe:

German: native

English: proficient in understanding, speaking, and writing

French: proficient in understanding, independent in speaking and writing (DELF unités 1-4)

Dutch: $\quad$ independent in understanding, basic in speaking

\section{COMPUTER SKILLS}

MS Word (proficient), MS PowerPoint (proficient), MS Excel (basic),

SPSS, statistica, e-learning tools 


\section{Publications and Presentations}

Jonas, K. \& Lebherz, C. (in prep.). Social psychology in action. In M. Hewstone, W. Stroebe, \& K. Jonas (Eds.). (in prep.). Social Psychology (4th ed.). Oxford: Blackwell.

Jonas, K. \& Lebherz, C. (in Vorb.). Angewandte Sozialpsychologie. In W. Stroebe, K. Jonas, \& M. Hewstone (Hrsg.). (in Vorb.). Sozialpsychologie: Eine Einführung (5. Aufl.). Heidelberg: Springer.

Lebherz, C., Mohr, C., Henning, M. \& Sedlmeier, P. (2005). Wie brauchbar sind HochschulRankings? Eine empirische Analyse. Zeitschrift für Pädagogik, 50. Beiheft

"Hochschullandschaft im Wandel", S. 188-208.

Lebherz, C. (2005). Leistungskennzahlen in der industriellen Gruppenarbeit: Potenziale nutzbar machen. In K. Jonas, G. Keilhofer \& J. Schaller (Hrsg.), Human Resource Management im Automobilbau (S. 213-229). Bern: Huber.

Lebherz, C. \& Jonas, K. (2005, July). Name-dropping as a self-presentational tactic: Does it work? Paper presented at the meeting of the European Association of Experimental Social Psychology, Wurzburg, Germany.

Lebherz, C. \& Jonas, K. (2005, September). Name-dropping als Selbstdarstellungstaktik. Paper presented at the meeting of the Fachgruppe Sozialpsychologie, Jena, Germany.

Lebherz, C., Tomljenovic, B. \& Jonas, K. (2006, September). Die Wirkung von NameDropping auf den ersten Eindruck. Poster presented at the meeting of the Deutsche Gesellschaft für Psychologie (DGPs), Nurnberg, Germany.

Lebherz, C. \& Jonas, K. (2007, June). Are we known by the company we keep? Effects of name-dropping on first impressions. Poster submitted to the conference of the Canadian Psychological Association (CPA), Ottawa, Canada.

\section{INTERESTS AND ACTIVITIES}

Singing (choir and solo)

1994-2000 Canto Bello, Youth Choir of the "Schwaebischer Saengerbund e.V.", Germany

2000-2001 University Chorale, University of Massachusetts Amherst, USA

2001-2003 Motettenchor, Chemnitz, Germany

2003-2005 ars cantata, Zurich, Switzerland

Participated in choir concert tours to Spain and Brazil.

Reading German, English, French, and Dutch fiction

\section{VOLUNTARY WORK}

1995-1997 Deputy conductor and secretary of a local choir in Mundelsheim, Germany

1997-1998 Tutored an American exchange student

2001-2003 "Patenprogramm" of the Technical University Chemnitz: Assisted

international students to settle in, accomplish their studies, and learn German; taught German exam preparation classes

2003- $\quad$ Amnesty International: Wrote “Urgent Action” letters to enforce Human Rights world-wide.

2005- "Nightline Zurich”, information and counseling hotline for students, joint project of ETH and University of Zurich: Provided psychological supervision for students volunteering in the hotline; co-developed and co-conducted training courses. 